


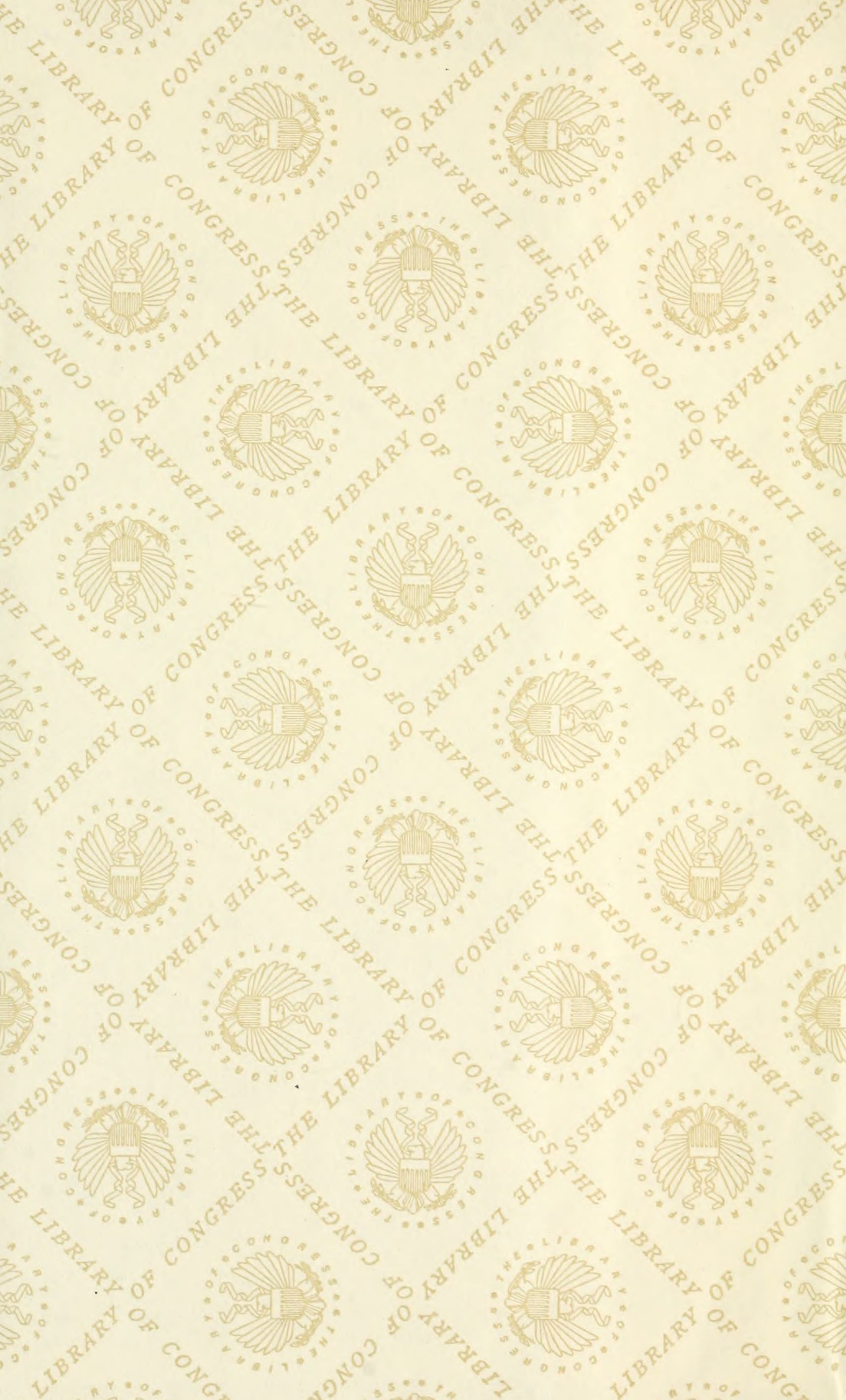




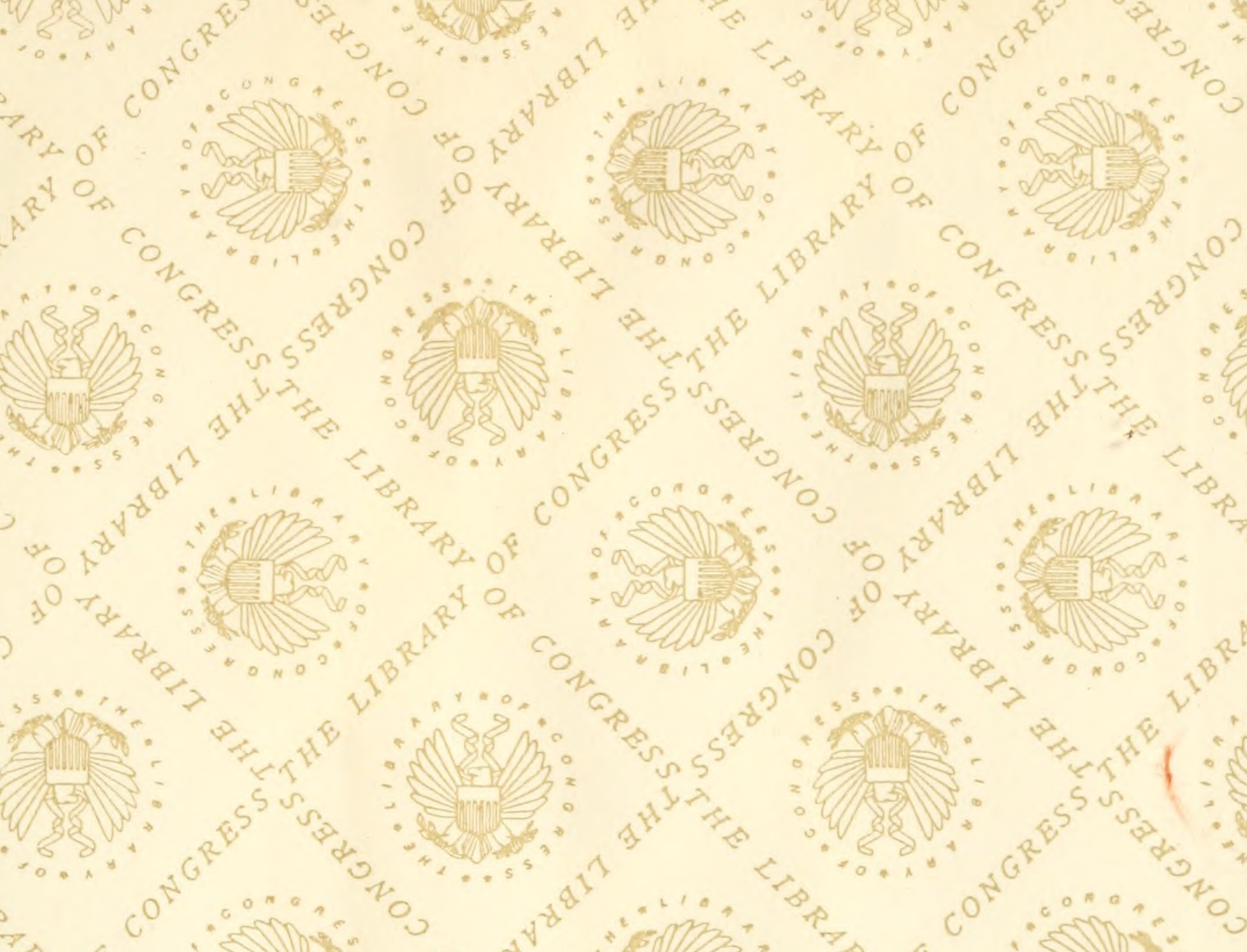






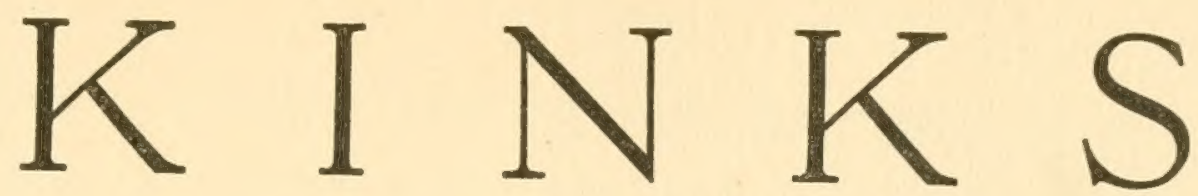

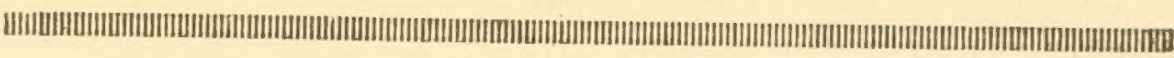

\section{A Book of 250 Helpful Hints for Hunters, Anglers and Outers}

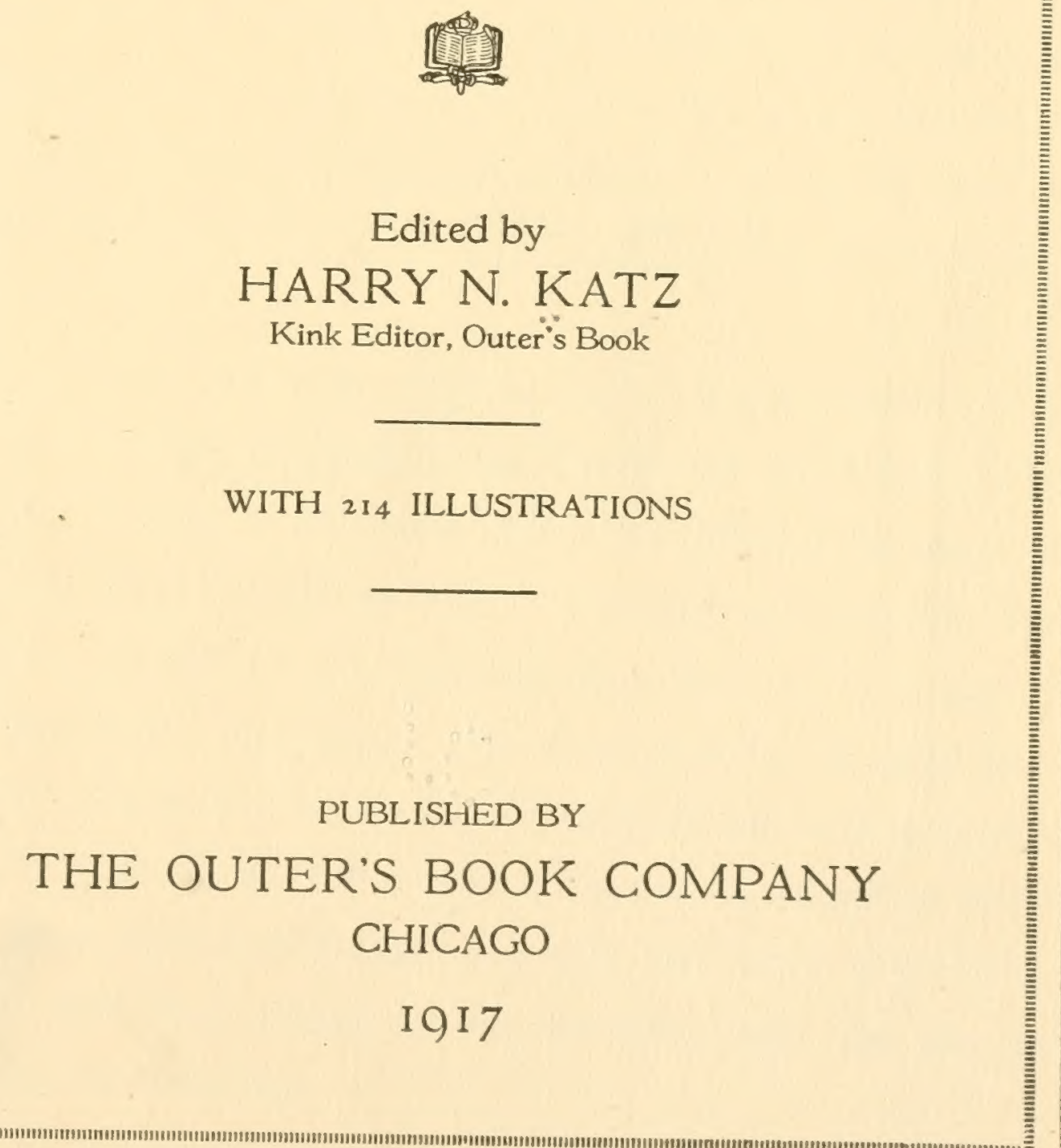




\section{SH 45 \\ $K 2$}

COPYRIGHTED, I9I7

By THE OUTER'S BOOK COMPANY

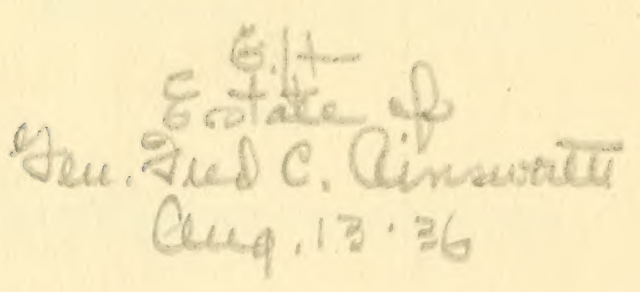

Press of the Blakely Printing Co., Chicago 


\section{FOREWORD}

S INCE time immemorial it has been the custom of publishers to preface their books with some sort of a foreword. This first edition of the Kink Book needs but little in the way of introduction. A single glance at the text pages will be sufficient introduction for any sportsman, and it is for those who indeed possess the sporting spirit of fair play that this book is intended. To appropriate a phrase from the Father of Angling, "It is too good for ought but honest men."

The many who have followed the Kink Column from month to month in OUTER's Book will require no explanation of the purpose of this book. Others, however, may be sufficiently interested over its inception and development to make worth while a few words in that direction.

A distinguishing mark of the true sportsman is his constant readiness to give freely to his brothers in sport the benefit of his knowledge and experience. Naturally the spreading of information by word of mouth is far too slow for the up-to-date American outdoorsman, and matters of major importance soon find expression through the pages of the various sportsman's magazines. But a vast number of small personal tricks and practices have heretofore obtained but little publicity in this way. Individually they are scarcely important enough to serve as the basis of a regulation magazine article, and their originators, moreover, are often too modest or too unskilled with the pen to attempt anything so ambitious.

It was to encourage the offering of these smaller items, therefore, that the Kink column was started in Outer's Book in March, 1915. 
The choice of the name "Kink" is almost self-explanatory. We anticipated that the column would be interesting, but there was little advance appreciation of the great popularity of the movement and the very large store of valuable information that it has opened up.

From the very beginning constant suggestions were received from readers for the publication of "Kinks" in book form, and with this volume the call is met. No claim is made that this book is either complete or authoritative. It is merely a collection of several hundred random facts, each vouched for by some sportsman who has found it of use during some phase of his outdoor life. Yet, as it appears on the press, there is every indication that this book will be found both interesting and profitable reading by those for whom it is intended.

The editor cannot close without a word of appreciation for the hundreds of splendid men and women who have furnished the material for this book. They have given freely of their knowledge and with but little idea of material reward. A limited number of them have received the modest prizes that have been offered from month to. month. But sheer love of sport has been the actuating motive behind every contribution. Many an old woodsman, to whom even the writing of a short letter is an awkward task, has sent in with knotty handwriting and vague spelling, a halting description of the fruits of his wisdom. There has been a good deal of labor expended in whipping these suggestions into shape for the printer, but there has been pleasure as well-pleasure in the knowledge that by this work we were perhaps also doing our bit for the splendid Brotherhood of the Open.

THE EDITOR. 
To Charlie, who taught me how to drop a far-flung bait into a pocket in the lily pads;

To Dorsey, who showed me how to dance a fly on a smiling pool;

To Bob, who told me how to draw a bead and press a trigger;

To Hughie, who guided my first awkward attempt with a canoe pole;

And to every Tom, Dick, and Harry who helps another, tenderfoot or old-timer, to enjoy the more, to understand the closer, that vast heritage of the outdoors which Nature has left in trust with such as them-

This book is dedicated. 


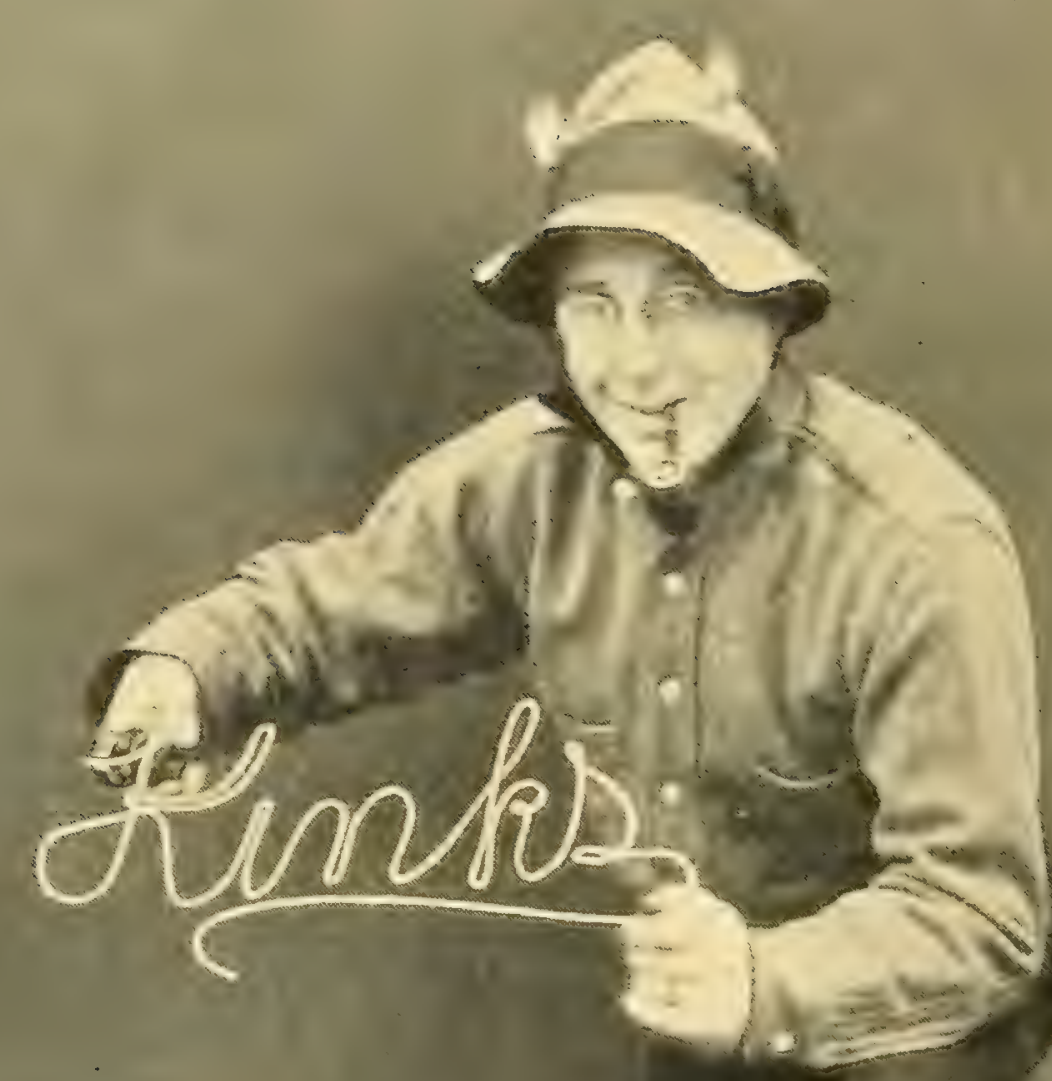

H. N. Katz, Kink Editor, Outer's Book 


\section{KINKS OF ALL KINDS}

\section{A DUCK KINK}

\author{
By O. F. Clatik
}

The outfit here described weighs nothing and takes up no room. It should be welcomed by those who enjoy fall sport with the scattergun.

Take a piece of cord similar to a heavy fishing line-a fish line will do-about six feet long. Tie a loop in each end. (See Fig. 1.) Now, in the middle of this string, tie a fishline or any strong string about 75 or $150 \mathrm{ft}$. long. (See Fig. 2.) Now roll it up on a small board about 2 by 4 in. in size, leaving the end with the two loops to be wound up last and put it in your hunting coat. Then when you go out and kill a duck out beyond your duck and by walking whichever way is necessary, you can pull the triangle over your duck and pull him in. (See Fig. 3.) Throw away the stick and roll up your cord and place it in your pocket and you are ready for as many ducks as you can kill.

\section{IMPROVING THE MINNOW CAN}

By P. E. Bradrick

The fact that minnows soon smother when shut in the usual nearly air-tight minnow bucket, suggests several improvements. These are especially for the angler who has to hike "way up the creek" for his minnows and then

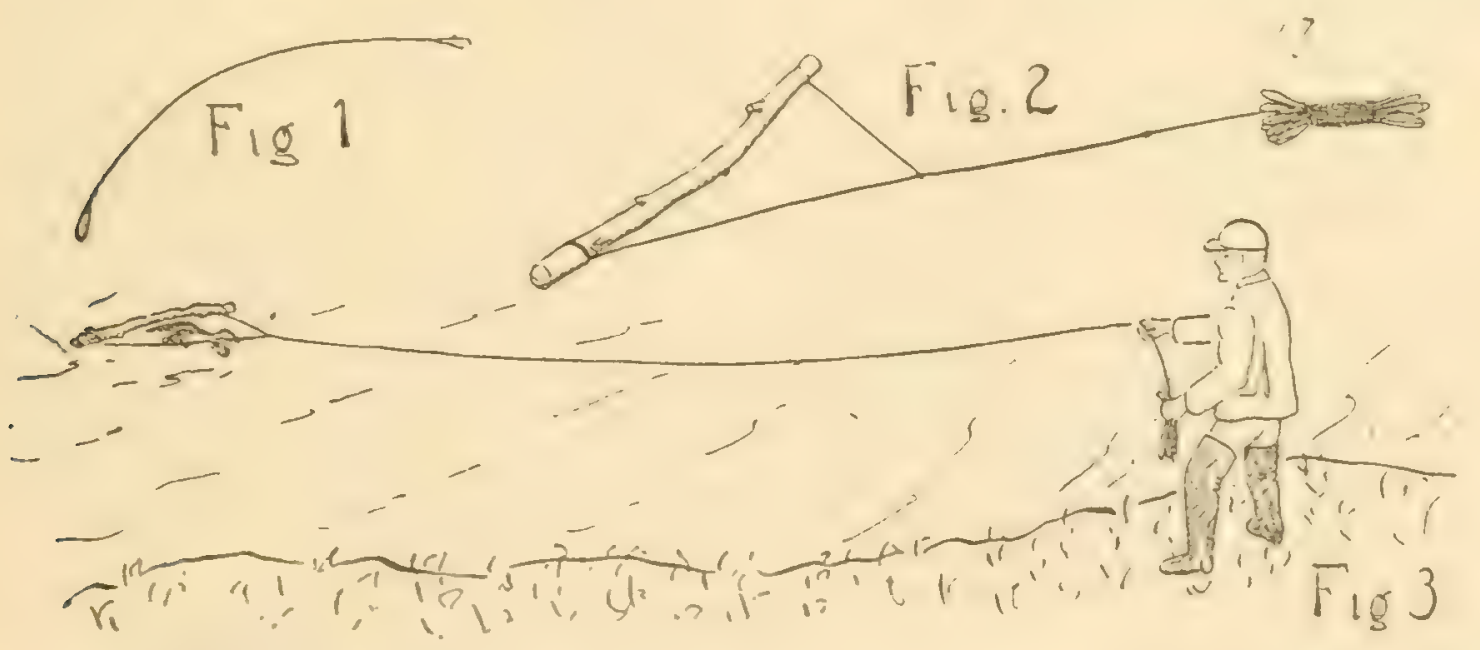

in some place where you cannot get out to it, just look around and find a stick about $4 \mathrm{ft}$. long. Slip a loop over each end and draw it tight. Throw the stick hurry back lest they all die before he reaches the river.

Take the cover of your bucket to the tinner and have him cut out the top, leaving only a strip 
around the edge as in Fig. 2. Use some quarter-inch mesh galvanized screen and have same soldered into the top in place of tin just removed.

Make a tin cone or funnel (aa, Fig. 1). Have this riveted in place under the mesh, point up, with braces (b-b, Fig. 1). This
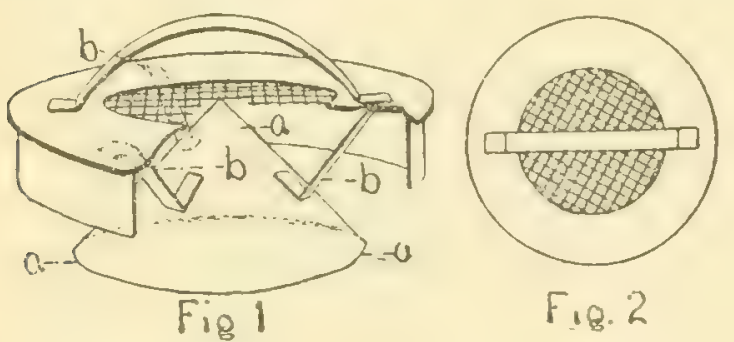

cone prevents the water splashing out while one is walking. With the cover arranged in this way the water is churned around and freshened up at every step as you walk along. With the ordinary cover one is inclined to step very easily in order not to splash all over. But with this cover the more the bucket is shaken up the better for the fish.

\section{DOCTORING THE LEADER}

By Arthur Burikman

The ordinary snelled fly is none too easy to remove from the leader loop after it has been settled into place by a few minutes flies in a hurry. Here is a kink that will save many a minute's fumbling: Just tie a small knot in the end of each of the loops on the leader. Hang the fly on this knotted loop the same as usual. Now, when you wish to remove the fly, take the knot you have tied between the thumb and finger of the right hand and loop on the fly snell between the thumb and finger of the left hand and pull them apart. You will be surprised to see how the little knot facilitates this. If desired you can also tie a similar knot in the loop of the fly snell, but this is not necessary.

\section{A FIRE JACK \\ By G. A. Cole}

Here is a fire jack, convenient to handle, compact for carrying. and easy to make: The upright is made of $7 / 8$-in. iron rod sharpened on one end so as to be easily stuck into the ground. It is 3 feet long. The cross-arm, also 3 feet long, is simply a $1 / 2$-in. iron rod with a hook forged at one end. The block can be either of hardwood or metal. It is 3 in. square and has two holes bored through it at right angles to one another, to accommodate the two

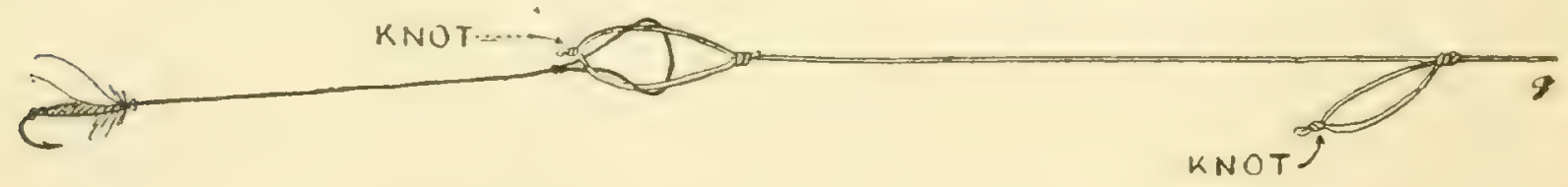

of persistent casting. It is sometimes pretty stubborn to bring away when you want to change rods. The holes are made 1-16 in. larger than the rod they are to take, and are bored to cross as 
closely to one another as possible.

To set up, push the point of the upright into the ground and slip the block over it. Then insert the cross-arm in its socket and you are ready to hang the kettle. The

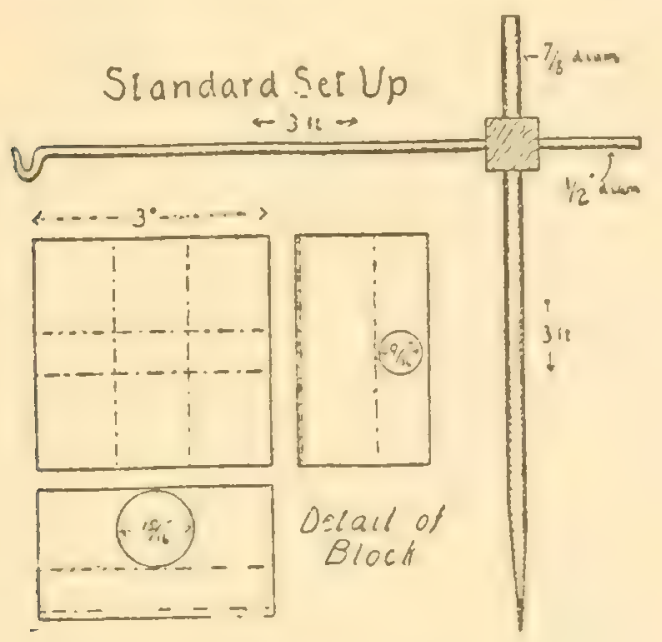

cross-arm can be raised, lowered, lengthened, shortened or swung in any direction and the friction of the block will cause it to bind and hold wherever placed. This little device will save many a singed eyebrow or spilt pot of Java.

\section{THE SQUIRREL TAIL BAIT}

By W. H. Greene

Here is a bait that has done good execution for me among the bass.

Take a squirrel tail and cut it off about five inches long. Fasten

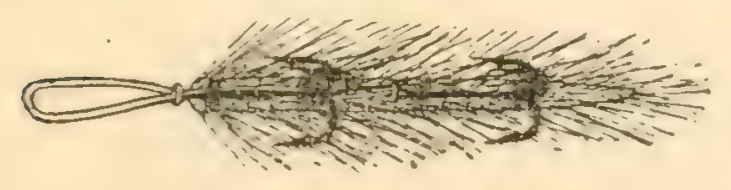

two gang hooks in tandem on a double gut leader and lash them to the tail with good silk thread.
The end of the tail should project about an inch behind the last gang. The lashings should be thoroughly made.

Where desired, a shorter bait can be made in the same style by using only one gang instead of two.

\section{MAKE YOUR REEL SELF- STRIKING}

By George Morton

The following kink can be used quite successfully when still fishing. It is especially good when the rod is not held in the hand or when the angler's attention is perhaps attracted elsewhere at the moment the fish bites:

Fasten a rather stiff rubber band to the upper end of the rod grasp. It may be lashed in place,

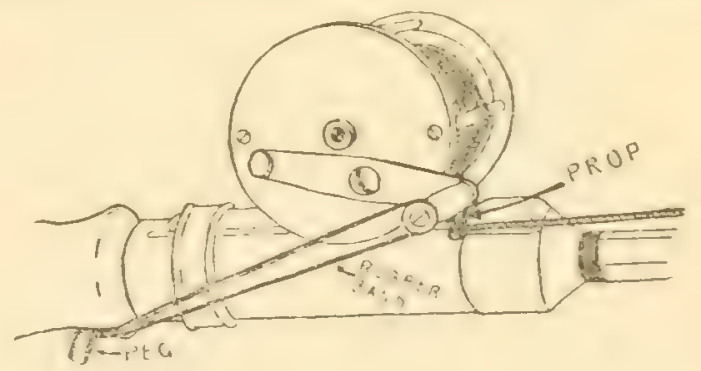

stretched over a peg as in the diagram, or fastened in any other way you desire. Whittle a small bit of wood to the right length so that it will act as a prop between the reel handle and the reel seat when the forward end of the handle is brought just slightly below the parallel with the reel seat. Pass the line around back of this prop, stretch the rubber band from the rod grasp to the reel handle and the reel is locked.

As soon as a fish takes the bait 
and straightens the line, he pulls out the small prop. The rubber band promptly jerks down the reel handle, causing the spool to wind in a few inches of line, just enough to set the hook. If the angler desires the fish to run with the bait for some distance before being snubbed (as when fishing with minnows, etc.), strip out the extra line in advance and let it lie in loose coils just back of the first guide.

\section{AN IMPROVISED TANDEM}

\section{By JoHn Philites}

Sometimes the bass insist on biting short on your minnow when you do not happen to have a regular tandem hook handy. You the simple hitch shown in Fig. 2. This hook goes through the lips of the bait and your tandem is complete. Better than a regular tandem in some respects because it is so easily adjusted to the length of the minnow.

\section{GANGS CAN'T TWIST OUT}

By George A. Wiggan

Last summer, after having lost several large pike and muskies, due to the tail hooks coming out, I inquired the cause from an oldtimer. He told me that the muskies and likely pike as well, have a habit of rolling over during their struggles and in this way twist off the hook. He showed me a bait on which the tail gatrg had been

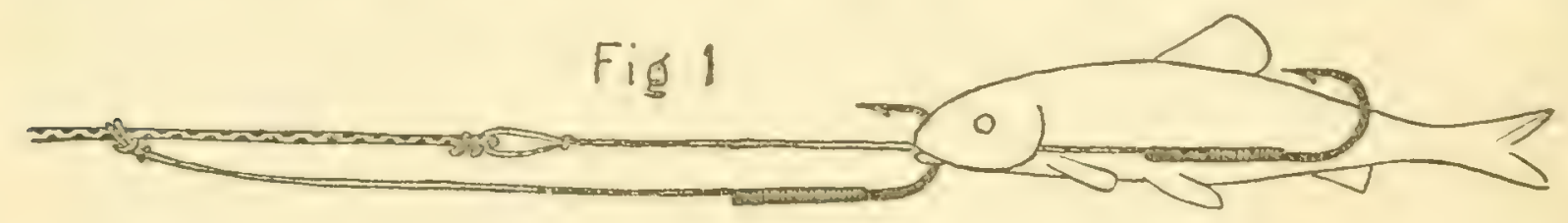

can't blame the fish for not wanting to get their faces full of hooks, but here's a way to fool them just the same:

Tie a 3.0 Aberdeen snelled hook on the end of your line and let

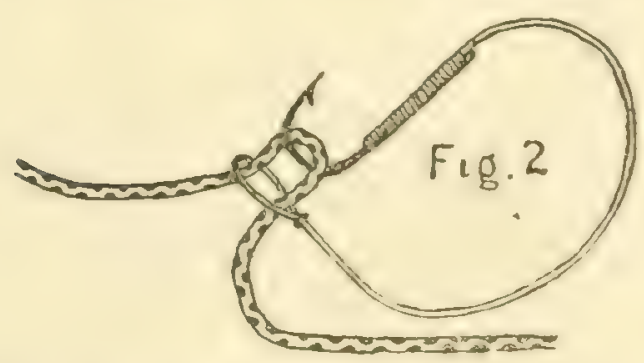

this run back through the gills of the minnow. Then loop another of the same hooks onto the line a little farther up, looping on with twisted almost straight by a small muskie.

I use baits having a single tail gang only.

I took one of these and after removing the hook from the tail, put on a small swivel and then put back the hook. I tried this for several days and missed about a dozen strikes. I then saw that the swivel put the hook too far back to hook any but those that came from the rear.

I cut the ring off one end of the swivel and also cut the eye off the screw eye that held the hook. The hole in the bottom of the 
swivel had to be enlarged to fit the screw shank, but I finally got a tight joint. After forcing this into the body of the swivel a little way I managed to flatten the bead out a little. Then a drop of solder made it fast. I tested it to thirty

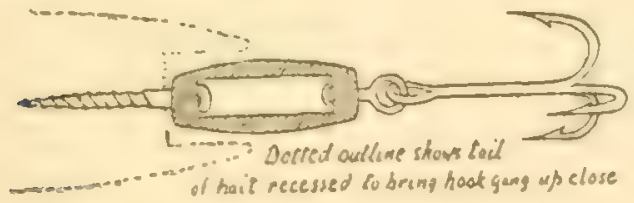

pounds pull (five more than any of my fish lines will stand), and it showed no signs of coming loose.

When the hooks had been put back on the swivel and the whole business fastened to the bait I tried it out again. This time I hooked six out of seven strikes in two days. Five of these were landed, the sixth shook loose. None of the hooks showed the least sign of being twisted.

\section{A HOOK THEY CAN'T SWALLOW}

By I. E. Catterton

How many of you have had trouble in removing your hook from the mouth of a fish after you have caught him, simply be-

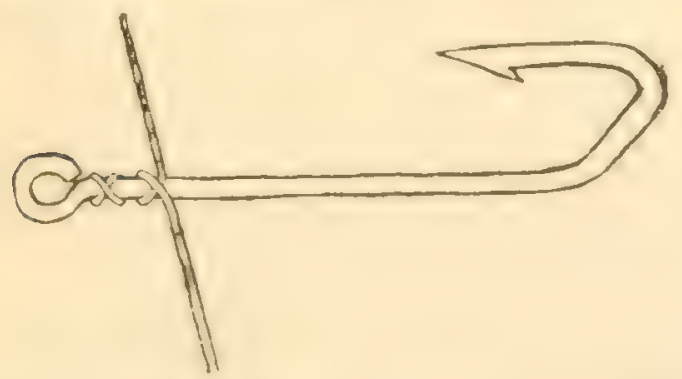

cause he had sivallowed the hook too deeply? Now if you will get a small piece of wire and twist it tightly around the shank of your hook, letting the ends project about an inch, you will have no such trouble. The wire prevents the fish from swallowing the hook. Do not place the wire too far down on the shank nor yet too far back. Use your own judgment in this and regite late your distance according to the size and length of the hook you are using.

\section{A SIMPLE KNOT}

By J. C. Bigelow

I am seventy-three years old and started fishing with my father long before I can remember. Last summer I had a grandson
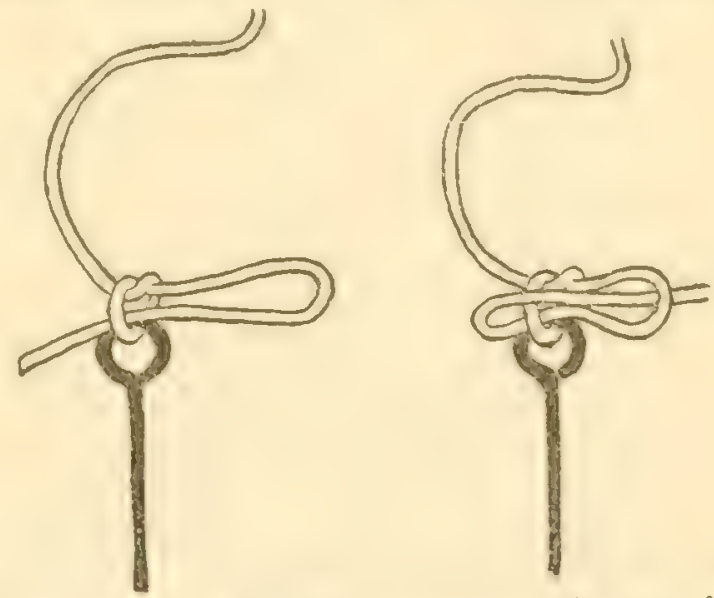

four and a half years old out in a boat with me fishing. $\mathrm{He}$ had his own pole and caught a number of good-sized fish. Maybe I didn't enjoy seeing him bait his own hook. Recently I became a reader of OUTER's and have gotten some bright ideas from the Kink column.

Here is something I have never seen in print. It is a method of tying a line on a ringed hook so that it can be readily untied again. Simply tie with an or- 
dinary single bow knot. Bring the end of the knot through the loop and pull all down tight. To untie, it will be found very easy to withdraw the end from the loop and then a single pull opens everything up.

\section{KEEP YOUR HOPPER ALIVE}

By W. H. Greene

Grasshoppers are frequently a good bait and a live hopper is better than a dead one. But if you hook them in the thorax they die almost immediately, and hooked in the abdomen they come off too easily. I find it pays to

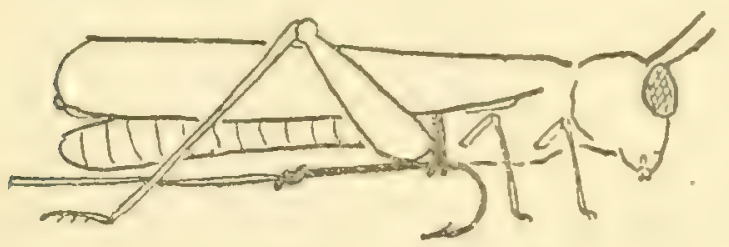

keep a spool of thread with me and when the fish will rise to nothing but hoppers I tie them on the hook with this. Just put a loop around the thorax, under the wings and ahead of the hindlegs. Run the hook through this loop under the hopper's body. Cast out and watch results as Mister Hopper kicks his protest.

\section{AN EMERGENCY FOOT REST}

By G. A. C. Clarke

On a recent fishing trip I found that my host's boat or punt had no footboard to brace my feet against while rowing, so I made one by cutting three sticks and nailed them as shown in the diagram. The ends A and B extended to the stern of the boat, resting on the floor; $\mathrm{C}$ is the brace

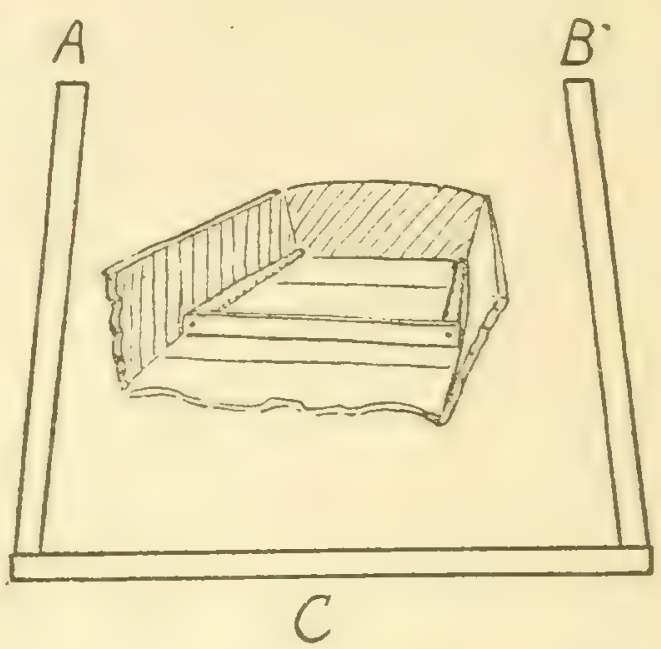

for the feet. $A$ and $B$ can, of course, be cut any length to suit the reach of the rower's legs. This rigging is in no manner attached to the boat, so may be readily taken out in order to clean out the latter.

\section{IMPROVING TUBE TIPS}

By A. Manning, JR.

With the tube style of tip guide which is still found on some casting rods, the line has a great tendency to cling to the rod when

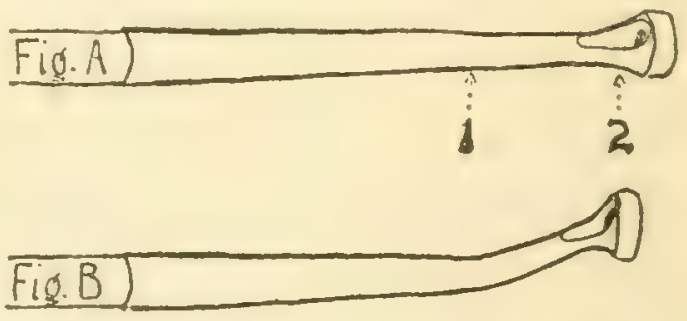

it gets wet, interfering considerably with its free running qualities. This can be easily remedied with a small pair of pliers. Grasp the guide with the pliers at the 
point marked 1, Fig. A, and bend upward to an angle of approximately 45 degrees. Then grasp at the point marked 2 and bend the extreme tip back into parallel with the rest of the rod. Fig. B shows the completed job. With this arrangement the line is lifted well above the rod so that it cannot cling and cause trouble.

\section{A HINGE FIRE RACK}

\section{By Geo. K. Parker}

The accompanying simple kink is a great help on a camping trip of any kind. It is easy to carry and will save many a turned-over coffee pot or frying pan. You take three 8-inch strap hinges and

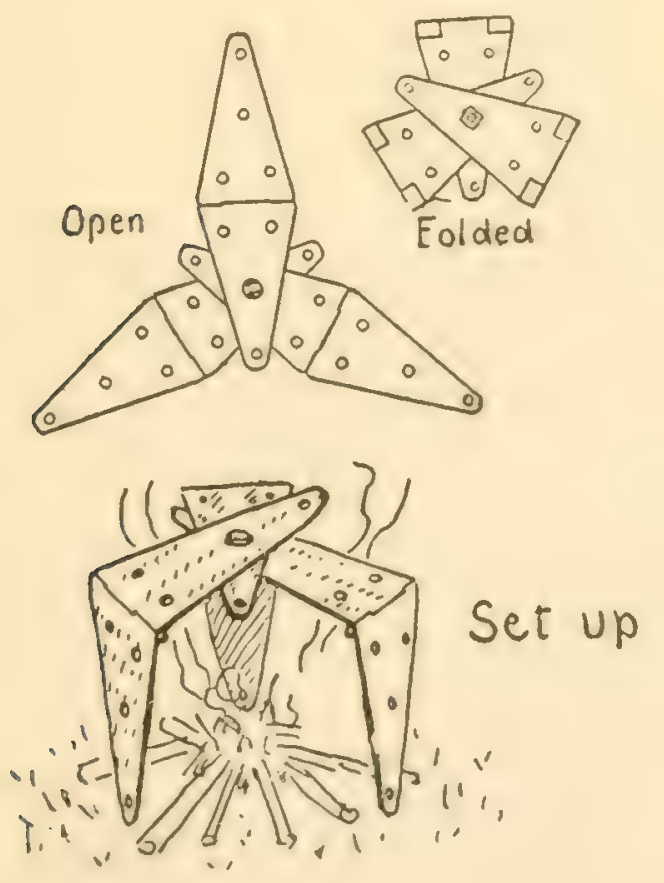

just put a stove bolt through the middle hole and you've got the dandiest little fire rack ever made. When not in use it can be folded and carried in coat or grip.

\section{THE NATURAL POTHOOK}

By F. H. Вонм

Trim a green limb, as long as desired, with the exception of a piece of one branch left near the butt to form a hook. Then cut a deep notch near the other end of the stick, hang the bail of your

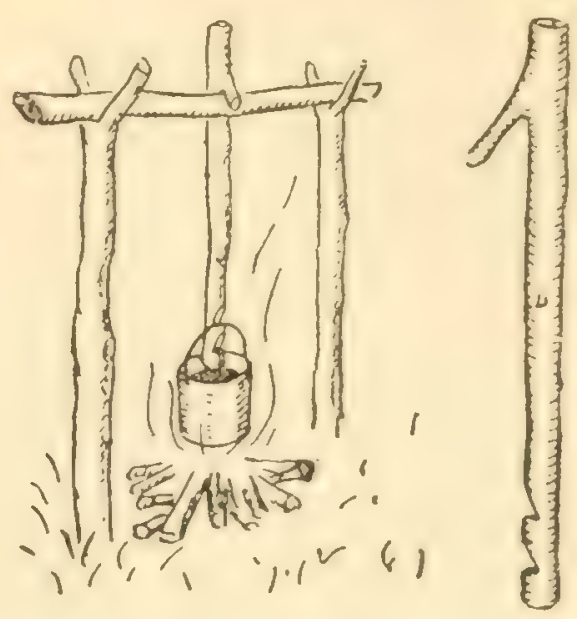

kettle in the notch and hook the other end of the stick over your crane. You will find this a firstrate pothook, saving the carrying of metal hooks or chains. This Kink is probably already known to a good many old-timers, but lots of campers do not seem to have heard of it.

\section{THE PICKEREL THROAT BAIT \\ By GlenN Prucia}

After the "big ones" get wise through being much fished, they will only hit a spoon or artificial bait once and then refuse to strike a second time as they are on to the deception. Sometimes you will troll for hours with only a little pound and a half "snake" to show for your pains. Don't toss the lit- 
tle fellow overboard in disgust. $\mathrm{He}$ will help you to get bigger game.

With your pocket knife cut out the $\mathrm{V}$ of tough skin directly under
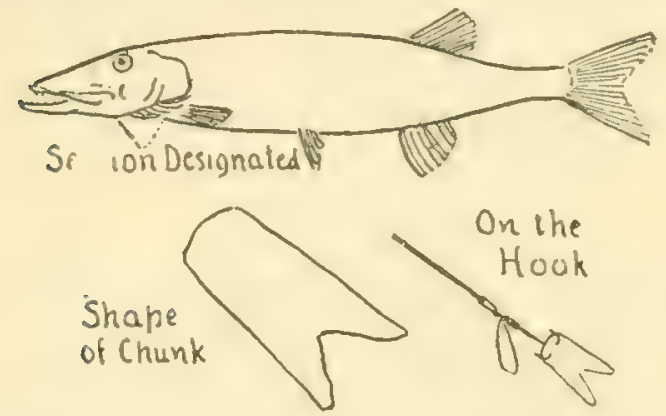

his tongue and hang this on your spoon. The next big fellow that strikes will find the bait soft and to his liking, and if he fails to get hooked the first time he will not hesitate to strike again. Try it out and see.

\section{DRIVING STAKES}

By Arthur W. Stevens

All of us who have ever tried to drive a forked stake into the ground in building a rack, crane

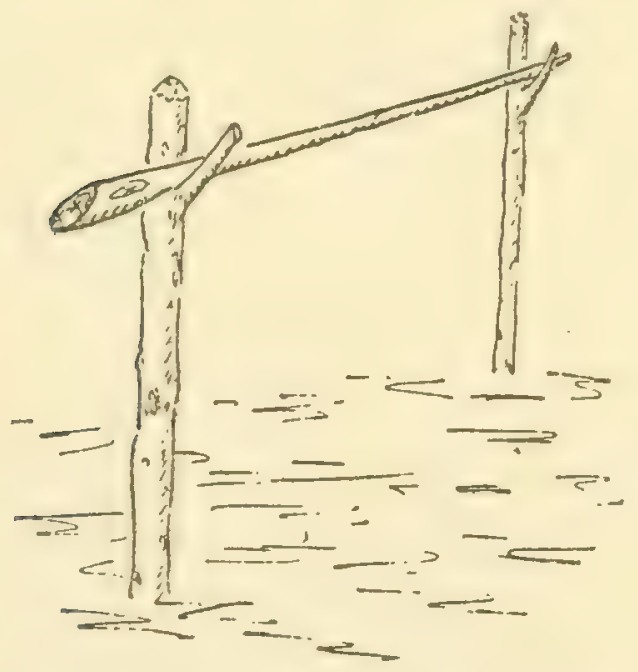

or the like, have found it difficult to do without splitting the fork. If instead of a fork a straight piece with a prong on one side is used, it will serve the purpose just as well and be much easier to drive. The sketch will make this clear.

Also if the top of the stake is carved with a jackknife or sharp ax before driving, it is not nearly so apt to split. This applies as well to tent stakes or any other stake that is to be driven.

\section{SAFEGUARDING THE REEL \\ By Henry Hill}

Nearly every caster has had trouble at one time or another with a reel band that will not stay in place. The following Kink will effectually put an end to this difficulty.

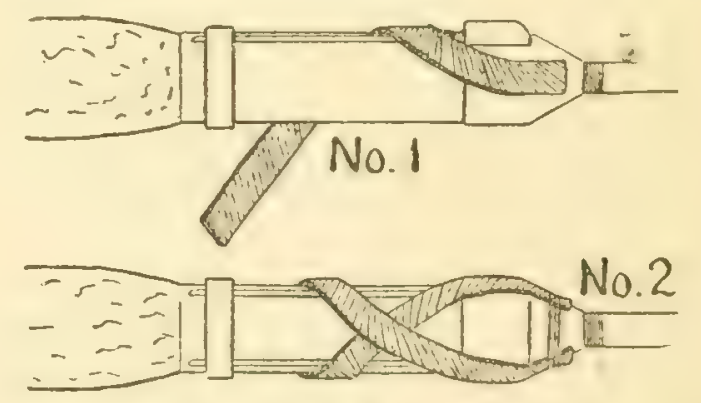

Take a heavy elastic band, or better still, a three-eighths inch strip cut from a heavy automobile inner tube. Place one end ahead of the fixed reel band as in diagram No. 1. Bring the other end diagonally around the reel seat and lash both ends as shown in diagram No. 2 . In putting the reel on the rod, slip the reel seat under the crossed elastics from the direction of the fixed reel seat. Then seat reel as usual. Elastic should be of such a length and weight that it is very 
tight when reel is in place. Diagram No. 3 shows how it looks.

For heavy rods elastic may be made as wide as five-eighths or

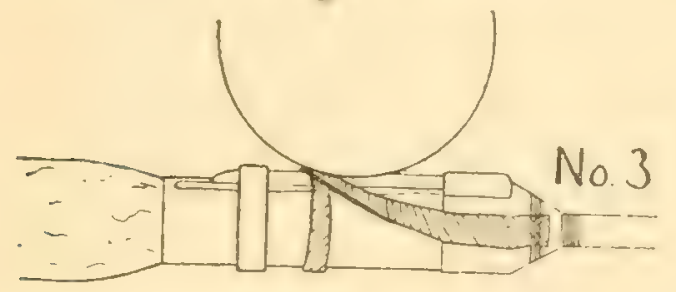

three-quarters of an inch. If preferred, a small stud can be soldered to the movable reel band and the elastic slipped over same as in diagram No. 4.

A variation of the same Kink is to fasten a small German silver

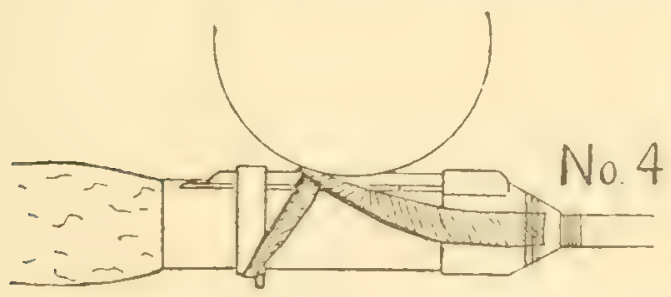

or brass hook ahead of the fixed band on the reel seat. Cut a piece of heavy elastic about three-quarters by two inches. Round the corners off and punch a threeeighths-inch hole a half-inch from

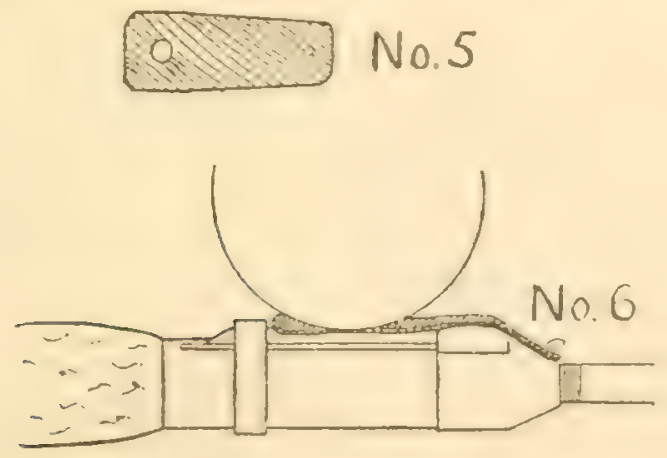

one end and a one-eighth-inch hole near the other as in diagram No. 5. A round punch should be used for the holes or they will be likely to tear. Stretch the large hole over the reel plate and seat the reel on the rod. Then stretch the small hole over the hook as in diagram No. 6. Either one of these methods will hold the reel firmly in place.

\section{A TEMPORARY MINNOW NET}

By H. A. Peters

Were you ever without a minnow net, for some reason or other, while on a fishing trip, when
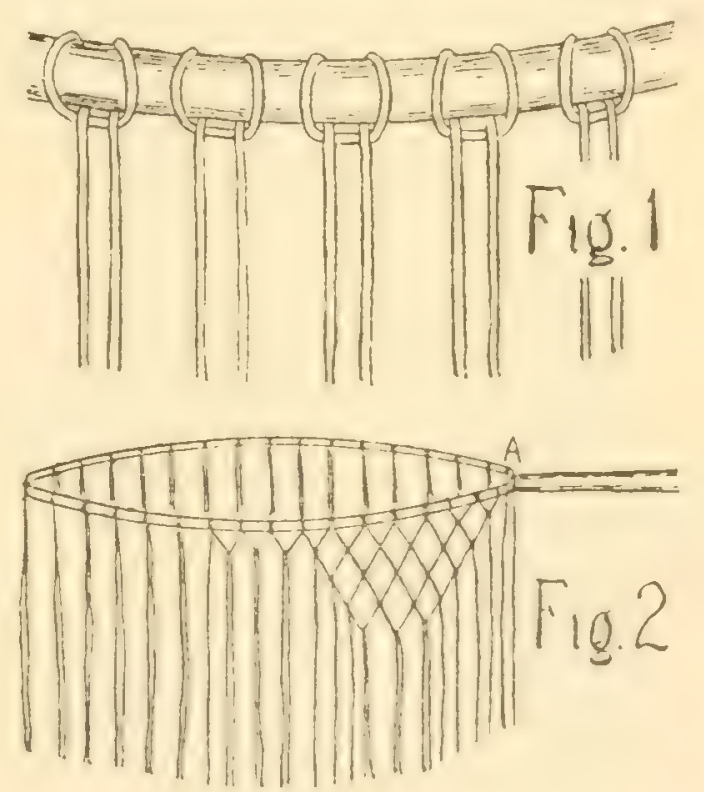

one could not procure one for many miles; and not only that, but you found that the "big ones" just wouldn't bite on anything else but a minnow? If you have never been in that predicament you are indeed more fortunate than I, for such were the conditions my camping party was in last summer up in Wisconsin.

We had a very nice net when we started out, but the third day in camp the net, somehow or 
other, got too near the fire and almost all the netting burned off. Of course, it was not anyone's fault, but that did not matter. We
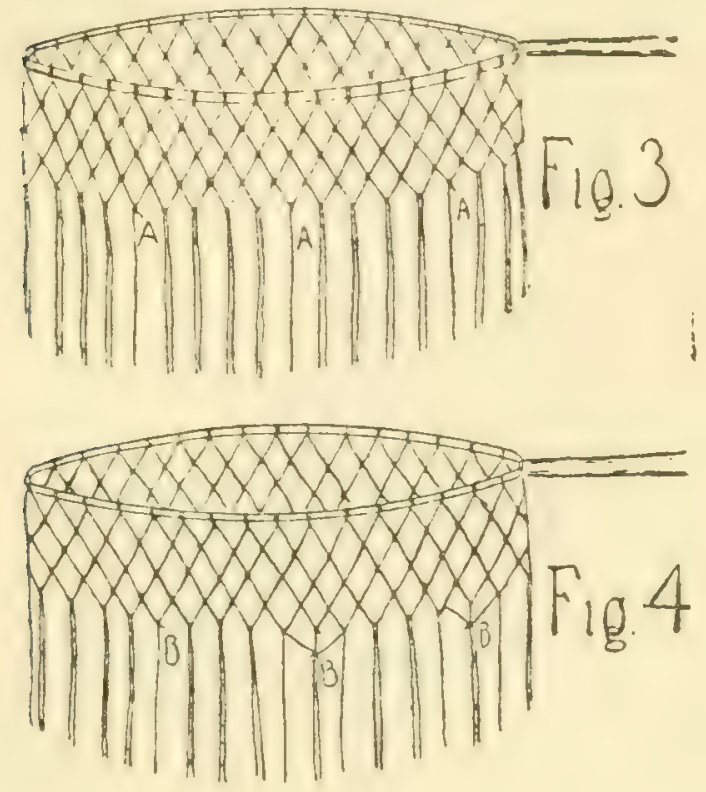

had to have a net. We each had a landing net, but we found it impossible to catch minnows with them because of their size. After looking over my outfit I found a ring and pole to a tree at a convenient height. Then I cut a number of pieces of twine about three feet long and fastened them to the ring as in Fig. 1. Starting at A, Fig. 2, I took one string from each adjacent pair and tied a simple double knot in them. After finishing the first row I made the second, third, etc., as in Fig. 2. After making about seven rows I decided to taper the net down. This was done by making the mesh smaller (that is, tying the cords closer together); also by cutting off, say six strings, from six pairs, at equal distances apart in the same row, as at A, Fig. 3. The knotting was done the same as before until a single line was reached. Then by taking one string each side of the single one, I tied the knot so that it came even with the rest in the same vertical row. Then I tied a sec-

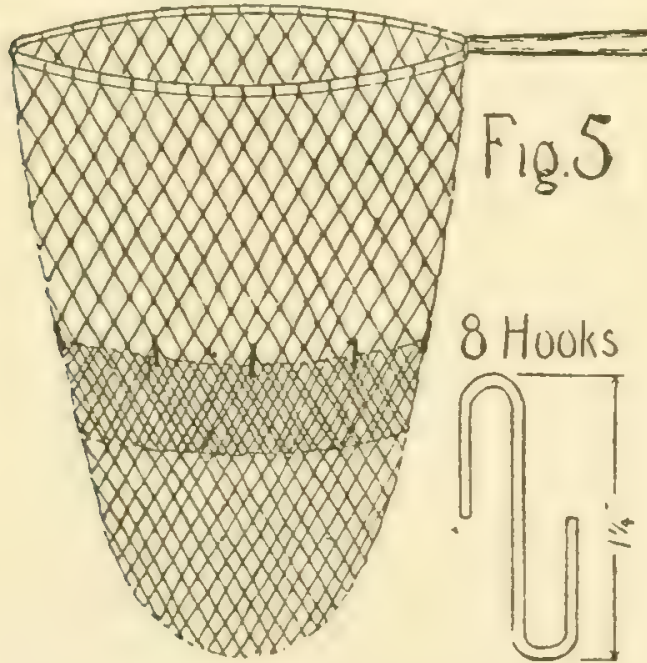

ball of twine and I decided to try to make a net. I did this as follows:

After cutting off all the net that remained on the ring, I fastened ond knot with the single line and one of the other two and cut off the single line short as at B, Fig. 4. Continuing in this manner, cutting six pairs from every horizontal row, I soon had the diameter of the hole in the bottom about eight inches. Then removing the net part from my landing net, I fastened it to the bottom of the minnow net by means of small hooks and my net was complete as in Fig. 5.

It took quite a time, but we were certainly rewarded for our 
work. Of course, it required patience but where is there a good fisherman who lacks that? The author used this net the entire summer, but has not seen it fail yet. So, brother, if ever placed as I was, just remember this Kink and you will catch your minnows.

\section{A SPOON FLOAT}

By Geo. Raveling

The ordinary bait-caster frequently has trouble when trying to cast a spoon. Either the spoon is so light that he cannot send it out very far, or else he gets a backlash and his spoon sinks to the bottom and snags. Here is a kink that will overcome both of these difficulties:

Take a piece of softwood and taper both ends as shown in the diagram. Coat with white enamel paint and fasten a single stout hook on one

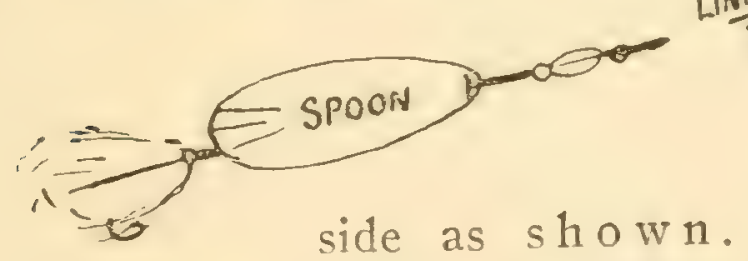

Fasten this float on your line by a couple of slipknots, about two feet ahead of the spoon.

\section{A FLEXIBLE GAFF}

By V. F. Malone

The following kink may be of some value to the week-end fisherman who wishes to diminish the contents of his tackle box and go without a net or gaff:
Take a number of hooks of the stiff steel variety and heat the eyes until they can be bent with pliers. Then hook them into

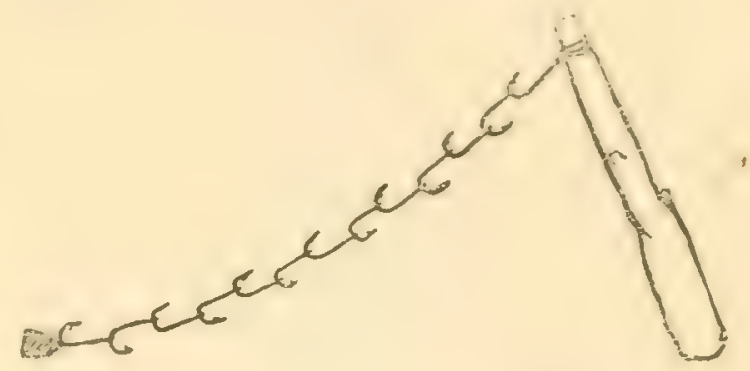

each other in tandem, turning one hook one way and the next the opposite. Then close the eyes until they will not come off over the barb. Two feet or more of this string of hooks makes a good landing tool when attached to "any old stick"

with a small

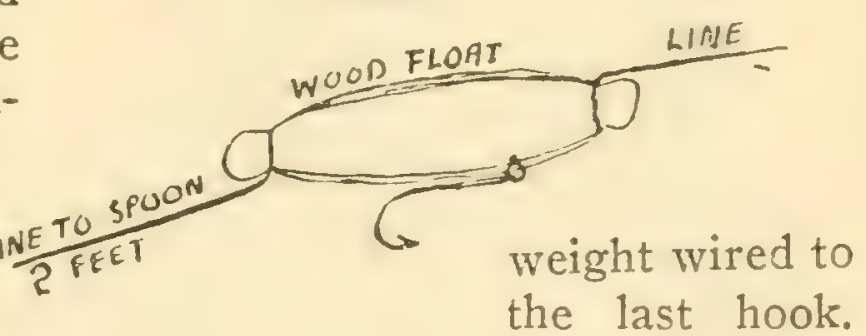

Let the size of the hooks be governed by the size of the fish to be caught.

\section{DEEP WATER TROLLER}

By Fred R. Semenetz

Here is a Kink that's as old as the hills. Maybe you have seen or used it yourself in your time, but it's good enough to report anyhow on the chance that some brother may not be familiar with it. I used it every year for from three to five weeks out at the 
Heads (Golden Gate) trolling for salmon. Used light tackle and No. 21 Cutty Hunk line. Believe me! you can have all the fun you

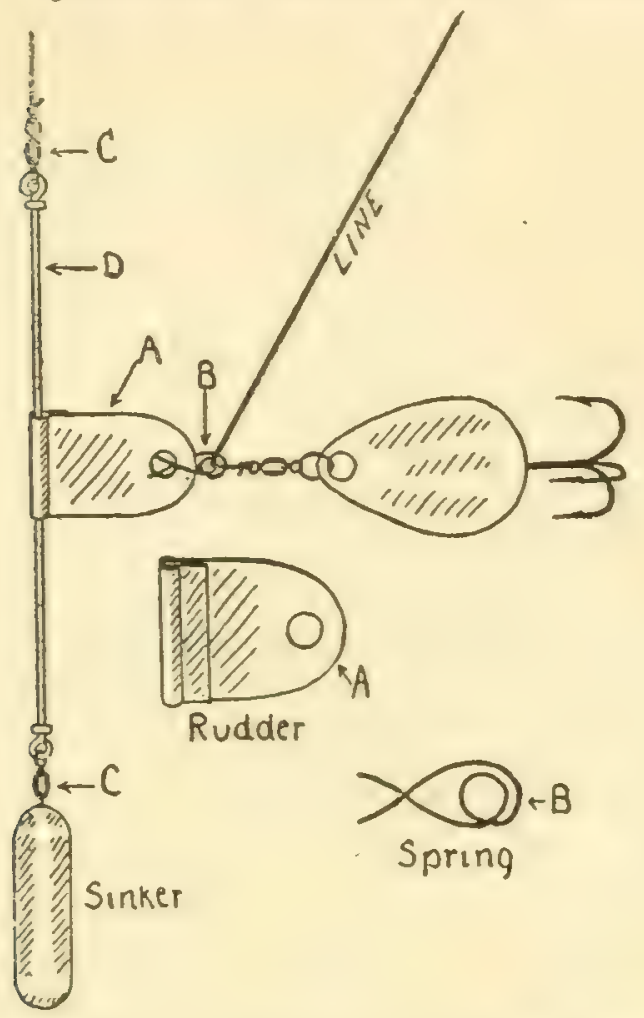

want with salmon that weigh from 8 to 40 pounds. I have also used the "Deep Water Troller" on lakes where big pickerel and big-mouth bass are caught on those days when the fish run deep.

The troller does away with the heavy sinker while fighting the fish. You can imagine the sinker you would have to use to reach a depth of 20 feet, using light tackle.

Take a piece of No. 9 brass wire 6 inches long. Slip a generous sized washer over each end and then form an eye at each end. This wire is labeled " $D$ " in the diagram. A swivel should be attached to each of these eyes (C-C) and the lower swivel cast directly into a good generous lead sinker shaped much like a sashweight, but much smaller, of course.

The rudder piece (A) is made out of a piece of No. 21 sheet brass, 2 inches long and 1 inch wide. A half inch at one end is bent so as to form a free working hinge around the rod D. The other end is rounded and a quarter-inch hole pierced through it.

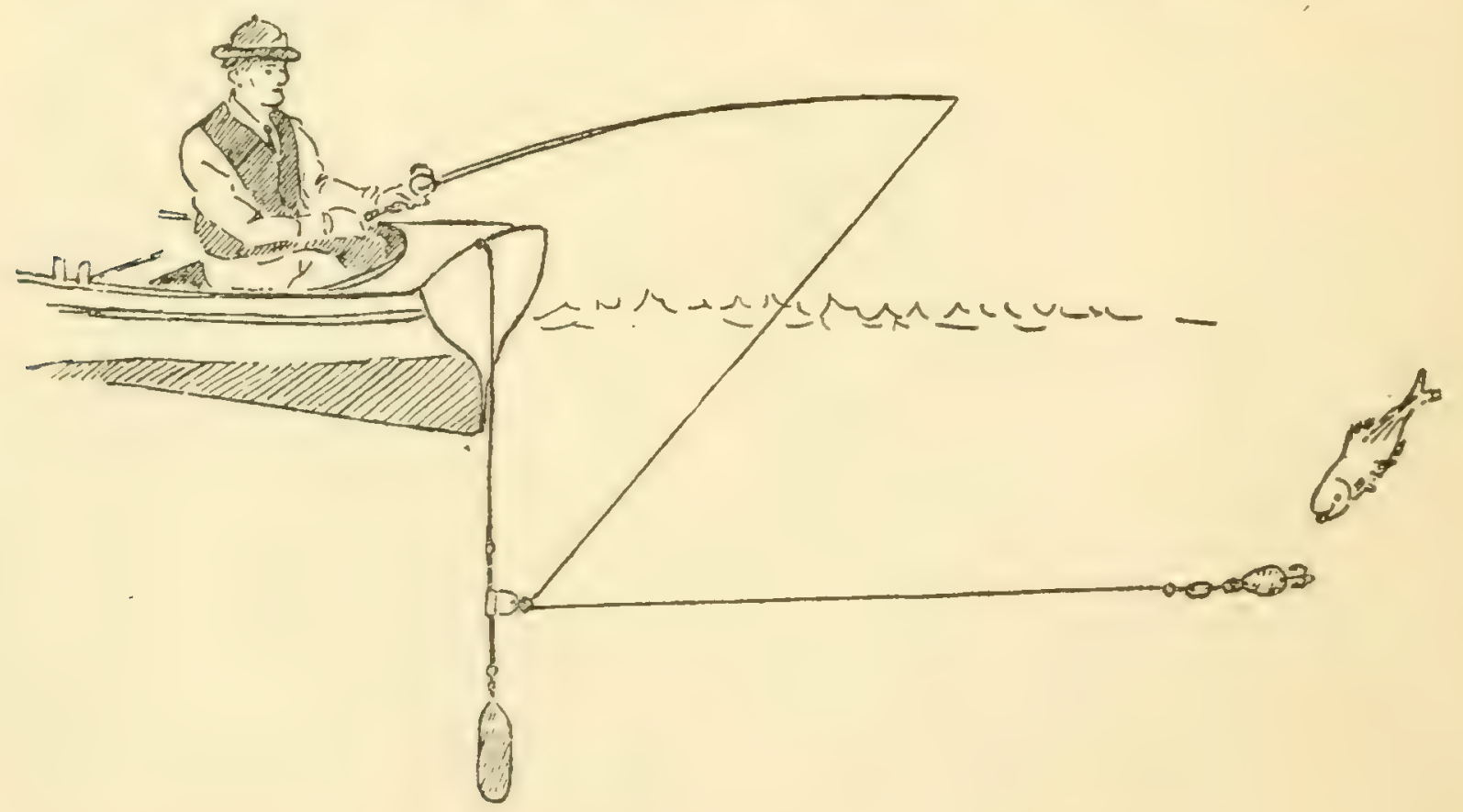


Next comes the spring B. This is made out of No. 18 spring brass wire and bent as shown. The forks should be given enough tension so that when they are run through the hole in $A$ it will take a pull about equal to that made by the strike of a three-pound fish, in order to dislodge them.

In using this device the fish line is run from the tip of the rod through the middle or inside coil of the spring $B$, which is then slipped into the rudder plate. The troller (which is suspended on any piece of heavy hand line) is lowered to the depth at which you want the bait to travel. The boat is then started and line paid out from the reel until the bait is as far astern as desired.

When the fish strikes the spring $B$ pulls out of the rudder plate at once and soon runs down the line until it is stopped by the hook. You are therefore fighting your fish unhampered by any heavy sinkers on the line. This leads to a great deal better sport, as it enables one to troll with lighter tackle than otherwise.

\section{FOR CARRYING CREEL OR CANTEEN}

By W. HERwig

Being tired of the way my canteen swung and pounded when hung from a long shoulder strap, I determined to try carrying it at my belt. The experiment was highly satisfactory, and, as the total materials needed for the change cost me only sixteen cents, I think this kink worthy of being passed along.

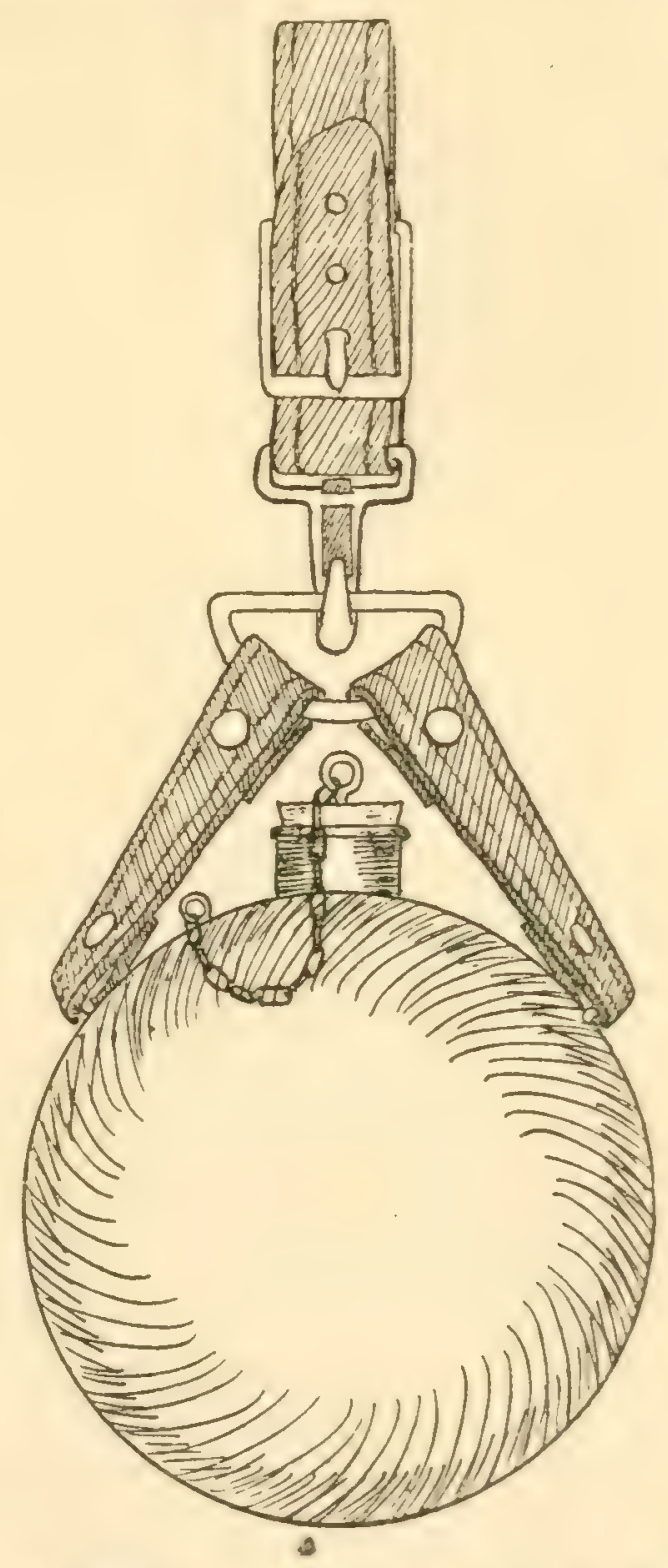

All that is needed is a D ring, a harness snap, an ordinary book strap and a nickel's worth of copper rivets. The diagram will show how these are put together. Two pieces of the strap are riveted to the canteen and the $D$ ring. The third piece, with the buckle left on it, forms a loop to slip over the belt and through the harness strap. 
The snap enables one to unsling the canteen in a jiffy.

Just try this combination on your own canteen or creel. To my way of thinking it is far more comfortable than the shoulder strap, and if you don't like it there is nothing wasted but a few cents' worth of materials, since the canteen or creel are not injured. But you will like it, I know.

\section{LINE-DRYING DEVICE}

\section{By Charles D. Leonard}

An excellent device for drying lines may be made from one of the heads of an old barrel. I attach mine to the sunny side of a woodshed, leaving it outdoors throughout the summer; but it could be adapted easily for indoor use. The expense of making it is practically nothing.

Procure a barrel head and cleat it across center to prevent split- holes, giving each hole a slight slant toward the outside of the barrel head. 'In each hole insert a meat skewer, which will probably be given you at the market. Drive the skewer entirely through head, otherwise the swelling of the wood in a rain will force skewer out. Cut off pointed ends of skewers flush with back of barrel head.

Attach head to casing at back of house, or other convenient place, by setting screw in hole, tusing washer on each side of head to insure easy turning.

A foot or more to right set screw eye in side of building large enough to take ferrule on butt joint of rod, and a screw hook spaced far enough back to hold grip of rod. I use a joint from a discarded rod, but no harm would be done to a good one if the hook were padded with felt or cloth.

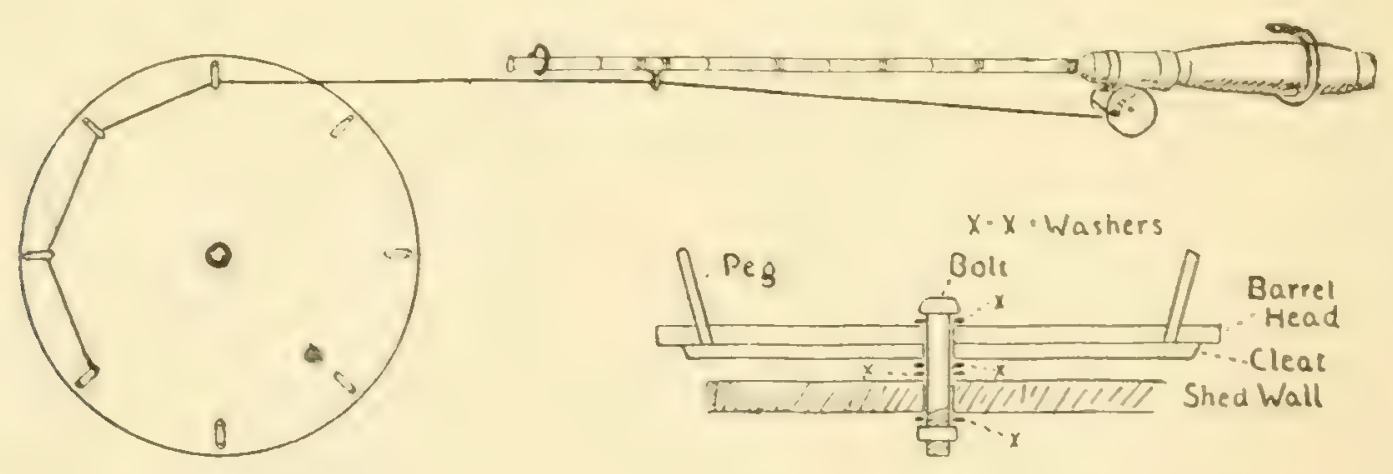

ting. Cleat should be on side to be attached to building. Bore hole through center to take screw, spoke or bolt upon which head is to turn. Draw a circle around head about two inches inside the circumference. At equal distances on this circle bore eight small
Attach reel to reel-seat in ordinary manner, thread line through first guide, pass it outside screw eye, tie loosely to one of skewers and start turning barrel head. One hundred yards can be transferred to head in a very short time. After drying, take rod from 
hooks, without disengaging the reel, and spool the line as if retrieving a bait. If more than one line needs to be dried, after running first line on to the drier, detach from spindle of reel, tie second line to end of first and keep on turning.

Care should be taken to attach rod hangers to right of barrel
For a burner I took a piece of $1 \mathrm{I} / 4$-inch pipe, 7 inches long. In the center of this I tapped a hole for the $1 / 4$-inch pipe. Then punched or drilled about 75 other small holes in the same side of the pipe

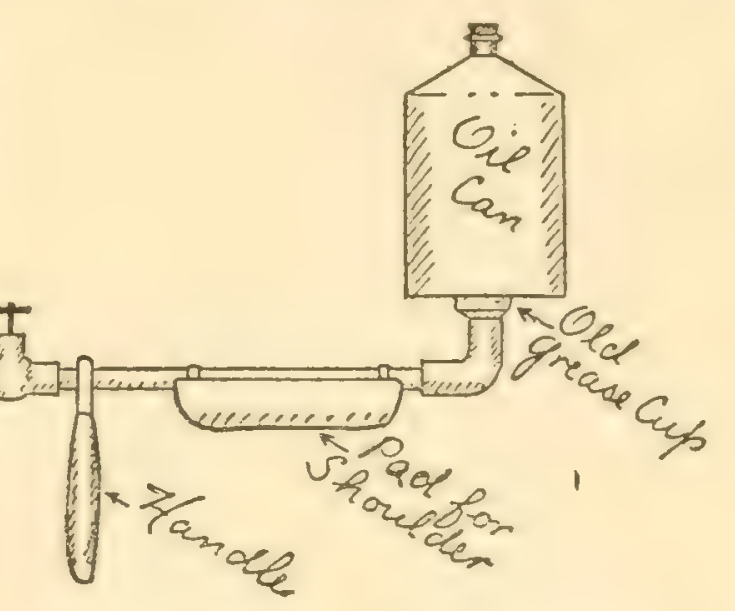

as tapped for the $1 / 4$-inch. Both ends of the burner were then plugged. A pad for the shoulder and a handle completed the outfit.

In operation, I fill the can with kerosene and turn the valve enough to fill the curl with oil. Then I heat the curl by burning a bit of oily rag under it. The pipe soon becomes hot enough to turn the kerosene inside of it to gas. It then burns freely at the burner and can be regulated with the valve exactly like any other gas flame.

\section{FREEING THE LINE \\ By Clarence Graham}

While casting for trout with a spinner, my hook got caught on the bottom. The stream was too deep and swift to wade and as it was my last spinner $I$ was up against it for a whilc. After trying all sorts of ways to get it 
loose, I finally picked up a piece of wood about three feet long and two inches wide. To this I tied a piece of string about onethird of the way from one end. I then made a loop in the string which would slide easily along

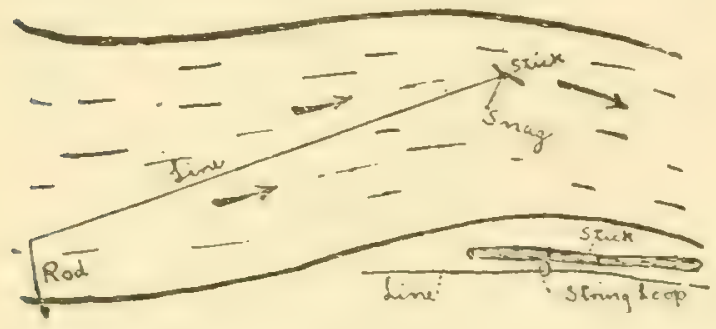

my line and set the stick adrift. The current carried it down aflying. I held a tight line and the stick went right over the spot where my hook was and danced around. In a moment the hook came free. This kink usually works very nicely and has saved several spinners for me since.

\section{THE PALOUSER}

\section{By A. W. Stevens}

The palouser is a very simple and efficient candle lantern well known to the miner and woodsman. It may be made of any good-sized tin can, but a lard pail, about $5 \mathrm{lb}$. size, works best.

Select a point in the side of the pail a little more than half way down and directly under one of the ears that holds the bail. Cut a slit whose length is a little greater than the diameter of a candle. Then cut another across it at right angles. This forms four points which may be bent inward. A candle thrust through the hole is prevented by these points from slipping out, and it may be pushed farther in as it burns off.

Loosen the bail from the side on which the hole has been punched. Squeeze the ends a little closer together and hook the loose end under the flange in the bottom of the pail. This forms a handle by which the pail may be carried on its side-and the lantern is complete.

The bottom of the pail forms a reflector and makes it a real searchlight. Although the whole front is open, it will burn in almost any wind because there is no other opening to carry the draft past the flame.

As to the spelling of the name, I am not sure, as I have never

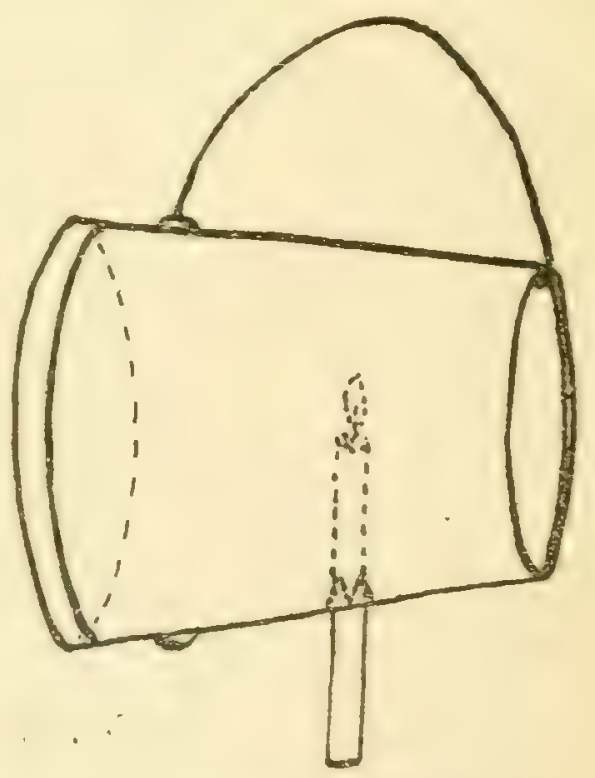

\section{palouser}

seen it in print. The great agricultural region of the state of Washington is known as the Palouse (pronounced paloos), and in the Northwest everything of a rural nature is supposed to have 
come from the Palouse region. It is, therefore, not improbable that the name originated there.

\section{A SIMPLE ROD HOLDER}

By War. Herwig

Desiring a rod holder for trolling, still-fishing and the like, I set about to make one. In a plumbing shop I found a piece of tubing that just slipped easily over the butt of my rod. This I purchased for the enormous cost of five cents. Next I cut off the tube to about seven inches in length and proceeded to pinch or flatten one end with a few blows from a hammer. In this flattened end I bored a hole

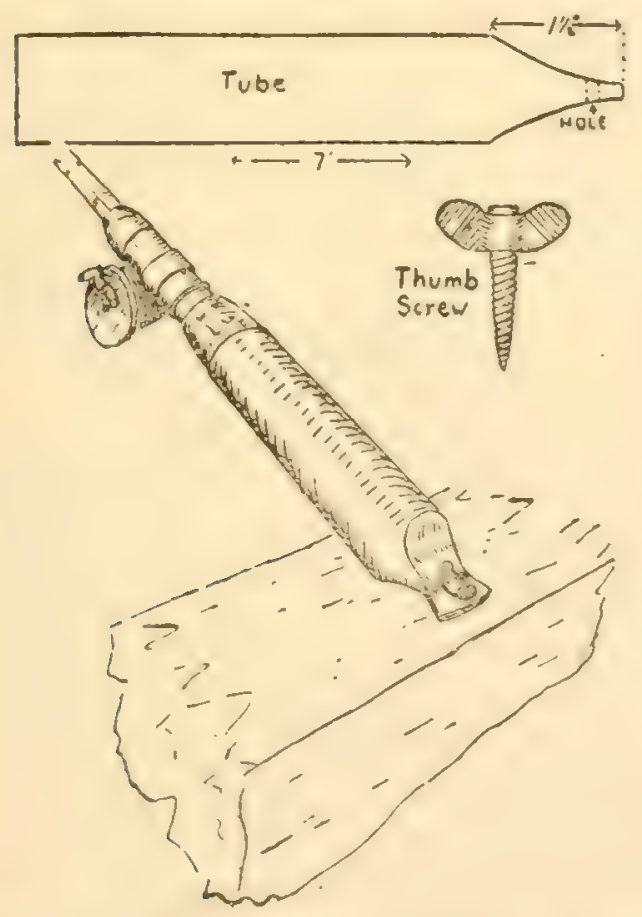

large enough to accommodate an ordinary thumb screw. Now all I have to do is to screw my bit of tube tight to the edge of the boat or pier, stick in my rod and I am all set. Where it is not desired to screw the tube tight, a bit of string may be run through the screw hole in the tube and tied to the boat. I find it best to have the tubing of such a diameter as to allow the rod handle a little play.

\section{A HOME-MADE CAMP STOVE}

\section{By Chas. S. Youngs}

I have noticed in your book, as well as in several others, articles upon camping outfits, and reading them brought to mind a stove

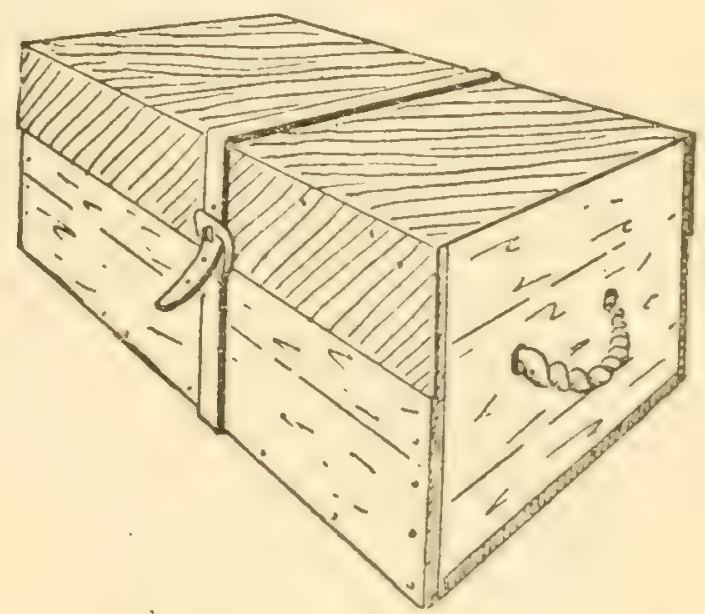

which I have used on several occasions and which proved very satisfactory in every way. I am enclosing a rough drawing to illustrate same.

The stove is very easily made and not very expensive. Get a sheet of Russia iron from a tinner and have two edges turn down, as shown in Fig. I, the size to be governed by any box or chest which is carried on the trip, as the iron can be placed on the top or bottom of the box or chest and strapped on out of the way. A fire built under the iron 
when set on the ground will be found to prove very satisfactory.

If a more elaborate stove is desired it might be fashioned after Fig. II, with both ends closed by riveting a strip of the same material in place and cutting a door

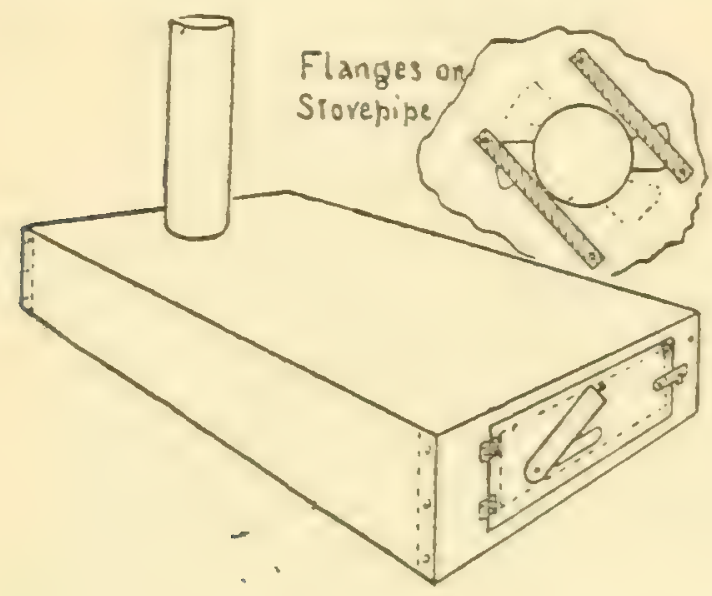

with draft in one end. A stove pipe made of a piece of small eaves trough may also be inserted through a hole in the top and fastened from the inside with the two flanges or cleats fastened to the underside of the top.

\section{MARKING A ROD}

\section{By Julrus Frank}

A very fine casting-rod was found and could not be returned to the owner because the finder knew no way to locate him. This on the rod I scraped the varnish and bared the wood.

I took a letter head that had my name and town address printed on it, and with a very fine grained sandpaper I sandpapered the back of the paper until the place over the name was very thin. Then with a very sharp knife I cut name from the paper.

Having paper and rod thus prepared, I spread a very thin coating of varnish (I used Valspar) on the rod in the place previously scraped; I placed the name in this space and spread a thick coating of varnish over all.

When the varnish was completely dry I found that the paper was entirely transparent and the name appeared as if printed on the rod.

Thus you see that I have plainly, inexpensively and permanently marked my rods.

\section{A CAMP KNIFE}

By John B. Cowing

The accompanying diagram shows a camp knife to be made from a piece of broken handsaw blade or from a carpenter's steel scraper blade, with a sole leather

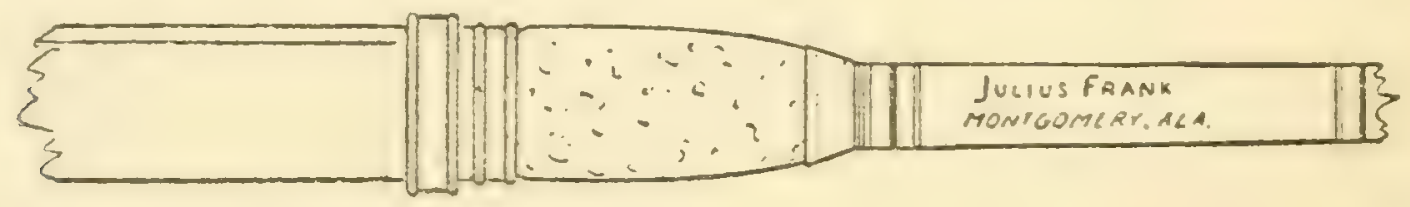

led me to mark my rods in a very simple and effective manner. Following is my Kink:

Just above the reel-seat in the first space between silk windings handle riveted on, and the handle sandpapered and varnished with good rod or spar varnish. This makes a light but useful knife, good for general use, but not in- 
tended for splitting bones or wood. The knife can be cut from a piece of tempered steel with cold chisel and file and after riveting on the handle, the knife can be trial was with aluminum paint, which wore off very quickly. Then we tried silver leaf with sizing and aluminum color in size, with almost similar results.

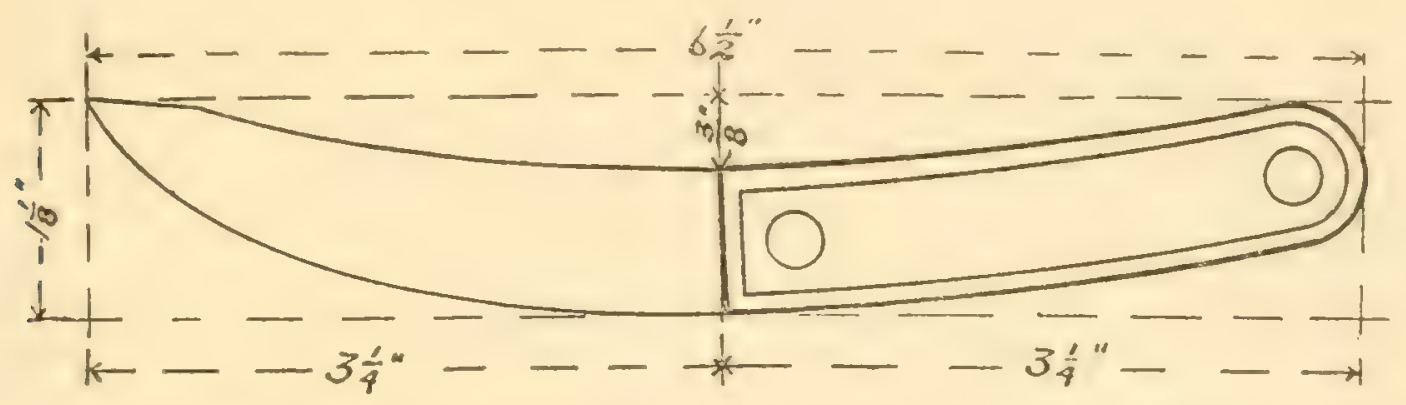

ground and finished as desired without any additional tempering, as it is not necessary to draw the temper to cut the knife to shape. A grindstone, with water, should be used to finish the blade to avoid drawing the original temper.

\section{BRIGHTENING THE PHANTOM}

By H. E. NeUMANN

About five miles above our city the Rock River is rather shallow with a gravelly bottom. It is well stocked at this point with small-mouth black bass, but the carp have also found their way here and in consequence the water is not as clear as it was in former years. This fact necessitates the use of a bright bait when casting.

One of the most successful baits in use here is a Phantom Minnow, but the anglers soon found that the color on the Phantom did not last very long and the problem has been to find a way of refinishing them. Our first
Finally I hit upon the idea of varnishing the minnow with a good spar varnish and after about half an hour, when the varnish had become tacky, covering it with a piece of tinfoil cut to size. This is brighter than the original minnow and does not come off. It also adds a slight weight, which is a desirable feature with this bait and, best of all, it gets the bass.

\section{INDEXING KINKS}

By F. C. Hajex

Ever since I subscribed to OUter's Book I have been interested in the Kinks it contains each

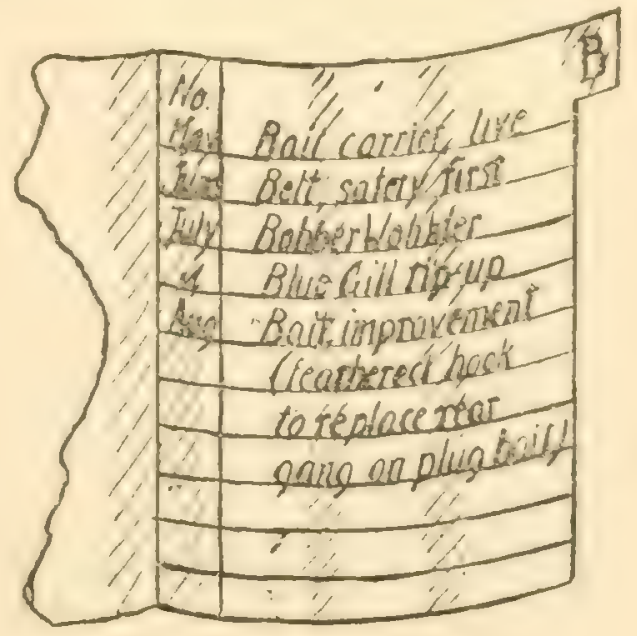


month. In order to keep a line on them I indexed a blank note book alphabetically and entered them as shown in the diagram. If I want information on a certain Kink I pick up my index book and in a second I know in what issue to find it.

\section{FISHING FROM THE BANK}

\section{By S. C. VANier}

Nearly everyone who fishes from the bank of a river or creek has tried the expedient of sticking the butt of his pole into a hole in

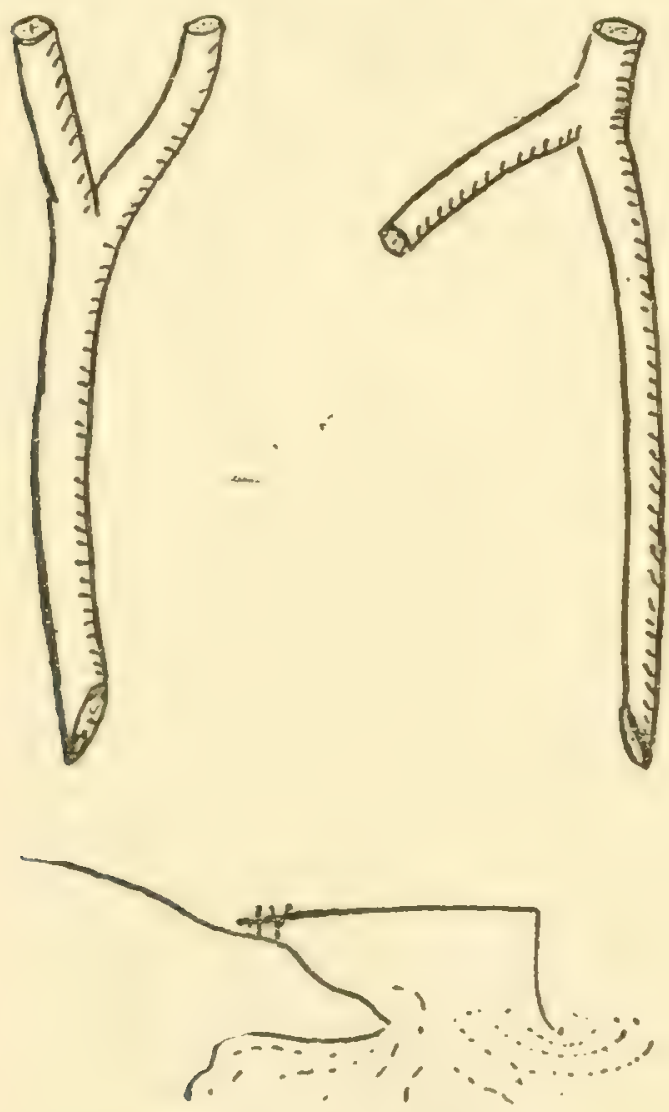

the ground so he would not have to hold it in his hands. Then, every time you pick up the pole to see whether you have a bite, the hole crumbles and you have to dig a new one. A couple of forked sticks, which you can cut on the spot, will remedy this difficulty and give you a much better pole holder besides.

Cut a fork-shaped prong about two feet long and rest your pole across it. To keep the butt from tilting up, cut another fork with one short and one long arm, like a figure " 7 ," and hook this over the butt of the rod to keep it down. You can now remove your pole and put it back again as often as you want. Hide the forks in the bushes near your favorite fishing hole and they will always be ready for you.

\section{QUICK COLORS FOR BAITS}

By Frank C. Hajek

Lately, when trying out homemade plugs, I have colored them with lumber crayon instead of enameling them. This looks as good as the enamel and eliminates the trouble of enameling the bait in case it proves worthless. This crayon resists water and lasts quite a while. It is cheap and can be purchased at any stationery store. I carry two pieces in my tackle box, one red and one yellow.

\section{A HANDY CAN-HANDLE KINK}

\section{By W. A. Stowe}

When a sportsman starts out on a trip, be it long or short, he tries to keep down weight and bulk of his outfit to as little as possible, 
and yet leave out nothing that will be necessary to his comfort or pleasure.

But when the time comes to pack up his duffle for the return trip, the enthusiasm that attended the start is lacking. Then he would like to just walk away and leave most of his stuff lie where he got through with it.

I have found a little Kink that costs nothing and helps a little toward this desirabe end.

Many sorts of provisions and groceries are now packed in friction top tin cans of various sizes, syrups and cooking fats, for instance.

Save three or four of these of the sizes you will need most, and when you take a camping or canoe trip leave your stew kettle, coffee pot and such utensils at home and take these cans instead.

The Kink consists of having two or three wire bails or handles for making use of these cans. You can make these bails in a few minutes with a small pair of pliers, and they will last for years. Any wire that has a little springiness is all right; piano wire or old bicycle spokes are perhaps the best. Make three or four different sizes, but of such size that they will go down in the can they are intended for so that the cover can be put on. Then you can fill your cans with milk or soup or coffee, for instance, push the bail down into the can, put on your friction cover and you can safely pack those cans of liquids anywhere or let them roll about in the bottom of your canoe. When you want your hot stuff you pry off the cover, pull up the bail and hang the can over the fire. The spring
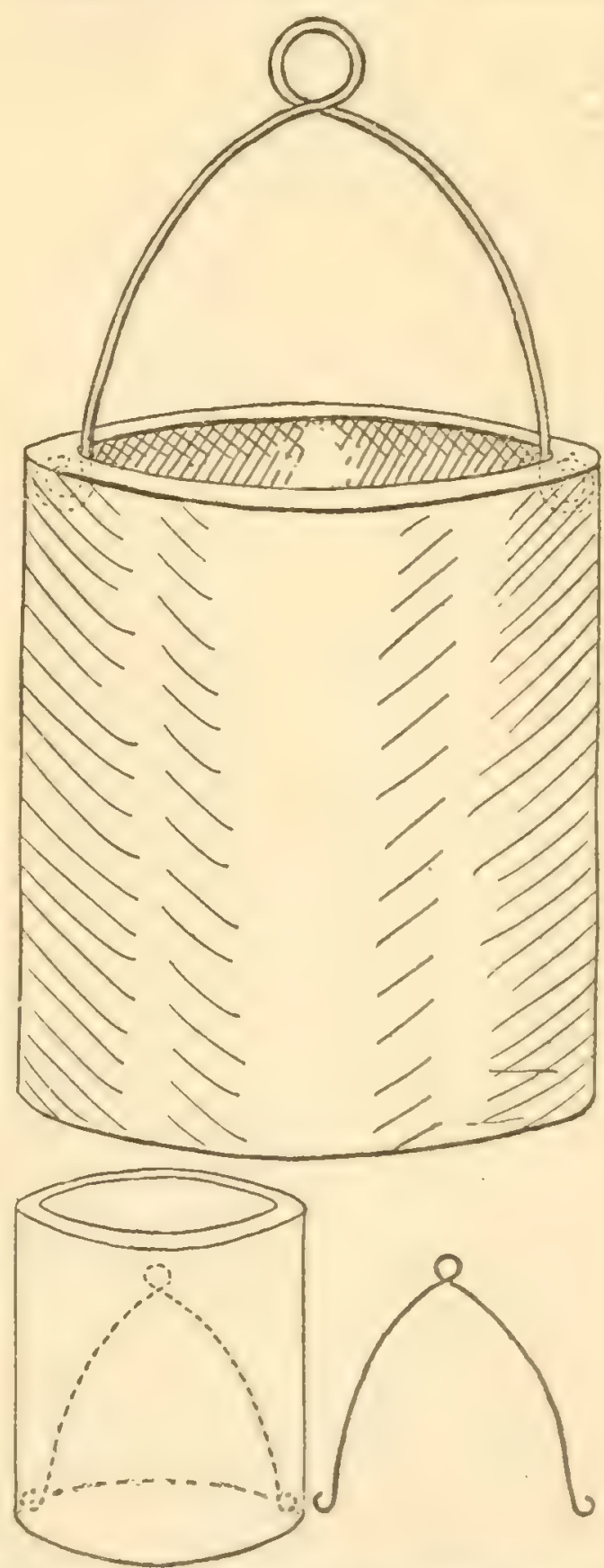

of the wire holds the bail up and the ends against the sides of the can where the eyes in the ends of the wire catch under the rim of the can. The bail automatically spreads to diametrically opposed 
points, therefore the can will always hang plumb from it. When your trip is over you keep the bails and can the cans. The cut explains the device sufficiently.

\section{WATCH SPRING WEED GUARDS}

By H. J。 Loud

Broken pieces of mainspring, which can be obtained from any watch repairer, make excellent material for constructing weedguards. A turn or two of fine wire and a drop of solder fasten the guard to the hook shank and it may be bent to any shape desired.

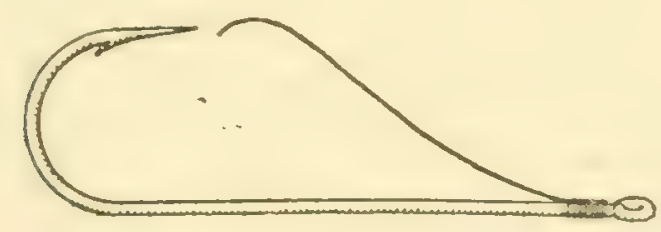

I have found the shape shown in the diagram to be a most effective one.

\section{AN ANTPROOF BREAD BOX}

By Frank E. Wilder

One of the most disagreeable experiences of camp life is to come home after a long fish or hunt, to the little log cabin for a good supper and find that red ants or cockroaches have beaten you to it by several hours. What's more, the women cannot be persuaded to join you on a few days' fish or hunt if they are "obliged to put up with the nasty insects." You say to yourself, "There is no use trying to keep food from hungry red ants; what more can a man do than to put his food into a good bread box?"

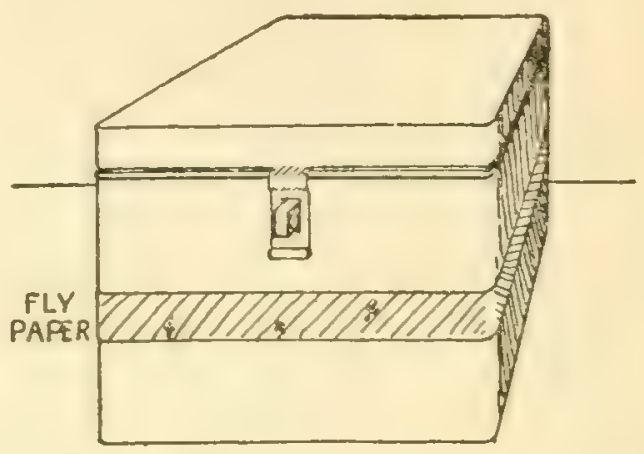

Here is what he can do to prevent those unpleasant raids on his food supply which keep his wife from being with him: Buy five cents' worth of fly paper. Take a sheet and cut it lengthwise in strips. Cover the back of one strip with paste (a mixture of flour and water can be used) and place it horizontally on the side of your food container, as in the diagram. Continute to paste on the strips in the same manner until you have completely encircled your container with fly paper. Now no bug that walks can get into your bread box and spoil that big meal you and your wife are going to have after a day in the open.

\section{A SIMPLE HOOK RE- MOVER}

By J. H. Robinson

Our friend, the Horned Pout, has a very bad habit of completely swallowing the hook. And

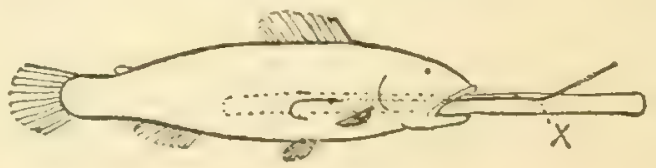


sometimes it is your last hook at that and you haven't even a pocket knife handy. Here's a simple way to recover your property.

Select a stick, round preferred, about half an inch thick and 7 or $8 \mathrm{in.} \mathrm{long.} \mathrm{Holding} \mathrm{the} \mathrm{fish} \mathrm{in} \mathrm{the}$ left hand, pass the stick down into the gullet and beyond the hook. Draw the line up taut and hold it against the stick with the right hand at the point marked $\mathrm{X}$ in diagram. Let go of the fish with the left hand and give him a rotary twirl around the stick. You will be surprised to see how easily the hook becomes loose and without being bent or broken.

\section{A GOOD HOOK TIE}

\section{By Martin Schuldt}

The diagrams show a simple hitch for putting a hook on the end of a line. This hitch is quite

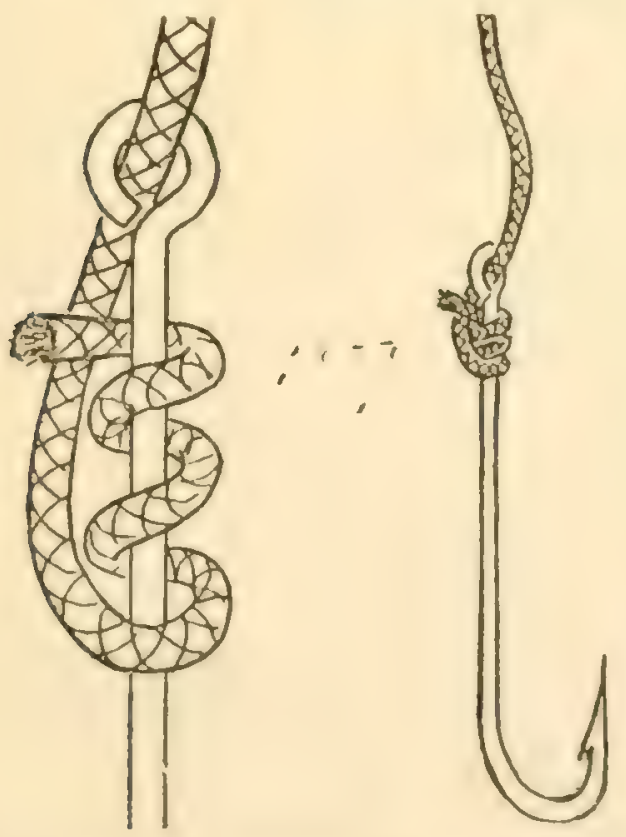

safe, for the harder the pull upon it the tighter it holds. Yet it can be unfastened in a moment.
Nearly all fly fishermen use this same hitch for tying their leaders to their line, but comparatively few anglers seem to have caught the idea that it is equally good for the purpose suggested herewith.

\section{A KNOCKED-DOWN FIRE GRATE}

By F. L. McAlenvey

The accompanying diagram shows a simple grate that has proven its right to recognition

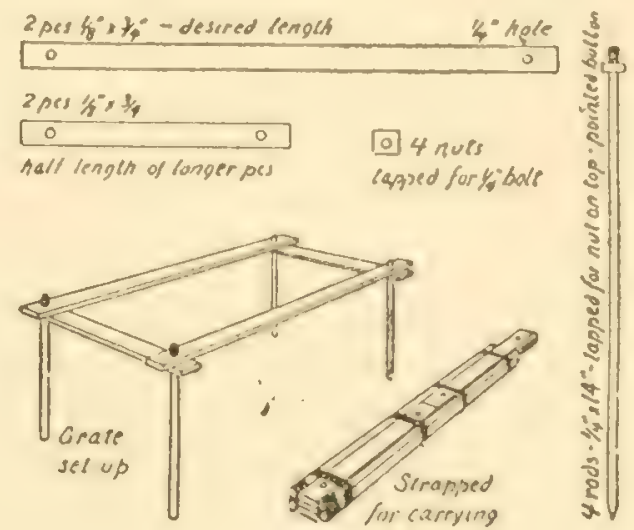

among those who cook their meals in the open.

The grate proper consists of four bars, two long ones for side pieces and two short ones for end pieces. These bars may be made any length desired, but if the short bars are made half the length of the long ones they will pack especially well, as shown in the diagram. The bars are made from $3 / 4$ inch by $1 / 8$ inch iron, and near each end are bored holes that will readily accommodate a $\mathrm{y} / 4$-inch iron rod.

The legs are simply $1 / 4$-inch iron rods, 14 inches long, pointed at one end and threaded at the other, so 
as to allow an ordinary nut to be screwed down on them for about half an inch.

The diagrams will show how the grate is set up and also how compactly it may be strapped for carrying. This grate is light, strong and inexpensive to build.

\section{THE EMERGENCY KIT}

\section{By Arthur W. Stevens}

Last spring when Outer's Book offered the Standard Tackle Box as an inducement for the renewal of subscriptions, I immediately decided that I wanted one. My subscription had not expired, and I didn't need any inducement to renew when I did. Also, I must confess, I am not much of a fisherman, so you might be interested in knowing the use to which the box was put.

$\mathrm{My}$ work of surveying keeps me, sometimes, several months out of reach of a doctor, and it behooves one in such a position to equip himself with some sort of an emergency medical and surgical outfit. None of the prepared outfits on the market appealed to me as the right thing; but the tackle box, with its numerous compartments, seemed to offer a possibility of making up an outfit to suit my own needs: It has proved so successful that others might wish to profit by my experience.

The contents of the box are as follows:

Two-inch gauze bandage.

Small roll of absorbent cotton.
Adhesive tape.

Phial of iodine in small box to prevent breakage; used as antiseptic.

Potassium permanganate crystals, for rattlesnake bites and antiseptic.

Compound cathartic pills.

Cascarets.

Potassium chlorate tablets, for sore throat.

Carbolated vaseline, best salve for cracked lips.

Three-grain quinine capsules.

Silver tweezers.

Short-handled manicure scissors. The curved shape of these scissors gives them an advantage over ordinary surgical scissors in cutting away loose skin and such minor surgical operations as one will ordinarily be called upon to perform.

The large compartment in the upper part of the box contains:

One package of picric gauze, for burns.

Two U. S. army first-aid packets.

This list is given merely as a suggestion. The really practical part of it is that the contents may be made up to suit individual needs.

I might add that just a few simple home remedies that we all know how to use are all I have ever found use for in the mountains. The more complicated outfits recommended by medical and surgical men are all right for the skilled man; but we, in our ignorance, are apt to get our wires 
crossed and do the wrong thing; therefore, I feel safer without them.

For a reference book, the First Aid Text Book, published by the American Red Cross, Washington, D. C., is about as good as can be obtained.

\section{A HOME-MADE FOLDING NET}

By L. W. Martin

A good deal of my angling equipment is home-made or homeimproved. So when I saw in a sporting goods catalogue a landing net with a short folding handle which looked desirable to me. I set about to build one with fairly good results.

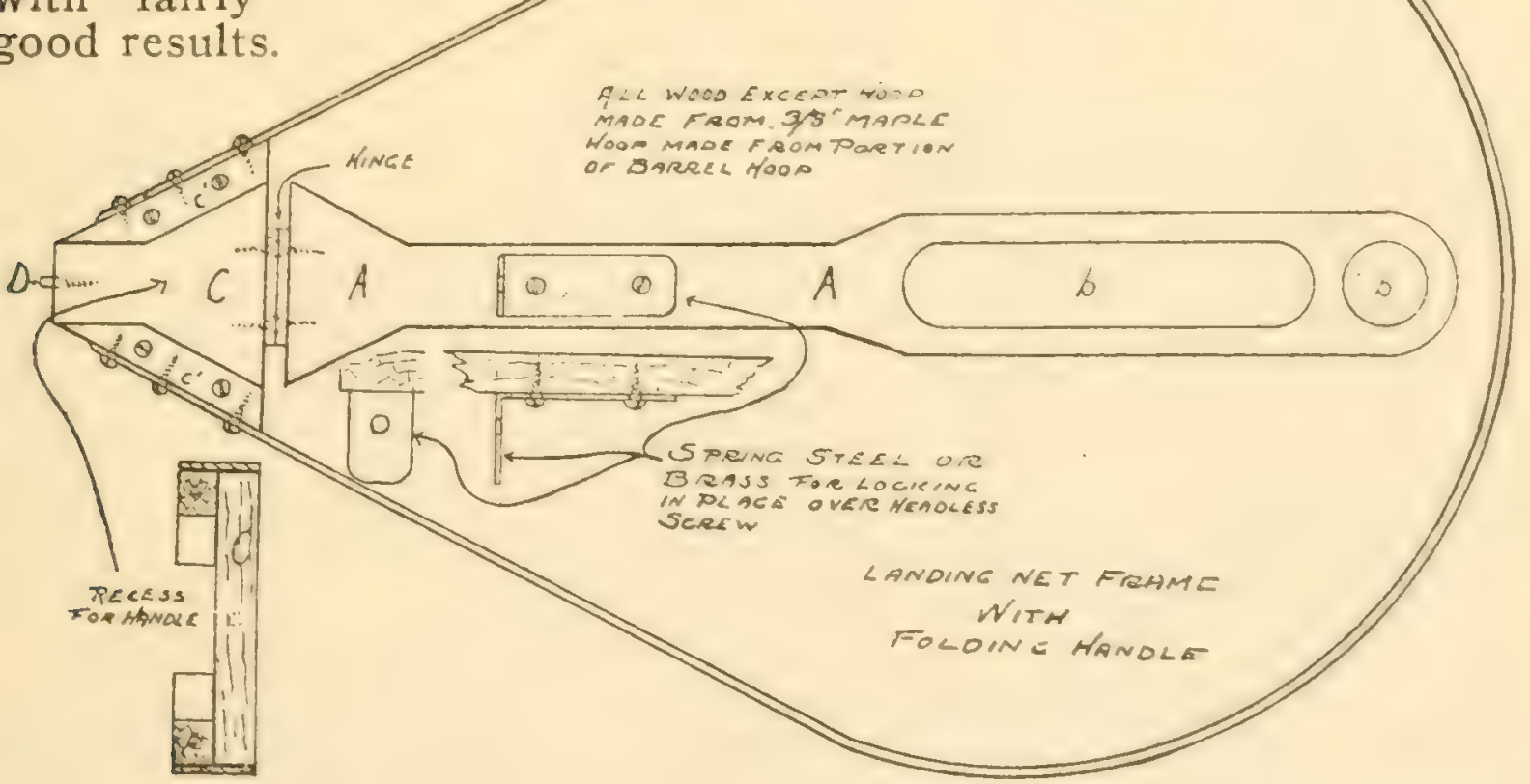

A piece of $3 / 8$-inch hard maple, planed on both sides and shaped as in the diagram (A) made an excellent handle. For the sake of lightness and looks, I even cut a couple of mortises out of it (b-b). A piece of flour-barrel hoop, planed down to the desired weight and width with a spokeshave solved the mystery of the hoop. For the throat piece another block of the $3 / 8$-inch maple was used (C) with a narrow strip of the same screwed on either side $\left(c^{\prime}-c^{\prime}\right)$ to form a bed or socket for the end of the handle to rest in. The handle was attached to the throat block by a small hinge, which allowed it to swing from the center of the hoop to the bed where it fit quite snugly.

Locking the handle in the open position was the next difficulty. 
block. The stud was made from another small screw with the head filed off. The trigger was left long enough so that it can readily be released from the stud by the index finger. When locked in place it is almost entirely free from strain.

A good coat of varnish completed the job. The net bag was not a difficult thing to make.

\section{FOR TROLLY FISHERMEN}

\section{By JoHn Connel}

Fishing with the trolly line is not especially a fine art, but once in a while I like to practice it, even when up among the bass and pickerel of the northern lakes. It is a relief to just loaf for a day and go after pan fish by a lazy man's methods.

Now, my little Kink is right here: Most anglers use gut

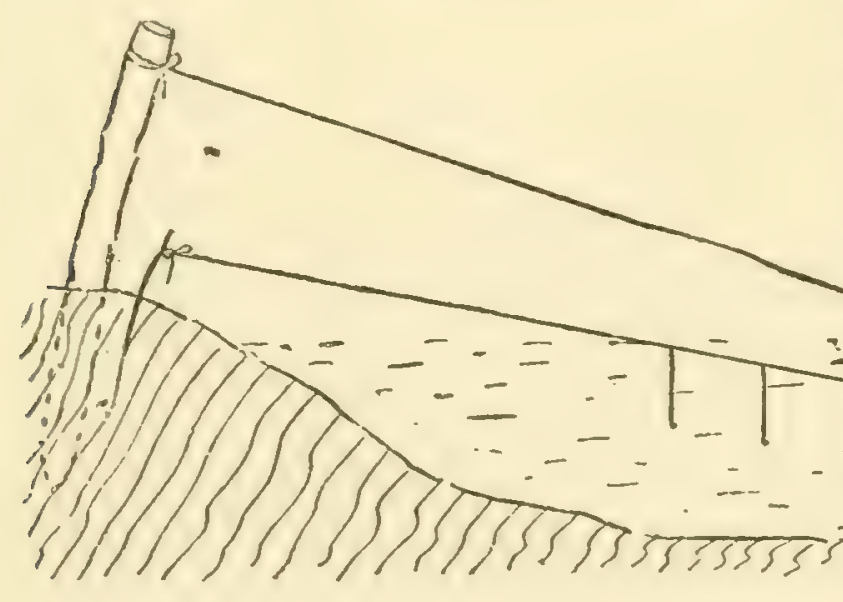

snelled hooks on their trolly line. I have found that the snells have a great habit of twisting themselves around the line, especially if there is the least bit of wave action in the water. So, instead of snells, I use plain hooks, fastened to the trolly by a short bit of line. About a half inch from each hook I place a single small split shot sinker. This is just enough to keep the hooks from swinging and tangling with one another or with the trolly line. After that, just bait your hooks and "let her go." Tie the end of your line to the little dingle bell and lie back and loaf, waiting for the tiny alarm to tell you when there is "something doing."

\section{WHEN THE STREAM GOT ROILY}

By Wilford R. Lutz

I was talking to an angler this morning who read me a kink that he had some experience with in Maine. It was a day when the fish would not bite. He had tried everything in the line of flies from a Black Gnat to a Red Dragon, without much success. $\mathrm{He}$ was whipping a stream below some gentle rapids, when he accidentally caught sight of the finest school of trout that fisher- 
thought the "stuff was off." But exactly the opposite happened.

As soon as the muddy water struck that pool, those trout seemed to have suddenly gone crazy. He changed from flies to a worm and in less time than it takes to tell he had landed six ont of that school of beauties, from a half pound to one and a half pounds. He said that it was not very sportsmanlike, but he was out of meat.

\section{A FISHERMAN'S WAR BELT}

\section{By V. L. McKinley}

I often thought about a way to carry a light but complete equipment for a day's fishing together miscellany. Not very often do I carry a rod. Most of my fishing is on streams where I cut a pole on the spot, so my equipment is rather simple.

No. 2 is a light sheath knife, suitable for scaling fish, making shavings for the fire and handy for many purposes. No. 3 is a flat bag containing the culinary part of the outfit. If you are very swell, you may carry in it a 7-in. frying pan with a folding handle. As for me, I cut off the handle of an ordinary sheet steel skillet and use the pliers to grip it with. The bag is made of heavy waterproofed muslin with a drawstring on the top and belt loops on the back. Along with the pan I carry

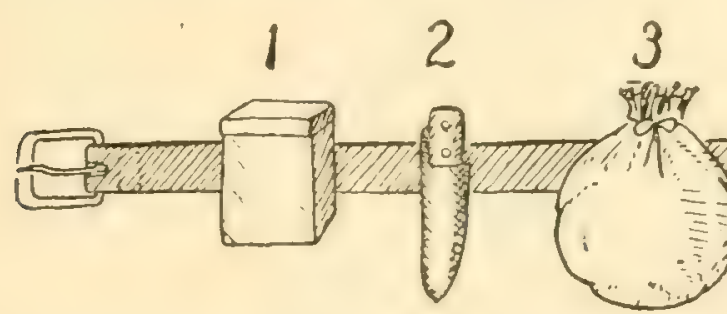

with the materials for a warm noon lunch, the whole to present a minimum of weight and bother in handling. The war belt Kink shown in the diagram solved the problem for me.

It will be noticed that there are five articles on this belt. No. 1 is my notion case. This is a small tin box with hinged cover and a couple of belt loops riveted on the back. Any small tin box will answer the purpose or a small cartridge pouch will do very nicely. In this box I keep my line, hooks, sinkers, a small pair of pliers, a waterproof match case and other

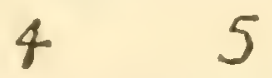


from the fire, together with hot water to clean the grease from the frying pan.

No. 4 is a light belt axe. It is useful in cutting through the brush to get at those likely looking holes and is worth its weight in gold when building a hasty fire after an unexpected ducking.

No. 5 is a pet crotchet of my own, an Eagle Folding Landing Net. The leather sheath protects it perfectly from the brush, yet it can be extended with one hand. By using it carefully I manage to catch most of my bait with it also.

\section{AN OUTDOOR STOVE}

\section{By Joseph T. Sproule}

The outdoor stove illustrated in this article is obviously very simple, consisting merely of two logs and three keg hoops. The hoops were taken off of an old keg and bent into an elliptical form which measured 3 or 4 inches the short way. They were then stored with

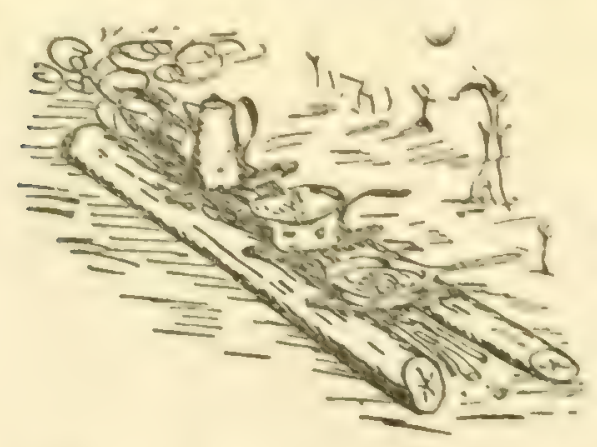

the rest of the camp outfit until needed.

To set up the stove all that is necessary is to arrange two logs about a foot apart and parallel to the direction from which the wind is blowing. Then lay the hoops across as shown, and the stove is complete. This form of outdoor stove is very convenient in that only the three hoops need to be carried in the camp outfit, and efficient in that most of the heat is concentrated to the area immediately beneath the cooking utensils.

\section{EARNING THEIR WAY}

\section{By H. B. Borce}

When traveling very light one might hesitate considerably before taking along even an extra pair of pants. Of course, you hope

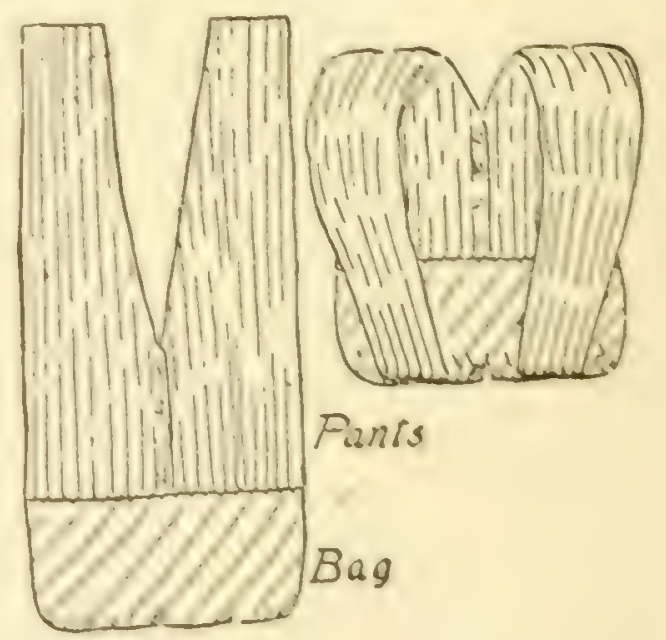

that the pair you have on will see you through. But "accidents will happen" and the nether garments, in particular, secm to be fatally inclined to mishaps. The diagrams show a neat way to make the extra pair of pants earn their transportation.

Make a shallow bag, the same in diameter as the waistline of the pants. Sew the edge of this bag with rough stitches to the waist of the pants. Then turn the legs over and sew them also to the 
bottom of the bag. Your pants have now become a first-rate pack sack. Articles may be put in and taken out through the fly, and the legs form the shoulder straps. And if anything should happen to the pants you have on, you need only rip out a few coarse stitches to make the extra pair available.

\section{A MINNOW BUCKET TRICK}

By Louis J. J. Tansey

Sink a small baking powder can in your minnow bucket, laying the can on its side in the bottom of the bucket so that the minnows can hide in it. When you want a minnow, lift the can out quickly and you will find two or three in

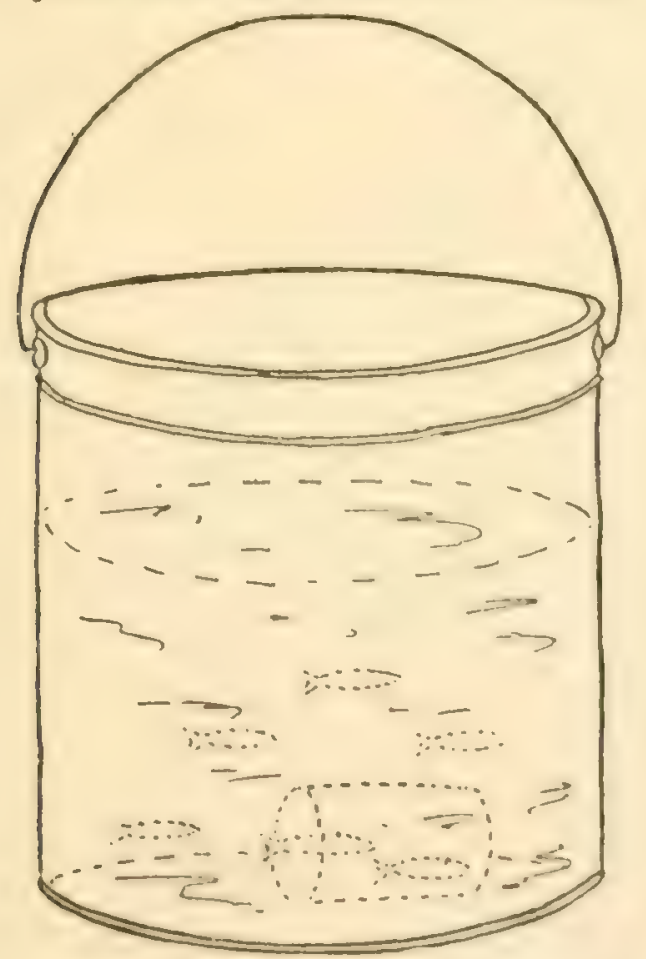

it every time. They always appear to be the largest and best ones in the bucket, too. This saves chasing the minnows around or spearing at them with a little dip net whenever you want one. (Courtesy R. D. V.)

\section{A CAMP CANDLESTICK}

By V. J. Nichols

A candle holder in camp? Sure thing. Take a split stake, a bit of

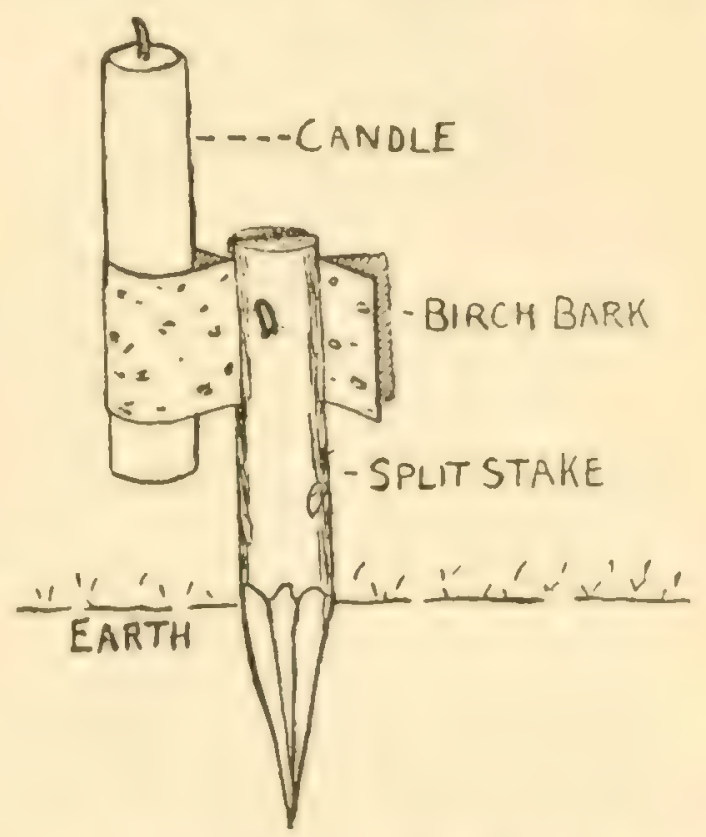

birch bark, and there you are. The diagram shows the combination better than words.

\section{IMPROVING THE MODEL} 1914 SAVAGE .22

By Wm. Gunrich

In the fall of 1915 I bought myself a 1914 model Savage rifle, .22 caliber, tubular magazine, which I fitted with Marble's peep rear and Vicker's Maxim front sights. I now thought that I had an ideal rifle, and this it really proves to be.

But my troubles began when I went out hunting. Going along an old logging road one bright morning I was surprised to see a 
partridge strutting up the road right ahead of me.

Of course, here was a chance to try the new gun, so putting the Vicker's Maxim around the bird's head I pulled the trigger. The result was a distinct click. Now I remembered having put a shell into the barrel, so this somewhat surprised me. But on looking it over I found the action partly open and no shell in the barrel.

Well, I pumped in another shell and kept on, carrying the gun in one hand, clutched around the middle, when presently I noticed the slide handle move back. I now saw what caused the action to open.

In carrying the gun my gloved hand had pressed the little lever which releases the action when the gun is to be opened before firing. This lever runs from instead of to the receiver, projecting at the front end for a distance of about a half inch or more. I don't exactly remember the length.

Now it occurred to me that if this projection were not so long it would not be so likely to be accidentally pressed. So accordingly I cut it off, leaving it about three-sixteenths of an inch in length. I find this plenty long to release the action when I wish it to be released, yet too short to be pressed by accident.

- Now you boys who do not own one of these rifles do not think that the rifle is no good, since a better rifle is not made of this class. This one little defect (which really is not a defect, since in target shooting the longer projection is the better or at least might be a little handier) can easily be remedied.

\section{A TWIST PREVENTER} By Dick

How often do we read an article written by some of our best anglers deploring certain baits because of their tendency, in fact their sureness, to twist and snarl the line when used even a short time! With what I call the Winged Keel (perhaps the editor can give it a better name) you can use the following baits for hours with little or no twist when used or reeled at fishable speed: The Archer spinner, Phantom minnow, Pearl wobbler, Cornwall spinner (with shortened wire), pork, frogs, shiners and, in fact, any bait that twists or turns itself.

Of course, the Winged Keel is useless on any bait unless a swivel is attached either on bait or line below keel.

By the way, the Cornwall spinner (shortened wire) is a dandy bait to cast, and it sure has proved a killer for bass and pickerel in the hands of myself and friends. I use the bottled shiners, they being hardy and tough, and lasting longer than freshly-killed bait in warm weather.

But to get back to my kink. Would advise adjusting keel either close to or away from swivel as needed in order to get 
swing of bait, the keel riding on top of line, wavering when being reeled in.

Take a winged sinker (Fig. 1), which most all tackle stores sell,

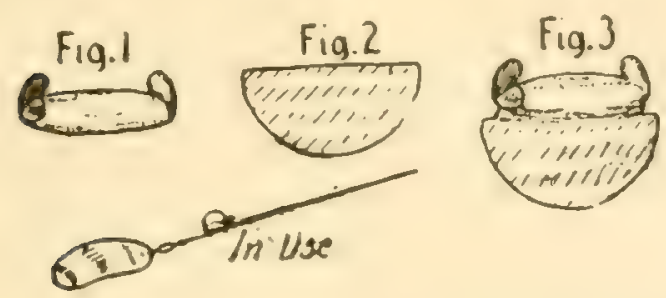

and a thin tin disc cut in half or folded if desired (Fig. 2). Solder to back or under side of sinker (Fig. 3), and the trick's all done.

The tin washer used for tar paper, tht disc on a circular typewriter eraser or a coin cut in half will do nicely and, believe me, you can cast what I believe to be some of the best baits on the market with pleasure and with no regrets for your line.

\section{TROLLING FROM A CANOE}

By Russell Moen

Many fishermen think a canoe is almost useless to fish from. No comfort-too tippy-car't depend on 'em-just for Injuns, etc., ete. Did you ever fish from a canoe? I have used many kinds of boats, but for trolling my canoe is my favorite. Here is my method of using it:

If fishing the left bank of the river I paddle on the right side of the canoe. I place the butt of the rod under the right knee with the rod resting across the gunwales so that the reel just clears the right gunwale, allowing it to run freely when the strike comes. I press the left knee against the left gunwale with the rod resting against it. This holds the rod

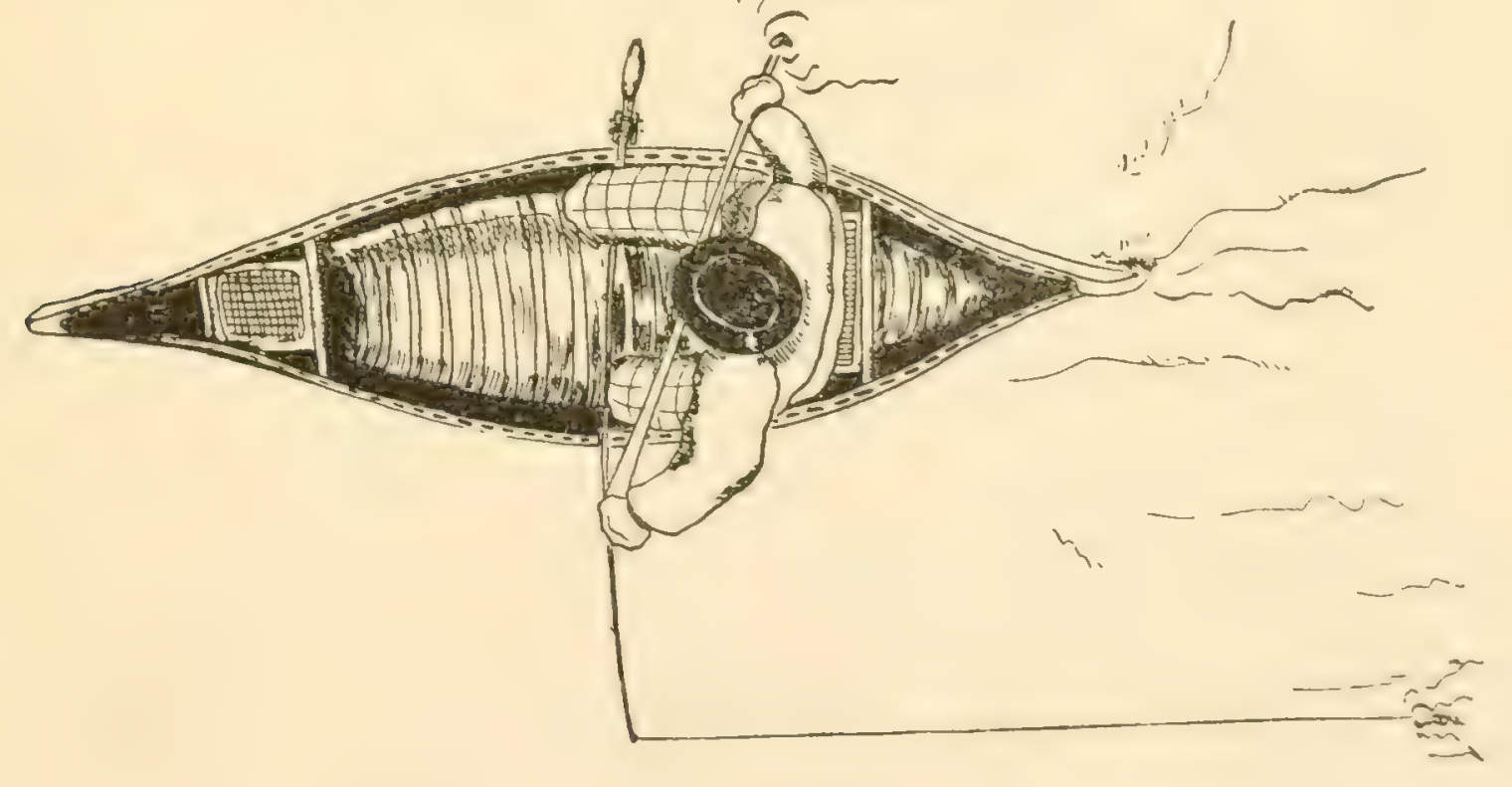


rigidly in position. The bait comes trolling along quietly on the left side of the canoe toward shore and the paddle, on the right side away from the rod, line and bait, makes very little fuss.

This method is practical and lots of fun. Try it out and see.

\section{AN INGENIOUS TACKLE BOX}

\section{By C. M. Mull}

The main idea in designing this tackle box was to have my complete outfit with me all the time, strapped to me so that it was easy to carry yet entirely out of the way. At the same time the contents of the box must be easy and six inches wide. The exact size should, of course, be determined by the amount of tackle to be carried. The trays and box proper are built of a good grade of hardwood or a very good grade of pattern lumber. The pattern lumber will weigh the least. The entire interior should be given two or three coats of shellac. The outside is intended to be covered with a heavy water-resisting brown canvas, fitted well to the box and then put on with a heavy coat of shellac.

The drawers themselves have several unusual features. First of these is the sling that enables the drawers to be pulled clear out and rested horizontally on the top of the box without falling off. The
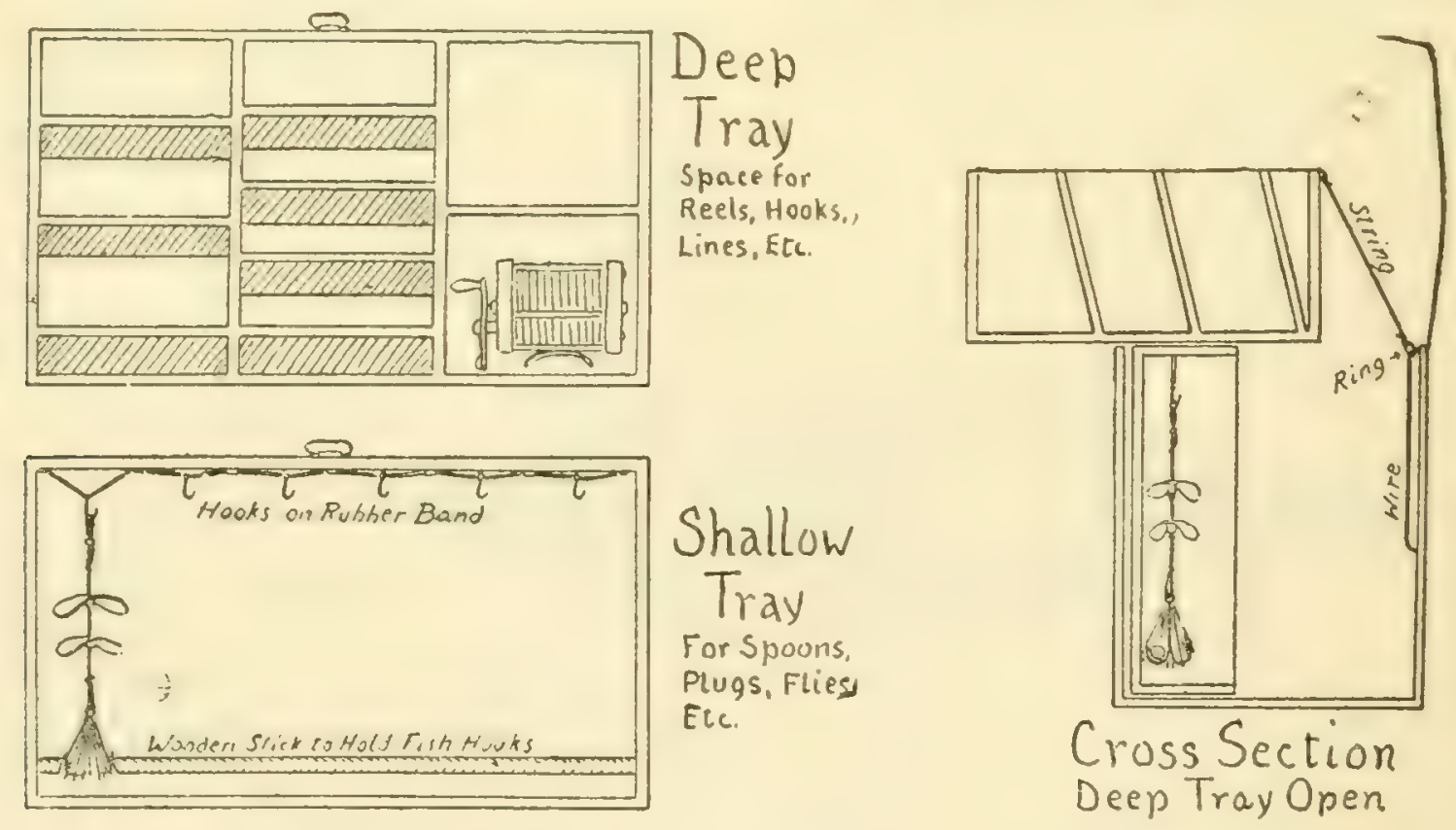

to get at. Every single piece

Shallow Tray For Spoons. Plugs, Flies Etc.

Cross Section Deep Tray Open

should be accessible without resorting to laying anything down to get at anything else.

The box as diagramed is about one foot long, seven inches deep

cross-section diagram shows how one of these slings work. A wire is put in each back corner of the box and fastened top and bottom, so that a small ring will slide freely on it. To this ring a bit 
of stout cord is fastened and run to the top back corner of the drawer. This string is just long enough to allow the drawer to rest horizontally on the top of the box without tipping or falling off. The forward drawer has the same arrangement except that the two wires are fastened to the ends of the box and act in addition as runs between the two drawers.

It will be observed that the partitions of the smaller compartments, intended for hooks, sinkers, etc., are set in on a slant. This is to keep the contents from falling out while the drawer is being lifted up. The two larger compartments are intended for reels and do not need to have the partitions slanted.

The shallow tray is made deep enough to hold the thickest plug or spoon hook. Along the top of this tray is a row of hooks attached to a rubber band, which is tacked to the box between each two hooks. About a half-inch from the lower end of the drawer and a quarter of an inch from the bottom a small hardwood rod is run from side to side. By hooking the tail gang of a bait over this rod and attaching the swivel to one of the small hooks fastened to the rubber band, the bait is suspended perfectly, so that it will not be thrown around, scratched or tangled with the other baits.

A fold of the canvas cover, fastened with a strap and buckle, forms the lid of the box. Buckles are attached at each end for fastening the shoulder strap. Two snap hooks are placed lower down for fastening a strap to go around

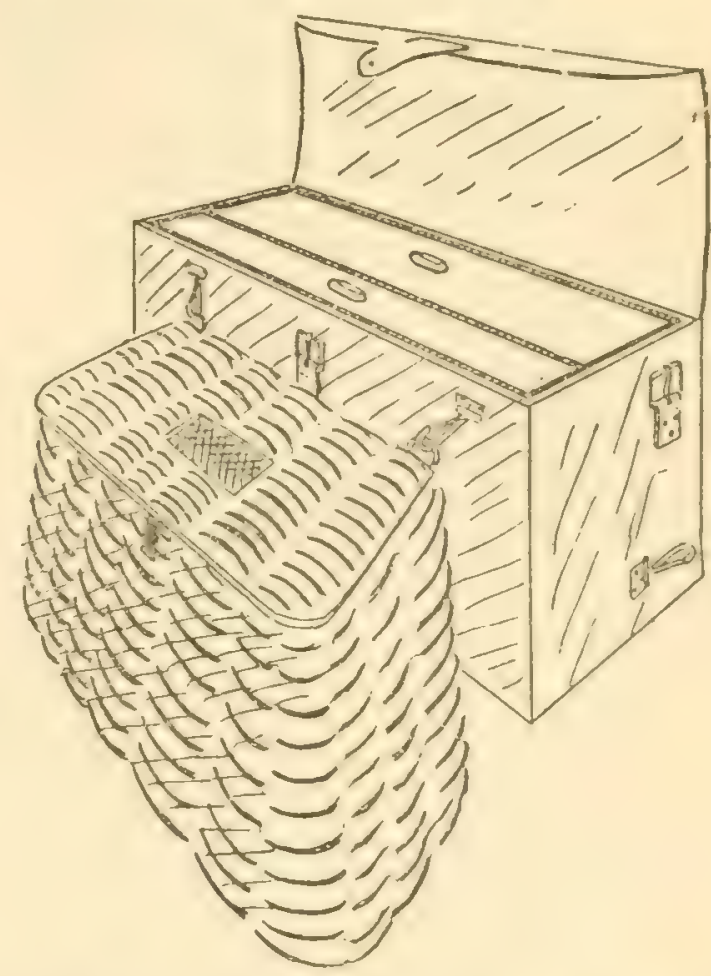

the body and keep the box from swinging while casting. If the box is carried on the back of the hips, the snap can readily be unfastened, so that it may be swung around to get at the contents. Two more snaps can be put on the front of the box to suspend a creel from.

\section{FOOLING THE SMALL MOUTHS}

By Bass Fisherman

While bass fishing in a small stream in the Middle West, Butler County, Ohio, to be more explicit, I was bothered by having the bass make exceptionally long runs with the bait (was using soft crawfish), with the resultant trouble of having the line foul 
and losing strike after strike. After having lost about a dozen fish in this manner on each of two consecutive afternoons' fishing, and not being able to connect in any manner that I tried, I started to study the situation with the idea of putting one over on Mr. Small Mouth.

After considering and rejecting several plans I finally evolved this idea. Being a bait caster as well as live bait fisherman, I had in my tackle box a small spoon with one treble hook. On my next try for bass in the long hole I took this treble hook and a spool of silk thread with me. Procuring a nice bucket of craws I commenced operations by impaling the craw close to the body with one hook of the treble, binding the tail to the shank with a few turns of silk thread. The first cast was productive of a strike. Keeping my thumb on the reel I waited until the tip of the rod started to bend-then struck with the result Mr. Bass was hooked fair in the mouth and after a nice fight creeled. Eleven more followed suit. This little kink netted me twelve out of thirteen strikes. The thirteenth bass was such a good one that he carried the hooks off with him.

While it is customary to use one hook in bait fishing, I do not believe that this can be considered unsportsmanlike. I do not think that it was so much the threehook feature that netted good results as the manner of presenta- tion of the bait. While I do not employ this kind of means ordinarily it did the trick when all other methods failed in a peculiar circumstance.

\section{MY HOME-MADE TACKLE BOX}

\section{By A. A. Hodges}

How many times has the question been asked in this magazine, "What is the best way to carry bass plugs?" There is always something new to be tried out, or your friend tells you of a bait which was the only thing "they" would look at on a certain lake. Of course, you buy one to add to the collection and then wonder where you are going to put it. I used to carry mine around packed in their original boxes in a small leather grip. Usually the bait I wanted was at the very bottom, and more than once I would find that it had come out of the box and mingled lovingly with several others thait were rattling around loose. So I decided that it was about time to figure out some better method.

I picked up a small leather case which had been discarded by a traveling salesman and started with that as my base. The outside dimensions were $12 \mathrm{~T} / 2 \times 9 \times 3$ inches. From a tin shop $T$ bought some sheet zinc, the cost, by the way, being thirty cents. A wood block or form was made to fit the case and the zinc shaped over it to make the lining. The corners were soldered and the 
zinc box then fitted snugly into the case with two rivets to hold it on each side. The form or block was then planed a little on the sides and ends and the tray made over it. In the tray I
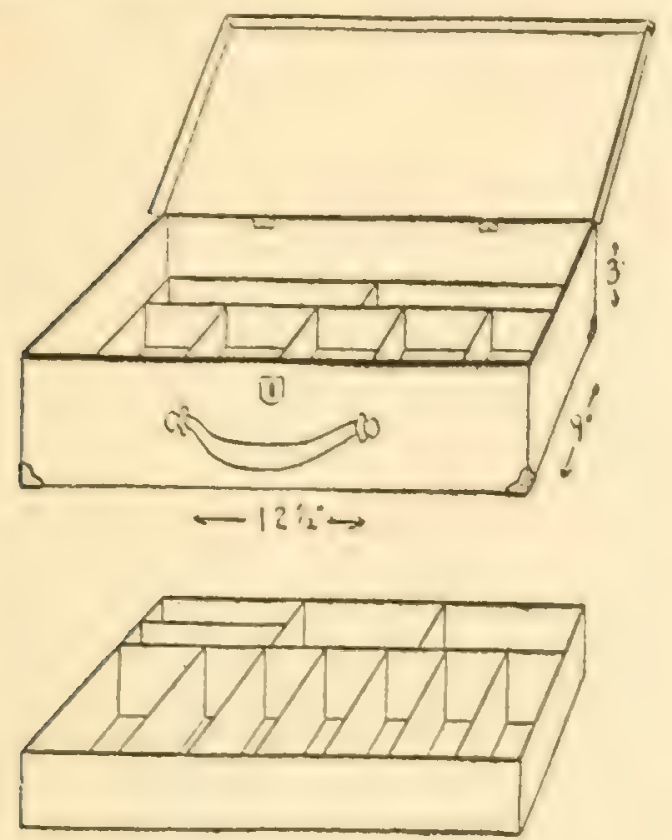

lapped the corners and turned back the edges so as to make it stronger and leave no sharp edges.

Then came the partitions. In the tray the compartments were made to fit the baits I had. It holds eleven baits, each in its own place and every one in sight. The lower part has wider compartments and holds extra baits, leaders, snelled hooks, a pair of pliers, small file, spoons, bucktails, extra hooks and spinners for the baits, etc.

As every thing fits tight there is no rattling and nothing loose. A set of brass corners cost $40 \mathrm{c}$ more, and with a couple of coats of spar varnish I have the handiest combination tackle and bait box for less than $\$ 1.00$ and all the fun of planning and making it.

The zine is light in weight and will not rust. Solder runs very easily and smoothly on it. All rough or sharp edges can be taken off with a file. The brass corners, are riveted to the zinc on the bottom of the case and on the cover they are just nailed with small brass brads and clinched on the inside.

As the case itself was only $1 / 4$-in. wood the zinc lining has made the whole thing exceptionally strong, and it can stand some hard knocks. Of course, you can't put it in your pocket, but it takes up very little room.

\section{CARTRIDGE BELTS}

\section{By A. W. Stevens}

Do you prefer to carry your cartridges in a belt, but refrain from doing so because they slip
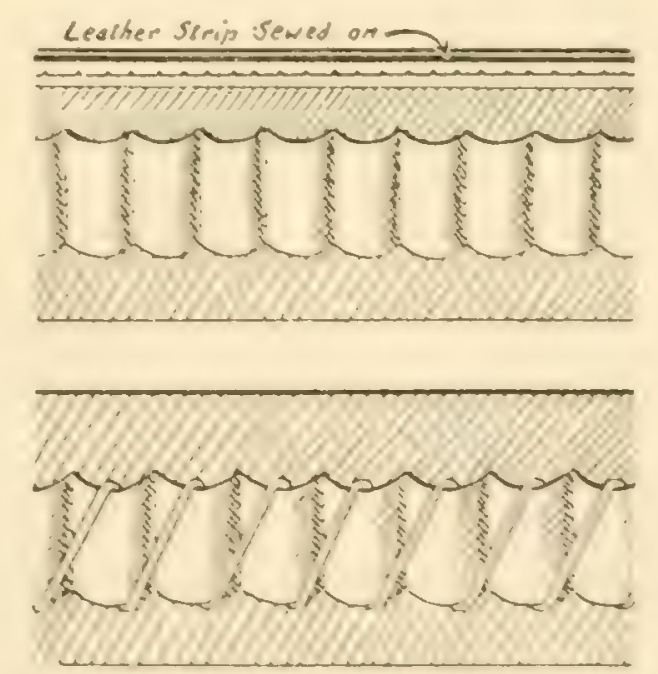

out and are lost? A strip of rather thick leather sewed on the belt a short distance above the loops will help hold the cartridges 
in. This is not an absolute insurance against loss, but it helps.

To carry cartridges in a belt made for cartridges of a larger size, lace a leather thong or thick string through the loops. If there is still too much room, lace back again so as to cross the strings.

\section{MOUNTING LEADERS SIMPLY}

By H. W. Buck, JR.

Some of us like to tie our own leaders, but after they are completed they may be somewhat of a problem if simply coiled and put together in a pocket of the tackle book. Even if kept separately, sorted as to size and length, there is always the trouble of pulling out three or four when we want only one. A very little trouble when the leaders are tied enables me to have them in perfect order slits as shown in Fig, 1. With a sharp pen-knife a half-dozen of the squares may be slit at one time.

With the pen-knife slightly lift the tabs made by these slits. Now coil the leader under the four tabs.

After the leader is in place take a strip of the same bond paper used in the card, having this strip about the same width as the tabs on the card and long enough to reach from the back of one tab to the back of the one on the other corner of the card. With the leader toward you press a tab down through the opening enough to let the strip of paper pass, thus enclosing the leader under tab. Push the strip through the opening made at front of tab as in Fig. 2.

Now press tab opposite down and run strip through from under

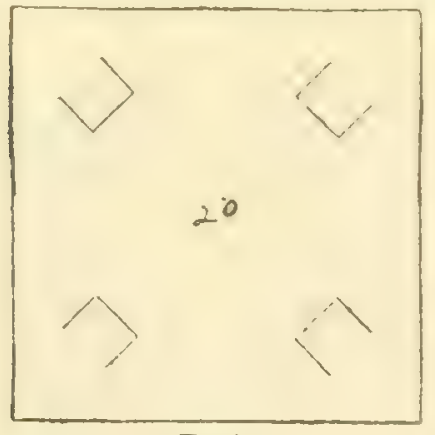

Fig 1

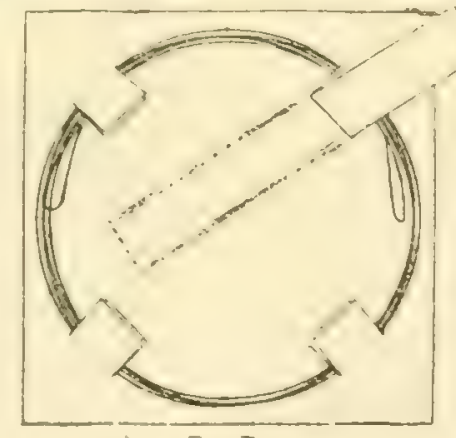

Fig II

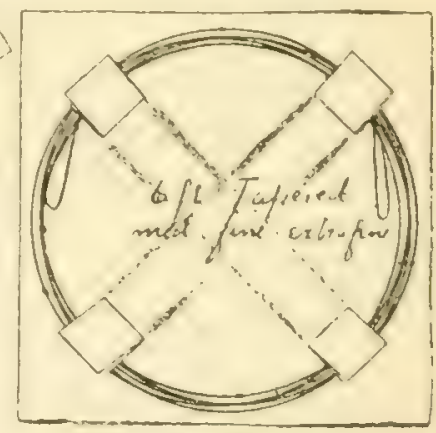

Fig II and labeled. It is done by a simple method of carding. The description may sound very involved, but the method is simplicity itself and the cards may be used time and again.

Take very stiff bond paper and cut it in squares of any required size for a leader card; then cut side. This completes the fastening of the first strip of paper. Repeat this operation with another strip of paper and the two remaining tabs and the leader is securely bound.

A drop of paste where the slips cross at the back will prevent them from being displaced, and 
another drop under the strips will fasten them securely to the card. This is not really necessary if the strips fit snugly. Fig. 3 shows the way it looks when completed.

This sounds very difficult, but it is really quite simple and is very quickly done. The cards are then marked and the leaders are ready for storing in the tackle book.

\section{THE BLUEGILL TIP-UP By Geo. W. Harvey}

When fishing for bluegills in the old way with a half dozen lines tied to the gunwales of the boat, one has to feel the lines with his hands to see whether he has any bites or not. Frequently one does this feeling at exactly the wrong time so that one scares the fish away.

Now I just take a few staples or double-pointed carpet brads

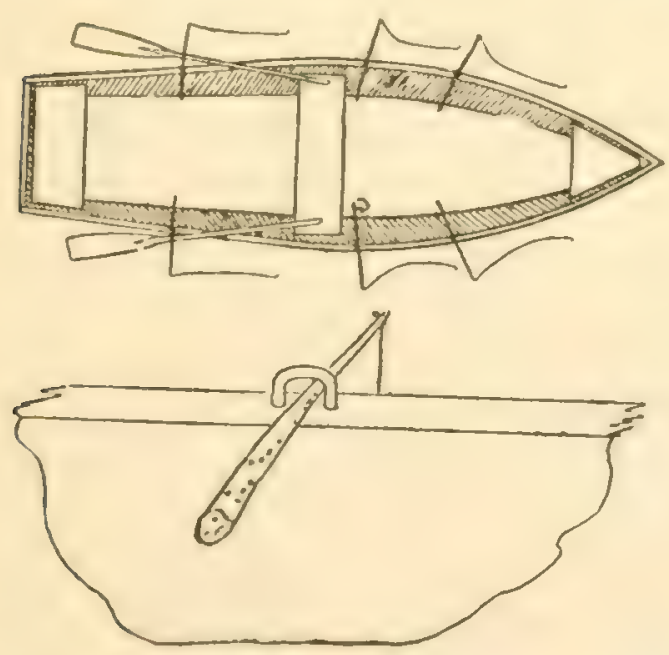

and drive them into the gunwales of the boat so that I can slip a tapered twig or a bit of whittled lath under them. With the line becomes a tip-up to signal when I have a bite on any of my hooks. With this arrangement it is easy to tend to half a dozen lines, and I rarely lose any bites.

\section{HOT BISCUIT TO ORDER}

\section{By E. S. Brooks}

Did you ever wish you had some warm biscuit for supper when on a fishing trip and nowhere to bake them? Well, try this.

Make a rather stiff dough of your pancake flour, stiff enough

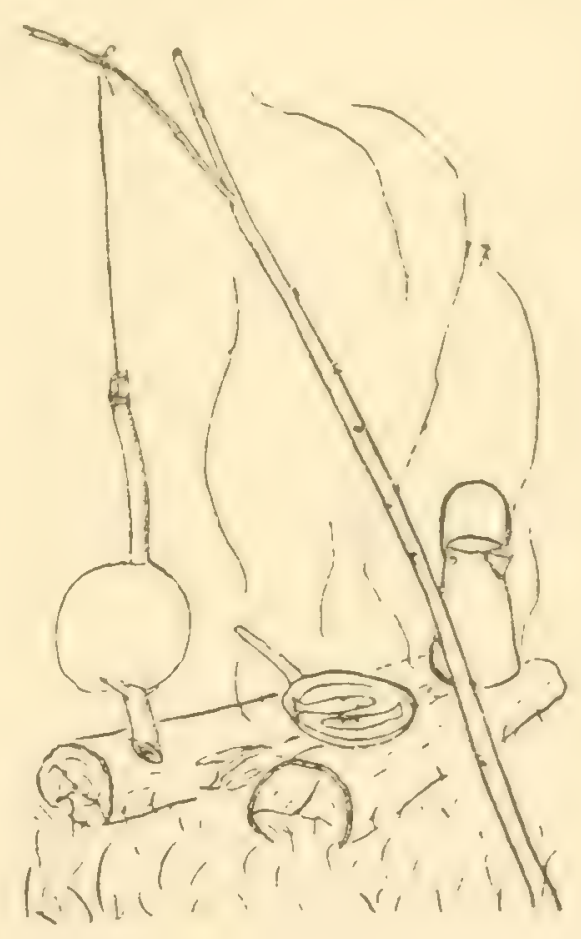

so it will hold its shape. Then take a stick on which there are a couple of prongs two or three inches long. Place the dough on the stick above the prongs, passing the stick through the center of the dough. Tie a string to upper end of stick and hang it before your fire. Give it a twist or two so it will revolve, thus 
turning all sides to the fire. If it begins to burn move it a little farther from the fire.

Will bake in ten to fifteen minutes. Keep the dough revolving all the time or it will bake on only one side. Don't hang it over the fire, but at one side and about ten inches from the ground.

\section{DRIVING SPLITTING STAKES}

By Walter K. Smith

When driving a wooden tent pin that looks as though it might split, take a $1 / 4$-inch or $3 / 8$-inch rope (usually the guy rope that the stake is intended for) and wind it tightly around the stake, beginning about two inches below the top and winding until the rope is about even with the top of stake. Hold the rope with the left hand and drive stake with the right.

\section{A TIN CAN OUTFIT}

\section{By F. W. Kendali}

This outfit is made from used cans from the household supplies. The tools used are a tack hammer, an old pair of shears, a pair of pliers and a nail. The time of making is about four hours, with no cash outlay.

The outfit is intended for two people, but with the addition of cups and plates, a couple more may be served.

To make the stove, get two gallon fruit cans and cut out the tops and bottoms, leaving the seamed edges for stiffness. Cut the cans up the sides to the top, then each way close under the rims, leaving half the top uncut. Straighten out the cut flaps. Place the caps about 16 inches apart, then measure for the side pieces. Seam on these and pound flat. Cut a piece of tin for a spider brace to go on the top. Make this an inch large all around and then cut in gashes so the tin may be bent about the wire rims of the holes. Bend down the ends of the spider over the sides of the stove, punch holes through the ends and through the seams. Make wire staples of hay bale wire, or the like. Place these in holes and hammer the ends tight down.

Use small round boxes for the stovepipe. Cut out the bottoms and hammer the edges flat. One can is cut off at an angle for the stove collar. Place the oblique end against the stove and mark for the smoke hole. Cut out the tin so as to leave a half-inch margin from the line. Score this margin to the line every half-inch, making tabs to hold the pipe in place. Bend every other tab out, then place the pipe inside these and bend all the tabs to fit. Fasten the point of the pipe and the lowest tab by a stable rivet. Crimp one end of each box so that they fit one over the other. Use pieces of tin for stove covers.

Dig out the dirt under the edge of the stove when in use for draught.

The fry pan is made from an octagon of tin with one side made 
KINKS OF ALL KINDS

45
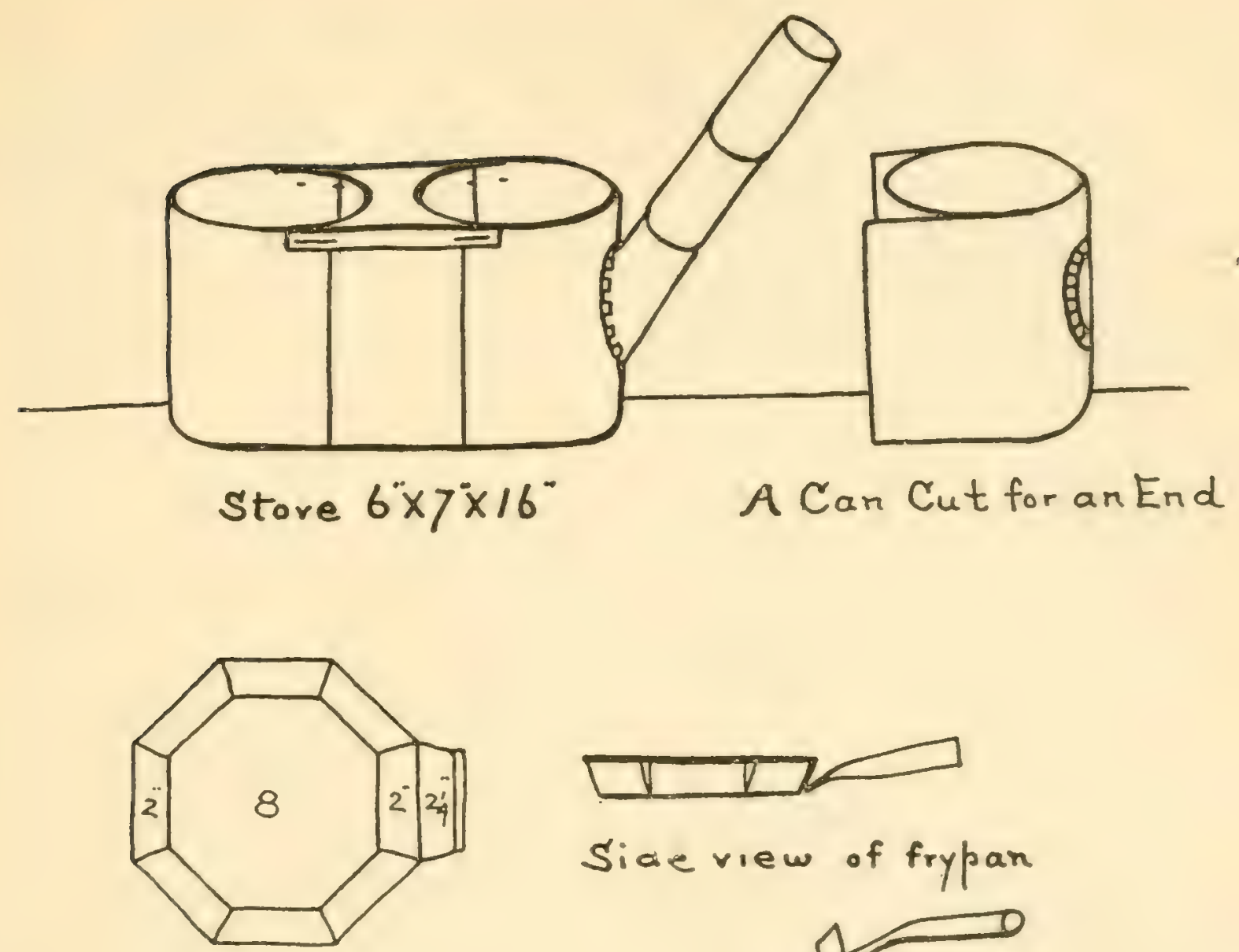

Sian view of frypan

Layout for $12^{\circ}$ Frypar

Handle octagon
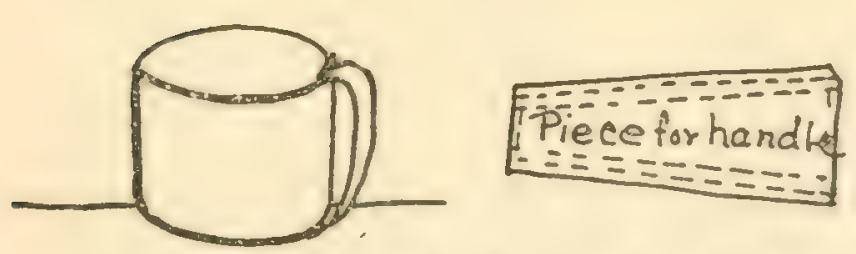

Cup with detachable handle.
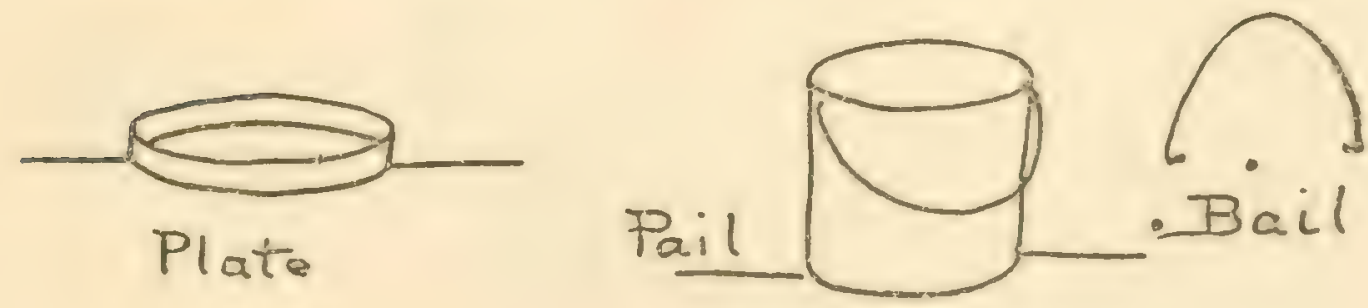
double into a socket for the handle. This handle is made by forming a tin tube with the end hammered flat and bent to shape.

Use small can for cups so that they will nest. The handles are detachable. Make these of strips of tin doubled over twice and pounded flat, then formed to shape. The spring of the handle keeps them firmly on the cups. Hammer the rims of the pails flat so the liquids will pour better. Make the bails of any annealed wire bent to fit.

Additions may be made to this outfit to meet the user's needs.

\section{FISH SCALER AND KNIFE}

\section{By A. P. JONES}

I am enclosing sketch of a home-made fish scaler and knife which has given me better satisfaction than anything $I$ have
I have found the size here given large enough for ordinary fishes with scales not easily detachable. Of course a machine hacksaw blade may be used. I use an "all hard" blade with sharp teeth.

\section{THE CANOE SHELTER TENT}

\section{By Norman F. Morse}

Here is a light, quick-pitching canoe shelter that has come out with colors flying in a service dating from 1900, for the one I now have was made in that year. It goés along on all our trips. We often pitch the tent without the canoe, using it as a lean-to; it is always spread as a cloth to eat on when friend wife goes along for the day only, and between stops it makes a fine pack cloth.

Flattened out, the tent makes a

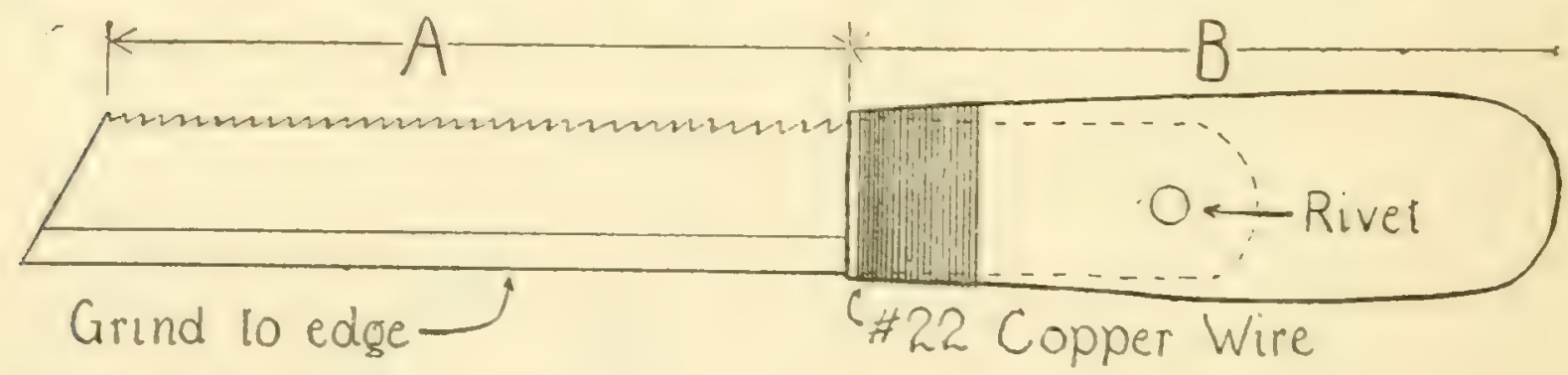

found in the stores. Referring to the diagram, $\mathrm{A}$ is hacksaw blade, 9-16 in. wide, 14 teeth to the inch, $23 / 4$ in. long outside the handle. The teeth on the blade point towards the handle. $B$ is hardwood handle, $25 / 8$ in. long. Slot with hacksaw; insert blade; rivet as shown, and wind with No. 22 copper wire. Grind the back of the blade to a knife edge if desired. plain sheet, seven by twelve feet in size. Only the center panel, five by seven feet, is made of heavy duck for the roof. The two end panels, each three feet six by seven feet, which form the walls, are made of drilling to save weight and bulk. Small grommets are put in, one in each outside corner, one in each corner of the roof, one in the middle of the 
back of the roof and one large grommet in the middle of the front of the roof.

The regular pitch is made by setting the canoe up on edge, bottom to windward, propping it by a couple of forked sticks. A long "Silver Lake" cord is tied to one of the corner grommets in the
The front guy cords are next passed out to convenient trees or else over forked sticks and then pegged down. Rocks or logs hold the sides to the ground (there is plenty of slack for these), and the tent is pitched. Takes a little, longer to do than to tell. The big grommet in the center of the front

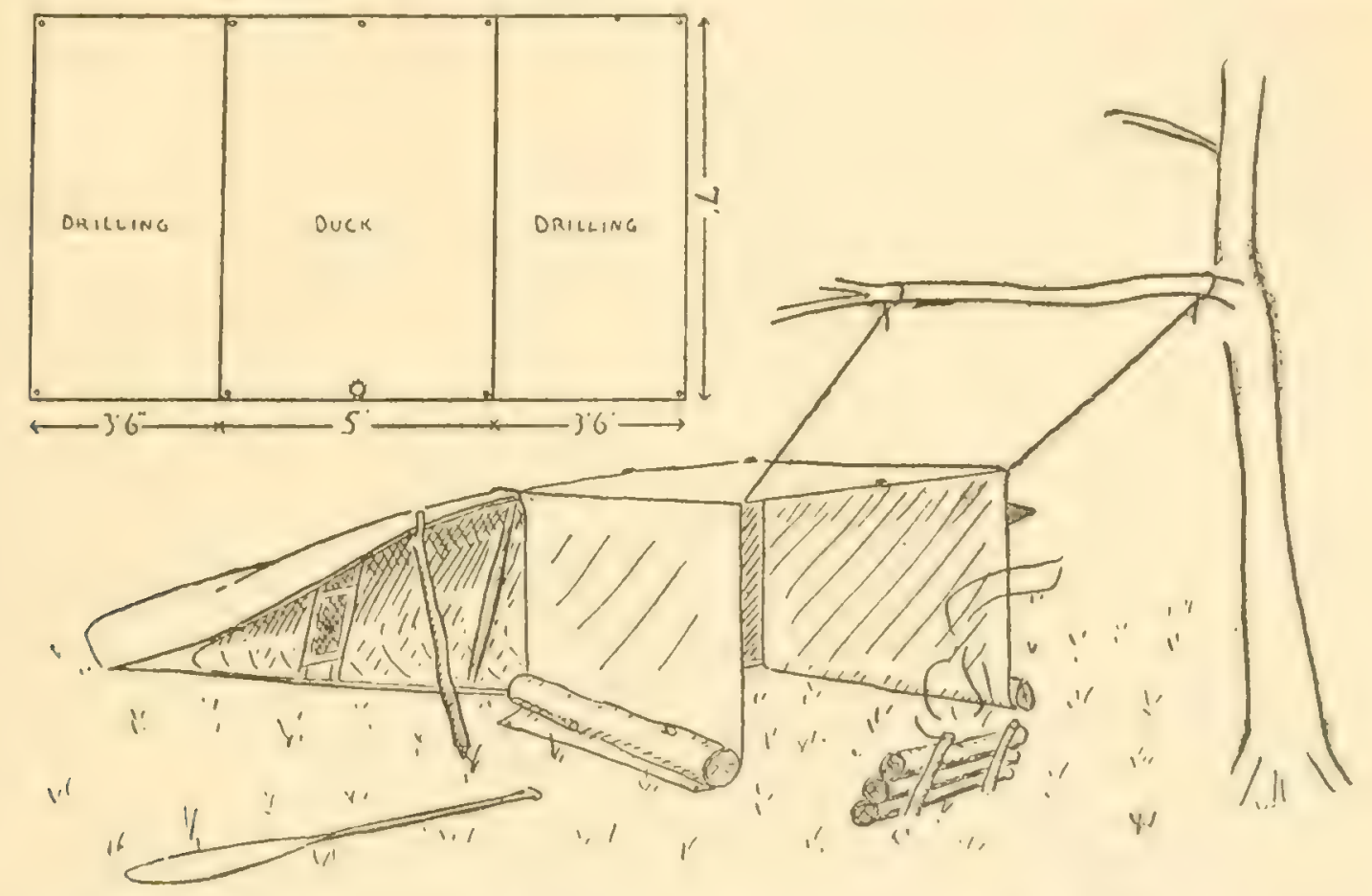

roof, run around over the bottom of the canoe, passed through a thwart and then run back up over the bottom of the canoe and through the center grommet. From here it is run back down over the bottom of the canoe, passed through the other thwart and back up to the grommet in the other corner of the roof, where it is made fast. From the rear the cord looks like a capital "W". run over the bottom of the canoe. The tent laps enough over the top edge of the canoe to shed water. edge is for an extra post if it is raining, as the roof sheds water better that way. This gives a roomy shelter, five by seven feet, and plenty high enough to crawl into, with the extra space of the canoe back of it to protect duffle.

\section{A HOME-MADE ROD TIP}

\section{By Dean O. Smith}

Some time ago I broke the tip of my bamboo casting rod and, since the rod was an inexpensive one and I did not wish to purchase a new tip joint, I made a 
tip that has given very satisfactory service.

I happened to have an old-style telephone receiver which was fitted with a detachable cord. The ends of this cord were tipped with

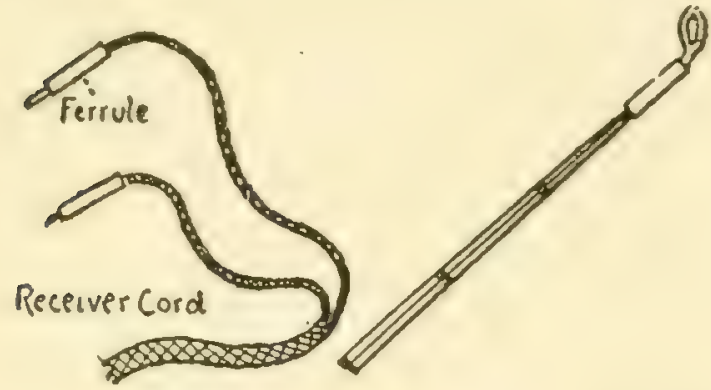

small brass pins and the joint between the cord and the brass tip was protected by a ferrule which slipped down over the tip. I removed the ferrule and dressed down the tip so the ferrule would fit tightly over the end and cemented it on. I drilled a small hole in the end of the rod, screwed in a small nickeled screw-eye, leaving about oneeighth of an inch of the shank projecting from the hole. I then bent the eye quite sharply upward and soldered the eye so that it was closed all the way around and smoothed the joint with fine emery paper. I also soldered around the hole where the screw-eye entered the ferrule, thus making the tip water-tight. Do not bend the screw-eye before screwing it into the tip because if the twist of screwing it in comes at an angle from the side rather than straight, the eye will likely break off at the bend. I rewrapped and revarnished the rod, and while it is now shorter by some eight inches, it is just the thing for the small, brushy streams.

A standard onion crate makes as firce a live box for use in a camp as anything I have ever used. The slats are placed about a half-inch apart and the crate is large enough to hold fish up to two feet in length. When not in use the crate folds up and takes up very little space in your equipment.

\section{A SLIDE FLOAT ARRANGE- MENT}

\author{
By A. B. Cotter
}

Take a large cork float. With a pair of pliers pull out the round piece of wood that goes through the float. Get a piece of cane (bamboo), the same size of the wood that was taken out of the float. Push it through float, trim the ends smooth and even with the

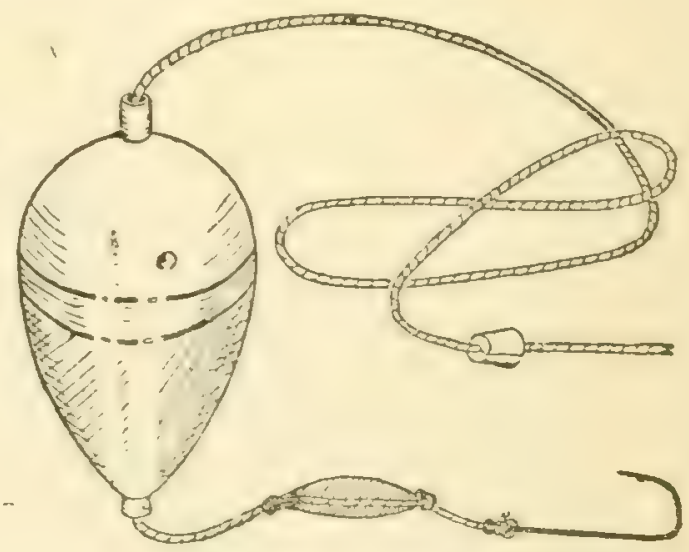

top and bottom of the float. Carefully round out each end of the stem so it will not cut line. Pass line through cork. Fit sinker and hook on line and use a small bottle cork on line the depth wanted to fish.

Now, when you want to fish 
three, four or five fcet, your cork will slide down to the sinker and all the weight will be at the end of the line, so that a cast can be made much easier than if the cork is some distance from the end. When the line strikes the water the line will run through the cork and stop when the small cork strikes the larger one.

\section{A HANDY HOOK HOLDER}

By N. C. Burnham

I have an article in my fishing kit for holding snelled hooks and for keeping small sinkers, split shot, swivels, connecting links, etc., that is very handy, and I have never seen another like it. I cut off a pine curtain pole so it would be just a little longer than a snelled hook, and so the hole in the end of the pole (the hole that holds the curtain spring) would extend nearly through. Then I fastened a piece of cork on the solid end with a couple of brads. The hooks are stuck into the cork and the snells fastened to the pole with a rubber band or two.

A cork can be fitted to the hole in the opposite end and the hole

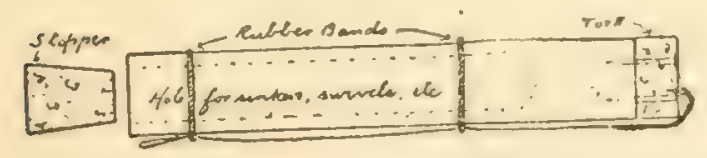

used for the small things-split shot, etc. A cloth case can be made to slip over the whole thing. I use the drill case that came with a jointed rifle rod. I have used my holder now for several years and I could scarcely get along without it. It keeps the snells from curling up and getting tangled, and the small things together where they can be gotten at handily. The drawing will make it clear.

\section{A MOTOR HINGE}

By Fred RUPERT

Outboard motors are a great blessing to the fisherman, but when one gets up into shallow wa-

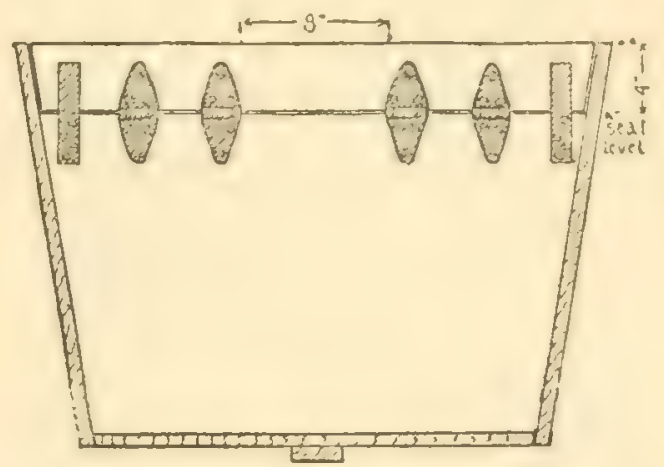

ter, especially if one wants to do any casting, the propeller frequently catches on the bottom.

To overcome this I hinged the top four inches of the stern board of my row boat and hang the motor to this. Now when I get into shallow water I simply pull off the rudder handle and tip the motor forward so that the propeller is brought free from the water.

I use four stout hinges, the center pair eight inches apart, to allow of the motor being hung between them. At either end I also place an extra piece of steel to act as a brace and take the weight off of the hinges.

This device also protects the rudder and propeller if they hap. 
pen to strike something when running, as the motor will simply tip forward and allow the propeller to rise.

\section{THE OVERALL PACK}

By Bull Hart

Just tie the legs and fill up the old bib overalls. One can also tie the bottom of the legs to the top

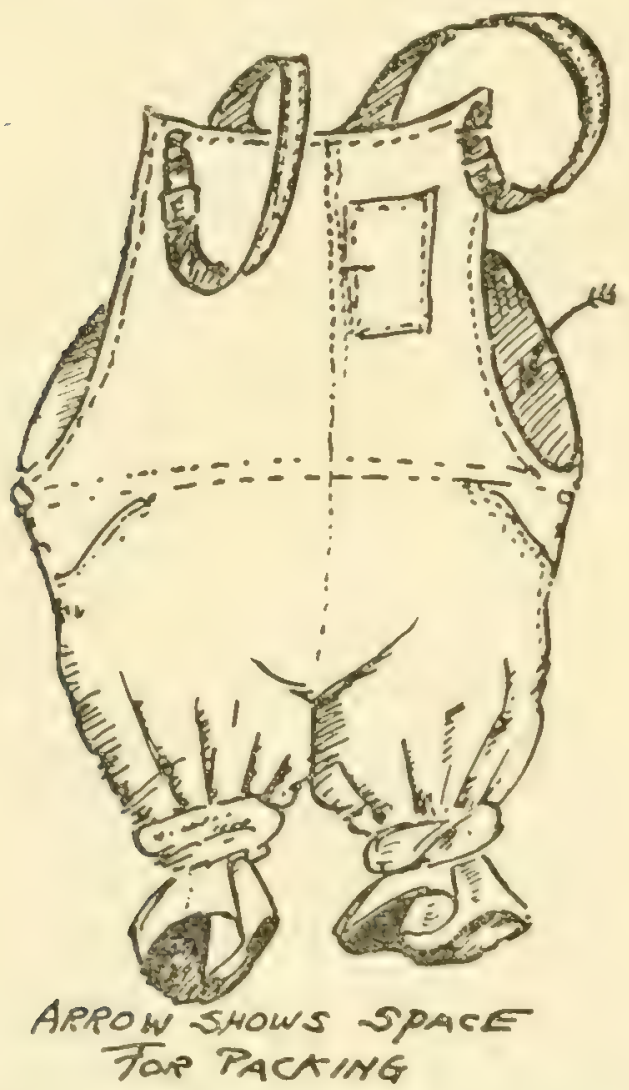

of the bib and use the suspenders to tie with.

Believe me, brother, this beats no pack "all holler."

\section{HOOKING YOUR FISH}

\section{By Daniel P. VAder}

I find that a great many of my friends lose a large percentage of their fish by getting excited when they get a strike trolling for bass. I do a lot of trolling with live bait and my choice bait is a live minnow from 3 to $4 \mathrm{in.} \mathrm{long.} \mathrm{In}$ trolling for bass I take my casting rod and reel, use a good-sized hook and hook my minnow back of the gill on one side, allowing the point to come out through the gill on the other side of the head. I let my line out about $120 \mathrm{ft}$., then row very slowly until I get a strike. Then I use my kink for hooking the fish. I just stop the boat and watch him. As a rule he will take the minnow and run about four feet. Then he will stop, turn his minnow and again run two or three feet while swallowing the minnow. Then he stops for a second and starts again. This is the time to hook him. Do not get excited when you get a strike, but take your time. You will land more bass.

\section{SHOOTING OUT OBSTRUC- TIONS}

\section{By C. J. Smith}

Here is a kink I have frequently made use of to gladden the hearts of Young America. Several times the boys came to me with a barrel of their little .22 badly clogged. A rag was stuck in the barrel or a bullet (often both) and in some cases examination showed a solid mass of obstruction from 4 to 6 in. long. To poke this out with an improvised drill would take a long time, so I decided to follow the system of the boy who had originally tried to shoot out the obstruction. But 
I improved upon the technique, for instead of leaving a resilient air space between cartridge and obstruction, I fill this space with water and a .221 . r. finishes the job. All that remains is to scrub up the barrel with the brass brush and the gun is again serviceable.

\section{A TAKE-DOWN LINE DRYER}

By J. A. Paxton

To make the axle (Fig. A) secure a square stick of wood one and one-half inches in diameter and bevel each corner three-sixteenths of an inch. Bore holes $(a-a-a-a)$ at each end to hold the side wires of the frame. Bore a hole in one end to fit the bracket $B$.

To make the bracket $B$ take a piece of copper or brass wire and file to fit the second joint of the rod, turn at right angles as in the illustration. A washer soldered on completes the bracket.

The side wires (C) are made of either brass or copper as is the wire (D). The ring on the end of the wire (C) passes through the ring on the end of (D), making the completed frame $(C, D$, C), of which there are four. The rings enable the frames to fold, making the dryer very compact when taken down, and as the ends are open, the line will dry quickly.

If $A$ is made four and one-half inches long and $C$ the same length the dryer will take up no more room than a wobbler bait and can be easily carried in the pocket.
By having the bracket $B$ fit the second joint of the rod it is possible to dry the line in the boat while eating lunch, or while com-

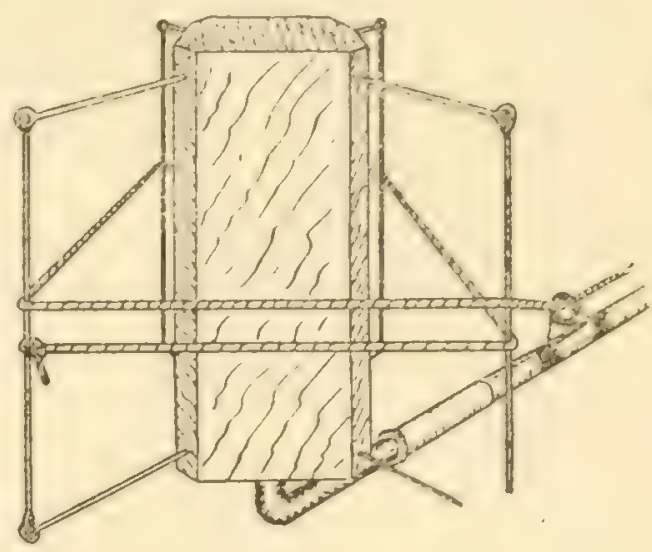

ing back to camp. It also makes it easy to change lines on a reel without going to bank, and, in fact, its convenience in many ways is apparent.

To make the dryer self-contained when knocked down a piece of one-inch brass tubing can be
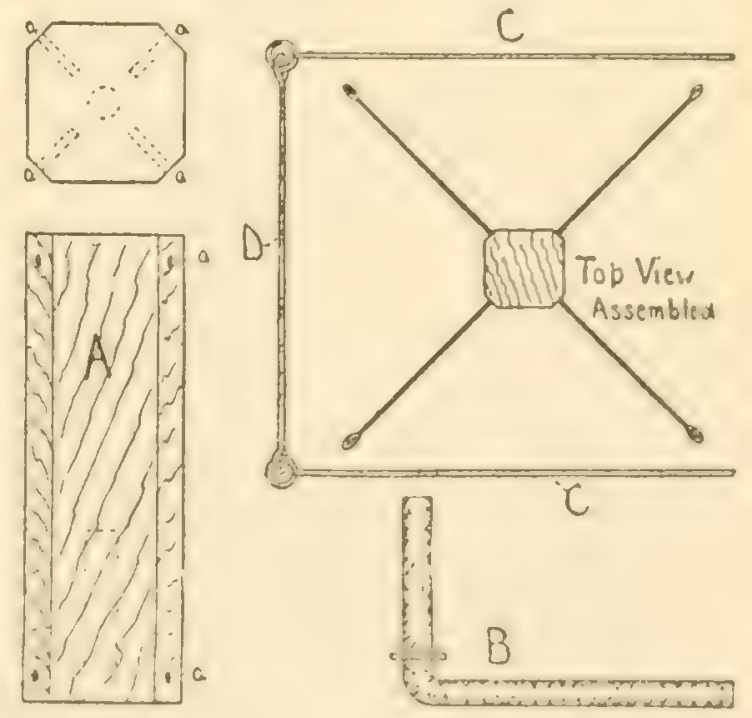

used instead of a block of wood in making the axle $A$. If the tubing is used it will be necessary to use brass disks in the ends in which the wires $C$ are placed. 
The arm of the bracket $B$ will be shortened and riveted in the brass disk in such a manner that the disk will revolve easily. After riveting the bracket, solder the disk in the end of the tube. The disk for the other end of the tube can be made to fit snugly and is used for a stopper.

The wires $C$ and $D$ should be of such a length as will allow them to be put inside of the tube.

The self-contained dryer will take longer to make than the other one will, but it is well worth the trouble of the discriminating angler who wants the best of everything going. Its cost should not be over twenty-five cents at the most.

\section{A CAMERA KINK}

\section{By E. B. Harding}

Some cameras are made so that they can be snapped by pulling a thread fastened to the shutter lever, allowing all members of the party to get in the picture and then some cameras are not intended to be used that way at all. Most cameras that can be operated with a string are too expensive to be risked on those very outings that afford the best chances for the pictures we want most. In an effort to explain how the ordinary little old box kodak can be manipulated with a string, I submit the following Kink:

Drill a hole through the shutter lever. Tie your fish line through the hole. Tie, or better still, strap your kodak to a tree, log, stone or something equally solid and at the same time focus for your picture. Now run the string up, over and across the top of the kodak, bringing it rectangularly around the crank that turns the film, the lever that unlocks the box for opening, the handle, or a tree-any old thing that comes in position. Now, be careful to have the shutter lever pointing down.

Better practice this without a film in the box. Raise it until it is about to operate the shutter; carefully stretch the line to the spot selected for the picture and, when you're ready, "strike your fish." When the film is developed, the fish may be admired.

I have taken lots of pictures in the above manner without the hole in the shutter lever. In that case I fasten a fish hook under the lever. However, the hook is hard to keep in place. Try it some time when you all wish to be in on the picture.

\section{A COLLAPSIBLE LANDING NET}

By C. H. BALDwin

I had a good collapsible landing net a year ago, but it turned up missing, and I must have laid it down just outside my boat after the excitement of landing a big one. So I decided to make one and save the cost for "bait."

Cut about 18 inches, or any length desired, for handle from a good broom handle. Take a piece 
of $3 / 4$-inch brass tubing (b), which you can get at any electrical shop. Turn down the lower end of handle (c) so the tubing will slip on

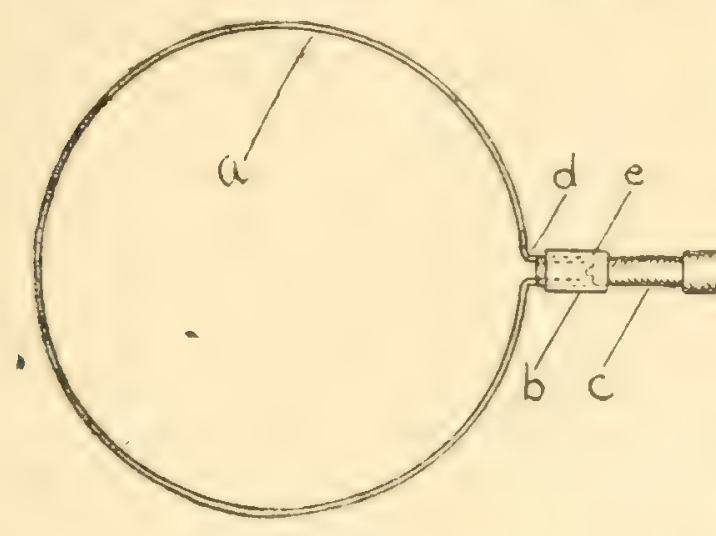

$3 \mathrm{I} / 4$ inches; use a wood rasp if you have no turning lathe.

Next take a piece of telegraph wire $\frac{3}{16}$-inch diameter, and make the hoop for the net (a). You can bend it nicely by wrapping it around a four or six gallon crock, or anything round of proper size. Then bend each end of the hoop as shown in the cut at "d," and again bend a hook " $\mathrm{e}$ " on each end; can bend with a vise and hammer, or if you have no vise, pinch the ends in the jaws of a monkey-wrench and hammer them down.

Next, bore a $\frac{3}{16}$-inch hole through the handle for the hooks to slip $1 \mathrm{n}$, and from this hole on each side of the handle gouge a groove for the wire to set in flush with the handle. If you have no gouge, burn the groove in with a piece of the wire, red hot. Buy a net for 40 or 50 cents. Slip it on the hoop. Put the tubing on the handle. Fit the ends of the wire into the grooves. With the hooks in the holes, slip the tubing down to cover the wire, and you have it.

Take an old fish line and wind the grip (f). Put a screw eye " $g$ " in the end of handle to hang net on hook in your belt and the kink is ready for business. Slip the

tubing back, fold the net back over the handle and the "kink" will go in your suit case.

\section{TO GET THE FROGS}

By ROY C. Harris

Did you ever crawl around on your hands and knees trying to catch frogs when the fish wouldn't bite your artificial lures, and after sneaking up on a big fellow have him slip out between your
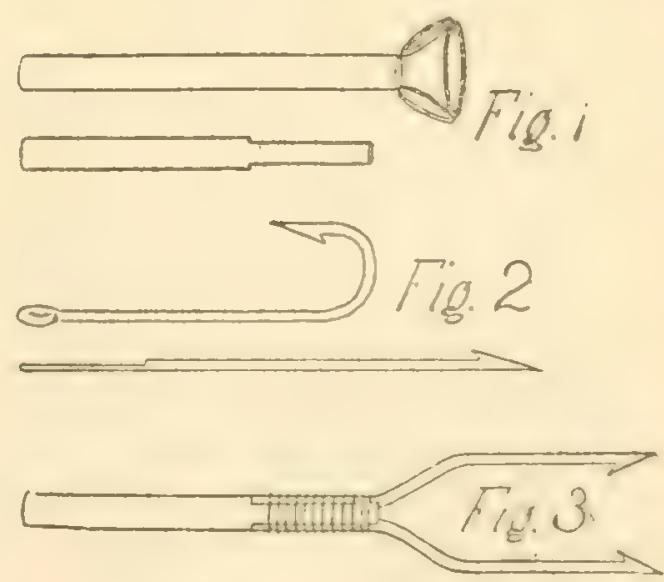

fingers and escape into the river? Well, if you have, try this kink:

Take an emergency tip or piece of wire two or three inches long that will fit into the ferrule of your rod. File the end flat on 
each side for about three-fourths inch back (Fig. 1). Then take two large hooks with long shanks and straighten them out. File off the eyes and flatten rear ends for three-fourths inch toward point (Fig. 2). Place flat end of hooks on flat end of tip and fasten in place with fine wire and solder if desired. Bend hooks to shape and store in tackle box until needed. When you wish to use it remove tip joint of rod and slip in the spear and you'll get your frog.

\section{A TWIG CUP HANDLE}

\section{By H. N. Cramer}

The easiest drinking cups to carry on a camping trip are those made without any handles, so that they nest one in the other. These cups have the added advantage that they have no seams or rivet holes to leak. Once in a while you want to dip up something hot, however, and then the lack of a handle on your cup is a disadvantage. If you are up

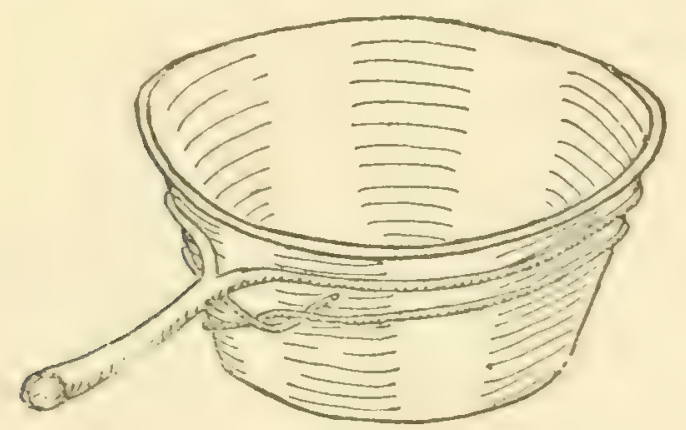

against this predicament, just cut a small, flexible, $Y$-shaped twig. Have the ends of the $Y$ long enough so that each of them will go clear around the cup. You will find that a single knot will hold the ends of the twig and the stem then forms a handle by means of which you can dip up your hot tea without any danger to your fingers.

\section{ICE CREEPERS}

By Chester R. Hall

An outdoors man's kit is not complete unless he has a good pair of ice creepers. I have found the pattern shown herewith to be most effective.

The material is band steel, an inch wide and $\mathrm{I} / \mathrm{s}$ inch thick. The

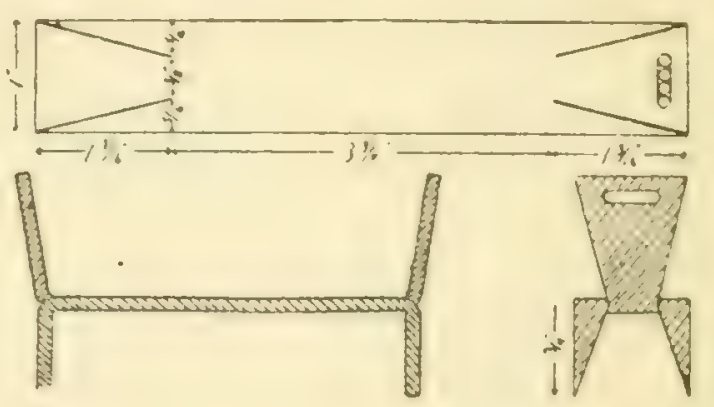

dimensions shown will fit the ordinary man's foot. After cutting the steel to length, take a hacksaw or cold chisel (saw is best) and slot the corners as indicated.

The mortise for attaching the straps is made by drilling four I $/ 8$-inch holes side by side near each end. Finish cutting out the holes with a cold chisel and smooth up the edges of them with a file. Next bend the ears up and the points down as shown. Regular band steel will bend cold. Some steel may have to be heated first. After bending, remove all sharp edges with a file and trim the points down so they are just three-quarters of an inch long. 
To harden the steel, get a small quantity of cyanide of potassium, which can be had at any drug store. Tell them what you want it for, as there are several grades. Heat your creepers red hot. Put a small chunk of cyanide on them and place back in the fire so the cyanide may melt and run all over the metal. When the metal is a nice red, plunge in cold water and you will have a real temper. The creepers are finished by riveting a strap and buckle to each one. Strap on over the instep, right in the middle of the shoe and you will have a creeper that will stay right where you put your foot.

\section{IMPROVING THE FRYING PAN}

By "The Rambing Buckeye"

Nothing like the old sheet-iron frying pan for a camping trip. But that long handle is always in the way when you want to pack it. Take your old ten-inch pan and

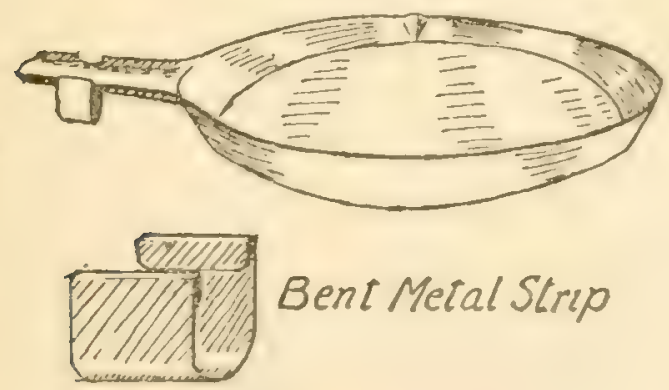

cut the handle down until it is about 4 inches long. Then take a strip of zinc about $3 / 4$ of an inch wide by $4 \mathrm{~T} / 2$ inches long. Bend hooks on each end about $3 / 8$ of an inch deep. Then bend your strip into a semicircle so the hooks will catch in the beading on the edge of your stub frying-pan handle. When you get to the campground cut a rough stick as long as you want. Whittle it roughly to fit in the metal loop you have made and the frying pan once more has a full length handle.

\section{SNAPPING YOUR OWN PICTURE}

\section{By George W. Harvey}

One of your kinks showed how to rig a camera so that it could be exposed by pulling a string, thus giving the operator a chance

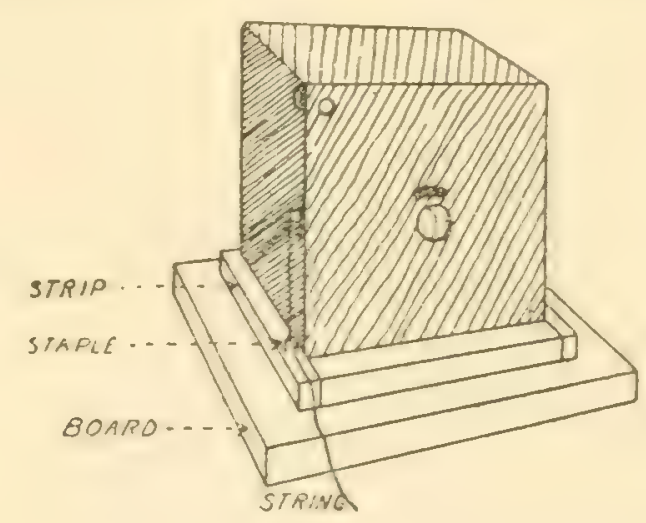

to get into the picture himself. The device as shown at that time wouldn't quite work with my own box camera, so I set out to adapt something along the same lines.

In order to give the camera solidity I used a good heavy board for a base. On this I nailed $3 / 4^{-}$ inch strips to form a socket in which the camera rests. Directly under the exposure lever in the strip, on the right hand side of the camera, I drove a staple. (In the left hand strip I drove a similar staple. This does not show in the drawing.) In the exposure 
lever itself I punched a small hole. When I want to "get in the picture" a string tied through this hole and run down through the staple does the trick.

For taking time exposures, in addition to the first string I tie a rubber band to the exposure lever. At the end of this is another bit of string which is led over the top of the camera and tied to the staple on the other side. (This is the staple hidden in the drawing. Thus I can pull the lever down and hold the camera open as long as desired with the first string. As soon as the pull is released, however, the rubber band draws the lever up again and closes the camera.

\section{MY CIGAR BOX TACKLE CARRIER}

By Rambling Bill

Desiring a light but fairly roomy tackle box to carry with me on my rambles, I secured a couple of good-sized cigar boxes and set to work.

I took the cover of one of these boxes off from its cloth hinges and reset it with a couple of small metal hinges. The second box was used merely to furnish material for the partitions, which were arranged about as shown.

On one side of the largest compartment I fastened a strip of stout leather that would not stretch, tacking it down in the middle and at both ends. This was to hold my plain hooks as shown in the diagram. Then I took a strip of tin and cut a sharp point at each end which I turned down. Along either side of the tin I made a number of short diagonal cuts the edges of which I afterward dulled with a tool.

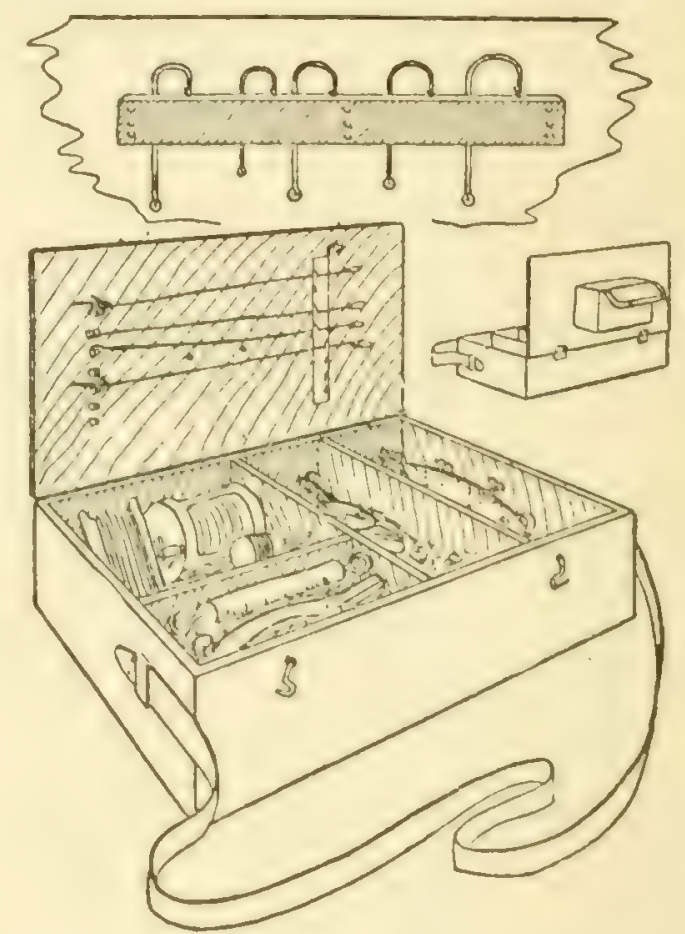

I turned down the two points at either end and by sinking them into the wood, fastened the strip of tin to the under side of the box cover. At the other end of the cover I glued a number of small bottle corks. This arrangement holds my snelled flies and hooks very nicely. I simply stick the points of the hooks into the corks and slip the snells into the slits in the tin.

On the outside of the cover I fastened a "Unity Mixture" tobacco tin for a bait box (Velvet and P. A. tins are too deep. One cannot reach the bottom easily with the fingers). 
Then with a sling strap fastened to the ends of the box and a couple of small hooks on the front for holding down the cover, the job was complete. This box holds a surprising lot of tackle, protects it nicely and carries very well with the strap slung over one shoulder and the box resting under the opposite arm. It is light, does its duty and costs almost nothing.

\section{A LIVE BAIT CARRIER}

By Henry D. Holley

Anyone who has ever engaged in the livel sport of bass fishing realizes how necessary is a variety of bait. With this necessity, however, there arises the question of transportation. While on my vacation last year I determined to overcome this need and having combined my efforts with those of an old timer, I turned out a serviceable carrier. It is about $18 \mathrm{in}$. long and $12 \mathrm{in}$. wide and stands about $12 \mathrm{in.} \mathrm{high.} \mathrm{The} \mathrm{top,} \mathrm{bot-}$ tom and all partitions are made of $1 / 4$ or $3 / 8$-in. stock and the sides being enclosed with screening makes the box very light and portable.

There are two layers with four sections on a layer, which I filled as follows: In the top section I put grasshoppers, crickets, katydids and dobsons, and in the lower spaces I put sandtoads, striped frogs, green frogs and tree-toads. As I have said, the ceiling and floor of each compartment is made of wood and two of the four walls are also, but the other two are enclosed by screening so as to admit air to the bait.

At the top of each section there is a hole large enough to admit a man's closed hand. A piece of tin (A diag.) covers this hole and overlaps it about one-half inch all around. This tin is secured at (A) by a screw, upon which it pivots. To close the cover you snap the tin, which has a small hole opposite A over the eyelet at $B$, and then push the hook C through the eye $\mathrm{B} . \mathrm{D}$ is a small knob such as comes on the top of a teapot, riveted through the tin. Then the end is filed off on the

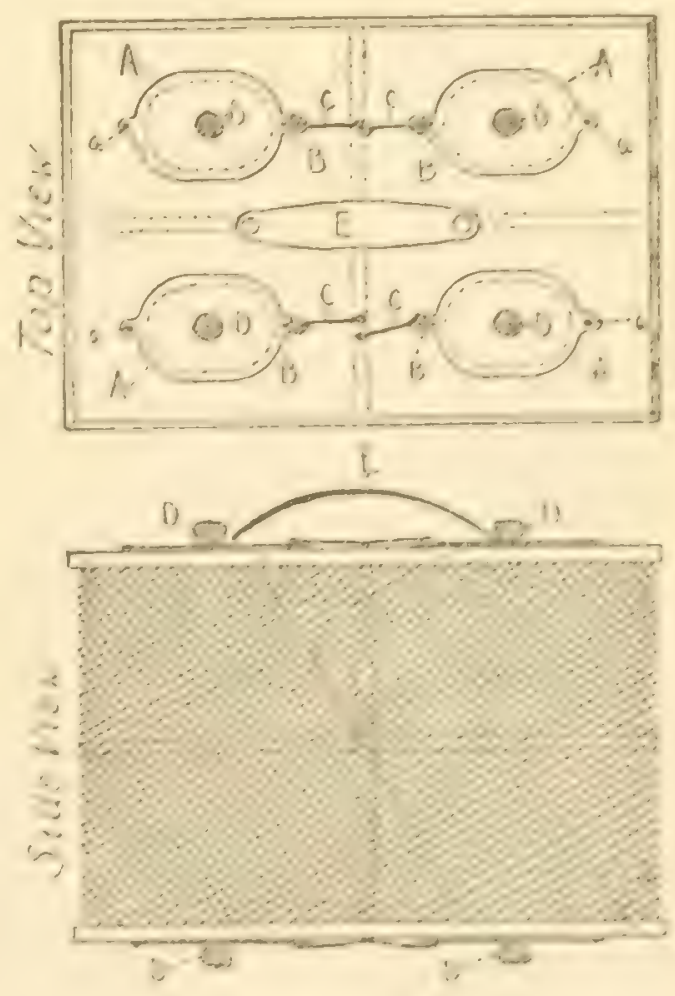

underside so as not to interfere with sliding of the tin shutter. Four shutters similar to the one just described are fastened on the top of the box to admit to the 
four upper sections. Four others are fastened on the bottom and the four knobs for opening them form legs for the box. When any bait is required from the lower compartments the box is inverted and thus access to them is gained. The box is carried by a handle, like those used on a camera, which is attached to the top of the carrier. With this box well stocked, I felt capable of being able to tempt any bass.

\section{A HANDY BERRY PICKERS' CAN}

\section{By H. B. Boyce}

Cut the top from a four-quart syrup can. Hang two little triangular doors from wires across the top, as shown in the diagrams. Each door is hung from a wire with an extra bit of tin bent around the end of the wire to keep the door from sliding out of place. Now if you stumble or

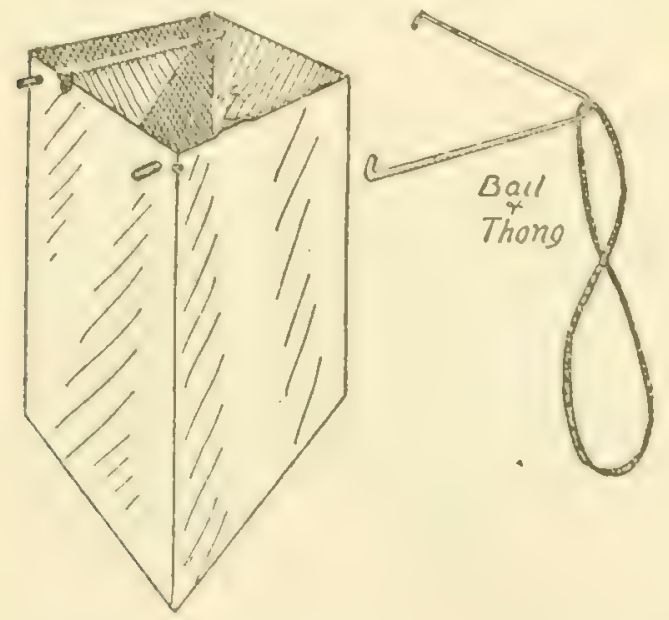

drop the can, these doors will swing shut ahead of the berries, so you will not lose them.

In opposite corners of the can, near the top, make holes and in- sert a wire bail. A thong to go around the neck completes the outfit. I have used several of these cans and like them much better than the usual baskets or bucket.

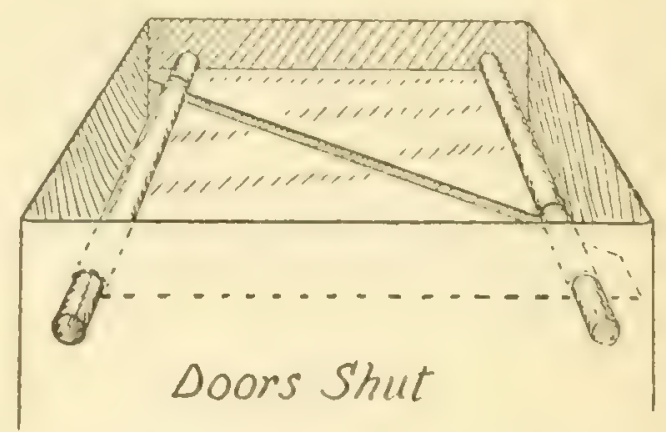

Your berries are safe at all times. Both hands are free for picking and the can, being suspended from your neck, is always convenient.

\section{A SHINGLE CREEL}

By Elton Hurning.

I live in an excellent trout country and manage to get about as many of the speckled beauties as the next fellow. For many years I have made my own creels out of the simplest of materials. I use shingles for the sides and ends and $1 / 4$ - or $1 / 2$-inch boards for the top and bottom. The boards may be cut curved to fit the side of the body without fear, as the shingles, which should preferably be of cedar, will bend nicely without splitting. The shingles are tacked to the top and bottom boards with small nails. Before the front is nailed on a generous notch is saved into it for a hand hole. A cover, fastened with a small pair of hinges or a strap, is made to fit this, leaving only a small hole for the insertion of the fish. The 
shoulder strap is tacked onto the back and the job is completed.

This type of box keeps the fish nice and hard, particularly if you lay a handful of green clover or leaves between them. The box can be made any size to suit your own ideas. I have made many of them and sold them, too.

\section{CORN FOR CARP}

By H. F. Hollmann, JR.

In several issues of OUter's I have noticed bait mentioned for catching carp, but do not recall seeing the following recipe: When other bait is scarce, a can of sugar corn can always be relied upon to do the trick. Or while the field corn is still in the milky white stage, or just turning, it can be used just as successfully. It surely is an isolated fishing hole where one will not have to pass a cornfield somewhere on the

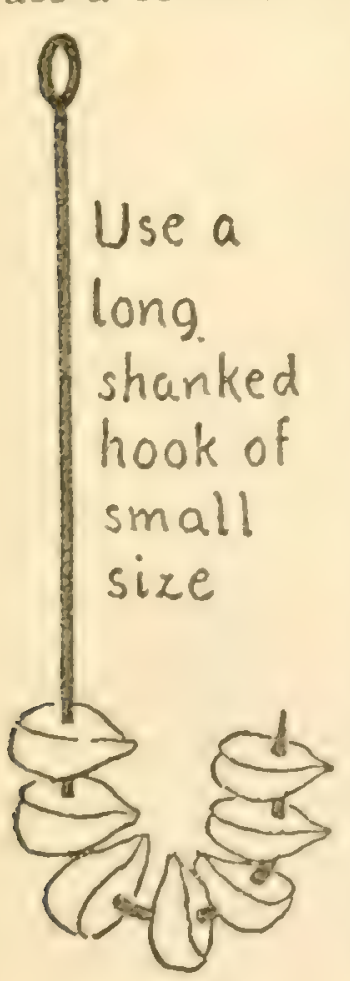
way. A few rows cut off with a knife will be suffic i ent $t$ or several hours' fishing, if they don't bite too fast.

As for baiting the hook, have not as yet found the one and only way. My personal preference is a small hook with a rather long shank and the corn placed on the point and just around the turn. This, for the reason that Mr. Carp belongs to the "sucker" family, and with a small hook can get hook and all without much trouble. If the corn is strung all the way up the shank he is liable to have a meal before he gets to the business end of the hook, not mentioning the excitement caused to the one on the bank, who is waiting for Mr. Carp to get the hook. Now if you can hook one weighing from five to ten pounds with light tackle, you are going to have some fun before he comes in.

\section{STEEL RING GUIDES By WM. GUNRICH}

Some time ago I received as a premium with my subscription to OUTER's Book a Heddon rod of the kind that sells for a dollar and a half. It has better action than my five-and-a-half-foot steel rod.

However, when I looked at the guides I saw that they were not
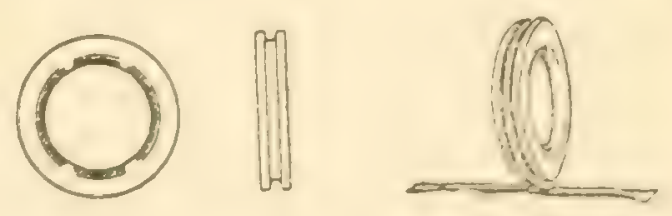

just as I would like to have them. They may have been as good as any, but I had an idea that they could be improved upon. As I happen to be so fortunate as to have the use of a footpower lathe, I set to work to make the improvement.

First I got a piece of steel out of which I cut the rings. These I 
made as nearly like the agates on my steel rod as I could. After turning them up and polishing them, I hardened them as hard as possible. Then in the groove on the outside of each ring I fitted a good stiff wire. Where the wire crossed on the lower side I soldered it. I then brought the ends out at right angles and flattened them.

After that I mounted them in place of the old guides, took another look at the job and chuckled.

\section{THE USEFUL SAFETY PIN} By Bert HecketT

We had pulled hard for about two miles to a rocky shore on Lake Winnepesaukee, N. H., where we knew there were bass. On getting to the grounds, I found the tip of my casting-rod broken by the fish tank resting on it (large zinc tank to keep fish alive in). You can imagine my feelings. Had come all that way to fish for one hour, 5 to 6 , and back with the wind in time for supper at 7 p. m.

It was out of the question to go back for repairs, and, without tools, I felt rotten Was just about to go back to camp and give up for the day when I saw a large-sized safety pin sticking in my old raincoat (probably been there since last year). I took it to try and pry the wood from the agate guide tip to refit it, but it would not come out. Then the Kink came to life. Why not tie the pin on the tip of the rod and use the round loop for a guide? No sooner the thought than the deed.

With an old rusty file, kept in the boat for sharpening hooks, I filed and broke off the clasp end and roughed up the sicles of the pin. Placed it on tip of rod, loop close to end of tip. Broke off a couple of feet of line and bound on pin, tight.

Threaded line through loop of pin, attached pork rind minnow
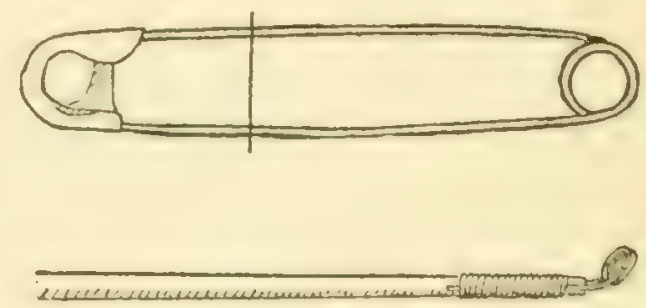

and went to work, and, incidentally, got four bass from $13 / 4$ pounds to 2 pounds and one pickerel of $43 / 4$ pounds, and arrived back at camp at 7:10 with the best catch for that one day. The pin guide appeared good for many more trips, but I repaired my rod that evening, and the pin guide is hing up as a memento.

\section{A CLOTHESPIN PLUG}

By James McCaffrey

From an ordinary clothespin I whittled a plug to the shape shown in the drawings. To the bottom of this I attached a treble hook. The treble does not swing free. It is attached by means of a screw and held more firmly in place by means of a small staple across the shank. A screw eye for fastening the line to completes the bait. 
I painted this a pure white and then splashed it with irregular markings of red and green. I have had fair success with this
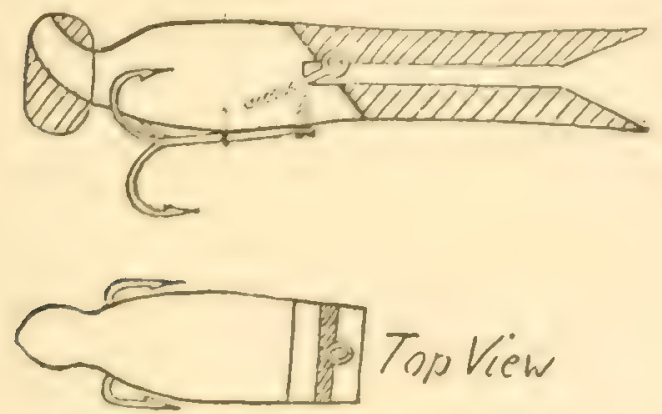

bait for small-mouth, and have had more strikes on it than on some of the costly plugs. This bait has the added advantage of being nearly weedless.

\section{THE FINGER RING SPOOLER}

By Jas. W. Birthong

Here is a simple Kink that will enable you to spool the line on a plain reel as well as any mechanical level-winder can do the job and with no complicated machinery to obstruct the cast. Get a ring that will fit the first joint on the index finger of your left

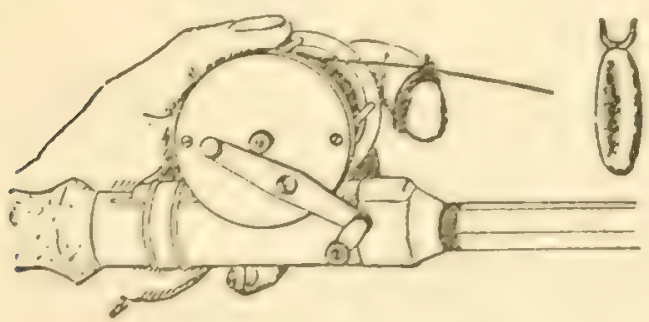

hand. You can have one made at the jewelry store out of silver or nickel if necessary. On the top of this ring is to be set a small yoke or crotch to guide the line with. The diagram should make the manner of using this device quite clear. When reeling in just palm your reel in the ordinary manner. Catch the line in the yoke guide it back and forth with the finger. It is positive in its work and handles as slick as anything you ever tried. Nothing simpler.

\section{IMPROVED OAR LOCK FASTENING}

By Harry F. Ries

The enclosed sketch shows an arrangement for the oar locks on small boats. The oar lock itself is screwed on to a wedge-shaped

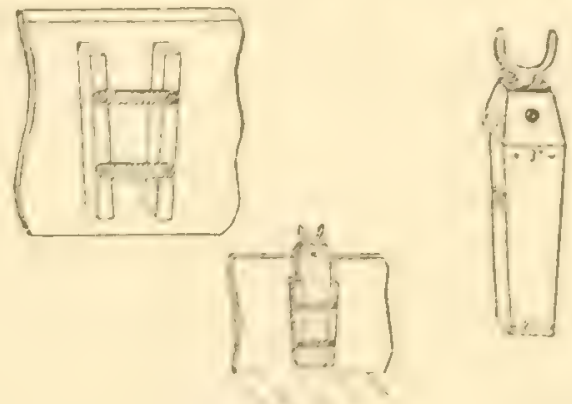

piece of oak cut with a shoulder to rest on the boat's side, and fastened by running wire nail through hole near top and twisting oar lock until nail is bent in shape to hold. Wooden strips are placed inside of boat and the cross pieces made of hoop iron.

You can readily see that this arrangement takes a good deal of strain off sides of boat. The screws will not readily pull out of oak as when placed in soft máterial from which boats are usually built. The locks are permanently fast, yet can be taken out when boat is not in use. The 
additional knee room in a flatbottom boat is also appreciated.

This idea was copied by me from a boat built many years ago. I've used it and found it so good that I want to pass it along. This was the only boat I ever saw so equipped.

\section{MORE BREAM FISHING}

\section{By J. H. ERvin}

I recently read the Arkansas boy's kink about bream fishing with roaches, and he didn't tell all about the tackle part of the game.

Get three or four canes from some rich bottom land, twelve feet long and, say, une inch in diameter at butt. Dry thoroughly and straighten over alcohol flame; select the one with best whip and "feel" and mount it in a handle two or three feet long macie of a piece of Japanese bamboo of a size to comfortably fit the hand. Have the hole in bamboo just fit the small cane. Cut four V-shaped notches in the bamboo and trim down to taper with small cane; wrap with small silk line, using the pull under, no knot way. Sandpaper the joints only, and varnish the entire ro: 1 .

Use sniall size sill: worm gut leaders; piece a nine-Foot to a three-foot and use enough hard braided silk line to make, with the snelled hook, just the length of pole. For the float get about four inches of peacock feather, hammer a BB shot very thin, cut the edges even and wap just below the joint of snell and leader. Wrap it to make as small a lump as possible, and let it be just heavy enough to sisk the bait slowly. A liti? practice and you can cast witis this outfit and make only a small ripplenot the splash and "ker-chunk" the quill and split shot make. Then when you hang one of the "big blue fellows" the fun you will have with that light tackle will pay for all the trouble of making it.

\section{A COMPACT OUTFIT}

\section{By James McCaffrey}

I have made a combination grate reflecting oven and cooking pan that I believe will be of interest to the readers of your kink column and I offer it, as follows:

The folding grate is made up of band iron that can be purchased at any sheet metal dealer's for a few cents, as it is used merely for shipping sheet iron from the mill and is of no use after the bundles are opened. The grate is made up as per drawing and the leg sections are looseriveted so they can be folded in.

The cooking pan is made of black iron and is 18 inches long, $9 \mathrm{I} / 2$ inches wide and 1 inch deep and the grate when folded just fits in the pan nicely. The reflecting oven is made so it can be knocked down and fits on top of the grate and its general dimensions is as sketched.

Oven is made of bright tin with edges hemmed or just bent over 
and hinges put on so that the ends fold in and under the top. This oven when folded just fits the top of the cooking pan, covering the grate and making the most compact outfit I have yet seen.

The grate cannot collapse after being put into the ground, as the

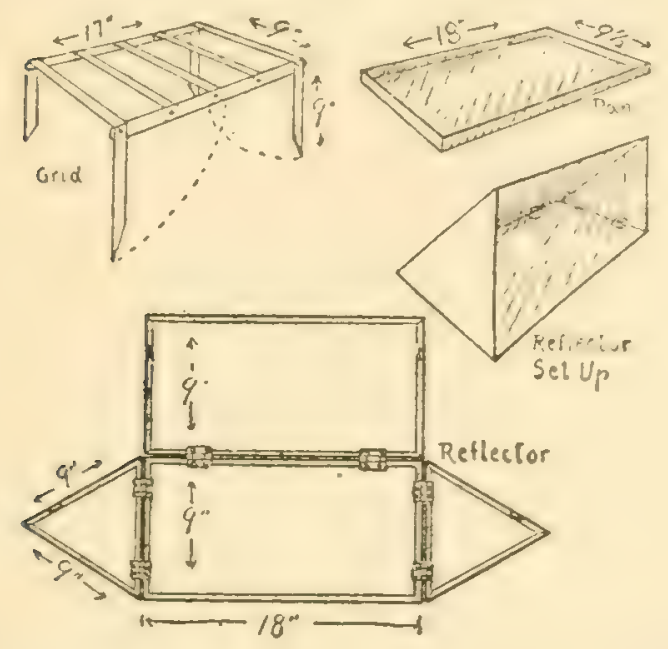

flat braces are held firmly in place by the side pieces. Band iron I used is $3 / 4$ inch wide and about 3-64 inch thick.

\section{GETTING THEM OFF THE HOOK}

\section{By E. N. Cartier}

We often hear fellows say that they have trouble in taking fish off the hook on account of sharp fins; or that they won't take their families on a fishing picnic because wifey and the kids keep dad on the jump unhooking their catch and give him no chance to fish. When going home time comes, father has nothing to show and the family have a fine time laughing at him. Father laughs along at his lack of a string, but his face hurts with every smile, and the next time he goes alone. In order to dispose of this trouble and still be able to take the family along, buy a box of ringed hooks in your favorite size when you are stocking up for the season. Instead of gut snells use remnants of discarded line 6 or 8 inches long.

Gather the family around the table some night after supper and proceed to tie one of these short leaders to each hook. When you go fishing tie your sinker on the end of the line and 8 or 10 inches above it make a plain knot, as shown in the diagram. Take one of your prepared hooks and tie it

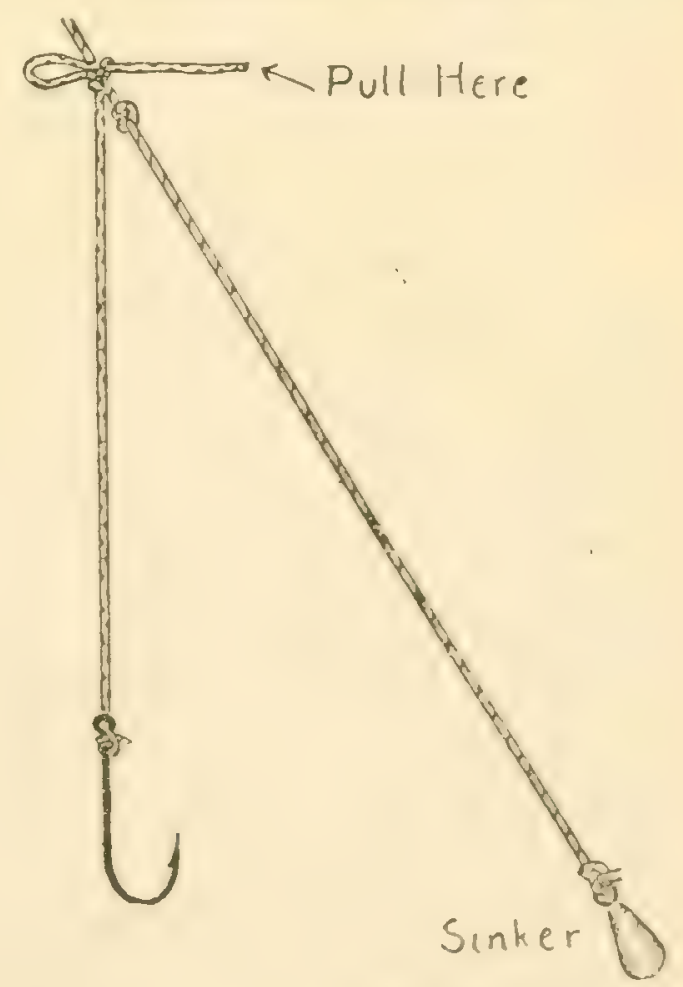

to the line above this knot with a plain bow. If more hooks are wanted, do the same thing with them above the first hook. The knot on the line prevents the bowknot from slipping down and the harder the fish may pull on the 
hook the more the bow-knot will tighten.

When you have landed a fish and find he has swallowed the hook, catch hold of your line above the hooks with one hand and with the other pull on the end of the bow and your fish drops into the basket. Then tie on another hook and bait up. Do not bother about taking out the hooks until you get home, by which time you will be cutting up the fish anyhow and the hooks will be easy to get out.

By this method mother, father and the kiddies can all have a good time and everyone can take care of his or her own line.

\section{SPLICING A BREAK IN A BAMBOO ROD}

By Wm. S. Cogswell

I happen to be the proud possessor of a Heddon casting rod that has been in continual use for the past eight years. While land-

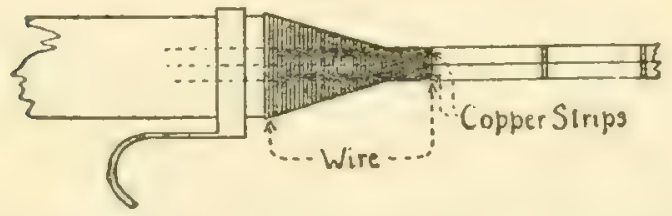

ing a fish one day last summer, said rod gave up the fight. On examiination I found the bamboo had become loosened in the butt and on removing the butt $I$ found that the continual run of water in the handle during its years of service had rotted two strips of bamboo. This rod, being an old pal of mine on many fishing trips, I at once declined to lay it away.
So I will try to the best of my ability to explain how I repaired my rod.

After removing the handle I glued the broken strips together. Then I gouged the center of each strip one-sixteenth of an inch and inlaid copper an eighth of an inch wide and one-sixteenth of an inch thick in each gouge across the broken joints.

Then putting the rod back into the butt, I, took No. 22 copper wire and, starting from the ferrule, wound it closely together down on the rod over projecting copper strips and slipped the end of wire alongside the copper strip under winding. After rubbing soldering paste on the wire winding, I then took hot solder and poured on winding and wiped off solder with a waxed cloth. That left the winding as smooth as a plumber wipes a joint. Using sandpaper to smooth out rough spots, my rod was as good as new. Enclosed you will find a drawing which I think will explain my method more clearly than I have written it.

\section{DOUBLING UP THE STOPPLE KIT}

By Julien Swanson

Being one of these fellows who delight in undermining their friends' digestive apparatus with what is known as camp cooking, and also more or less infected with the "golight" bug, I soon fell for a Stopple Kook Kit. And although it has proved the ideal 
cooking outfit for the two-party, week-end hike or fishing trip, it has its limitations when it comes to an extended trip or a larger party. Not wanting to invest in an expensive, nesting aluminum outfit, nor liking the bump that one of these make in a pack sack, I got one more Stopple (giving me two in all), and figured out the following kink. It fills the bill fine, and I can joyfully go ahead and poison six or eight at a time now if I want to.

I had a tinner make me a container $23 / 8$ inches wide by $93 / 8$ inches long and $91 / 2$ inches high, with a cover that goes down on the container $2 \frac{1}{2}$ inches. We used the heaviest tin we could get and made it with lock seams so that heat could not melt the solder and open up the joints. Where the lower edge of the cover comes we made a small bead in the rim to stiffen it up a little. On the ends of the container and just below the cover we riveted on flat ears wide enough to take a one-inch carrying strap, and $I$ also fasten a wire bail in these when cooking. Into this container go my two Stopple Kits edge to edge, and I have a nice flat package that fits fine in the pack sack or carries with a shoulder strap without rolling all around my equator.

Arriving at camp, I set up both grates side by side with my large container on the windward side, where it gets a lot of heat besides helping considerably as a wind- shield. This large container gives me a mulligan or spud kettle that holds about a gallon, and when I don't need it for cooking it makes a good water pail. The inverted cover makes a good mixing pan or small stewpan. The two Stopple stew-kettles (one at each end of the grates) fix me out for coffee and dessert. The four frying pans can be used as such or as plates, and I have four cups. Sometimes I use one Stopple outfit for bak-

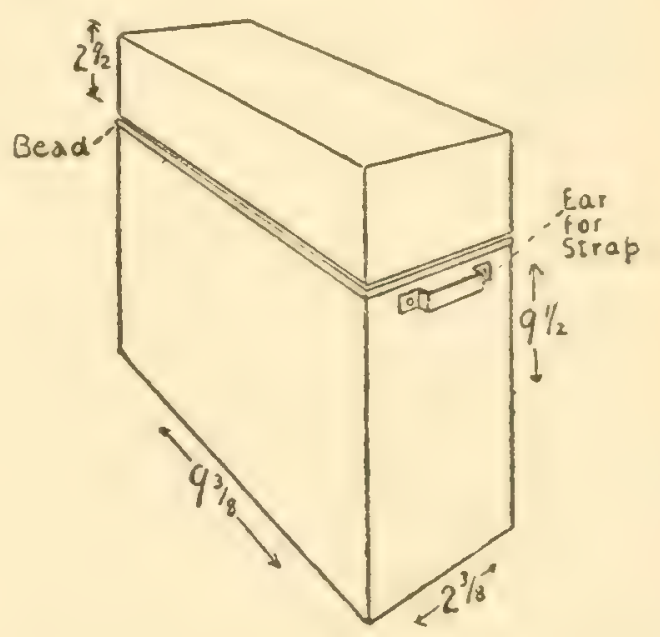

ing, as per Stopple directions. There is no limit to the various combinations. Figure them out for yourself. I am going to make a waterproof canvas carrying case for the container, which will be mighty handy as an extra water pail in this country, where our water must come from the nearest well.

\section{KEEPING MINNOWS}

\section{ALIVE}

By W. E. Clader, M. D.

For the past few years I have been very successful in keeping 
minnows alive while carrying them. I use an ordinary workman's dinner pail with two compartments, such as can be purchased nearly anywhere for a very small price. I fill the top compartment with ice and put the water with the minnows in the

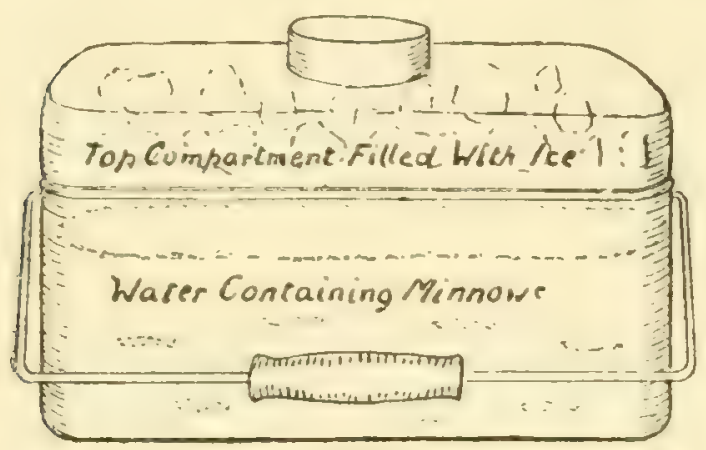

bottom compartment. A small hole punched through the floor of the top compartment allows the melted ice to gradually drip into the bottom compartment. The ice can be renewed very easily and on very hot days a wrapping of heavy paper around the bucket makes it better.

\section{A SELF-STRIKING HOOK}

By H. J. Heath

The diagram shows a kink that has been used successfully many times. It can be made in a few minutes with a piece of spring-

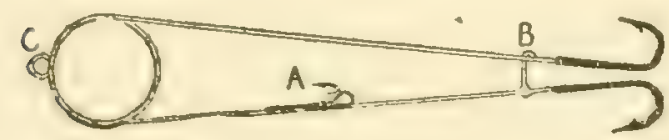

brass wire, some hooks and a little solder, and is just the thing for trolling for bass, pickerel and other game fish. The diagram shows the principle fairly well.
The two large hooks at the end are held close together by an arm, $B$, which is soldered to one of the hook shanks and has a bend in the end which catches the other hook shank just enough to hold it. The bait is fastened on the small double hooks marked $\mathrm{A}$ and extends backwards as far as desired.

When the fish strikes, the upper trailer hook is immediately knocked loose from the small bend in the arm, B, that holds it and the spring thrusts the two hooks apart vigorously, striking them well into the fish's mouth.

$\mathrm{C}$ is a small loop for fastening to the line.

\section{REPAIRING STEEL RODS}

\section{By E. J. Holloway}

A broken steel rod may frequently be repaired by a very simple process. Usually the ends of the tube where broken have

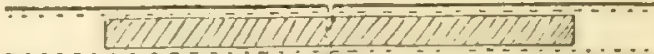

become somewhat pinched or distorted. If this is the case insert the tang of a file or any other convenient tool in the opening and by rimming around and around the circular cross section can be restored. A pair of pliers judiciously used may help in this operation. Then with the file smooth the face of the break square across. Take a piece of wire slightly larger than the interior of the tube and file it to a tight fit. Heat the broken end of the 
tube so as to expand it slightly. It need not be heated so much as to destroy the temper. A very moderate heat will expand it considerably. Warm one end of the prepared wire. Cover it with a bit of solder and while the latter is still soft push the wire down into the tube for half its length. Repeat with the other side of the break. A drop of solder run around where the two ends of the break come together will make all smooth and complete the repair.

\section{A BARBECUE FORK}

\section{By A. H. Froom}

Out here in California we barbecue a good deal of meat. I am enclosing herewith diagrams of a fork and jack that I have found very handy for this purpose.

I get an ordinary four-tined pitchfork and have the blacksmith straighten out the tines. For the handle I have fitted on a plain

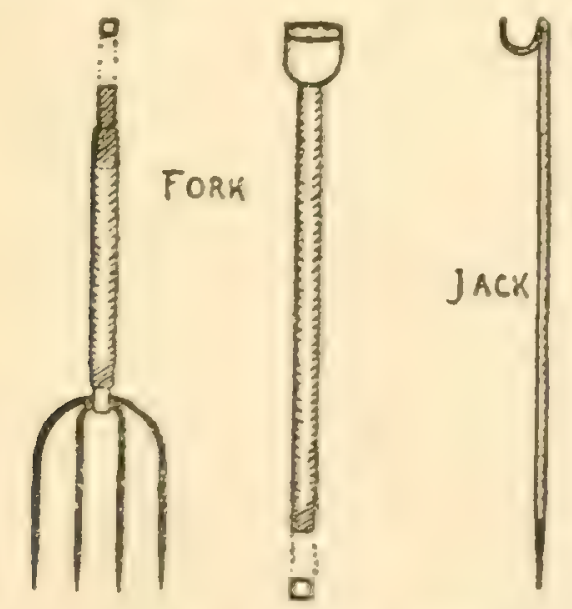

piece of gas pipe about sixty inches long, so that I can stand well back from the fire. I usually put a ferrule joint in the middle of the handle and also simply slip it on to the fork socket. This makes it take down easily for carrying. I have these joints beaten square so that the fork will not twist when the handle is turned.

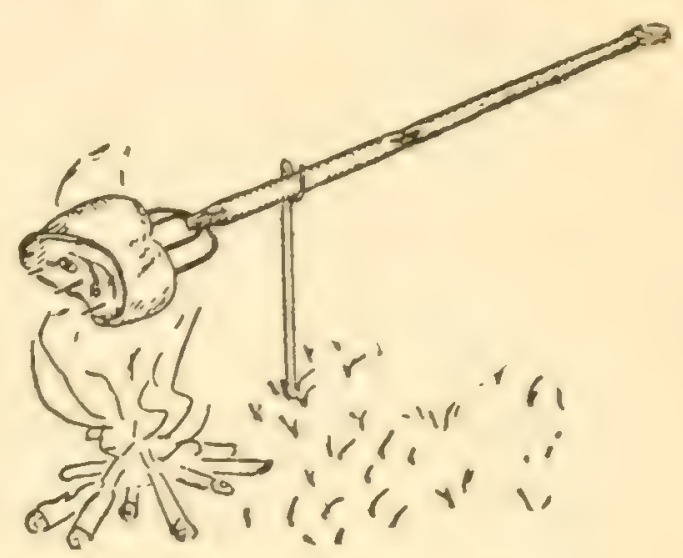

The jack is made very simply, as shown in the diagram. If one uses about $3 / 8$-inch rod for the jack it may be slipped into one of the handle joints for carrying. By resting the handle of the fork in the hook of the jack one can turn the meat at his leisure, thus holding the juice in the meat instead of losing it in the fire.

\section{A SAFETY-FIRST BELT By ARThur JoHnston}

Here is a Kink that I thought out several years ago. Now I cannot do without it. Get a piece of heavy duck or canvas (about twelve or fifteen ounce weight) nine inches in width and ten inches longer than your waist measure. Fold and sew into a tube using heavy linen thread. Machine stitching is preferable. Leave five inches at either end unstitched and slit the opposite edge at the fold so that you have two fiveinch flaps at each end. 
Now turn the tube inside out and get six small buckles and the same number of small leather billets. Tuck one flap at each end of the tube in and bring over the other flap. Mark where it comes and rivet three of the buckles at each end of the tube to meet it. Then fasten three of the billets on each of the overlapping flaps so as to fit the buckles. Fasten a good belt buckle on one end of the main tube and a six or eight inch length of belt to fit it on the other end. It is worth while to give the canvas a good coat of shellac or varnish, as it is then not so likely to be penetrated or torn by sharp sticks and hooks. If varnish is used, let it dry thoroughly and then dust the inside of the tube with powdered soapstone.

Go to a bicycle repair shop and get a piece of discarded motor-

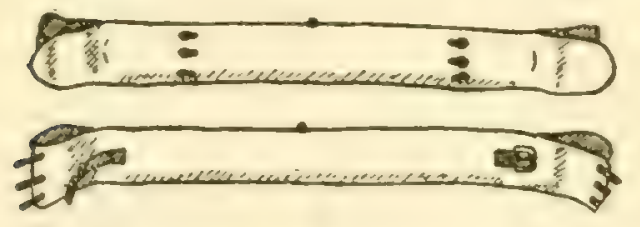

cycle inner tube the length of your belt. Have this thoroughly repaired and a valve and stem put on. Make sure that both ends are firmly sealed and test the tube by inflation under water. Lay the inner tube on your belt and mark where the valve stem will come. Cut a round hole in the top edge of the case and reinforce it with a small patch of leather. Now insert the inner tube into the casing and bring the valve stem through the hole provided for it. Partially inflate the inner tube, making sure that it is not twisted or pinched at any point. Then tuck in the loose flap at either end of the casing. Bring the other flaps over and buckle them down. Finish inflating the tube and your safety-first belt is ready to wear. With this belt around, your waist you need have no fear of slipping into deep holes while wading. Or if you are a poor swimmer and go boating with that cursed fool that rocks the boat. you will have no appointment with the undertaker. I use one of these belts on all of my trouting trips. When I come to a pool that is too deep to wade I just float down the middle, casting right and left. Incidentally I have taken some of my best fish this way.

Rolled into a coil this belt makes an excellent cushion or a dream of a pillow for your weary head at night. Deflated, it slips into a small pocket and weighs less than two pounds. The materials for mine cost me less than a dollar and I did the work myself. It is necessary, of course, to carry a small brass bicycle pump with this belt and a couple of rubber patches and some cement in your repair kit.

\section{ANOTHER SLIDING FLOAT}

\section{By J. W. Noyes}

Many times when out bait-casting and "they" wouldn't hit the plug, I have longed to use my 
short rod for still fishing. Plenty of froggies on the bank and a float in the tackle box. But I want to fish deep, perhaps, and just imagine making a cast with fifteen or twenty feet of line out

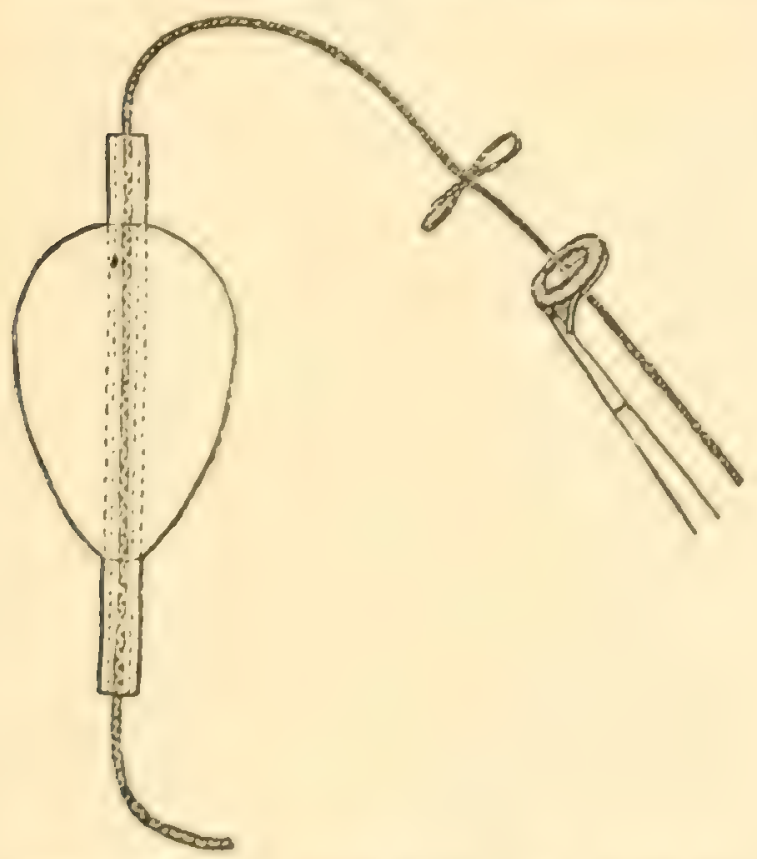

between the bait and the rod before you start out. Pretty awkward. And then, even if you are successful in getting the line well away from the boat, imagine what it will be when you get a fish on and can't reel in any farther than the float. Here's a way out of the difficulty:

Remove the stick which runs through an ordinary float and substitute therefor a reed pipestem. The smoke conveyor from a cob Willie will about do the trick. String the line through this and tie a small bowknot in it above the float at the place where you want the float to stay. Reel this bowknot right in and the float will slip down to the hook. Make your cast and the weight of the bait will pull the line back through the float to the desired depth.

In playing the fish, if you should be so fortunate as to get one on, the bowknot usually comes untied. If not, it still reels easily through the guides.

\section{RAPID FIRE FISH CLEAN- ING}

By G. H. Strohm

Don't scale your bass or clean him. Just lay him flat on his side and make a clean cut through the skin from head to tail over the backbone. Do the same thing on the under side, but slightly, just breaking the skin. Cut the skin also around the head and tail as indicated by the dotted lines in the diagram.

Grasp the point of the skin at the top of the head between knife
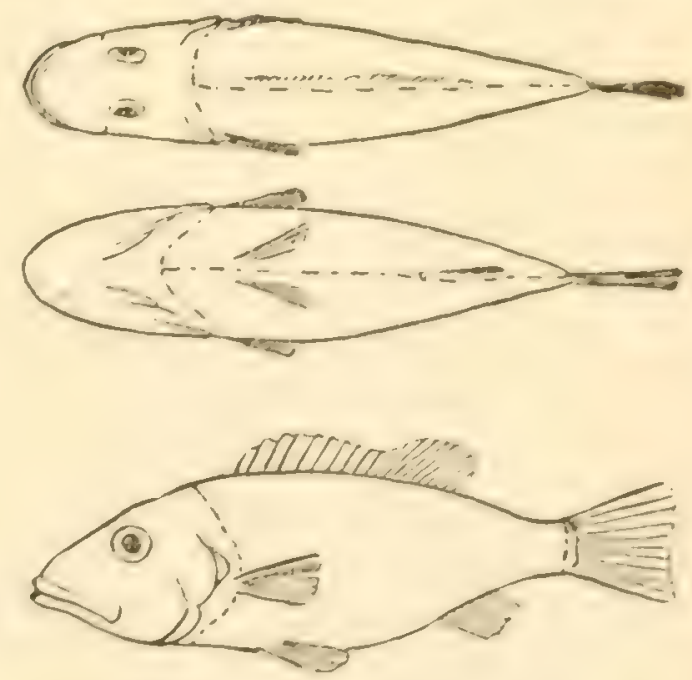

blade and thumb. One good pull and that side is skinned. Do the same with the other side. Then slice off a nice strip of boneless flesh on each side and throw the rest to the birds. You can do this 
without cutting into the entrails at all.

At first glance this looks like a waste of good bass meat, but one really loses very little and does away with all bother on account of the bones. If you really want your appetite whetted you should see the job done by a Canadian guide at lunch time when everyorfe is too hungry to wait for the eats.

\section{A FANCY STITCH}

By J. Everett Willis

One often wants to sew a pistol, knife or rifle scabbard with buckskin or some other leather, because it will wear longer, be stronger and last longer than if sewed with thread. Many people like to have things useful as well as ornamental and the following stitch will be found just the thing for sewing the many leather articlas to be found in the sportsman's kit.

Buckskin is the best for sewing, though fine oiled calfskin is also good. Cut the strings a little wider than wanted and thoroughly soak and stretch them. They may be softened by rubbing them with a soft soap made by boiling shaved white laundry soap in an equal amount of water. English Crown Saddle Soap is the best.

You can punch the holes, or make them with an awl. The latter will make the best job. Begin just as though you were going to sew a regular over-and-over seam, only don't pull the loop tight, but take another stitch through the loop, instead of through the leather again. Then pull the loop tight and make the next stitch through the leather.

The stitch begins at the top. The first stitch is a regular overand-over stitch, and the second is the fancy stitch. The string is sewed through from right to left, both in the stitch through the leather and the stitch through the loop. If the stitches are pulled tight and evenly, it will look just like three braid on top and will be an added strength as well as an ornament to any holster.

\section{KEEPING EYED FLIES}

\section{By Sherwood Buckstaff}

Many of the fishermen who use eyed flies-and there are more who do each season-carry their flies with them in a tin tobacco box. This is easy to carry and holds plenty of flies. But it is very inconvenient. If you want a small fly it is sure to be at the bottom of the box. When you finally get it, three or four other flies are usually hooked in with it, and you must put down your box and disentangle them. Quite often they drop apart unexpectedly and fall into the grass. This is very annoying and loses much time.

Now for the Kink. Before you go, when you are arranging your tackle, cut several sheets of rather stiff paper to fit your fly box. Stick the points of your flies in these sheets, arranging them according to size, color, or any other 
way you prefer. Be sure that the barb is pushed clear through the paper. Then, on the stream, when you want a fly, take out the sheet containing that fly, and jerk out the fly. Never mind if you tear a big hole-you can stick the fly back in a little to one side. Probably, if you are like most anglers, you will want to rearrange your flies before each trip anyway. This Kink takes little time at home, when your time is not valuable, and saves precious minutes on the stream.

\section{THE SELF-PULLED WIND- ING KNOT}

By Charles F. Speort

Here is a simple and effective way of making the concealed finish on rod windings:

Lay your winding silk along the rod in a loop as shown in the first diagram. Then go right on

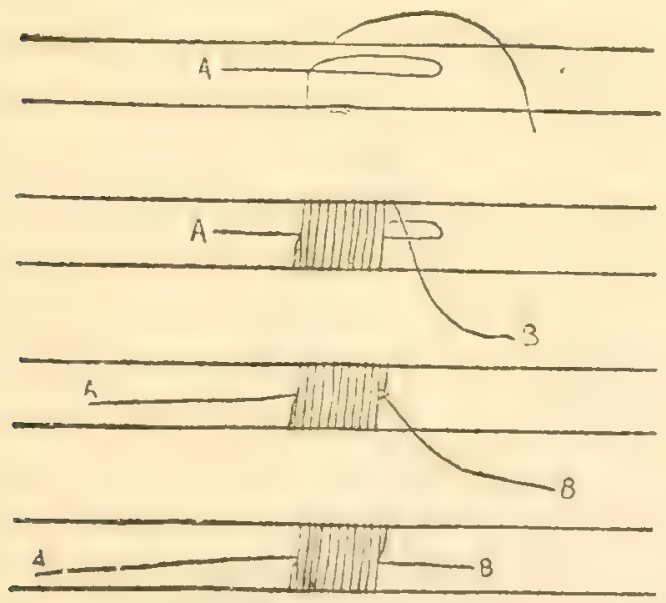

winding over this loop. When the winding is as long as you. want it, break the silk, leaving an end a couple of inches long. Bring this end (B) through the loop.

Still holding onto end $B$ to keep the winding taut, pull steadily on end $A$. This will pull the loop back under the winding. When the end of the loop has been pulled about half way through, cut both ends of the line that are left projecting and your winding is fastened both neatly and secure1y. Be careful not to pull the loop too far through, as this would leave the beginning of the winding insecurely fastened.

\section{HOME-MADE BAIT SOCKET}

By A. L. Weaver, Jr.

Being quite a novice at the fishing game I like to have a number of different kinds of bait. so I
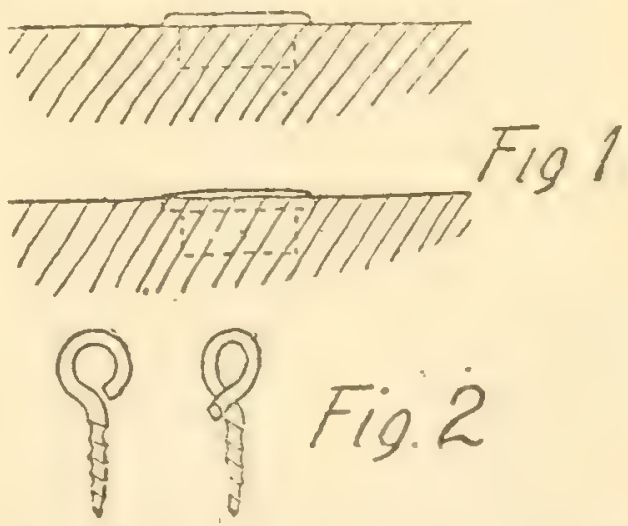

make them during the winter months. One of the propositions I ran up against in making my own baits was some method of securely fastening the treble hooks to the bait and after unsuccessfully trying to buy some screw eyes such as are used on the "regular" baits, I finally hit on the following scheme:

I bought a box of No. 2161/2 screw eyes and a box of stationer's aluminum eyelets. Then bored a hole in the minnow just the 
size of the eyelet and put in the eyelet until the ridge came down to the bait and drove it flush with a hammer (Fig. 1). I took a screw eye and with a pair of pliers bent the eye slightly on one side (Fig. 2 ). Then put on the treble hooks and screwed them into the bait in the usual fashion.

I used one of these home-made baits on my vacation trip and of a total of twelve strikes did not lose a fish due to the hooks pulling out.

\section{KEEPING AGATE TIP FROM CHIPPING OR BREAKING}

\section{By. C. L. Creutz}

During August, when on a fishing trip in Wisconsin, I had the misfortune of breaking the agate tip on a Heddon casting rod. I always use a wire leader in casting, as it is very much easier to change "plugs" if the bass are not "looking 'em over" as they should. After a cast I retrieved the lure too closely to the tip, causing it to break the agate. Luckily, I had

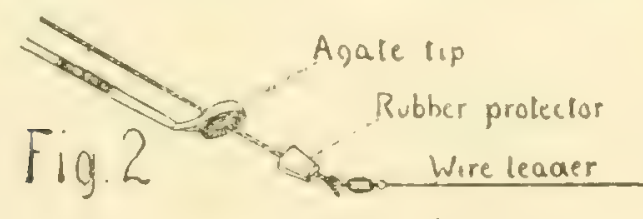

another tip with me and had an inspiration to keep this one intact. Found in my tackle box (for some reason or other placed there several years ago) an Eberhard Faber rubber pencil eraser. Then the thought struck me, "Why not make a protector for the tip?" No sooner said than done. Took the eraser and with a knife cut it into about six or seven "protectors" looking something like Figure 1. Took a small nail and poked a hole through from top to bottom of "protector." Drew my line through it and fastened line to leader as in Fig. 2. Had no more trouble and did not even have to watch the leader when I retrieved the lure, as the moment the rubber protector struck the tip I had to quit winding her up. Intend to have a couple of erasers in my tackle box for emergency cases in the future.

\section{A HELGRAMITE CAN}

\section{By A. R. HARPER}

The best thing I have ever found to carry helgramites in is one of these perforated aluminum cans which are designed to convert the ordinary coffee pot into a percolator. They can be procured at any hardware store at from ten to twenty cents according to size,

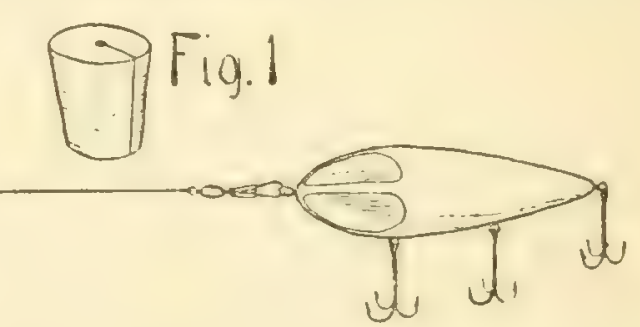

quality and material and nerve of the emporium you happen to visit. I have seen these in ten cent storès.

Mine is about five inches high and three inches in diameter. It 
is perforated on the bottom and the sides, but the top is solid. Being of aluminum, it is light, does not rust and is easily kept clean.

I catch my supply of helgramites, put them in the can with

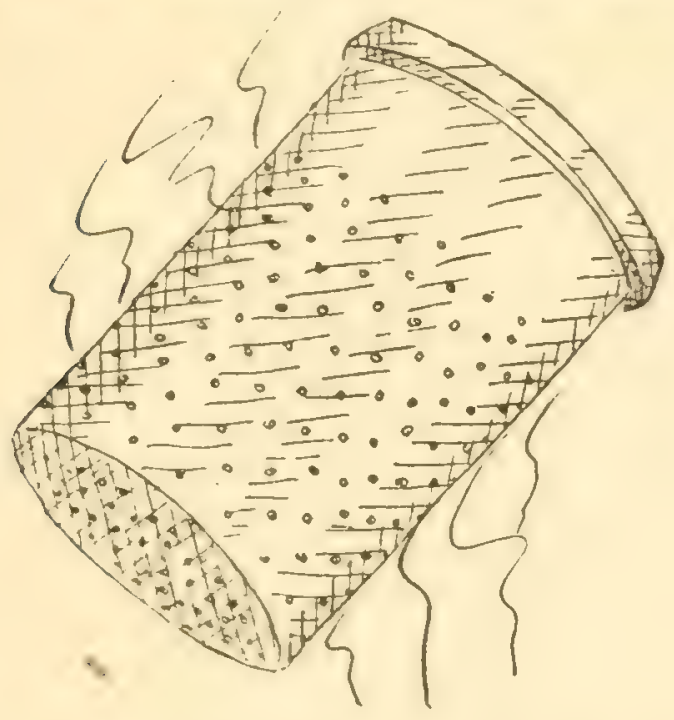

some leaves, close down the lid and then hold the can under water a moment.

A vigorous flirt throws out excess water, so I can put it in my creel. Every half-hour or so I give them a fresh wetting.

They have so much fresh air and water that they keep in fine condition all day.

\section{HANDY GAME CARRIER}

By M. C. Stark

The illustration of my Handy Game Carrier inclosed herewith is almost self-explanatory. It can be made at a cost of about 75 cents. The shoulder strap is good, strong harness leather, $17 / 8$ or 2 inches wide by 24 inches long. The end pieces are whang or beltlace leather, 4 by 8 inches, which are cut into eight strips, 7 inches long, to within 1 inch of one end, which is sewed to the end of shoulder strap.

Each one of these strips is slit for 4 inches to within one-half inch of the end. To hang game, make a loop of one of the strips and put the head of game through. The loop will slip down, holding game firmly. Two, or even three, birds may be hung in one loop.

This carrier is easily slipped in a coat pocket and will hold all the game one man wants to carry, or more ducks than the law allows

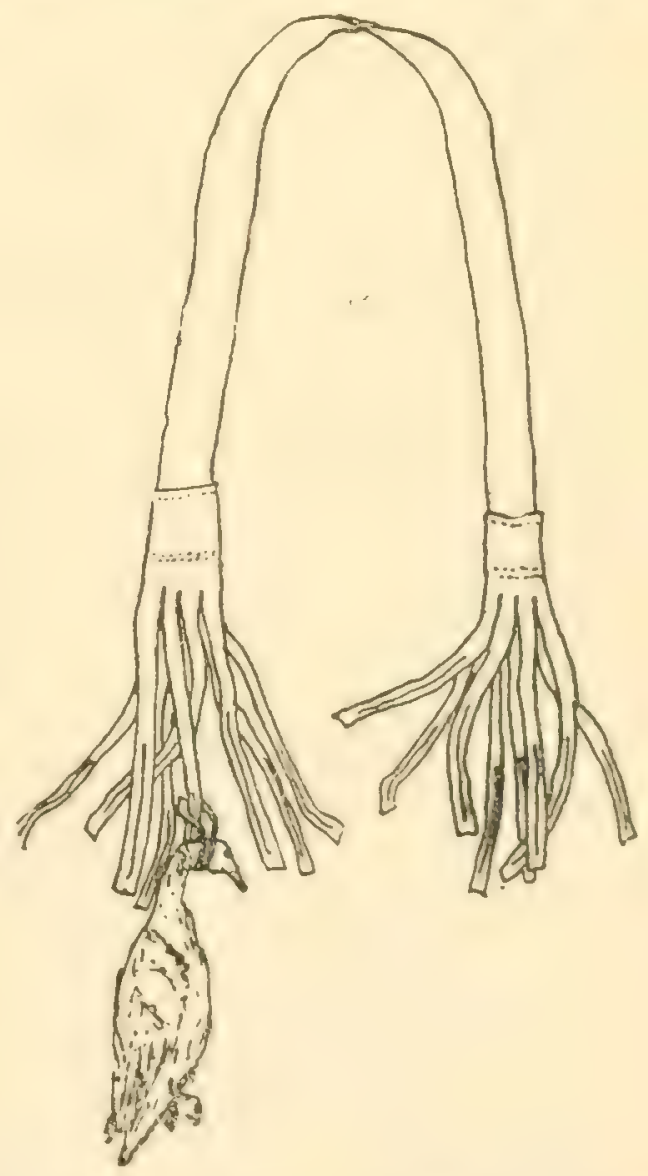

one to have in a day in Iowa. The game is kept cleaner and in better shape than when stuffed into pockets or game bags, and. it may be shifted from one shoulder to the other, or may be hung over 
a stick and carried by two men if necessary.

I have never been lucky enough to have my carrier loaded to capacity.

\section{SETTING YOUR WATCH BY COMPASS}

By H. B. Schelt

Ever have your watch stop while out in the woods and no means of setting it? It probably won't happen the second time, but if it does, try this:

With your compass, or by means of a stream or lake from your map, determine which direction is south. Then point the hour hand in the direction of the sun. Slowly turn the hand around the dial, keeping it pointed toward the sun, until the south comes half way between the hour hand and 12. Pay no attention to the minute hand.

This is merely the problem of using the watch as a compass, except it is solved for another factor, namely, the time.

If the sun is not shining, hold the point of your knife, or a pencil, vertically against your thumbnail. A close examination will reveal a faint shadow on the dullest day, from which the direction of the sun can be found.

\section{A RUBBER TAPE IKINK By "NutMEG"}

Here is a little kink in shaping scabbards and holsters for rifles and pistols: After wrapping the arm with a greased cloth, take a roll of rubber tape, such as is used in winding tires or electric wire joints, and wind over the cloth tightly, lapping slightly so as to make a moisture proof cover. The tape not only protects the arm from moisture, but binds all together, so that the arm may be taken out and replaced readily. If the tape has a tendency to stick, dust the outside with powdered chalk, talc or similar powder.

\section{THE BAIT WITH AN OVER- COAT}

By Paul Skoberg

One never-to-be-forgotten summer we were enjoying life in camp at Lake Augusta. We were well supplied with underwater baits, which thad done their duty nobly when it came to filling the larder. But there came a time when the bass would touch nothing but floaters. Of these we had but one in camp, an old Heddon which was totally lacking in paint. The dark color of the wood when wet did not prove very attractive to the fish, but there was no paint available and it would take a week to get some new baits into camp. Meanwhile I did not intend to be idle. I took a piece of birch bark, split it pretty thin and lashed it around the bait back of the collar with a few bits of old line. Then I punched out a hole for the belly hook and hung it back in place.

When I got through it was 2 o'clock in the afternoon, a bit early for the evening fishing, so 
I sat down on the bank to consider a bit. My partners returned to camp and laughed with glee at my homely makeshift. Cooney offered to make every meal for a week if I caught so much as one

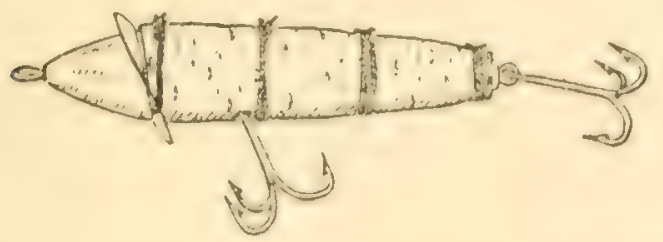

bass on it. The laugh was on him, however, when we started out fishing later that afternoon, for we returned to camp with no less than twenty nice bass.

If you should look into my tackle box to-day you see this very bait with its original covering of birch bark as well as another which I rigged up like it later with a few improvements. These baits have done business for me on many different lakes. The trick would work equally well with any other make of plain floating bait.

\section{THE ALCOHOL BLOW LAMP}

By Geo. C. Whitney

About the handiest little kink that I know of is this little alcohol blow lamp. It burns alcohol and one filling lasts a long time, as it has a cap which makes it airtight when not in use. It fits in the vest pocket or tackle box, costs about a dollar and can be made at home out of a piece of brass tubing, a wick and a piece of camera hose.

It is operated by lighting, and then blowing the flame (which is very hot and clean) on the article to be repaired, at the same time running soft solder or cement on the work.

It can be used to solder fish hooks together in gangs or tandem, temper points or weed guards, opening eyes in hooks, adding solder weights, soldering tips on steel rods, guides, cementing on agates, making small molds, melting rosin or cement onto flies, mending leaky minnow buckets, tackle boxes and a hundred other little jobs. And I saved the day on my last trip by repairing a puncture in the canoe with it by running hot ceiling wax in the hole over and under the

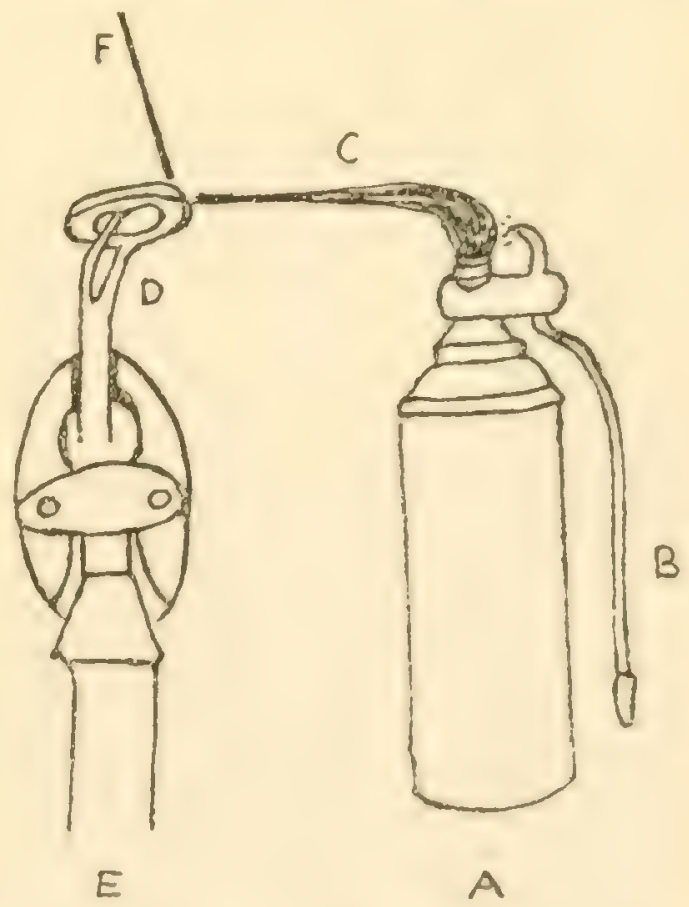

canvas. It is always in my tackle box with a piece of soft solder, a little soldering paste and a piece of jeweler's cement. It is handier than a soldering iron and makes a much better job. 


\section{A BOBBER WOBBLER}

\section{By Joseph W. Boyle}

One rainy Sunday before the season had opened I was practicing casting on the lawn. I searched my tackle box for a proper casting weight, but the best thing I could find was a small eggshaped float or bobber. The wind was pretty strong and the bobber rather light to cast well. I was just figuring on adding a weight to it when an idea struck me. Why not make a real wobbling bait out of this bobber? You see, I had been reading in the cataogs about the new wobblers and

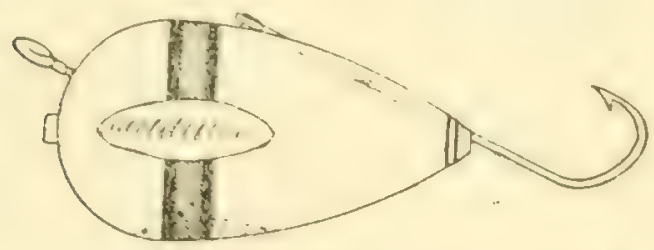

I wanted one to try out. So I retired to shelter to do a bit of figuring. In a few minutes my wobbler was competed. This is how it was made:

On either side of the bobber I gouged out a fluting with my jack-knife, about an inch long, a quarter of an inch wide and deep in the middle and growing shallower at each end. Then I cut a narrow groove down the back and fastened a long-shanked Sneck hook in it. A bit of copper wire at the end held the hook firmly in its groove. On the under side of the bait I sunk a ringed sinker for a balancing weight. A screw eye at the forward end, located a bit above the center, completed the job. Total cost a few cents only.
This bobber had a red head, a yellow middle stripe and a green after part, making it a brilliant bit of color. It dived and wobbled very nicely and the hook being set with the point up, made it practically weedless.

\section{A WATERPROOF MATCH SAFE}

By Charles Barton, Jr.

I suppose all the readers of the OUter's Book have seen and heard of several dozens of waterproof match-boxes, but for an inexpensive home-made article mine should take the cake. The necessary apparatus consists of one empty brass shotgun shell, the smaller the gauge the better, and one ordinary cork stopper to fit the same.' Take a handful of matches, place in the box and close with stopper, thus making a waterproof match-box. To prove this I filled the case with matches and left it in water for three and one-half hours, and at the end of this time the matches were perfectly dry.

\section{A BAIT IMPROVEMENT}

By Fred J. Schildhauer

While out fishing on one of the lakes near my home, I got one of those "dandy" strikes. But the fish was a better warrior than I and carried off the tail gang of my artificial minnow as a trophy. I did not have an extra gang along and was wondering what to do when my eye fell on a feathered fly attached to a spoon 
hook in my outfit. It was short work to put this in place of the missing gang and I was soon plugging away again. At the close of the day I found that I had been the lucky one out of the entire bunch that were fishing. Apparently the fish had favored my patched up bait above all other offerings. Try this out yourself and you will find it a real improvement.

\section{A LEFT-HANDED CASTING REEL}

By W. J. Baldwin

The average left-handed man using any regular casting reel places it on the rod in a reverse position from that used by righthanded anglers. In this position, using the left hand for casting, the hand often gets too close to the reel so that in making the cast

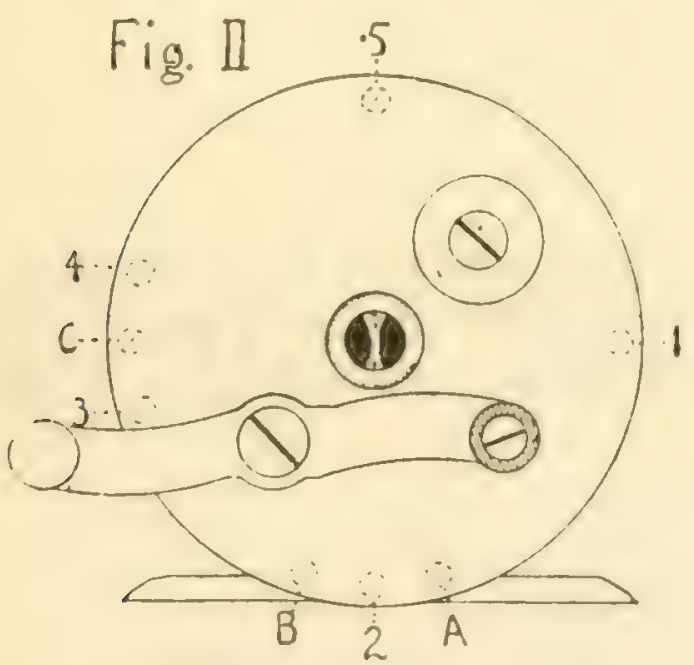

the balanced handle of the reel tears a bunch of skin from the knuckle of the finger.

Having had the skin torn from my knuckles on several occasions, I made my casting reel over so that now I can cast without fear of torn knuckles.

The enclosed sketch explains how I did this.

Figure 1 shows reel as it originally was. Figure 2 as it now is.

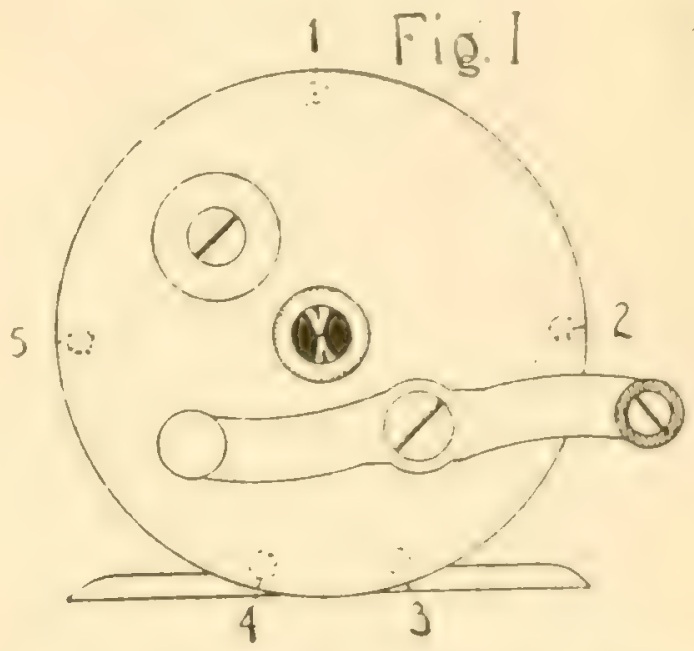

To make change, remove handle, side plate, gears and inside plate. Turn reel clock-wise until rod screw hole No. 5, Fig. 1, is in the position of No. 5, Fig. 2. It will then only be necessary to drill three small holes in each side plate to correspond with rod holes A, B and C, Fig. 2. Then replace all screws in cross rods, gears, outer plate and handle and the reel will then have the handle in position shown in Fig. 2, in which position the handle cannot possibly hit the knuckles.

\section{THE EMERGENCY MATCH SUPPLY}

\section{By "Pug" Moen}

While on a canoe trip down the Wisconsin River from State Line, Mich., to Stevens Point, Wis., I came upon a hunting camp near a 
spring. I stopped to get a drink, and noticed some empty shotgun shells lying about. I picked up some, trying to get two that would fit tightly, to be used as a waterproof match box. I had a bottle full of matches in my pocket, but was afraid of its breaking. A member of the hunting party from Madison was watching me and said, "Here is my waterproof match box." It was one of those little metal boxes that had contained Gillette safety razor blades. The box was filled with matches and then sealed with paraffine, making it watertight. It is very small, light in weight and quickly opened when needed. This is to be used only in case of emergency, of course. I think this little article should be in the pocket of every outer, and sometimes may save a life.

\section{A GOOD FROG HOOK}

\section{By J. A. Potts}

After losing my frog hook one day, I struck upon the following plan: Take an ordinary treble hook, such as used on all brass plugs, and cut one hook off. Next take a plain hook and slip the point through the eye of the treble hook. Now slip the single hook through the frog's lips and the double hook up through the frog's legs. This makes a good hook that is semi-weedless and will help to get the big ones. The hook can be used this way for small frogs, but for larger ones a piece of wire or, handier yet, a snap and swivel must be placed between the single hook and the double hook.

\section{AN EXCELLENT FLOAT FOR LIVE BAIT FISHING}

By Frank E. Wilder

Everyone, I presume, has gone trout fishing when nothing in his tackle-box would bring a rise, but still trout could be seen eagerly looking for some insects which dropped into the stream. You try putting some of these insects on your hook, but they are very delicate and after they have been in the water a few seconds the weight of the hook drags them under the surface and they look like anything but the insects they are.

Here is a kink to make this method of fishing practical: First, take a sound cork and cut a small piece three-eighths of an inch long and three-sixteenths of an inch wide and of the same thickness. Round the edges so that the crosssection is egg-shaped. Now cut the gut of a snelled hook, as in Fig. 1, just below the knot. Soak the gut for a short time in water and then thread in a small-sized darning needle, as in Fig. 2. Bend the end back and run the needle lengthwise through the center of the cork. Slide the cork down to the end of the winding as in Fig. 3. Unthread the needle and tie the loop in the end of the gut. Fig. 4 shows the way the hook looks when baited. 
Now all that there is left to do is to get your fishing outfit and go to your favorite trout stream

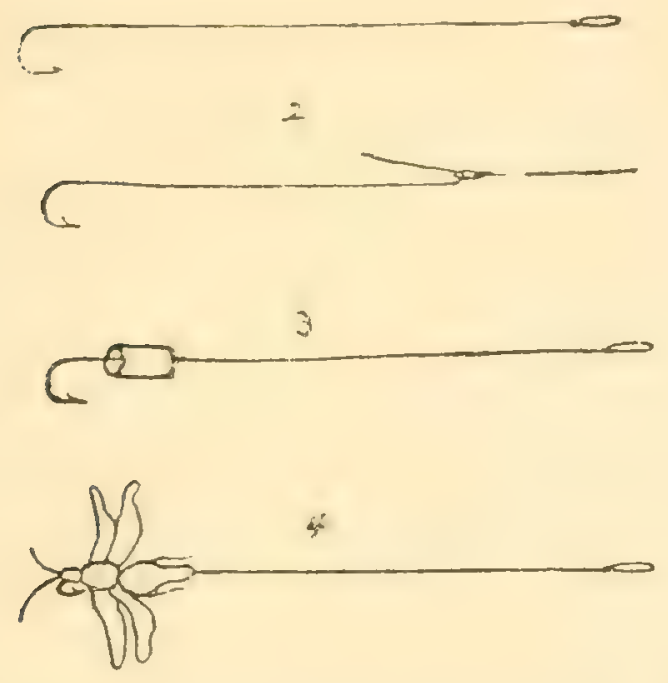

where I hope you will try out this little kink and come home with a good catch.

\section{THE LOOP WINDING PULL}

\section{By Sidney V. Ray}

One of the simplest, easiest and quickest methods of laying rod windings so as to conceal the ends is the following:

The winding is started by laying the free end under and taking three to five turns over it as shown in Fig. 1.

Have ready a bit of thread, either the same as the winding is being made of or, if that is too light in weight, a bit heavier. It is good policy to wax this bit of thread with ordinary beeswax. Make a loop of this bit, lay it on the rod and proceed to wrap it under the last three or four turns of the winding. (Fig. 11.)
Then clip the end of your winding silk, leaving an inch or two free and holding the wrapping firmly meanwhile with the thumb. Insert this free end into the loop as in Fig. 11.

Then grasp the loose ends of the loop, which should be long enough to give a secure hold, and, still holding the wrapping to prevent loosening give the loop a quick, snappy pull. This brings the loop out from under the turns which were taken over it, and with it the free end of the winding. Cut off both free ends closely and the winding is complete.

Do not use the same place in the loop thread for more than one tie, as the friction of dragging the free end under wears it pretty thin

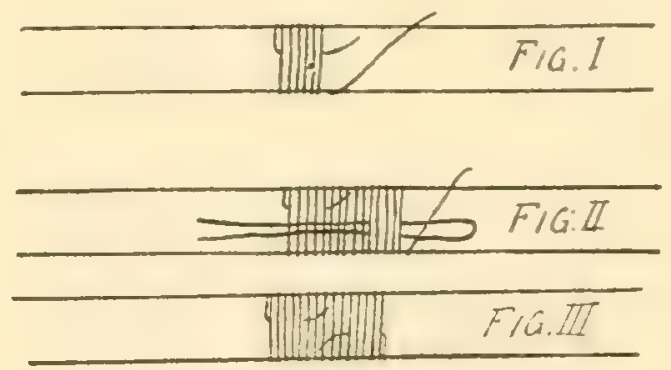

and it is annoying to have the loop break just as one has nearly completed the winding.

\section{GREASING DECOYS}

$$
\text { By. "ANON" }
$$

Although an enthusiastic fisherman, it warms my heart to know that the hunters and other outdoor men are going to get a chance at that Kink Department. It never seemed quite fair to me to confine that interesting part of the good old Outer's Book to 
one class of enthusiasts. "More power to it!"

The first kink that occurs to me is one that I am afraid will be known to all the old duck hunters, but I know that it will be a great help to any of the "crew" who are not familiar with it.

Have you ever sat out in your blind, or hung on to a "clamper" when the thermometer is way below the freezing mark, and watch your decoys gradually, but surely, become completely encoated with ice? They look as much like a duck as one of the small chunks of ice floating near by, and if there happens to be a sun they shine like the proverbial pair of nigger's heels. Did someone say "ducks?" Absolutely no chance these days with an average of two hunters to each bird.

How can you avoid it? Easy! Just give each little wooden birdie a nice warm coat of any colorless grease. Anything will go; from lard to vaseline, and I have found that it more than repays for the small amount of inconvenience, and they will shed water like a real duck's back.

\section{MAKES FOR ACCURATE STATEMENTS}

By E. E. Rowlandos

You know a fisherman wants to be accurate in his statements regarding the size of his catch, so in order to tell the folks at home just how long the "big one" was, I devised this plan last season: I took a small brush and some red enamel and painted small figures an inch apart on the under side of the first joint of my rod. It is handy, no weight and out of sight except when you want to see it.

\section{A PLUG CARRIER}

\section{By Dean O. Smith}

I expect that all of us have had more or less trouble finding a satisfactory pocket carrier for bass pugs while fishing, as every person always carries several for a change of baits during the day. For quite a while I carried mine in their original pasteboard boxes,

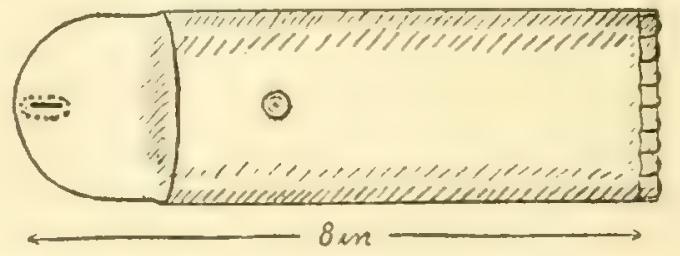

but these were bulky to have in the pockets, and of course you get them watersoaked, and when in this condition the boxes often came apart and the hooks attached themselves to the different parts of your anatomy. After enduring this for a while I fitted up a carrier which has given very satisfactory service.

I procured a piece of automobile inner tubing about eight inches long and sewed one end of it shut, using heavy waxed thread. On the other end I left one side longer than the other and cut a buttonhole in it, sewing around it with a lighter waxed thread to keep it from tearing out. 
I sewed a button on the shorter side, buttoned it shut and it was done. I made my carrier out of a small tube and it holds two minnows easily. If desired a larger tube can be used and a seam sewed through it lengthwise, dividing it into two compartments: If you wish, the lower end may be vulcanized shut. This makes a neater job, but is no more serviceable. The hooks do not catch in the rubber or penetrate through it easily and it takes up less space than any carrier I have ever used.

\section{UNHOOKING THE BULL- HEAD}

\section{By Jos. Gierisch}

Bullheads are such slippery fellows and capable of inflicting such mean wounds with their "horns" that taking them off of the hook is not the easiest matter in the world. To make things worse, they have a habit, when they take a hook, of swallowing it way out

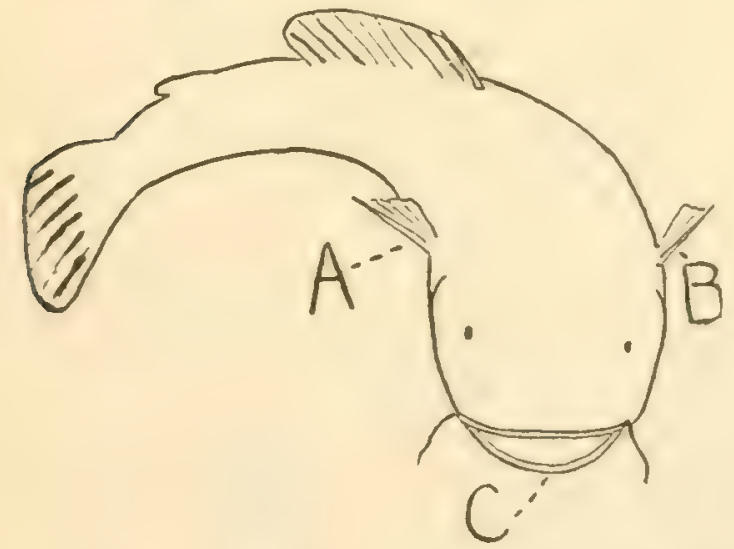

of sight. The following method will make the hook extraction comparatively simple: Place index finger of left hand behind fin $A$ in diagram and second finger behind fin $B$. This leaves the thumb of the left hand free to force open the lower jaw at C, while the right hand manipulates the hook.

\section{AN EASILY MADE LIVE $\mathrm{BOX}$}

\section{By E. H. Coultas}

There are many different styles of good live boxes. A very handy one can be made in a short time if you happen to have an old pack-

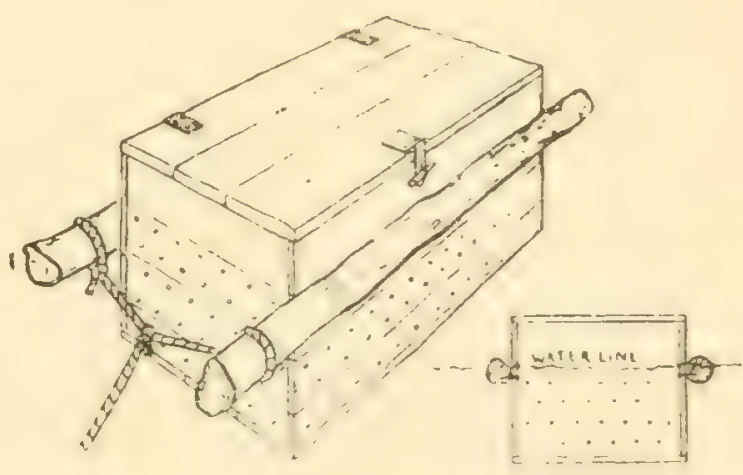

ing case and an auger. Cleat the top of the case for a cover and hinge it with a couple of bits of leather strap if you have nothing better. Get a couple of rough logs and nail one on either side of the box as shown in the diagram to serve as floats. Put through the spikes to hold these log floats, from the inside. With the auger bore holes in sides, ends and bottoms to provide for circulation of water. Put a hasp an the cover and the job is done.

Just anchor this box anywhere that the wave action will not batter it to pieces. When you want to take out your fish don't bother trying to net them. Just drag the box ashore. The water will drain 
out as fast as you pull it up and then you can reach in and pick out what fish you want with your hands. Set the box adrift again and the rest of the fish in it will be none the worse, of course, for their momentary air bath.

\section{FOR BEE STINGS}

\section{By M. A. Mueller}

Here is a Kink many of the brothers will be thankful foranyway those who have been stung by yellow-jackets and bumble-bees, and as they are now ripe, this Kink will be in good order. Here it is, and see how simple: Get a bottle of Winchester Crystal Rifle Cleaner and as soon as stung by a bee rub a little of the "dope" on the spot or little hole left by the sting. It is a good plan to first squeeze out as much of the poison as possible before applying. There is no danger from the use of this chemical and results are almost instantaneous.

\section{A CAMP REFRIGERATOR By Donald Duncan}

Hang a covered tin bucket from the limb of a tree. Take any kind of a cloth bag big enough to just slip over the bucket. If you haven't a bag handy, a few coarse stitches with twine in a bit of old burlap will make a nice one. Put a few handfuls of dirt in the botton of the bag, slip it up over the bucket and tie with a draw- string. Wet the dirt thoroughly and your refrigerator is complete. The wet dirt will keep the entire bag moist, and the bag in drying will cool the contents of the

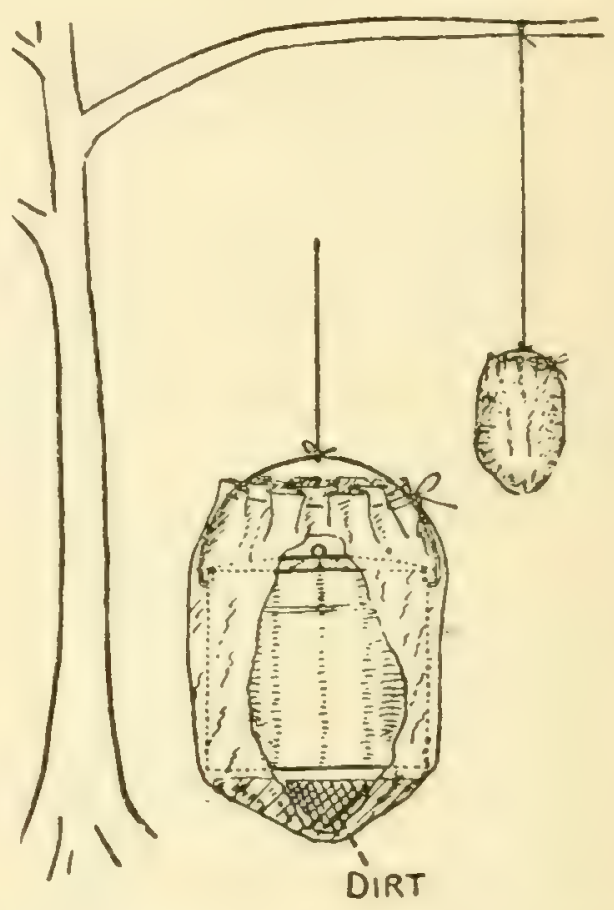

bucket nicely. Drinking water, milk, butter, etc., can be cooled very nicely in this manner.

\section{A FISH BAG}

\section{By Wilber Dowlin}

I have discarded fish stringers. I use a fish bag of my own manufacture instead. I find it to be handy and humane. I take a gunny sack and run a hem around the mouth about one inch in width. Leave a slit in the hem through which to run the rope. Take a piece of slight sash cord about six feet in length and tie a knot at one end and run the other end through a seine float and then through the hem in the bag, bringing the end out through the 
slit and pass the end through the float in the opposite direction, then pass the end through another float and tie a knot in the end of the cord. The cord should be the right size to work snugly in the float. To fasten the bag draw the loose end of the cord through the float next to the bag. It is then impossible to open it from the inside. It is easily opened by drawing the cord through from the inside. By using this bag you can keep your catch in the water all the time. When you stop to fish a pool drop the bag into the water and the loose float will show you where your catch is at all times and you can keep it near you. When you are ready to start home fill the bag with grass or leaves and dip in the water. The filling will hold enough moisture to keep the fish alive a long time. In this way you will preserve the flavor of the fish. A fish should never be killed till it is ready to be dressed for the pan.

\section{A SNELLED HOOK CARRIER}

\section{BY A. F. DRESEL}

I usually snell my hooks myself, using tourndown-eyed hooks, and let the gut dry straight by hanging up with a weight at the bottom. I make a very satisfactory hook carrier as follows: A cardboard mailing tube of, say, $1 \mathrm{I} / 4$ inches in diameter is plugged at one end by a glued piece of $1 / 4$ inch cork. The stopper is a bev- eled cork, cut through lengthwise. To the inside surfaces of the cork glue, or cement, a lining of felt, as per diagram, the felt forming
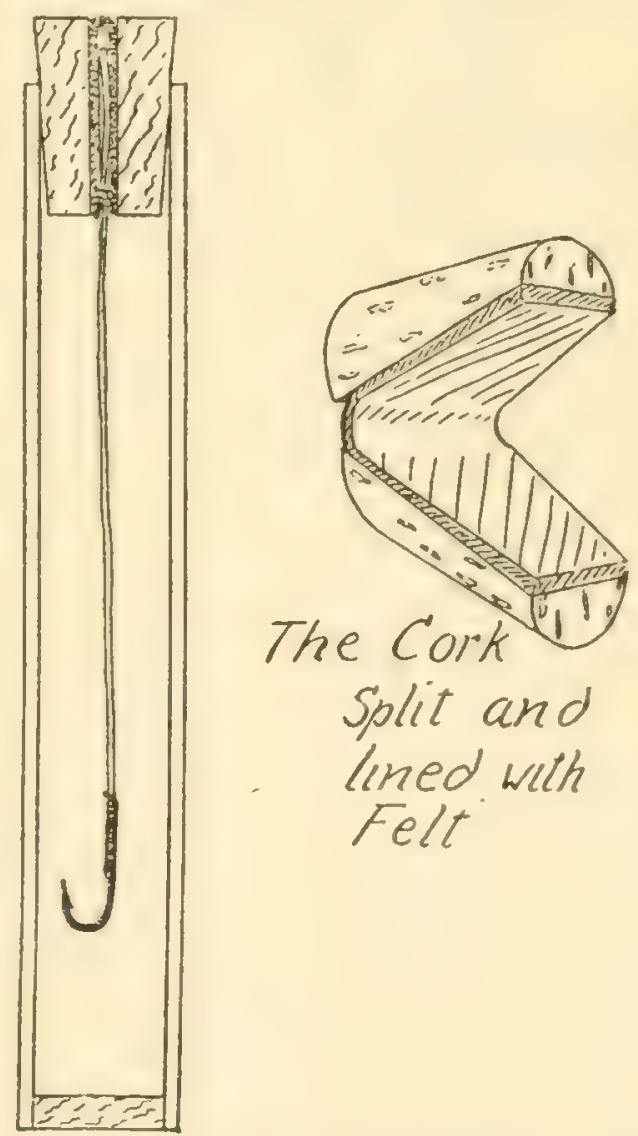

split and

lined with

Felt

a hinge at the wider end of the cork.

When on a fishing trip, moisten the felt and place several of the looped ends of the snells therein, and they will be pliable when wanted.

\section{FOR GILLETTE USERS}

By Ben P. Lippy

No doubt a number of the readers of Outer's BOok own a Gillette razor and throw the blades away after using a short time, owing to the difficulty of having them sharpened satisfactorily. I have owned one of these valuable 
friends over seven years and am still using the blades that came with it. After shaving I simply strop the blade by holding it firmly between the thumb and index finger, left hand, edge from you, and rubbing the thumb of right hand over the edge on all four edges. Do not strop too much. Go easy at first and you'll learn just the amount. Try this and note how your blades will last.

\section{A TURTLE TRAP}

By Wm. Sims Bunn

While the following kink may not be new to all the readers, at the same time it is worth trying for those uninitiated in this way of catching turtle. The plan is as follows: First get a rough board, say 12 inches wide and as long as the water and bottom justify. On this board nail a quantity of stout ringed hooks a few inches apart

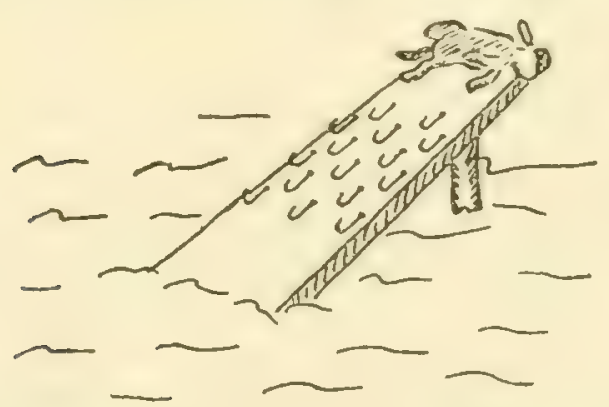

diagonally, and at the top of the board (which will be sitting in the water at an angle of about 30 deg.) tie securely a chicken or rabbit. In a day or two a gentle (?) odor will be wafted over the face of the waters which will stir up the turtles' olfactories irresistibly. They will all answer the summons of the decayed bait, and will try to climb up the board, with the result that the hooks will catch them in the foot. By way of anticipating and brushing aside any suggestion that this method is not humane, I believe any turtle would rather have a hook in his foot than through his bony mouth, and that the above method will be the less painful. Have the chicken or rabbit a few inches above the water.

\section{TWO OLD FRIENDS}

By R. T. ERVIN

Take two empty wooden spools and drive either a screw or a nail through the hollow center into the side of a wall at such distance as you wish (ordinarily some five or six feet apart), so that you can stand and pass the line over one and then over the other, and back again without having to move, letting the line run off the rod onto the wooden spools. This spreads the line out, so that the air will dry it, and yet it never comes into contact with any metal substance.

The other "kink" is how to tie the two ends of a silk line together so they will not slip. Tie an ordinary single loop in the end of one line. Run the other line through this, and then tie a similar loop with this end around the other line. Draw the knots tight around each line. Then catch the lines and pull them until the two ends are drawn together. It will be found that each single knot 
locks the other so that it cannot slip.*

No doubt many of your readers have used each of these "kinks," but there are others who have

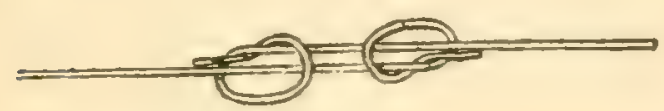

not, and they may be of service to them.

*Editor's Note. -This is the wellknown and efficient Waterman's knot.

\section{JUST ADHESIVE PLASTER}

By C. E. McOormand

Speaking of kinks, do you know that a strip of common adhesive plaster, or electrician's tape, pasted over a smooth steel or rubber shotgun butt-plate, makes the very best substitute for a checked one? You can't make it slip. I tried it on my old Maynard some five years ago and it is still doing service as well as the most expensive imported butt-plate.

\section{A "REAL" OIL FOR REELS}

By Frank Harris

Here's a good home-made oil for reels, and, by the way, it is also fine for typewriters, sewing machines, etc. It will not gum, and in every way is fully equal of standard oils at a cost that's next to nothing.

These are the "makin's": Onehalf pint kerosene, one teaspoonful good, pure olive or sweet oil, and if you want to be extra fancy, a few drops of oil of peppermint or spearmint, to kill the kerosene odor.

Don't condemn this without a trial. You'll be surprised. "It's slippery as an eel."

\section{A WIRE GAME CARRIER \\ By Harry O. HANNA}

All of us who hunt rabbits and other small game have often wished for a hand carrier, especially after hunting all day and getting a good bag, as carrying eight or ten rabbits in a coat gets very tiresome on the shoulders. Most of us also have wanted to hang the game in the spring-house over night and had to search for a piece of cord or wire to string them on. Have found the following simple device very handy:

Take a piece of stiff wire about 19 inches long and bend in nearly

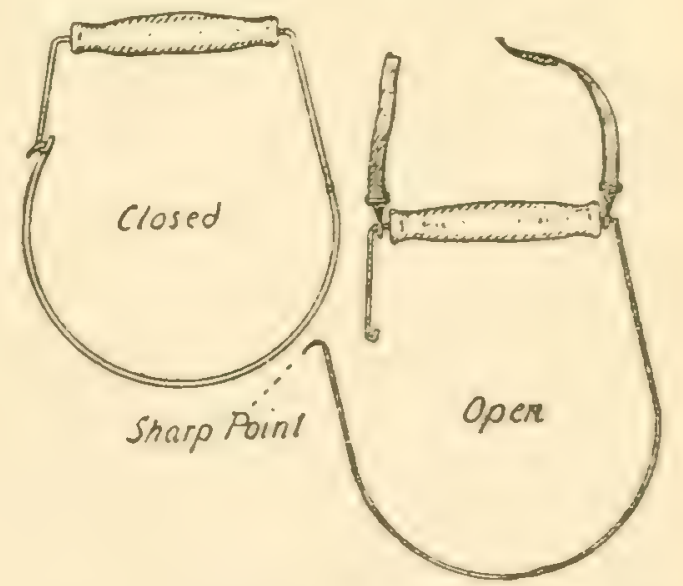

a circle. Then take wooden handle from an old bucket bail for handle, as per illustration. Next put small hook on both ends of wire and sharpen lower hook.

To use, run sharpened hook through rabbit's leg and engage lower hook with upper. 
The carrier is very handy for the muskrat trapper also. Can be used with shoulder straps if desired.

Brothers, stick one in your pocket and try it this fall.

\section{NEEDLES AND THREAD}

By D. Wiggins

Many of us wish to sew on a button or a patch for ourselves when out conversing with the red gods. We usually find that needles and thread have been left behind.

In my haversack is a spool of linen thread, with the hole through the spool reamed out to a sufficient diameter to accommodate a paper of large needles folded up into a roll.

In this manner the needles are always where I need them, and are not sticking me in the back. I always have one threaded with a good, long thread, as when your hands are cold or you are tired, it is a great help.

\section{ANOTHER PORKER}

By L. K. Harvey

Here is a good dress for a bit of pork rind on a No. 4 Skinner spoon that has proven very attractive to the bass at times. Cut a wedge of pork rind about a quarter of an inch thick, an inch and $a$ half wide at the base and two and a half inches long. Let it run to a triangle as shown in the diagram and shave the under side until it runs down to a true point. Slit the base of the triangle into three equal parts and hang one of these pieces over each hook in the treble gang. Then pull the pork rind straight out
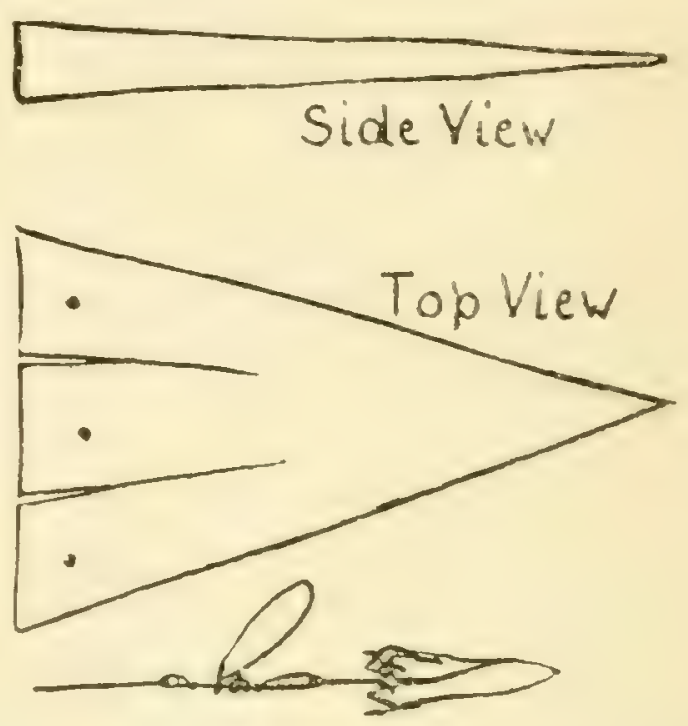

with thumb and finger and give it a little twist. This will tend to make it spin when in the water. This bait has caught bass for me sometimes when all others failed.

\section{RAW ONION POULTICE FOR SNAKEBITE}

By G. E. Whitmore

Take an onion or several of them if they are small, crush or pound them to a pulp and use as a poultice on the wound made by the reptile. Whisky, if at hand, should be taken in moderate doses, and of course, a doctor should be sought as soon as possible.

Twice I have used-and with good results-the onion poultice on dogs that were bitten by rattlesnakes. I also know of two persons who were bitten by rattlesnakes and whose lives were 
saved by no other remedies than the onion poultice and whisky! One of these was a man of 76 , the other was a boy of 12 .

\section{THE TIN CAN RANGE PHONE}

\section{By E. A. Crolins}

I think it best at first to give you a little history of ourselves to show how the kink herein described was developed.

Several members of the Fort Dearborn Rifle Club of Chicago, including myself, have been going out Sunday mornings for outdoor practice. As the club at present has only an indoor range, we have selected a good place along the banks of the Chicago Drainage Canal, just west of Argo, Ill. Argo is a small town southwest of Chicago and can be reached on the street car from where we live in about 45 minutes. We are then compelled to walk about a mile to the range.

Anybody living in Chicago will know that hills suitable for target butts are scarcer than hens' teeth in this vicinity. The spot which we have been using all summer is ideal as a range, owing to the fact that the engineers, when building the canal, obligingly left miniature mountains of clay and limestone about 25 to 30 feet high along the banks of the canal. These make a fine backstop for even the wildest shot.

As there is no habitation or any place to keep equipment near our range, we are obliged to carry all the necessary articles with us, which means pack them about a mile. We have overcome this handicap very nicely as follows:

Last spring we carried a couple of two-by-fours, three feet long, and a board twelve inches wide, one inch thick and three feet long, out with us on our first trip. This lumber nailed together, using the two-by-fours for legs and sharpening same, makes a good arrangement to hold our targets. We simply drive the pointed uprights into the ground. When we are through we pull the whole thing up and hide it under some near-by shrubs until the next time. The rest of our equipment consists of some paper targets and thumb tacks.

Our rifles are .22 caliber and we use long rifle Lesmok or semismokeless ammunition. We shoot at 50 and 100 yards. Right here I wish to state that the .22 long rifle cartridge is exceedingly accurate even at 100 yards, and will penetrate our one-inch pine board at that distance and never even hesitate. I think that is pretty good for a .22, don't you?

Thus endeth our history. Now for the kink.

This fall the weather. has been very windy, and we found it difficult and sometimes impossible to shout loud enough to call the shots from the target to the firing point, even with the assistance of a small megaphone.

One windy day, after all of us had strained our lungs while tending target, I began to figure out 
how this difficulty could be overcome. Suddenly I remembered the telephones I used to make when I was a small boy, out of two tin cans and a piece of thread. This gave me a hunch, and I immediately proceeded to get busy in the following manner:

After procuring two tin cans about four inches in diameter and five inches long, I soldered two strong hooks, one on each side of the cans well up toward the top or opening. The hooks I placed opposite each other running lengthwise, with the points toward the bottom of the can.

I then purchased one-quarter of a pound of No. 5 music wire, which runs about two thousand feet to the pound and possesses great tensile strength. The boring of a very small hole in the bottom of each can finished the job.

The following Sunday I started out with the rest of the fellows, entertaining considerable qualms as to whether my field telephone would work at so great a distance. Upon arriving at the range we cut four sapling stakes about three feet long and drove two into the ground at each end of the range, just far enough apart to allow the cans to fit in between. The hooks on the cans of course encircled the stakes. We then inserted the ends of the wire through the holes in the bottom of the cans and after threading them through a small glass bead about one-quarter of an inch in diameter, twisted them around the bead. The bead was placed on the ends of the wire to prevent it from pulling through the hole in the can.

All that was left to do was to stretch the wire tight enough to clear the ground so that it would not touch anything, and we were all set.

Much to our delight the telephone worked fine. Although it was a very windy day and there was considerable hum caused by the wind vibrating the wire, we experienced no trouble at all in communicating with each other at 100 yards. Of course, it was not as distinct as a regular telephone, but by speaking slowly and distinctly we could understand everything that was said with very litthe repeating. We found that loud talking caused too much vibration and that a normal tone of voice worked much better.

The total cost of the outfit was about 50 cents and about thirty minutes' labor, but it certainly paid for itself the first day. It not only made our juting pleasanter, but relieved the strain on our vocal organs.

One word of advice to anyone who desires to make a telephone of this character: Considerable care must be taken in handling this fine music wire, as it is steel and has a tendency to curl and kink. However, should you kink and break the wire, it makes no difference, as the damage can be easily repaired by simply tying the ends in a figure eight knot. Confidentially, I wish to state that we had four knots in our line before we had it installed, but it did not 
seem to affect the transmission of sound in the least.

In taking the 'phone down, all we did was to unhook the can at one end and wind the wire around it. After binding the wire tight around the can with a rubber band and placing everything in a small cloth bag the 'phone was ready to be transported home. The whole thing is not very large and does not weigh over a pound.

\section{A KNIFE SHEATH KINK}

\section{By Tom Moore}

I have seen many of the ordinary sheath-knives carried in the ordinary sheath, which is sewed along the edge against the inside of which the keen blade of the Tatro rests, with the handle usually protruding handily. I have seen knives thus sheathed edge their way out through this seam, and while in my observation it only resulted in a lost knife or a damaged case, it might also easily have resulted in a damaged leg or a spoiled trip. My kink was to put two copper rivets through the sheath in front of the knife edge, one about one and a half inches

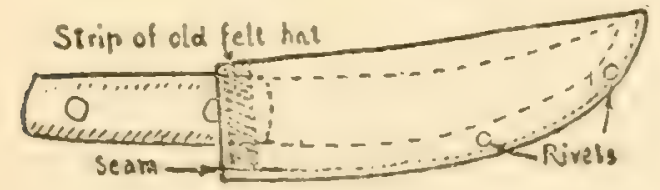

up from the point, and one about one-third the way up. If these are put through tightly they will keep the knife edge away from that seam, uninjured and uninjuring. I also sew a strip of old felt hat around the inside of the top of my sheath to keep Tatro at home, regardless of my position. For safety's sake and the preservation of a good knife, hunters should try these out.

\section{AN EMERGENCY ANCHOR}

By C. H. Baldwin

Here is a kink that may save the day for some lone fisherman. Last year I rented a cottage and boat at a small inland lake in northern Illinois, and when ready to use the boat I found it had no anchor, and not a stone in sight or any weight of sufficient size. I discovered an old pair of overalls hanging on the garage. I cut off about two feet of one leg, tied one end securely and filled it with gravel. Tied the other end, tied anchor rope around the center. and had an anchor that held for keeps.

\section{GATHERING INFORMA- TION}

By A. L. Weaver, JR.

While talking to some friends (who are rather enthusiastic fishermen) one day, I asked, rather casually, if they knew of any good places to fish. In the course of a few minutes I had quite a number of them-too many of of them to remember, in factso I decided I must have some way to keep them on record. A file was too unhandy, so after much labor and thinking I finally 
"got down to brass tacks" in the following idea:

First-Two pads of paper about 6 by 8 in., one pink, the other white. The pink sheets I use for my fishing "dope" and the white ones for my hunting "dope." I use the following form, which

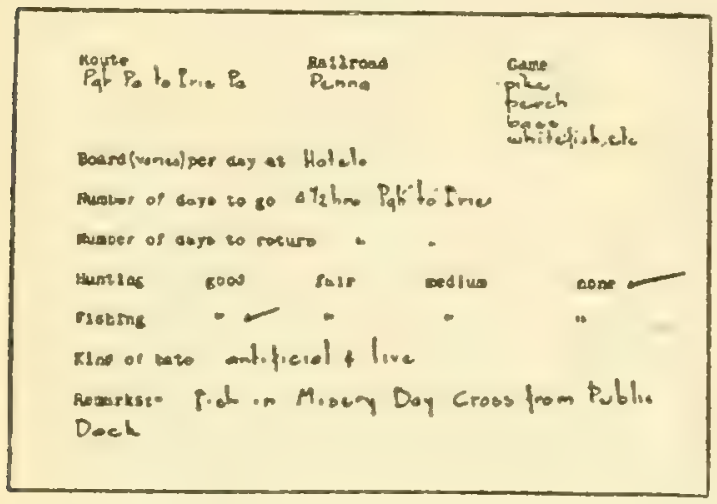

gives me all the information "right off the reel":

This form with a small sketch map (if available) gives me all the information that I desire. These sheets are kept in a portfolio. This "kink" has met with great favor here among my numerous sportsmen friends.

\section{A SHOTGUN CLEANER}

By D. WigGINS

To effectually and harmlessly clean your shotgun, use the brass cloth used for straining milk. Purchase about a dime's worth and cut a patch of it just big enough to cover the head of a cleaning rod with a piece of cotton flannel under it. Use a little oil on the brass cloth, and you will be surprised to see how quickly it takes out lead, powder fouling, rust, etc., and gives the barrel a fine polish. It seems cheap, effective and harmless.

\section{A GOOD CARRYING CASE}

By M. J. HewitT

An old leather camera case makes a convenient carrying case for fishing tackle or many other things when on a trip. These leather cases pack well, carry nicely and protect their contents fully. Being made of good leather they are quite stout.

\section{THREE KINKS FROM ONE KINKER}

\section{By Bert Richardson}

Did you ever shoot out a wooden minnow and on retrieving find the hooks sticking out at all angles? Of course you did, like myself until I "got onto" this kink. I am not very strong on the explanation stuff, so you will have to watch the sketch if this gets by Ye Editor's waste basket.

All you need is a piece of heavy tin of thin brass cut out to shape of "A," Fig. 1. Bend the ends
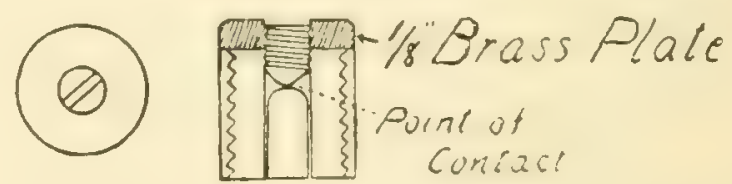

around screw eye and secure with a drop of solder.

I have found that this kink makes a wooden minnow as near weedless as it is possible to get them, as the hooks are always in the shadow of the body and presented right for the strike. 
Also take notice of the bend in front screw eye ("B," Fig. 1). This gives the bait a wobble that is a wobble as you are always pulling off center.

In casting spoons, I find that I need a little extra weight, and so adopt the following method:

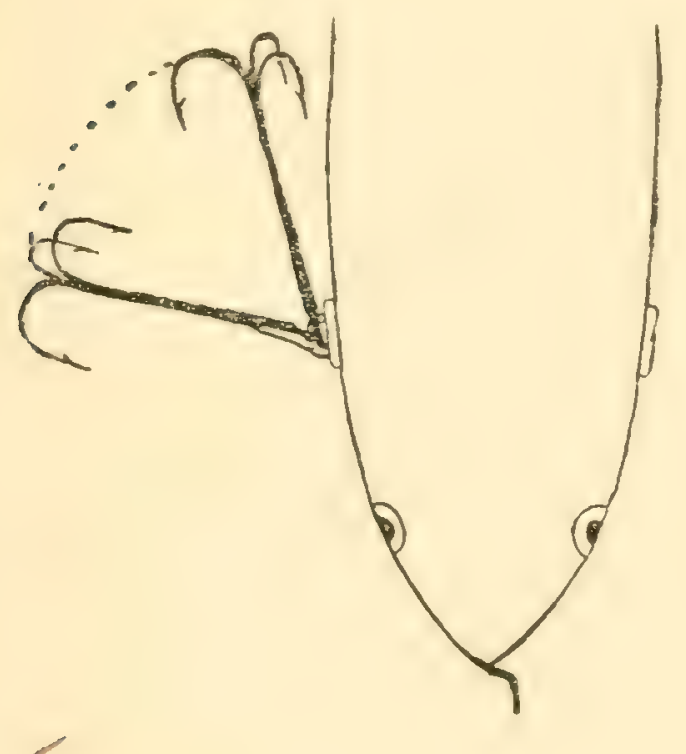

I purchase a few small dipsys, the kind with a wire loop in the ends. Straighten out the loops and twist the wire around the shank above the spoon. This weight balances the bait and presents your fly right side up the instant it strikes the water. It also does away with swivels as the bait will not twist more than a half turn and then drops back. Try this out in the bath tub, as yours truly did, and be convinced.

By the way, did you ever try to patch up your old spoons and find trouble in getting a lug for the spoon and shank? Well, here is the dope: Take a link out of a chain, the bath tub stopper kind. Bend it in the center, slip on spoon, and insert shank (Fig. III).

The next kink, which it requires a little more mechanical skill, is what I call THE kink.

Would you like to have in your old trusty reel the casting qualities

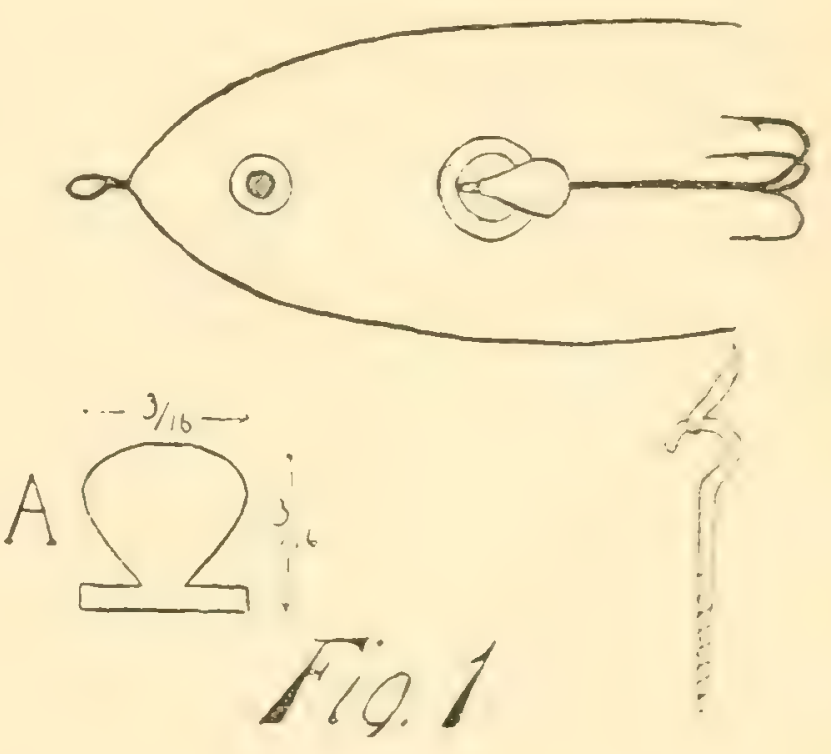

found in a high-priced jewelled reel, minus the outlay necessary to secure the latter?

Take off the oil screw cap opposite the handle and solder a one-eighth-inch piece of brass to the top of cap and file off the edge to a nice smooth finish; this will give you plenty of metal for

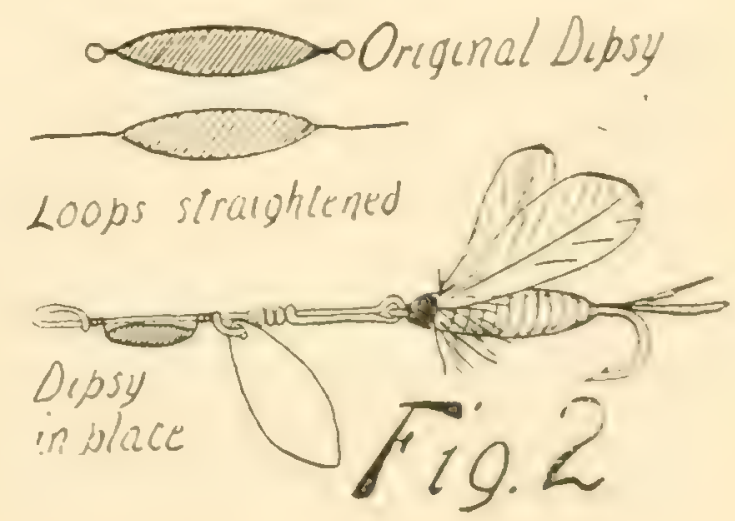


the next operation. Next, drill a hole in center of screw cap, right thru the metal you have just put on, the drill to be tapping size for a six-thirty-second-inch screw. Top out the hole with a six-thirty-

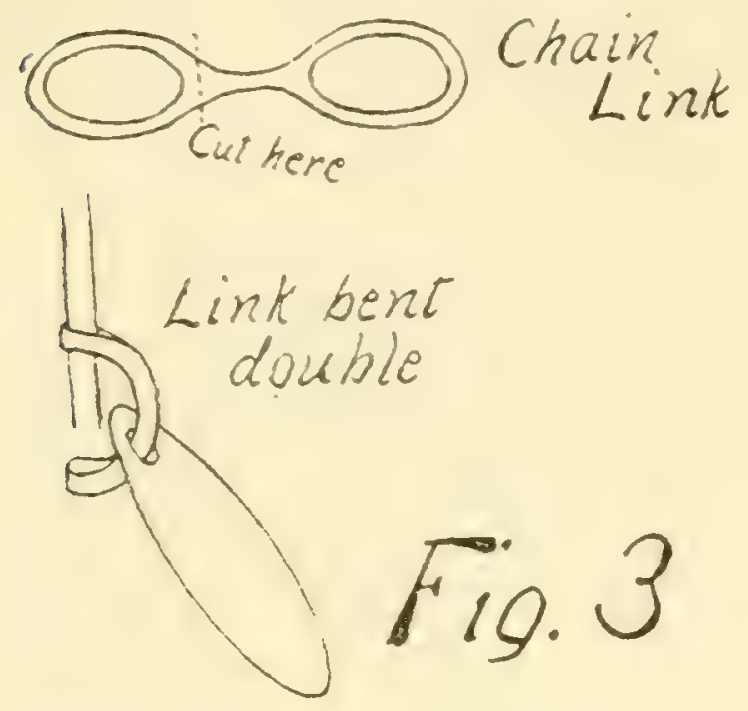

second-inch tap and that finishes the screw cap. Take an ordinary machine screw and grind or file the end to about sixty degrees. Cut off about three-sixteenths inch of screw and cut a slot for screwdriver. Put the cap in place and adjust screw until it is resting on the end of spool shaft. The sketch will show you about all there is to it. I used this kink on my old $\$ 4.50$ reel for two years, and it is still better than ever. The high speed of the spindle appears to crystalize the two points of contact, and in checking up my reel I found that the wear was only .010 of an inch, and this in two seasons of casting. I had a little trouble at first with back lashes, as the reel, when in a vertical position, runs very fast, but I soon "got onto" that and now I can "shoot it a mile" without the old strong-arm work.

\section{THE CREEL COVER FLY BOOK}

By Abram Hammatt

The accompanying sketch depicts a device for carrying flies on the stream that I believe will prove very handy. The materials are a piece of leather six by 5 inches, a metal rod five inches long and one-eighth inch in diameter and a small spring the same length.

The rod is heated and the ends flattened. The ends are then drilled with a small hole. The spring is stretched until the gut of a fly can pass between the coils tightly enough to hold it,

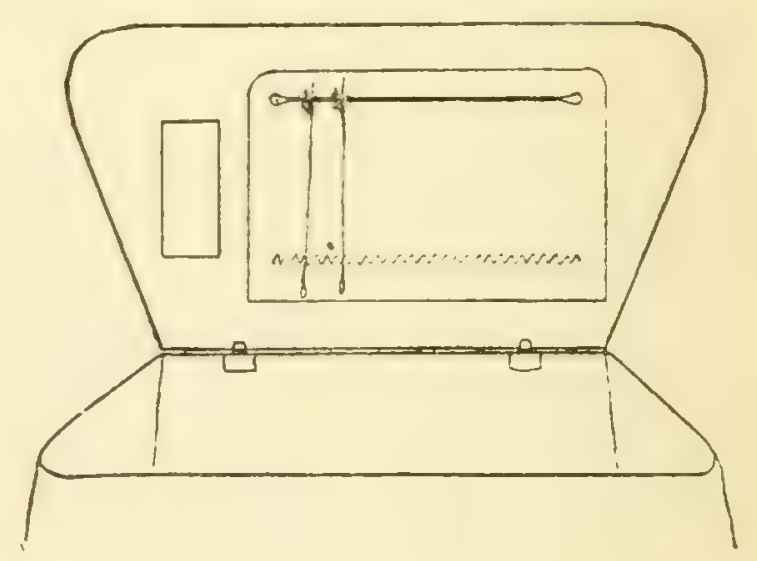

the spring is then cut off the same length as the rod.

The two corners on the longer side of the leather are rounded; this is to be the upper side. The rod is then sewed along this side about one-half inch from the edge by means of the small holes drilled in the end.

The spring is sewed one-half 
inch from the opposite edge. The whole thing is then sewed to the under side of the creel lid with the rod at the loose edge of the creel lid. The fly is then hooked over the small rod and the gut is held by the coils of the spring.

\section{FOLDING LINE DRYER}

By Gerald E. Mull

As a line dryer is necessary and those on the market which iooked good to me were expensive, I set about to make one myself. The idea of the dryer as well as the construction is very simple, so that anyone should be able to make one.

The first thing to make is the axle on which the spool turns and which also holds the dryer to table, bench or wherever you wish 10 place it. This is made of stiff, springy wire, bent in the shape of Fig. I, and should be long enough so that the top of the wire will extend through the top of the spoul. The part lettered $\mathrm{A}$ in
Fig. I is to slide onto the edge of table. The twist in the wire loolds it upright and is bent so that the bend will lie flat on the top of the table.

The next step is the ends of the spool. These were made of $3 / 8^{\prime-}$ inch pine, 4 inches square. The blocks are cut to size and then each corner is cut off about $3 / 8$ or $1 / 2$ inch back; giving the block eight sides as shown in Fig. II. Next drill a hole through the center of the blocks at C, Fig. II, to allow the wire axle to pass through. A hole is then drilled in the edge of the block, where each corner was cut away, E, Fig. II. These holes should be the size of the wire to be used for sides of the spool.

The side wires of the spool are made of copper or other wire which will not rust. Four of these wires are necessary. They should Le bent to the shape shown in Fig. III. In making these the parts marked A-A, Fig. III, should be about $11 / 4$ inches long,
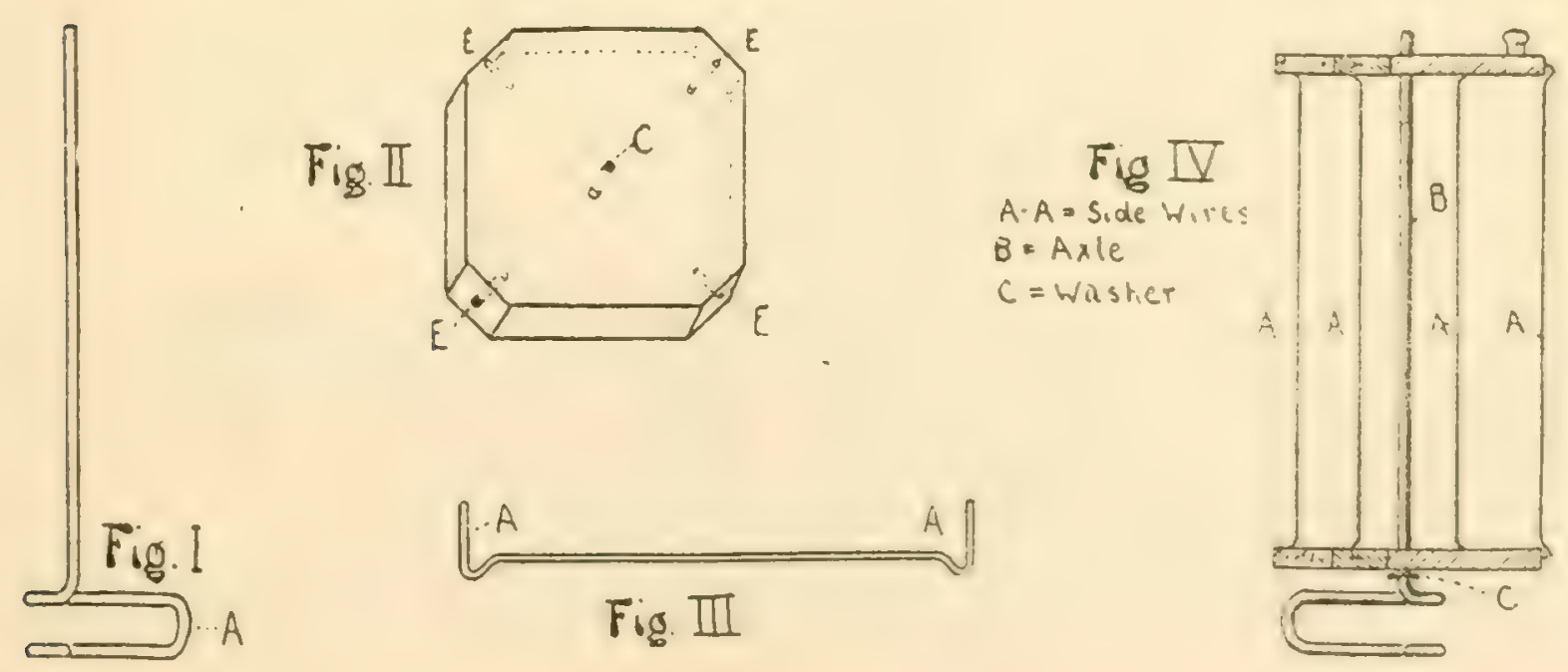
to make a good solid fit. These ends fit into the holes in the corners of the end blocks. It is a good plan to make one wire complete and then cut the other wires the same length and bend, using the first one as a pattern.

My finished spool measured a little over 8 inches long and 4 ready to go anywhere. Very simple and costs nothing but your time.

\section{A BAMBOO ROD CASE}

By A. E. Buck

A great number of bait-casters are partial to a single piece rod

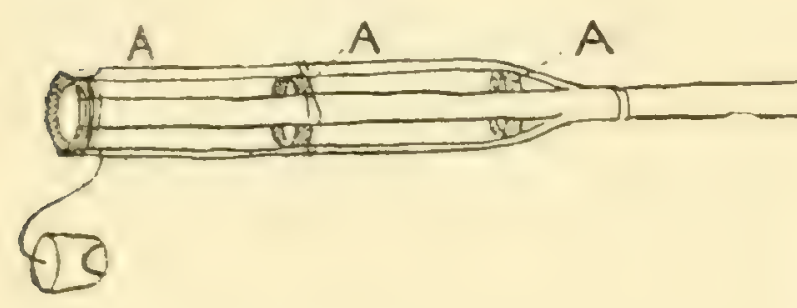

inches square, and will take 15 inches of line at a turn. In assembling the dryer the axle is first clamped to the table. Then the side wires of the spool are inserted into the holes in the corners of the blocks and the spool slipped onto the axle. A small wooden knob may be fastened to the top of the spool to turn it by.

If there seems to be too much friction between the bottom end of the spool and the bend in the wire axle, a comple of notches may be filed in the wire and a copper washer, which will just slide over the wire, slid down into them and slightly flattened edgewise to make it stay in place.

Fig. IV will give some idea how the completed dryer looks. To fold the dryer up, simply remove the spool from axle and pull out the side wires; lay the ends flat, side by side, and lay the wires and axle on. Snap a couple of rubber bands around it and it's

for many reasons, but use the jointed rod on account of the difficulty experienced with the single piece in going from one fishing ground to another. I use a single piece bamboo and have been put to a great deal of inconvenience in carrying this rod about. So I have been trying to devise a convenient way to carry same and still go light, and think I have at last solved the difficulty in a very satisfactory manner.

Take the butt of a common cane fishing pole, split it entirely across twice, running splits down to a convenient joint. Then slip in two thin ferrules that are just large enough to slip over the butt of your rod. Force one in as far as possible and leave the other at the end and bind with fishing line.

A hole can be easily bored through the nodes or joints of the cane with a long bit like electricians use, or burned out with a hot iron.

A cork in bottom ferrule finishes the job and you have a tight, 
convenient case that will hold rod perfectly central so nothing will touch but the grip. You can go horseback, buggy, auto or train with never a thought of your rod till you want to use it, and if the case is in your way in the boat, throw it overboard and tow behind on a string.

\section{THREE HANDY ONES}

\section{By Donald Smith}

When casting for bass with a frog, haven't you ever come to a place that was made to order for a plug? The weedless frog harness is tied on so tight that it takes a knife and a few polite words to get it off. By the time the line is free your boat has the loop over the rear hook. The loop slips up tight and will hold until the line is all worn out. This loop is handy when you dry the line. The bowline is the best knot because it will not slip and is easy to untie if it is necessary. It comes off as easily as it goes on, by reversing the process.

When you see a nice hole in the weeds you immediately cast your frog so that he strikes the farther edge of the hole. Now. if the hole is small the frog stirs up a lot of commotion if he comes sailing fifty feet through the air. Do you see the tall, rank grass lust at the edge of that hole? You will notice that it bends right over the edge. Just put your frog on the grass. When
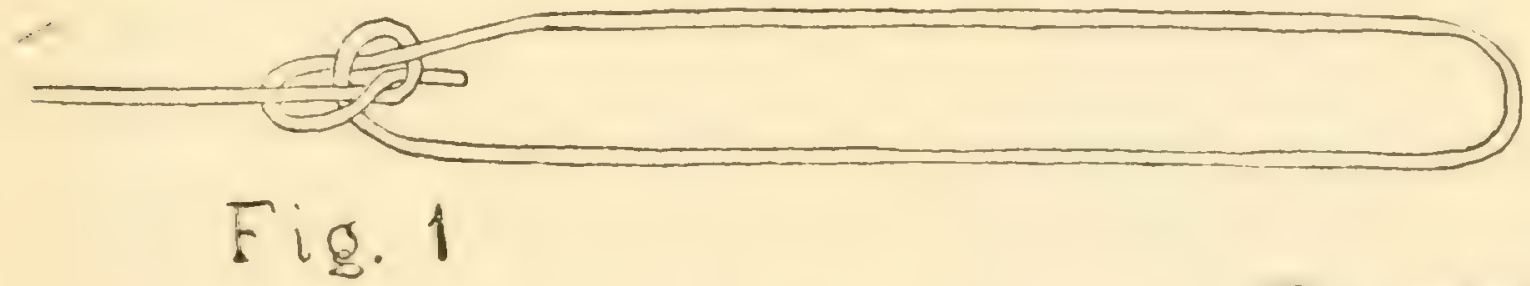

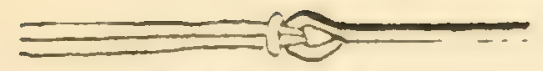

Fig. 3

drifted right where you wanted to cast. This occasions more polite language. Now for the kink. Tie a bowline knot in your line. Leave the loop about three inches long. Just put the loop thorugh the eye of the harness and slip you get ready give the frog a littie twitch. He will jump into the water in a much more lifelike manner than the other way. If $\mathrm{Mr}$. Bass is at home he will make one mighty grab and the fight will be on. 
When you are whiling away the time with blue-gills, waiting for it to get later in the afternoon, you will sometimes wish they would bite a little oftener. Just take that heavy underwater plug and cast out about thirty feet. Reel it in very slowly, so that it will go deep. Do this on all sides of the boat. When the blue-gills see the minnow they just follow right along to see the excitement. They notice a fat, juicy worm and think they have gone far enough. If you are the owner of the worm you will have fish for supper.

\section{A HELGRAMITE HARNESS DE LUXE}

By E. H. Coultas

Nimrod, can yout hook a big husky Helgramite, cast him to all points of the compass endeavoring to secure a strike, and at last take him off your hook, and still have the consolation of finding him as mean and devlish, as anxious to nip your fingers as when two hours before you jammed your hook under his shell-like collar? I doubt it very much, because this particular Helgramite will be as dead as a doornail and will have no more crawl in him than an Egyptian mummy.

You simply cannot appreciate the good qualities of this brute as one of the very best live bass baits until you have given him a real chance to twist, squirm, craw.l and bite when affixed to your hook. Why, Fisherman, he has the vitality of a marathon runner if you simply eliminate that "solar plexus" you hand him with your hook. Think of it, a natural live bass bait, as easily used in shallow as deep water! A live bait equipped with a tremendous amount of kick and fight, that will actually goad a bass on to strike when his acrobatic stunts under water have failed to tempt the wary fish.

On that very next "whirl" you take at the mighty bass, how would you like to have your live Helgramite so attached to your hook so that he-

1 st-Will be as active as if in his native element.

2nd-Will live for hours without torture, unless you get a strike, and finish as strong physically as when you made your very first cast.

3rd-Will present the hook in the most effective position for the strike that is known.

4th-Will never tear hook loose from collar in casting, losing and killing bait, perhaps at the worst possible moment.

Listen, give a moment to the following simple directions and I guarantee that you will cast the liveliest live Helgramite (and one that will stay alive) that was ever on your particular hook. It is the strong, vigorous, active live bait that does not sap away its life while suspended upon your hook, that "turns the trick" after all. This is the cry of the live 
bait bass angler, and here is your salvation when you use Helgramites.

Purchase ten cents' worth of elastics of a size in circumference that will slip easily over the butt end of your lead pencil. Slip one of these bands over the tip of your first finger of your left hand (if you are a "south paw" reverse the operation).

Grasp the Helgramite securely between first finger and thumb of right hand by the collar, bearing in mind to always hold him by the side of the collar, not with finger on under side of collar and thumb on top. At once press his entire length, right side up, against the inside of the first finger of the left hand, being sure to have the end of his nippers on a line with the elastic band. Press the thumb of left hand down on top of collar of Helgramite, and remove your right hand entirely. You now have the bait held firmly and securely in your left hand, and though he may try to cause trouble it is impossible for him to nip you.

Next lift the elastic band on your left finger with the right hand and draw the band over the Helgramite's nippers and head and well down to the shell-like collar. Once more take the Helgramite in the right hand, as outlined above, and then draw your first finger of the left hand out of the rubber band. You will find the band has settled firmly about the collar of the Helgramite.
Shift your bait now to your left hand and with right hand insert barb of hook between collar of Helgramite and rubber band. Push hook through as shown in the illustration, and then give band two or three twists by twisting hook. In tightening band about the collar of the Helgramite you will have to use your

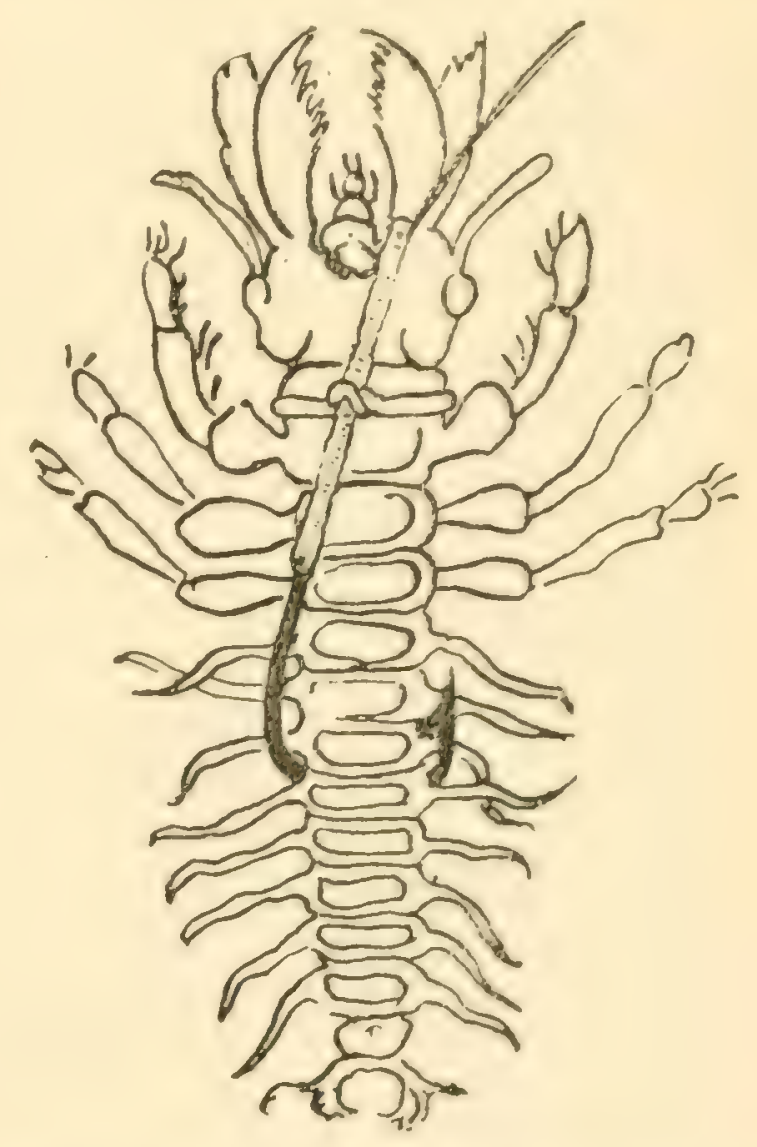

own judgment, as they differ in sizes. It should be twisted sufficiently to hold firmly, but not so tight as to buckle the collar and ruin bait. The last operation is to bring the point of your hook under and over the rubber band. This fastens the twist you have just made. Then you push point of hook down as far as you desire, slip the hook under his tail 
and the Helgramite, though mighty mad, is secure and ready to perform his duty.

I have found that placing hook as outlined above (also see illustration) gives best results, but you can readily see there are any number of positions you can give to your hook, as your own judgment may deem fit. The directions may sound somewhat long, but you will find after a few trials that it will take you but a fraction of a minute.

On a sandy bottom let your Helgramite crawl about as he wishes. On a rocky bottom use a small float, and personally I feel that in having a squirming and angry Helgramite floating down stream at a depth just above bottom cannot be beaten as a lure.

In the majority of cases (I do not consider the class of people who like to hook a bass in the stomach) the rubber hand slips turn the Helgramite loose in your bait box with rubber band about his collar. It will not bother him one bit.

Real, live, husky, active bait always spells better luck. If you use the outlined method you simply cannot blame the bait. So here's luck!

\section{A KINK POLE HOLDER}

By Chas. Forsyth

Many is the time you have all been on the creek trying to induce the juicy bullhead to taste the bait in which you so skillfully hid the hook, and oh my, how tired you would get holding your pole when they were a little slow about taking hold!

You no doubt have set a couple of forked sticks in the bank (we all know how it is done), or tried to push the end of your pole in the hard bank and came very near

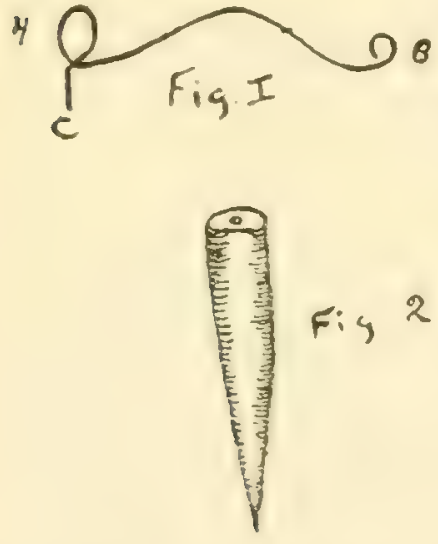

up the gut when you strike and holds Helgramite safe and fast, and he is not injured a bit in the contest.

When you stop fishing, simply remove hook from elastic and

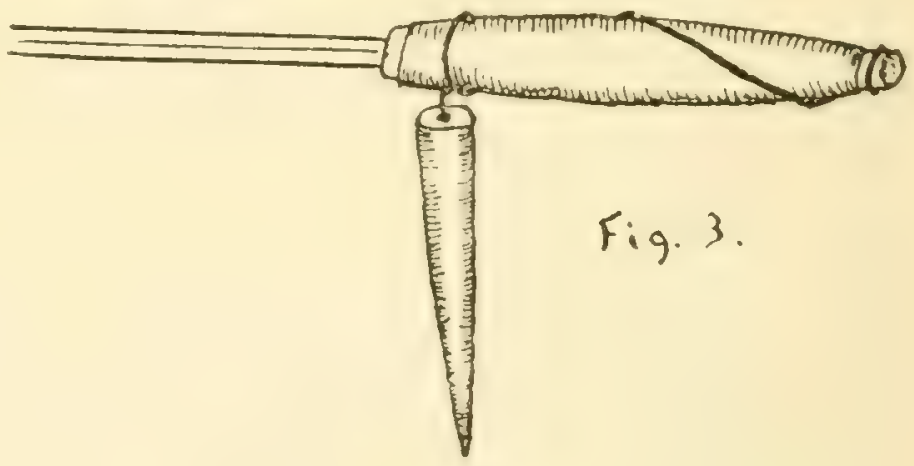

slipping in the creek yourself. Then when this was done you would sit back and wait for the nibble that was sure to come; and when it did come and you got a tremendous bite, your float going 
clear down under the water as though a submarine was hitched on to the lower end of your line, the dirt would suddenly give way and "kersplash" your pole would go in the water. And when you finally pulled it out, expecting at least a five-pounder, you would be minus fish and bait both.

Possibly you had your pole set in the forked stakes. You got a "real" bite. You grabbed the pole with both hands and, Ye Gods, it was stuck. By the time you succeeded in getting it pried out from the forks, Mr. B. Head was ambling off down the creek enjoying the lunch. Of course you didn't say anything. Just a few remarks on the weather.

Now, if you will make yourself one of these "Kink Pole Holders" and give it a trial, your troubles in that line will be over. It can be made for any kind or size pole.

Material needed: 1 piece of heavy wire about the size of an ordinary .22 cal. wiping rod; 7 inches off the end of an old broom handle.

Cost: About the time it takes you to make it.

Take your piece of wire, about 18 inches long, so that you can handle it easily, and bend around a stick-a broom handle, for instance-in the shape of Fig. 1. Have the loop on end marked A, just large enough to slip over the bulge of the hand grip, if you are using a bamboo pole, and loop at $B$ just large enough so that end of pole will slip in nicely. Let the loops $A$ and $B$ be turned in a complete circle in order to make it rigid and give it strength. Let the loop A lap a little before turning down to enter stake. Make just a little tight, then there will be no danger of it slipping off of pole. C should be about $1 \mathrm{~T} / 4$ inches long.

Saw off about 7 inches from the end of an old broom handle; bore a hole in one end a little larger than the wire so that the wire will slip in and out easily, then sharpen the other end so that it can be pushed into the ground.

You can slip the stick inside the wire and carry it in your pocket. When you get ready to set up, put the wire on your pole, push the stake in the ground at any desired angle and set the turned down portion of the wire in the hole as in Fig. 3. The wire remains on the pole and when you get that real bite, take hold of the pole gently and lift out of stake, then pull out your fish and string on the "Kink Fish Stringer." Easy, ain't it? And simple, oh gee!

\section{MEASURING BY THE ROD}

\section{By E. B. LYMAN}

This drawing will explain a couple of kinks, both of which will be found useful to bait-casters.

The place marked A represents a common rubber crutch tip which 
may be easily fitted to the butt of the rod. It will act as a buffer or pad while reeling in the bait with the butt against the body, and will also protect the rod to an extent.

The angler who rewinds and varnishes his rods during the closed season, might try this kink. in the Blue Ridge Mountains this summer. It was late summer when all the minnow branches were low and the water clear, a condition that required one to be an export with the dip net or seine if any minnows were to be landed, while we could always se-

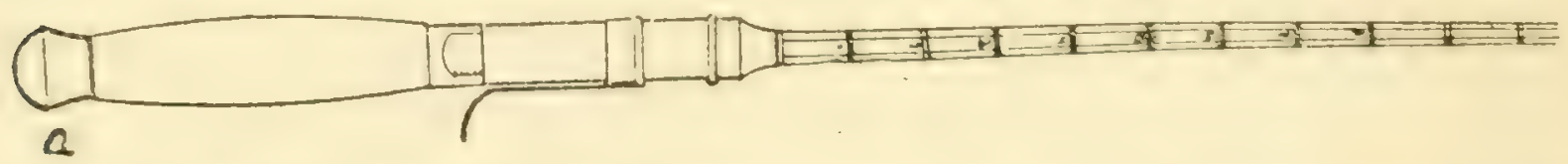

After the old varnish has been scraped from the rod, put on the windings, space them an inch apart for a foot or so above the reel seat. Now number them 1 , 2 , 3, etc., with India ink, and varnish.

You now have a convenient place to measure your catch.

\section{A MINNOW TRAP}

\section{$\mathrm{BY}$ RICHARD K. WOOD}

Did you ever have a fishing trip result in a failure because you could not get minnows? No doubt many bait fishermen could answer this question in the affirmative.

The methods most often employed in catching minnows are seining, trapping, and fishing from the bank with a light pole, thread and minnow hook. Sometimes for one reason or another all three of these methods may fail. For instance, the water may be so clear that the minnows will escape under rocks before the seine reaches them, or chubs may not be biting This luck happened to the writer on a fishing trip while

cure sorre minnows, we could never get a sufficient number to fill our needs and here is where my kink came in handy-and it may come in handy for you some time, too.

We had worn out and patched up our seine until there was a real cause for a "discovery." We took an ordinary burlap sack with a barrel hoop in the mouth and placed it in the brook, obstructing the way on each side of it. Then going up stream we would drive the minnows down by wading and thrashing the water with a brush. We found that one man could get more minnows with the sack than two could get with a seine in the same length of time. They would dart under and around a seine but would enter the sack irap readily.

\section{REMOVING A FERRULE}

By E. H. Peckinpaugh

Whenever I had occasion to repair a rod, removing a ferrule used to cause me lots of trouble.

One day several years ago I broke the tip of my rod at the 
ferrule, and as I had only brought along the one tip it looked as though I would have to cut my trip short, since I carried nothing to make repairs with, and did not ?ike to risk breaking the tip a second time by cutting it down and using it as it was.

I had carried with me a few flies and hooks, a wooden minnow and a small piece of copper wire that I used to string my fish .n (if by any chance I killed one). The case looked hopeless until it struck me that I might take one of the screw eyes from the wooden minnow and by screwing it into the broken picce i might get it out.

After drawing out the pin with my krife, I finally succeeded, with the aid of a straightened fishhook, in screwing the eye in. I then twisted the copper wire around the ferrule to use as a handle while I heated it.

Is soon as it was warm I slipped the largest fishhook I had
It struck me that I had found a way to remove a ferrule with the smallest amount of heat, and no chance of marring it.

Since then the simplest thing about repairing a rod is removing a ferrule. If the rod is broken I drill a small hole in the wood and remove the pin. After screwing in the eye I make my loop of wire and fasten it somewhere and pull tight.

When the heat is applied just as soon as the cement is melted the wood slips out and you never get it hot enough to do any damage. If the rod is not broken you don't need the screw eye.

\section{THE CHICKEN NECK BAIT} By C. E. Wakeman

I will contribute a little kink that has helped me to get many a nice trout, and if tried by others of the angling fraternity I know that they will be well paid for their trouble.

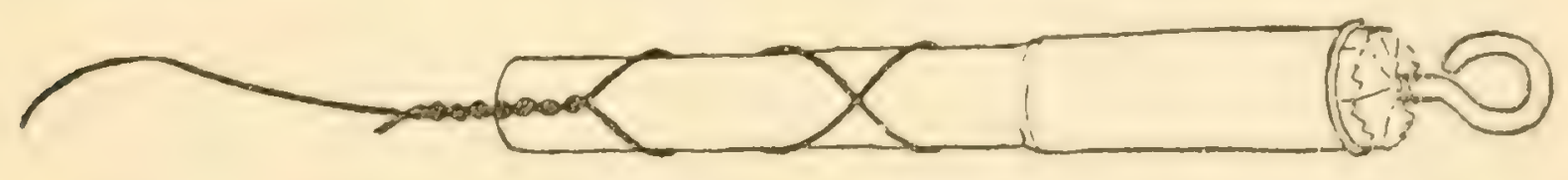

through the screw eye, with the intention of drawing it from the loop of wire so that I might catch hold of the ferrule with my handkerchief and pull the wood out.

What was my surprise to find the wire held like a vise, and a gentle pull was all that was necessary. I made the repair then without any trouble, and went on with my fishing.
The kink consists of a hook. to your own liking, treated with a piece of skin taken from the neck of a chicken after it has been cleaned for cooking, but before it has been singed. You will notice that this skin is covered with fine silvery hair. I cut this in fine strips not wider than one-sixteenth of an inch, and three or four inches long. I wind this 
spiral fashion from just below the barb on the hook to the eye, or to where the snell fastens on, tying each end with a piece of white silk thread. I then lay it away to dry, when it is ready for use. The silvery hairs will stick out all around the hook, and when cast on the water it makes as tempting a bait as any decent trout might wish to get his eyes upon.

This kink may not be new to some, but I have passed it along and am helping to boost the kink department.

\section{DRIED HOUSEFLIES FOR BAIT}

By RoBert Marshall

Catch a quantity of flies in an ordinary wire fly trap. Soak the flies in sweet oil and pack them hard in a small butter mold. Let the resulting balls dry hard in the sun and you will have a fine bait for still fishing. By leaving out the oil you will also have a good bird food.

\section{A FROG SAVER}

By Dr. E. A. Chatten

Every bait caster who uses frogs has had the experience of snapping the bait off his hook. Sometimes, when frogs are hard to get, this is doubly annoying. A good many anglers are probably acquainted with the following Kink, but not everyone seems to know it, so I give it for what it is worth.
Hook the frog through the lips as usual. Take a bit of old line and loop it over the hook below the frog's lips. Bring the two ends of line back and tie in a

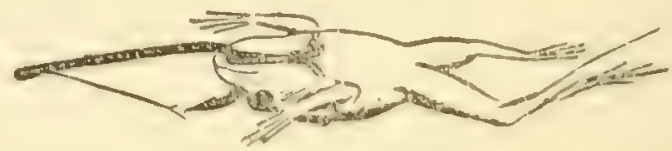

square knot just between the frog's front legs. Carry ends of line over the frog's back and tie securely. The loop of line will take the strain off the lips of the bait and make it good for many hours of casting.

\section{THE CLOTHES HOOK ROD HANGER}

$$
\text { By J. E. D. }
$$

Take an ordinary twisted wire clothes hook and slightly solder the place where the wires are twisted together. Then cut off the end of the loop as shown in the diagram, and slip a short piece of rubber tubing over each of the points.

In our fishing camp we always put these hangers up in pairs.

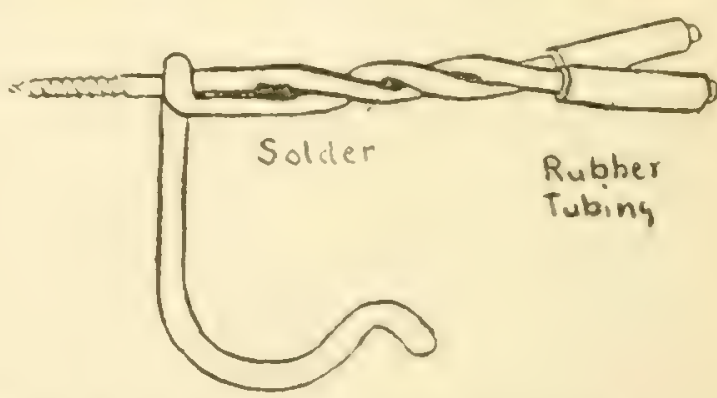

The first pair should be put up as high as one can conveniently reach, one at either end of the wall. The next pair goes about four inches lower and the same 
distance inside of the ones above. And so on down the wall. The first man in at night winds his line from hook to hook on the upper set of hangers and hangs his rod in the fork at either end as convenient. The next man in takes the next lower pair. These hangers are also very convenient for handling the joints of rods that are being repaired or varnished.

\section{A BACKLASH TOOL}

By R. C. FIELDS

Many of you probably still have trouble with backlashes. To those who do, this little tool will be a great time saver. Take a com-

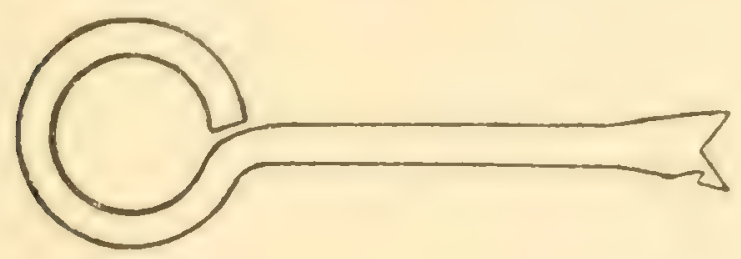

mon shoe buttoner, cut the hook off, pound the end flat and file two notches in it, as shown in drawing, and you will have an excellent tool for untangling those awful backlashes.

\section{AN EMERGENCY WEED- LESS}

By Stanley Mendlick

On one of my trips I found the bass feeding close up to shore among the rushes and the bottom covered with a thick mattress of grass. None of my regular weedless baits got a strike, so I decided to try something new.
I took the hook gangs off from a V. L. \& A. chub minnow and with my pocket tool kit cut a narrow slot in the back of the minnow, just wide enough to hold a 1-0 hook rather tightly. The pits

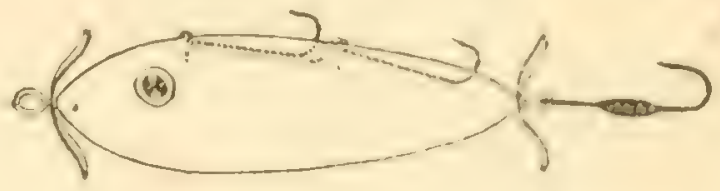

for the screw eyes were countersunk so that the eye was about half covered. I placed two hooks on the back and used a single weighted hook for a trailer. This bait worked nicely through the weeds and was fairly successful.

\section{THE TIGHT HOLSTER}

By "Blisters"

Nearly every man who has toted a six-gun at his belt knows that by having a good bunch of "pants" above the cartridge belt the draw will be facilitated. An open holster must hold the gun snugly or some day-out flops the gun. But if the holster fits snugly
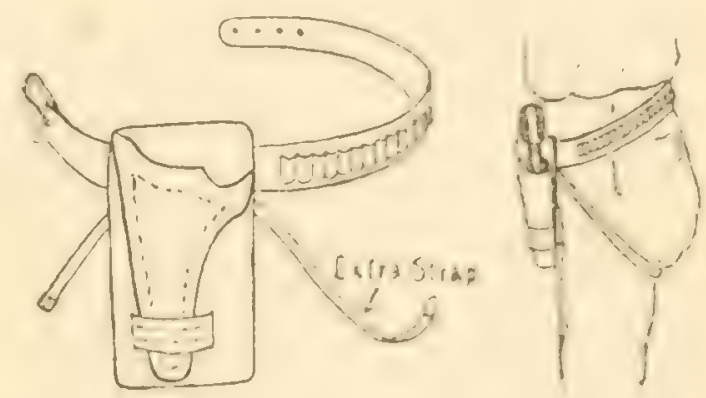

and the belt does not hold it down, one is under the awkward necessity of grasping the holster with the left hand while drawing the gun with the right. Not very speedy, to say the least. Some of 
the old-time gunfighters used to tie their holsters down to their thighs by the muzzle, but one can't do much walking that way.

A little idea practiced by myself and perhaps others as well, is to run a light narrow strap through the belt loop on the holster. Bring this down low across the thigh and it holds down the holster securely without interfering with walking. Try it and see how you like it.

\section{THE ALDER BAIT}

\section{By Harold W. Greene}

When I saw your article in the March Outer's Book about the Fishing Kink Contest, I called the Littlest Lady's attention to it, and she said, "Why not describe the Alder bait?" The Alder bait is one of those makeshifts that you stumble upon while knocking about on the lakes and streams.

One day I packed the cooking outfit and fishing tackle into the canoe, handed the Littlest Lady into the bow, and stepping in, shoved off. It's only a little stream, but very pretty, and the only nice one within our reach for the occasional Saturday afternoon and Sunday that we have to ourselves.

After paddling about threequarters of a mile upstream, trolling and casting for pickerel on the way with indifferent success, we came to our usual camp site. The Littlest Lady laid out the kit while I gathered wood for the "Injun" cook fire, and after eats had been disposed and camp tidied, the Littlest Lady wanted a lesson in bait casting. So the canoe was hauled way ashore to give plenty of room, with no obstruction on the bank. This made good casting across the river.

The rod is a Jim Heddon and I had on a Dowagaac minnow when she cast, and did it well, too. But she failed to retrieve it fast enough, so the plug got hooked on the bottom. I cut it loose and she cast again, but let it overrun, and it landed in the brush on the other side. Once more I rescued it, and in a short time it was hung up again, so I decided to overcome this nuisance.

I cut a young alder shoot about a half-inch in diameter and three or four inches long, notched it around about a quarter of an inch from the larger or butt end and with the end of the line bent two half hitches into the notch. This worked fine the first time, for it floated, while the bird's nest was straightened out, but it darted and revolved so in retrieving that the line was all kinked up into snarls.

I cut the line about two inches above the half hitches and whipped out the kinks, then fastened the ends with a swivel between (illustration No. 1) to overcome the kinking. Then I gave the Littlest Lady another illustration in the art of placing the bait and thumbing the reel, and showed her how to spool level while retrieving. The stick dove and darted this 
way and that so well that I decided to cast again, and in retrieving to show her a little tip work.

Well, I placed that stick in a nice little hole just at the roots of a tree on the opposite bank, spicuous in the water, so I figured that must be the reason that he struck, considering the indifferent success we had on the way up. Naturally we decided to make that stick into a bait.

The Littlest Lady was very in-

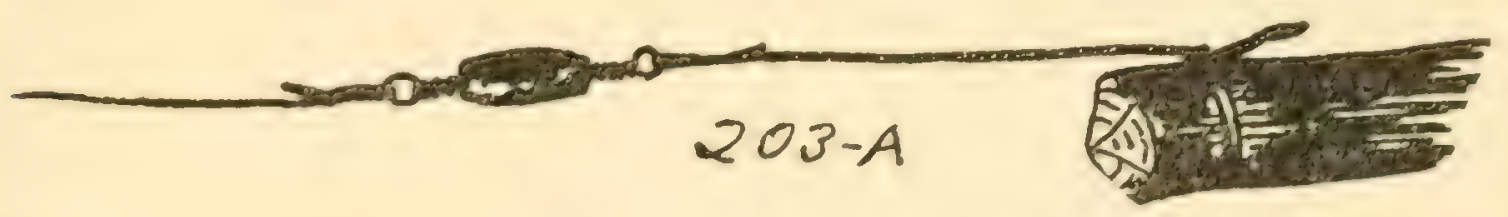

where some brush overhung the stream and made a shady little nook (you know exactly that kind of a hole), and just as I placed the thumb down hard I gave a steady upward tip motion while bringing the rod back to my left hand ( $I$ always hold the rod in my left hand while retrieving), which caused the stick to dive and dart to the left. Bang! A pickerel struck; and twice now I felt

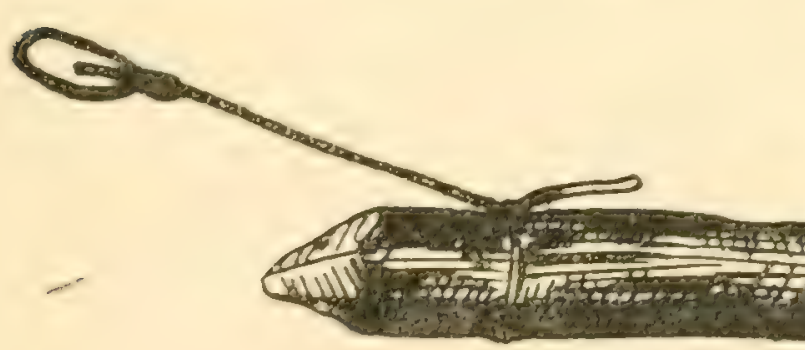

him snub the stick before I could get it in for another cast.

"Well," says I, "that must look pretty good to him." So we sat down and talked it over.

You know that the young shoots of alder are a dark bronze green and when the bark is cut the white wood shows up very distinctly. There must have been just enough white showing on that stick and it wasn't too con- terested and brought all my gear to me. I searched through the mess and finally found a plug with a double hook put on with a screw-eye, which I unscrewed and put into the middle of the alder stick and had a bait something like illustration No. 2.

I sure landed that "pick," and it was what we call a "whalloper," a little over nineteen inches long, measured from the rod butt to the third winding up. I didn't have thes scales along, but I'll bet that he weighed-well, if I told

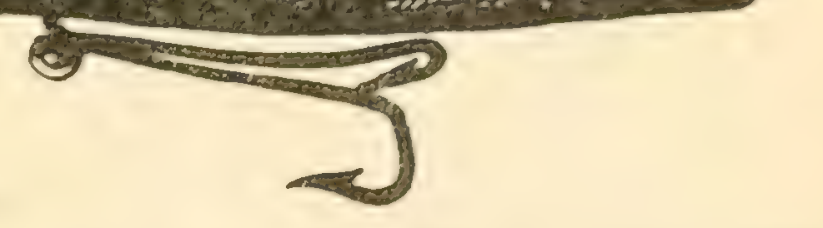

you you might think I came from Tennessee as Dock Gushwa says in his article on "A Trip on the Kankakee."

We catch lots of small ones here (Rhode Island), but never keep one under ten inches, even though we go home without any fish. A pickerel over eighteen 
inches in this locality is a whale. So now you know just why it was that we didn't broil him right away. You see we knew there was sure to be a crowd at the boat house about the time we would get back.

The little stick worked so well on that occasion that I decided to try it out again under different conditions and in different waters. I gave it that tryout in a pond about five miles upstream. On this occasion we took along all of our gear so as not to get skunked, but we didn't have to use anything but the little alder stick and I made a fairly good catch. Several times now I have taken my rod, reel and line, a swivel and the double hook to some pond or stream, cut an alder sprout for the bait and had fairly good luck, and didn't have to swear and prick my fingers untangling a snarl of plugs.

No, I haven't given up plugs. I use them all I can and keep getting new ones. But now I know that when it's "go light" I can take along a spoon bait in my hat band and a double hook to make the alder bait and get fish without making the air blue over tangled baits.

\section{LIGHTING FIRE WITH WATER}

By Walter Rademaker

One time when out in the woods I found I had no matches. Looking for my burning glass I found I had lost it. How was I to start a fire? I took a leaf from a tree, looped the stem as in the illustration and dipped it in a brook. The drop of water caught
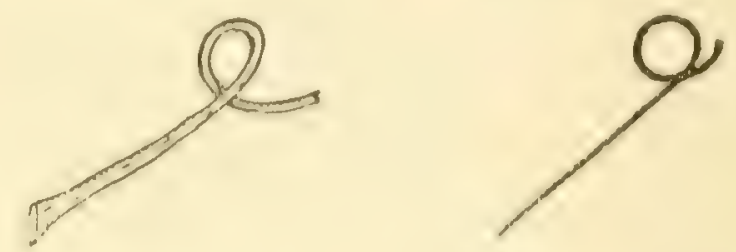

in the loop made a perfect miniature lens. This I used as a burning glass.

I first lit a cigarette with it and used the cigarette to light my fire. This may seem hard but proves very simple.

A blade of grass or a bit of wire may be employed for the same purpose. If wire is used, see to it that all grease is wiped off first, as the water will not stick to form the necessary lens drop.

\section{A HOOK DISGORGER}

By J. H. SEvErin

Often while out fishing a person will hook a fish decp and generally he finds he has left his

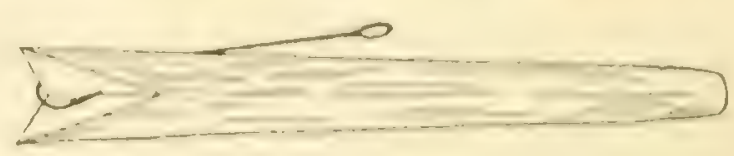

hook disgorger behind or lost it, as I did several times. Now I whittle out my own. Just take a small branch of any tree and cut to suitable length. Notch 
wide end and cut incision on dotted lines, as illustrated. You can make these to suit any size hook or fish.

\section{A SPOON MINNOW BAIT}

\section{By W. Hugh Sawyer}

Did you ever use an artificial minnow of the treble hook style with a small spoon attached in front of bait instead of spinner? If you never have, here is a kink are not hung so tight as in some other baits I have used.

As for the spoons, I find the Hildebrandt Idaho size $\mathrm{C}$ the best. It works easily, is light, does not foul readily and is easy to attach and detach. Of course the tail spinner must be off of the bait, and the bait should be reeled slowly.

This makes a bait that will cast easily and still not be so heavy, and bass seem to hit it when no

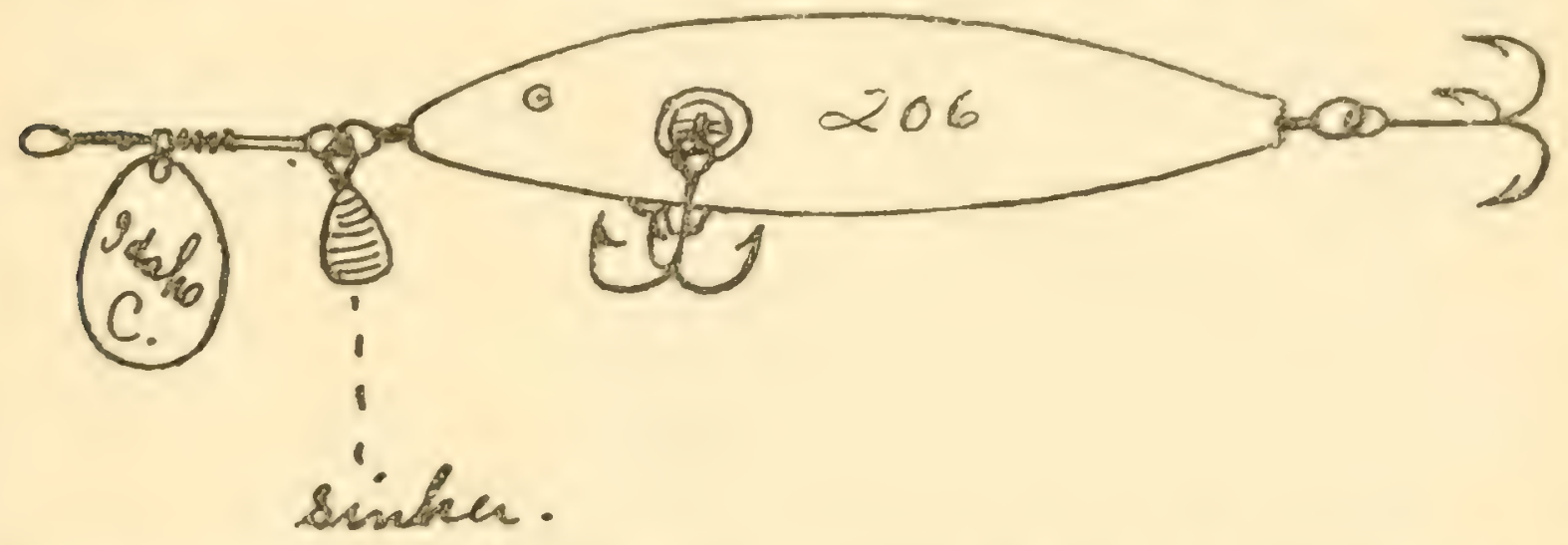

that may help some on your next season's outing. I will try to explain how to do this and what baits I find it works best with; also the best time of year and weather conditions.

The bait I think best for this use is the Shakespeare nine-point bait with the solid red for bright days and clear water, especially in August, September and October, when all the rest of the fellows have quit the artificial bait and taken to the live minnow game, which I never follow.

I like the Shakespeare baits best for this purpose, because they are a smaller bait and run better in the water, and the hooks other bait will get results. A little dipsy sinker fastened to the tie loop of the spoon helps some on a bright, still day, when they are not feeding on top and you don't get them with the regular under-water bait.

In fact, I have found that on bright days, when they were not inshore feeding and all other baits failed and most people had got discouraged, then I would get out to the deep and put out the freak spoon bait with a sinker attached and make long casts to the edge of the offset and reel very slowly with an occasional quick jerk of the rod which makes the bait go in small jumps as 
minnows and crawfish often do close to the bottom. This bait will also get results in early spring, when bass are not very lively.

I took five one time with this bait that weighed twenty-two pounds.

\section{HOME-MADE ENAMEL FOR THE PLUG}

By Jefferson HiNes

Is there a "plug" caster among us who has never tried out some model bait of his own invention and found that the greatest drawback to the success of his creation was the lack of a proper system of enameling the wood so that it is entirely waterproof as well as sound in color? Here is a kink in this line that the writer has developed and put to the test many times and found satisfactory:

After the sandpapering of the bait body is done and the sockets are neatly drilled for the hookmountings and the small screw eye hole is drilled in the nose of the bait and you are figuring on what to enamel it with, get some white shellac already mixed from the paint store.

First of all, thin a little of the shellac with alcohol and "size" the bait with it, either by brushing it on or by dipping. Let this sizing dry well (over night, say) to be sure it is well set.

Now get whatever colors you wish for the bait, in dry form in either pigments or metallic bronzes. Mix whatever body color you desire in regular solution of shellac. Use just enough shellac to the amount of dry color required so that it will flow smoothly from the brush in applying.

Mix the color always just before the immediate time of applying, as it is better fresh. Use a small flat brush and rapidly lay the resulting shellac-enamel on the bait in a smooth, thin coat. Hold the bait upon a large pin or sharpened wire stuck into the screw eye hole in the end. Hang the bait up for this coat to dry over night.

Next day look the bait over, and, if not well covered, give it another body-tone coat. Again allow to harden for several hours.

If desired to have the back of the bait colored or spotted with a different tint, mix this next and apply carefully, either by brushing on or stippling with the end of the brush.

Do not forget that these shellac enamels must be applied quickly and deftly to be smooth.

Allow the last coat to dry over night and apply a coat of clear lacquer (by "clear" we mean as colorless as can be procured).

This will set very quickly, as it is prepared in "banana oil" (amyl acetate), and furnishes a coat that is impervious to water.

$\mathrm{Be}$ sure and get the lacquer brushed well into the hook and screw-eye holes. When the lacquer is dry, the bait is ready 
for its mountings and then for business.

Mountings and hooks may be removed from some old wornout "plug" and made to serve on the new bait body.

Shellac is only semi-waterproof and requires the protection of the finishing coat of lacquer. Shellac is used instead of oil in laying on the colors, as it is not softened and run off by the "banana oil" in the lacquer as the oil would be.

The writer has experimented with many methods of coloring and waterproofing casting-baits of his own "get up" and out of all the systems this is the only one that has satisfactorily stood the test.

A few artists' flat fitch-hair or soft bristle brushes of assorted sizes, not exceeding a half-inch wide, is all the equipment necessary. Use an old dish or small tin can to mix color in, being careful that the receptacle is clean.

\section{A KINK THAT SAVED THE DAY}

By VAL

Did you ever cast all morning and never get a strike? Well, this happened to me some time last June, while on a fishing trip in the Fox Lake region, near Chicago.

My partner, whose name is Bill, and I were out with the birds in the morning before "Old Sol" had shown his beaming countenance to warm up the day, as it was somewhat chilly.

"Looks good to me this morning," was Bill's first exclamation, upon reaching the boat landing.

"Yes, the wind is right and we ought to get a few before breakfast," was my retort.

After assembling our tackle, we started out, each of us going in opposite directions, using separate boats. I choose the left shore, while Bill choose the right and with parting words of "Good luck to you, Val," and a wave of hands we were off.

I started in casting and worked until I thought my arm would
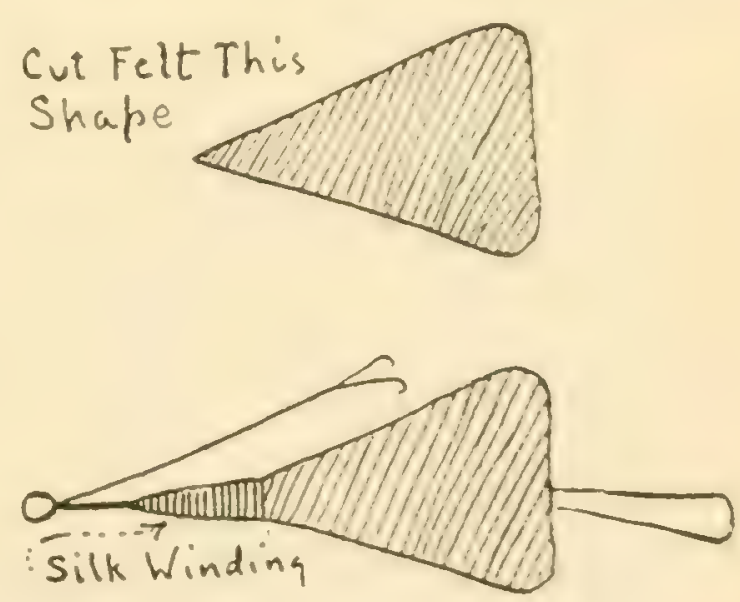

break, trying out every inviting hole that was known to me on that lake on the left short line, but never got a rise. I was thoroughly tired out and had tried every bait I had in my tackle book and was just about ready to row in, when the breakfast bell rang, calling us in to the "big eats."

When I reached the boat landing, Bill was already there with his face all smiles and I knew he 
had a "few" by the way he acted.

"Well, Bill, how did you make out?"

"Oh! not so bad. I got three, one a pretty fair sized bass, and the others will reach about two pounds each."

Of course, my first question was: "What wind of a bait have you been using?"

"A Hildebrandt No. 3 single, with Red Ibis fly tied on a number $3 / 0$ hook."

"Have you an extra Ibis in your tackle book?" I asked.

"Sorry, Val, but this is the only one I have with me, but you may use this one after breakfast if you like," Bill replied.

Of course I refused to rob Bill of his sport, but right then and there I got to thinking how I could rig up a fly of this sort. All during breakfast, I had nothing to say, but was doing a heap of thinking, and while pondering over my coffee and cigar an idea hit me.

"Bill, I am going to make a Red Ibis," said I. He laughed and said: "All right, go to it, but you can go out with me and we can use this Ibis fly I have in partnership." I told him there was nothing doing, that I'd have a fly in a few minutes. Starting for the veranda where my tackle book, net, rod, etc., were lying, I proceeded to dig up some red felt, which I cut in a " $V$ " shape, one for each side; my partner watching with wondering eyes. (See illustration.)
After trimming the felt nicely, rounding the corners, etc., I dug again, this time for a spool of red winding silk, which I usually carry with me for emergency. Then I picked up a Mayer Weighted Weedless Hook, bent back the guards, and proceeded to wind my felt on the leaded part. Bill laughed, and said: "Some fly that!" I took it good naturedly and told him to wait. I was not through yet. Then I cut a small piece of pork rind about an inch long and also cut this in a " $V$ " shape, the largest end being about a quarter of an inch in width and stuck the pointed end of the rind on the hook to make the feather tail.

My partner looked at me in amazement and said: "Of all the kinks that is the best kink I have ever seen!"

I attached this home-made Ibis to a Hildebrandt Spinner, No. 3 Idaho, and told Bill I was ready for that big one.

We started out again in separate boats and I covered the right shore line this time and Bill the left. With a parting remark from Bill to the effect that he hoped I'd connect that home-made Ibis to a nice bass and a wave of his hand, we were off for the forenoon's fishing. To make a long story short, that home-made Ibis was the "ticket" and I connected all right; came in at $11 \mathrm{a} . \mathrm{m}$. with four bass and one small pickerel. The total weight of the five was fifteen pounds. Since then I have 
made up several of these homemade affairs and have landed many a bronze back, as well as numerous pickerel on them.

\section{THE WORM WEED GUARD}

By Clark H. Gallup

Trout fishing being next on the program, I am going to tell you about a hook kink that has served me well in my search for the speckled beauties. I have tried it out in the waters of Montana, brush and among the logs and snags. You can bet it gets right in where the trout live.

If I do not get a bite I do not pull my hook back too rapidly when I retrieve, but pull it out gently and seldom get snagged.

When using large worms one is enough on a hook. Start the hook about one and one-half inches back from the head of the worm and run it toward the tail, as shown in Fig. 1. Then run the point of the hook right into the

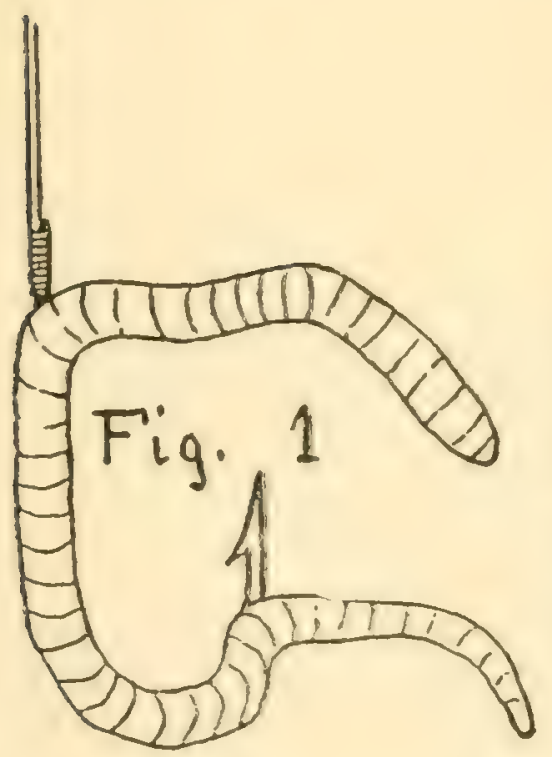

Wyoming, Colorado and Wisconsin, and it has always done excellent work.

The stunt is nothing more nor less than placing an ordinary angle worm on the hook, so as to make the hook practically weedless. It works so well that in small brush streams where the current is not too swift I do not use a sinker at all, but just let my "patent" worm guard hook float with the current right into the holes under the bank, in the center of the head, well past the barb, as shown in Fig. 2, and you have a weed guard that will work in the tightest place, if you do not jerk too hard. Fig. 3 shows how the same trick may be worked with two smaller worms.

\section{A BROKEN RING GUIDE}

\section{By David Stewart}

It is the sad realization of many sportsmen that they cannot be sportsmen all of the time; that is 
to say, the outdoor sportsman, the kind above all the rest. Even those of our brotherhood who are well to do do not have the time that they want to themselves, or perhaps better, to the bass and trout and the enjoyment experienced in their capture. How many of us have not felt the anguish of passing by a beautiful stream on a good day because of lack of equipment or time in which to get things ready? Tlis has led many to carrying manypieced rods in their suitcases while traveling. But even these require time to get ready. When one imagines evcry unused moment an unused chance at some beauty of the dark water, any means of adding rapidity to preparation and still not hazarding the efficiency of equipment is hailed with joy and enthusiasm.

The impatience experienced on numerous chilly mornings when cold-stiffened fingers made it hard to thread the line through the guides, led the author to adapting or perhaps transposing a device known for years on the family sewing machine, which allowed threading through an eye, without pushing the thread through. All of us know of it, and some, too, may have used the scheme in this application, but it is not widely known, and is too good to keep. I have only tried it as a two-piece wire guide (Fig. E), but variations of many kinds have occurred to me. The form used patterns somewhat after common snake guide, but as the chief advantage of this form (strength) is lost by breaking the wire between the attached ends, slightly heavier wire should be used, although this is not compulsory.

The means of making these is very simple. Phosphor bronze wire was used by the author, but German silver does very well. The wire is carefully flattened for $3 / 8$ inch (according to size of guide) with a light hammer and a smooth iron surface. A nail the size of the guide aperture is then filed off on one side (Fig. A), and the flattened end of the wire (Fig. B) is held here, parallel to the nail, with a pair of pinchers. With another pair, or the fingers, the wire is bent sharply to the left and spirally around the nail for nearly a complete turn. The unflattened end of the wire is then bent slightly out away from the nail (to avoid any chance of the line getting caught while in use), and the wire is here cut off.

The upper edges of the flattened base should be ground with a stone or file to avoid the silk winding being cut, and the round cut end of wire should be finished off a little, too, with a stone. Each part of the guide is made in the same way and is wound on the rod with space enough between to let the line through. (See diagram, Fig. D.)

One-piece guides could be made very simply with machinery, the guides being stamped out of thin sheet metal (Fig. F, 1) and fin- 
ished to suit the carefullest of tastes. With this style the guide might be belled to reduce friction.

I have had to be satisfied with the regular form of tip or end guide, because the spirial type (also adapted from the sewing machine) does not work very well, because fly casting and bait

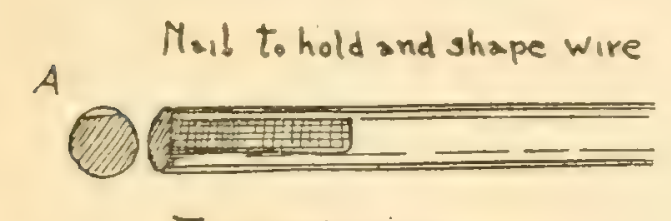

B Ti.ttened wire

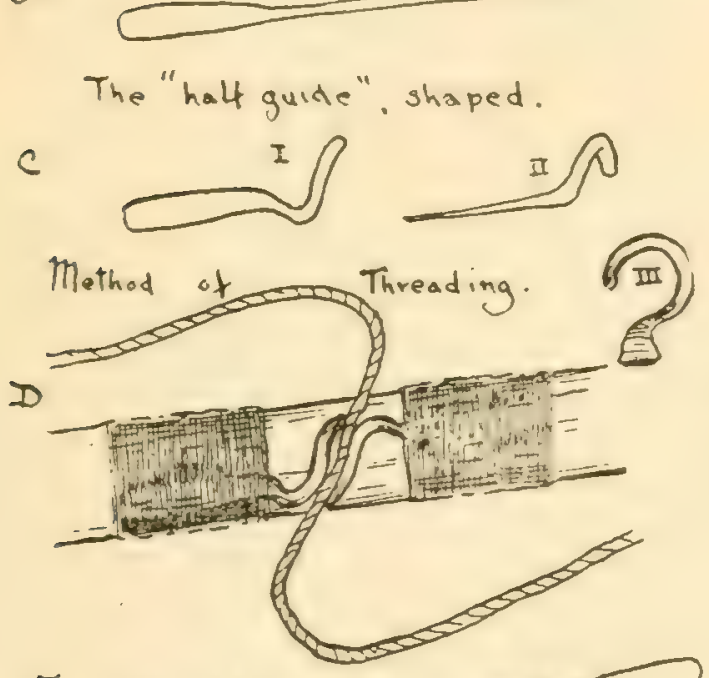

E The Guide
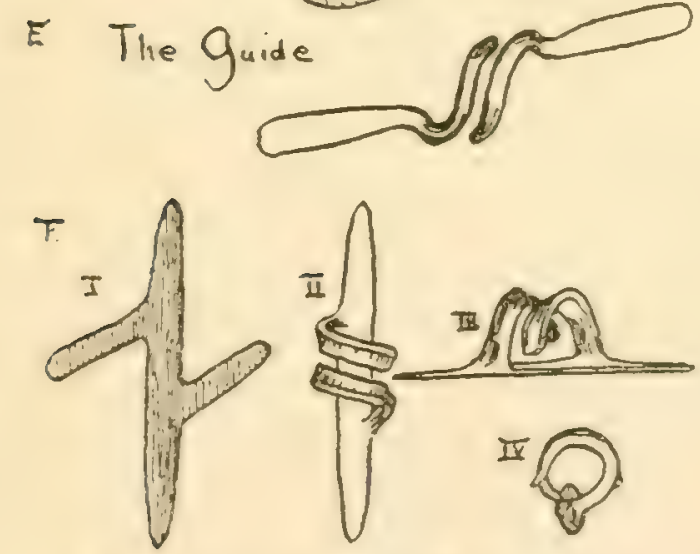

Sheme tor Cne Piece Droken Ting guide.

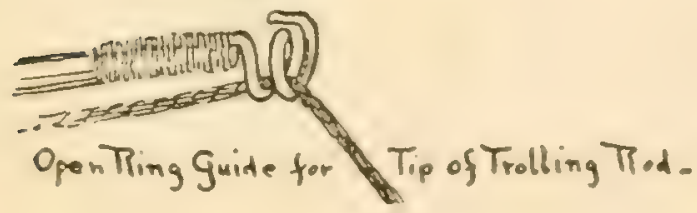

fishing in brushy trout streams it has often unwound, or at least tangled the line. It has been used, though, to good effect in a rod used for trolling, and has the significant advantage that one may take down his rod and wind up his reel without taking bait or sinker from the line:

I don't doubt but that some of OUTER'S Book readers, with more ingenuity than the author, will, if they try, find a way which wili not allow the line to tangle at the top.

There would, of course, be no need for carrying the fine parts of this type of guide too far. With the large guides of a bait-casting rod there is no need for this broken ring guide, and it would be folly to try to substitute it, but in the little outfit that you want always with you, the getthere-quick variety, it seems very likely that this should find its place and keep it.

\section{A QUICK UNTYING KNOT}

By Philip H. Greeley

The knot shown in the sketches is one that will be found very convenient in tying fishing line to bait, hooks, leaders, etc., as it can be untied instantly, yet, if made correctly, it will stand a line breaking test without pulling out. The knot makes a clove hitch that has a loop so that it can be pulled out quickly.

In the sketches A represents a ring like the eye of a swivel, B 
the line from the reel, and $C$ the end of the line.

To make the knot pass the end of the line (C) through the ring twice as shown in Fig. 1. Then bend the line to form a loop at $\mathrm{D}$ and pass the loop (D) through my assortment of flies and never fail to take advantage of the opportunity afforded for casting, where these streams broaden out sufficiently or are kind enough to flow through a brushless meadow or the like.

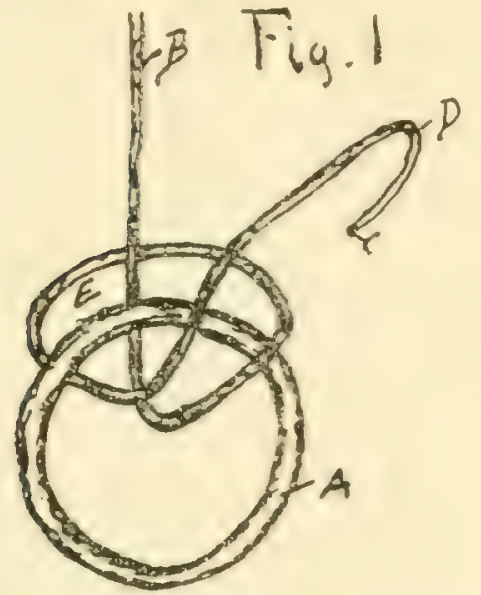

the space marked $E$, as shown in Fig. 2. Hold the loop (D) in position and pull the ring (A) and the line (B). The finished knot is shown in Fig. 3.

The knot is confusing at first, but after making it a few times it is easily and quickly made and can be untied by pulling $C$, the end of the line.

\section{CREEL COVER BAIT BOX}

BY W. H. FORD

Perhaps I will be degraded in the eyes of the true trout fisherman for ever thinking of anything to encourage or assist in the unmanly art of "baiting" for trout. I have but one excuse to offer-most of my fishing has to be done on the narrow brushbound streams of Connecticut where fly-fishing is quite impossible, although of course I carry

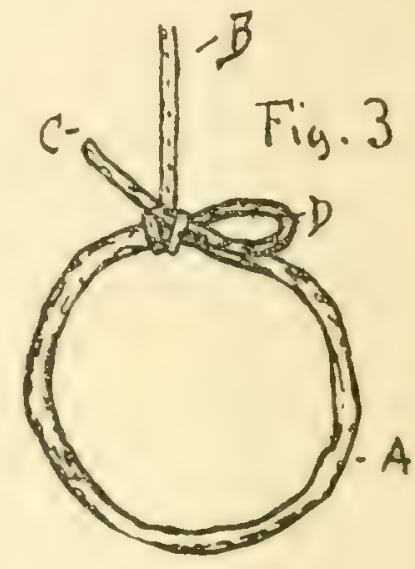

If you have ever fished these "Southern New England Brooks" you can appreciate what I mean for here all the trouting hazards that I have occasionally seen published as originating with the "Pessimist" are present, and one is pretty busy manipulating even the lowly worm.

The bait boxes commonly furnished are of two shapes. One, the Crescent, through which the belt is run, is a clumsy, unhandy article which not only bulges out the coat, but necessitates opening the coat to get at, unless one cares to wear it with a belt on the outside, which then makes a very convenient thing to catch in the brush and delay one's progress. The other is a sort of miniature creel shape, and is made in two ways, either to fasten on the belt as the Crescent is, where the same difficulties obtain as for the latter, 
or with a large blanket pin which may be punched throutgh the clothing on any part of the anatomy, which is not particularly good for the clothing. But the trouble with both these is that one can only manipulate two fingers inside them and this with difficulty and danger from being cut. These things always bothered me, but the greatest argument against them to my mind is that they are not convenient, and thereby require too many operations or movements, a condition which is not to be desired when you are standing above a likely hole, fishing down stream as one usually must in this kind of fishing.

Well, I decided I'd had enough of this trouble and got busy. The sketches enclosed, I think, show about everything except the materials used, and this is where the beauty of the "kink" comes in. It consists of one flat type tobacco box, two large size brass counting house fasteners with the round heads removed; and the outer end of the main spring of an old clock (though most any piece of flat spring steel would do) riveted to the cover to keep it closed. The brass fasteners are inserted through two rectangular holes in the bottom of the box and securely soldered on the inside of the box (a rough job is good enough to hold it). These easily slip between the reeds of the creel cover and when the prongs are bent over, hold the box flat and tight to the creel cover. The box is mounted so that it opens away

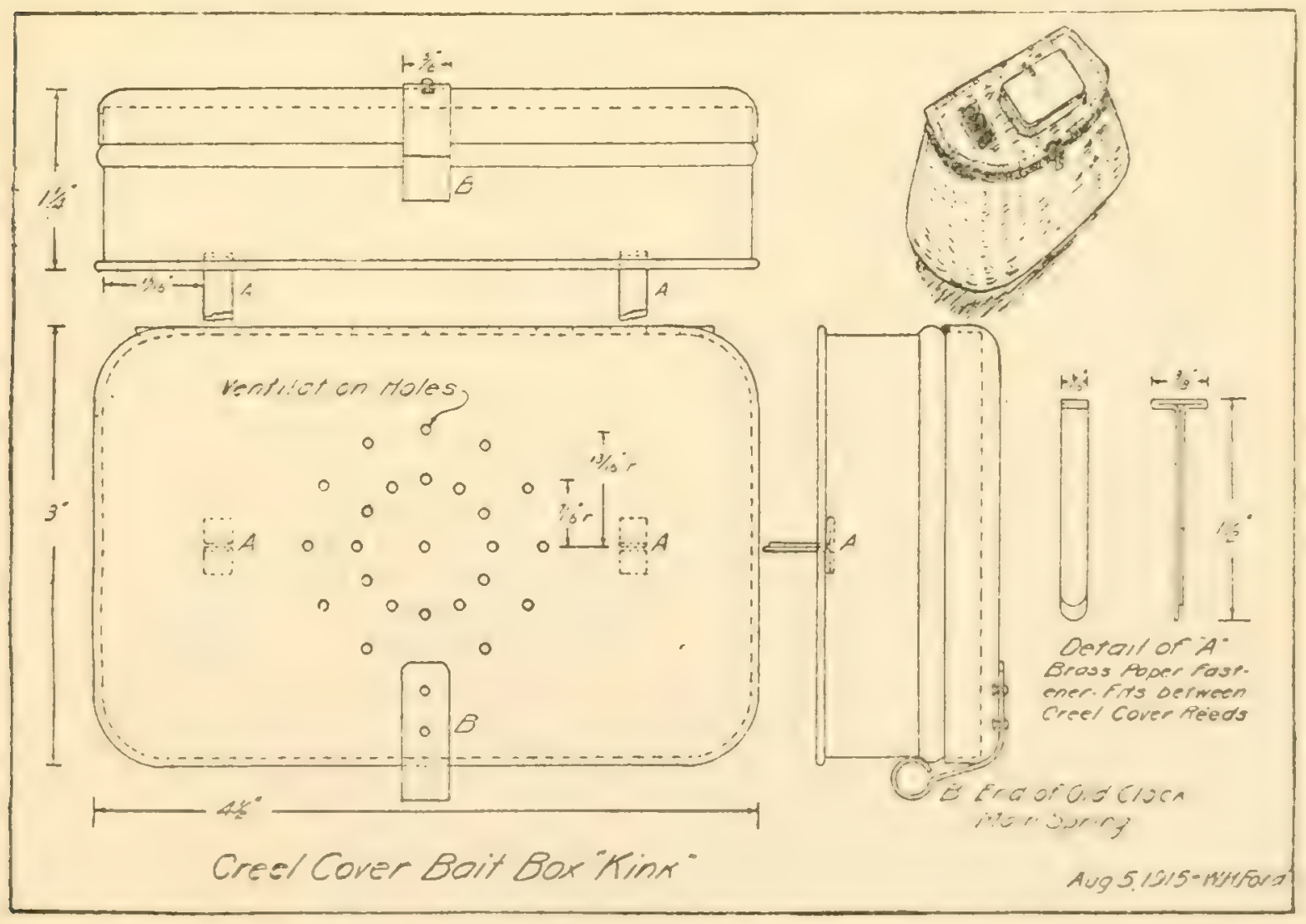


from the fisherman, i.e., the fastener towards him. Of course, the cover is punched or drilled with enough holes to allow for ventilation.

This done, the article's convenience is very evident, for after having dropped the last "catch" into the creel through the opening in its cover, there, almost in the same spot is the fresh bait for the next. I have used the first one I made four seasons, and have made several for friends who have urged me to do so, which demonstrates that it is not a mere "fancy" but a tried and true "kink."

\section{TO THE BAIT CASTER AND DUCK HUNTER}

By C. C. Kelty

Here is a kink I intended to send you last fall, but it slipped my mind until you started your "Kink Contest." While it isn't a kink to catch the fish, it has to do with tackle and has been of considerable use to me and may be to some others. In fact, a fellow gave me a big, round cartwheel for the use of it about five minutes once and I decided then that he had paid enough to give it to the world at large. through OUTER's.

For two seasons I have used a casting rod, reel and line in getting out ducks I have shot in small inland lakes and potholes where it is impossible to wade or swim. The first year I used a floater, one with a tin collar and three gangs of hooks. But that wasn't very successful, as the hooks were too small and would slip over the duck at times. So last year I made three different plugs for the purpose and I will give you a description of the one I found the best.

Take a piece of light, dry wood (I used pine) and cut it eggshaped and a little larger than an egg. Then cut a groove on the bottom about $1 / 8$ inch wide and a little over $1 / 8$ inch deep and half the length of the plug, with a small hole at the end of the groove or center of the plug. Then get a large hook, 12-0 or larger, and fasten it in the groove with double point tacks, so that the eye protrudes for an eye to fasten line to plug. Then fill the groove and hole with enough lead so it floats nicely and cover with a couple of coats of enamel and you have it. Two hooks on the bottom will work better than one unless you have to use it where there are lily pads, and then it catches too many of them.

In using this plug cast over the bird, holding the tip of the pole up. Then let the line down over the bird and reel in. Set the hook same as in a fish. If you should want to get a rod for this work and haven't anything against using a steel pole, the Union Hardware Company have one called Samson steel rod that is just the thing. It joints up short and has locking reel seat which locks on the lower band and this 
makes a fair grip. Pole only costs $\$ 1.50$ and will stand all kinds of abuse.

I use a Meisselbach "Tri-part" reel, and want to say I find one good point about it I never see mentioned, and that is that there

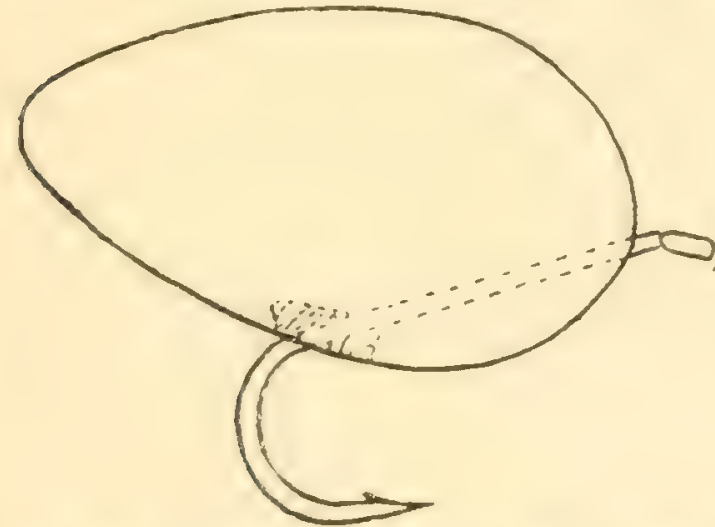

are no screws that can work loose and let you cast a part of your reel in the lake. This might not happen with a higher-priced reel, but I mean for a reel of its price. The man that has a good dog (mind I say good) won't have much use for this kink unless he wants the fun of it or to save his dog some trips into the cold water. If this kink finds a place in your magazine to help some other fellow that is in my fix (hasn't a good dog) I will feel amply repaid for writing it. I have found many to whom it was new and for some reason ye duck hunter seems to be a baitcaster as well. I am sure he will get much sport out of combining the two.

\section{NETTING AND STRING}

BY "KINKER"

Brother angler, did you ever take, along on your fishing trip several yards of mosquito netting and a ball of twine? And did their usefulness ever appear to you?

Assuming you are off for several days or a week-end, go to the corner store and procure whatever amount of netting appeals to you to get and a ball of twine.

1st. Because when you get to the fishing grounds the first thing you need is bait, and in order to catch bait you need a net. A good serviceable light net for catching minnows, crawfish, frogs, grasshoppers or crickets can quickly and easily be constructed. Cut a slender sapling about 6 feet long and bend the top into a good sized loop. Cut a piece of netting of proper size so that the four corners may be nicely folded around loop, forming a net. Fasten corners by running a string spirally through netting and around loop of bended sapling.

2d. Having a net, you need a minnow pail or cage, as the case

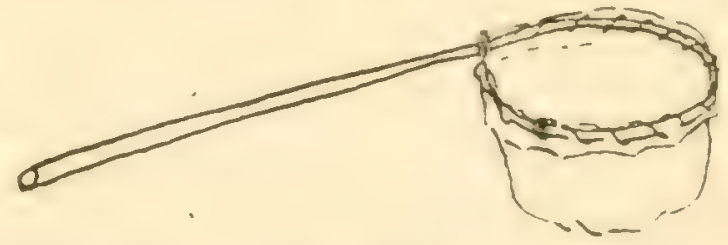

may be. Take any pail, preferably as large as you have, and tie a piece of netting over the top after the manner that a farmer's wife ties paper over the top of a butter jar, viz., lay the netting over the top and run a string around the outside about 1 inch from the brim. If it is desired to use this for minnows, crawfish 
or frogs, a small flat stone should be laid in the bottom to help to keep it upright when in the water; if for grasshoppers or crickets a

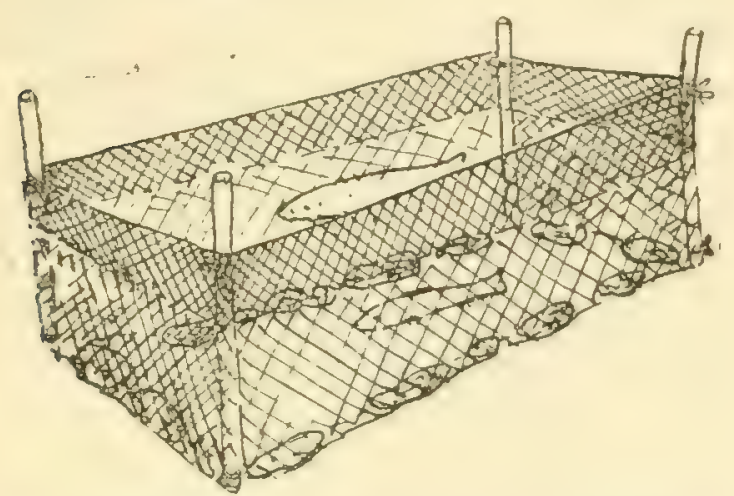

few handfuls of grass is all that is needed on bottom.

$3 \mathrm{~d}$. If you are fortunate enough to catch several fine fish you surely would like to take them home to show the boys that you can "deliver the goods." You have no ice, but if you could "keep 'em alive" till you are ready to make your retirement all the better. Here you are as lazy as can be-keep all you wish as long as you wish.

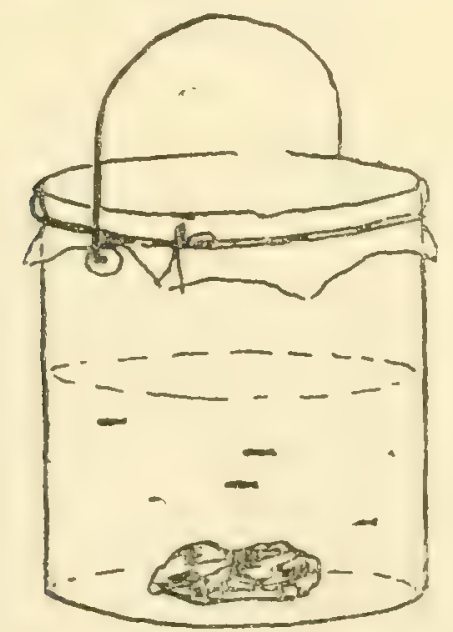

Set four stakes in about 1 or 2 feet of water. String your mosquito netting around these just as though you were building a chicken yard at home. Be sure that the netting goes well to bottom and projects out of the water about 1 foot. Tie the netting to stakes at top, with twine; place long, heavy stones on edge of netting all along bottom. Thus a fish pen is built. Throw in all you wish. Should you wish to remove them, use the net already made. Such a pen should never be built on mud bottom. A branch or two laid over the top will help to keep off the sun's rays, which makes fish more comfortable.

4th. While dreaming over those bronze backs down in the pen that you will kill in the morning to take home and show the boys, it will add to your comfort and the tranquility of the night if you throw that last piece of netting over your face to keep off those malaria distributors, in order that you may retain good health to return with a few more yards of fresh netting and another ball of twine.

\section{FOR FLOATING LIVE BAIT} By Fred R. Semenetz

A few fishermen realize that wall-eyed pike and black bass are as ready to feed at night as in the daytime. I have met with great success during the months of August, September and October, and most of my fishing was done at night. I have found that walleyes will strike at angleworms much quicker than at any other bait that I have used, though I 
have caught the wall-eyes by feeding them live minnows also.

The accompanying cuts will show the method I use in working my kink. Fig. 1 shows line in proper fold. I use common small corks, cut about half-way in the you can hook the worm twice; use at least ten or twelve worms, so as to make a big mass (see Fig. 2). Be sure to strike fast or you will lose the game.

I have given this kink to many brother fishermen and invariably
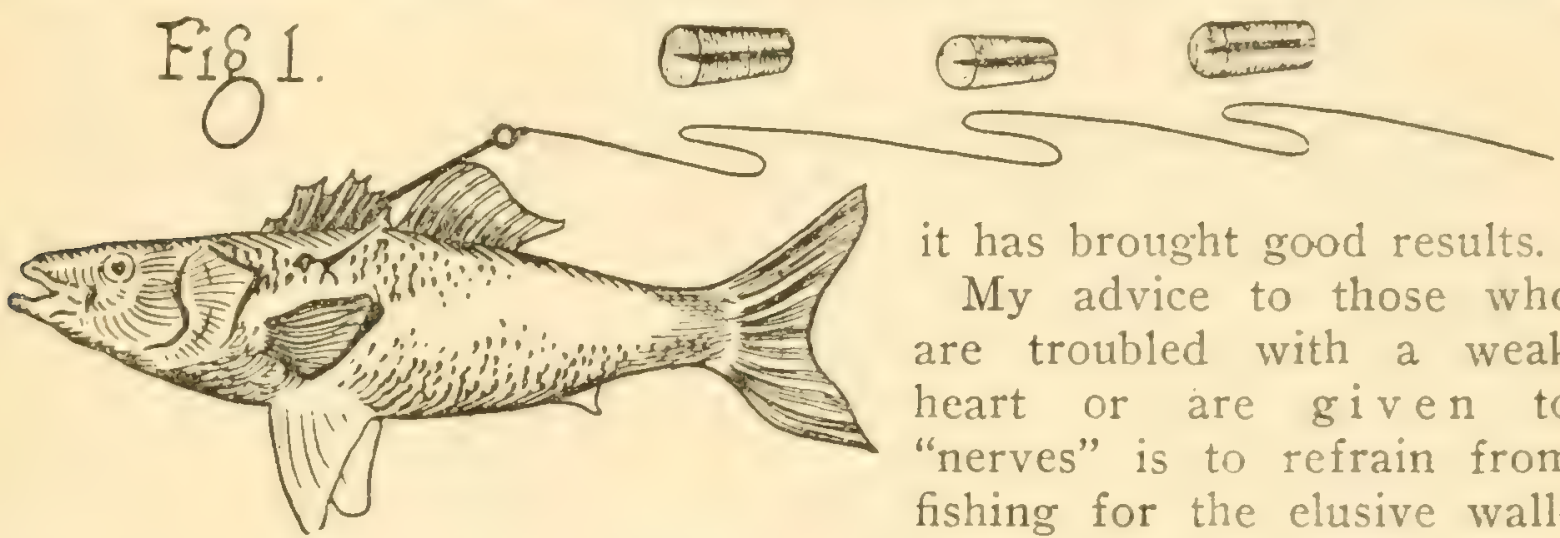

it has brought good results.

My advice to those who are troubled with a weak heart or are given to "nerves" is to refrain from fishing for the elusive wallcenter. Fold line in the cut corks, using three corks, and if necessary, four. You will find that when the bass strikes, the corks will fall off, leaving the line free for play. The distance between first cork and leader is from 12

eye or the fighting bass at night, for when you are lucky enough to get a strike from a four or fivepound wall-eye or bass it is as if you had received a kick from a mule. The suddden fright is disconcerting in the extreme. Those

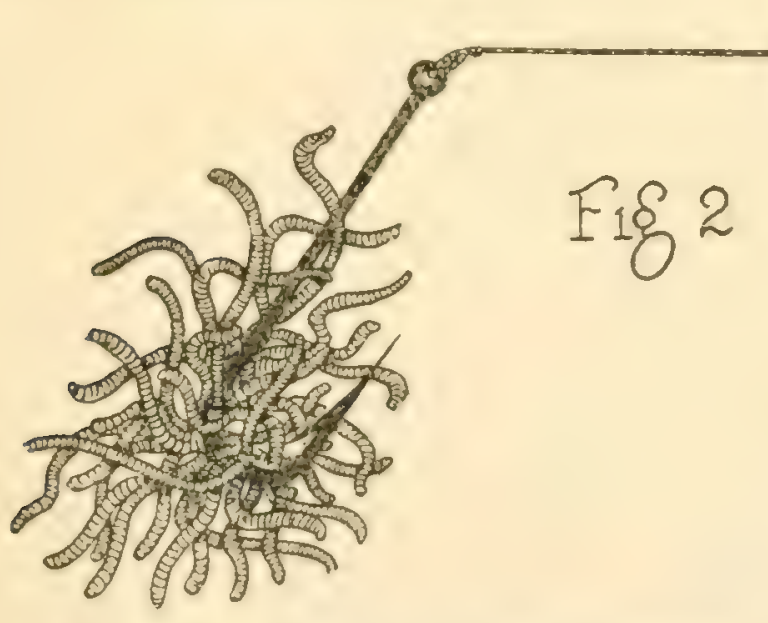

to 15 inches and from the second and third the same. If you use minnow be sure to hook him under the top fin; care must be taken to avoid piercing the backbone. In using angleworms for wall-eye, place the worms so that

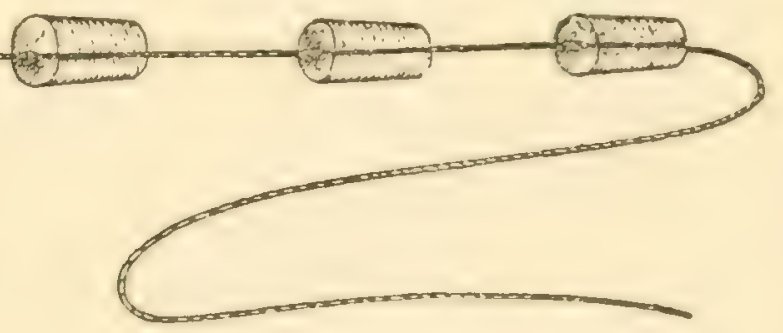

who are in the habit of fishing at night for these fish can verify this statement.

When I had my first experience at night fishing I was fifteen years of age. It was also my introduction to the "floating bait," and that night will remain a redletter night in my memory. Father and I started up the Cedar River (in Iowa, at Linwood, above Cedar Rapids) on the night of the 23rd 
of October, 1888, about 9:30. We reached the fishing grounds about $10: 30$. I baited father's line with a live cinub minnow and started it down stream. To this day I can't remember the exact length of line I had out, but it did not seem to be over fifteen or twenty feet. Suddenly something happened; I realized that I had a strike, and I struck simultaneously with Mr. Bass. Excitement ran riot in the boat. I knocked over the minnow pail, also the lantern, putting it out. Father came to the rescue by getting the anchor in the boat and put inshore. After pulling and tugging with this savage fish for over twenty minutes, I finally brought him to shore. Father scooped him up with the dip net and into the boat. The bass weighed $53 / 4$ pounds. That was all the fishing $I$ wanted for that night. Father had better success as the night progressed, landing three more bass, of $2 \frac{1}{2}, 3 \frac{1}{2}$ and 2 lbs. weight, respectively. Father accused me of having been frightened out of ten years' growth.

I have great confidence in the Cincinnati bass hook, and I have used it continuously and have landed some big bass with its aid. Some of the striped bass have weighed as high as 28 lbs.

I have used the cork floats in fishing in Nevada, on the Truckee River, where it was impossible to get within forty feet of the "holes." I used four or five corks and floated my fly or bait down the riffles to the deep holes. I landed some trout that would do credit to any fisherman.

I have used the cork float on other rivers in California and have been usually successful at Tiburon, using in this instance clams and sardines as bait.

Black bass strike at different baits at different times of season, helgramites, soft shell crawfish, angleworms, minnows, flies, spoons, grasshoppers-all have their turn. Bass are like human beings in that they know the kind of food they prefer, and giving them food out of season is comparable to giving a chap who goes into a restaurant and orders corn beef and cabbage, mush and milk.

\section{CRAWFISH AND CANDY}

By Holland Greer

When I was a boy of twelve, I was a great lover of what we now call crawfish.

Many a day I would play truant from school. Going down by the old creek I would sit on the bank and fish for those mischievous "devils" for hours at a time. Often I had little or no suiccess. In those days about the best method of catching crawfish was to tie a piece of fat pork on the end of a string, let the pork end of the string sink to the bottom and then wait for results.

This was very tiresome, and at times caused me to go home in disgust, and get the usual ha, ha. Realizing that the pork and string idea was on the bum, I began to 
think up a new scheme of my own.

Early one morning I decided to try my new scheme out. I went down to the grocery and bought five cents' worth of this old-style stick peppermint candy. I tied the candy on the string and sent it to the bottom. When I raised it up out of the water there were about ten crawfish hanging on, and before sundown I had about 300 of those devils.

Crawfish certainly love candy. Try it!

\section{A BAIT BELT \\ By F. J. Minck}

The question of carrying my artificial lures for bass fishing has always been a problem until I hit upon the idea of carrying them in the tin boxes that Prince Albert and Velvet tobacco came in. These boxes are fine, as the lid is hinged on and the lures fit just snug enough so that they do not rattle, which also saves the enamel on them. By pressing the ends of these tins the middle will bulge a little and you can easily slip in the lure, even if it's a little snug. The Prince Albert tin will hold almost any of the underwater lures for bass, also some of the surface lures. The Velvet tin is a little bigger, but not quite so deep, and will easily hold such lures as the Decker surface.

I have six of these tins fastened on a leather belt which I wear around my waist when fishing (Fig. A). I wear a thirty-four belt, so of course a man that wears a forty-four might be able to fasten on another half dozen. It is very simple to make, and costs but little. Get a fifty-cent belt and two copper rivets with washers for each tin. The tins won't cost you anything, as you can get them from friends if you don't smoke. I think my belt cost me about seventy-five cents, all told.

Now, punch a hole near both sides of each tin on the back by first putting a piece of board that fits the box snug and hammering a nail of the right size thru. Then cut holes in your belt to correspond with holes in the tin. Take

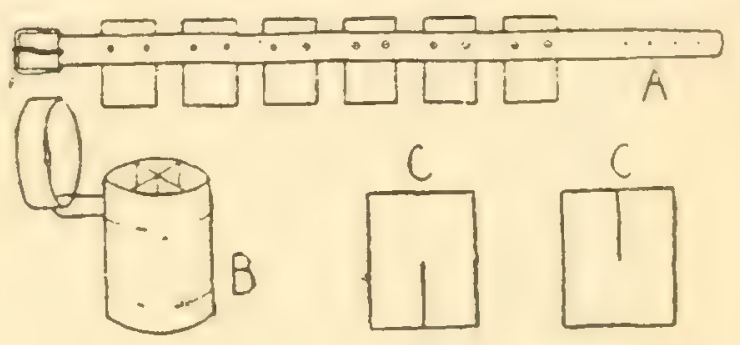

your rivet (these should have a flat head), and insert them thru the tin first; then thru the belt. Slip washer over end of rivet and hammer head on rivet by using a piece of iron inside of tin so that you won't bend tin while hammering head on rivet. Or you can use very small bolts which have a thread the whole length, and screw on the nut. You can buy these at any hardware store. Fasten the tins about two inches apart on the belt, which allows you space to fold it up and also lets it fit better around the waist. For my larger lures such as wob- 
blers and surface baits with a collar, I use a one-half pound Prince Albert tin (Fig. B). I take two pieces of tin or heavy cardboard and cut them the length and width of the inside of the tobacco tin. Now slit each piece half way to the middle (Fig. C-C). Then slip them together so that the slit of one fits into the slit of the other, and slip into the tin, making four compartments which are large enough for any artificial lure. Have the ends of tin or cardboard straight, so they will fit snug in the bottom of tobacco tin, but do not fasten, which allows you to bend the sides a little either way if necessary. You can fasten the lid on this box by making a hinge of wire. This box fits in my pocket or I carry it in my creel.

\section{A PICK-UP KINK}

By Clarence Graham

One day I was fishing from the end of a $\log$ overhanging the creek. I took out my knife to cut some bait and when through with very necessary operation, stuck the knife in the $\log$ beside me. the small end for about six inches back. Then I forced a small stick down into the split so as to hold it apart. After that it was a simple matter to shove the stick down over the knife. The small stick fell out as soon as the knife was forced back far enough and the spring of the wood held the knife strongly. By means of this kink a fellow could pick up a rod or almost any kind of an object that had fallen into the water.

\section{THE SLIDING FLOAT FOR BAIT CASTERS}

By C. T. Winston

Did you ever fish a small stream with low, overhanging branches all along and want to place your minnow into a likely looking spot on the other side, and find that most of the time you caught a bunch of leaves, or when you did miss them you couldn't cast half way across? Well, I have, and to get my bait across I worked out the following:

An attachment on the float which lets it rest just above the sinker when the cast is being made, thereby placing all the
Shortly afterward I hookèd a nice fish and in landing it knocked my knife into the water. The knife was a good one and I didn't like to lose it. The water was nearly ten feet deep and very clear. With my belt axe I cut a pole about twelve feet long and split weight practically at one spot, then lets the bait and sinker drop to a pre-determined depth. To make the outfit procure an oval cork float about one inch diameter by four inches long (the short, thick ones or the very slender ones will not work) and some "Gem" pa- 
per clips. Straighten a clip and make a loop about 3-16-inch or $\mathrm{I} / 4$-inch diameter in end. Then wrap wire tightly around stick in end of float a couple of times and cut off. Repeat operation on other end of stick and float is ready. The rings must be far enough from stick to prevent the line from touching side of float (see sketch). Now make up a dozen or so of rings about 5-16 inch inside diameter of the same material as used for guides on just above bait, lower rod to horizontal position and snap it out.

In lake fishing this kink keeps the minnow from getting away down in the weeds and hiding from the big fellows.

\section{A PERMANENT REEL FILLING}

By Grant R. Lynch

Everyone knows that the size of reel most used and suitable for bait-casting carries more line

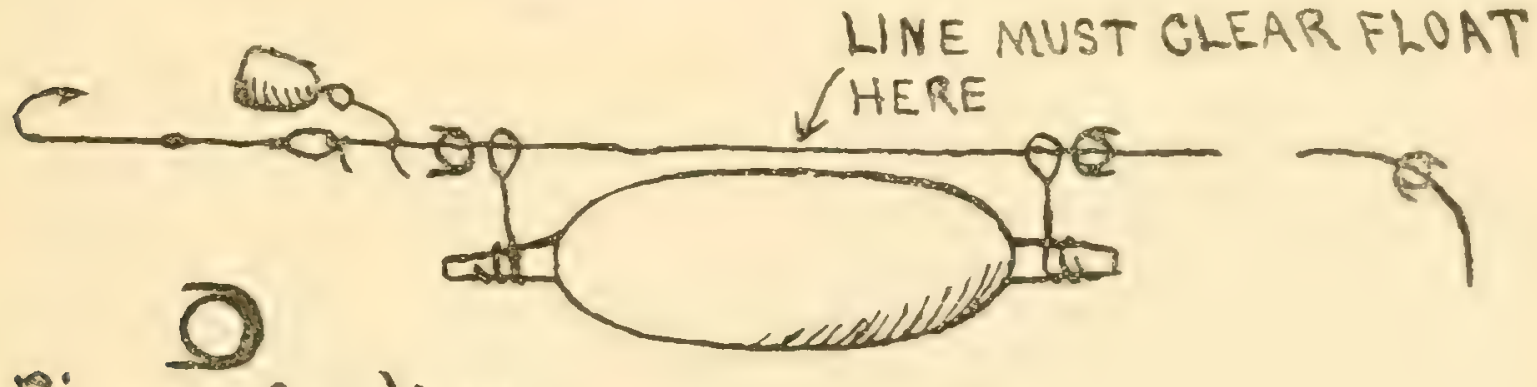

\section{Ririgs for line.}

\section{[Make several]}

float. A lead pencil makes a fine former for this. Make a turn and a half around pencil, letting wire touch all around. Allow the ends to project slightly, which will make it easier to insert line.

The paper clips are somewhat springy and do not rust easily, and I believe are better than copper wire. To use outfit run line through a ring and force it between turns at depth wanted, slip on float and place another ring just above end of line. Attach sinker of proper weight just below this line and then the hook.

Bait hook, reel up line until upper ring touches tip of rod, grasp line between thumb and finger of the size we want to use than is necessary in fishing. Nearly every one uses 150 feet and puts a core of old line on the reel. Of course that will do, but every time the line is used the old as well as the new line must be dried. If the new is only dried and then wound on over the wet line it is nearly as bad as not drying at all. The moisture comes through and rots the good line. For those who fish only once a year, line drying is no bother, but for those who average as much fishing as I (once every three days from opening day until ice) line drying is a bother to be cut as short as possible. 
Corks may be split and shoved over the spindle of the reel, but require fitting and fussing with to get a good neat job. I overcome the difficulty by winding on the good line and then filling the reel with common cord or old line. Then I unwind and wind on the cord or old line smoothly next to the spindle. Before this I buy at the drug store some $3 / 4$-in. adhesive plaster and a small botthe of alcuhol shellac. From the plaster I cut three strips long enough to go around the core of twine on the reel and lap $3 / 8$ or $\mathrm{I} / 2$ inch. I put one strip around the core at each side of the reel and let it lap up about 1/64 of an inch on the sides. The other strip I put right in the center of the spool and it overlaps the two side ones. Then I coat this carefully with the shellac and after an hour or so give it another coat. That makes a good solid waterproof core, but it can be removed or changed with little or no trouble. A coat of shellac can be applied at any time and makes it good as new. This can be done just as easily on a solid reel as on a take down model without taking anything apart for fitting.

Now just a word on saving a little work when drying lines. Any hardware store will sell you enough brass screw hooks for $5 \mathrm{c}$ to rig up a good outfit. Select hooks without sharp points. Find in your home a space between two doors or windows on the same wall and screw in a hook on the casing of each. If you are using more than one line, set a pair of hooks for each one. My windows are in a hallway eighteen feet apart and it takes only a few turns back and forth to wind a line on or off the reel. The hooks are not unsightly and if made of small stock will hardly show a mar on the wood when necessary to take them out. I generally use a light and a heavy rod and my wife usually fishes with me, so I have three sets of drying hooks, and every time I use them I smile to think of the miles I used to walk around chairs and other fool things drying lines.

\section{TROLLING FOR CALICOES}

\section{By Ira Dintaman}

Here is a kink that the brothers will find handy when trolling for the Calico, Strawberry or White Bass. Take any kind of a rod upwards of nine feet long (the longer the better), and swing out your line a foot or eighteen inches longer than the rod. Attach your sinker about four feet from the end of the rod. Use a No. 20 Cincinnati bass hook. For bait cut about an inch and a half from the tail end of a small perch or blue gill. Split this lengthwise so as to leave one-half of the tail fin on each piece. Run the hook through the larger end of the piece. Now you are ready to troll.

Set your rod across your knees so that it reaches up and back at 
an angle of about 20 degrees or the pitch of an ordinary shed roof. The lead sinker should be about six or eight inches above the surface of the water, causing the line to hang straight down. This is one of the chiefest reasons for the success of this kink.

Row slowly along near the edge of the weeds. When the fish strikes he first takes up the slack that the hanging lead gives him and by the time this is gone he
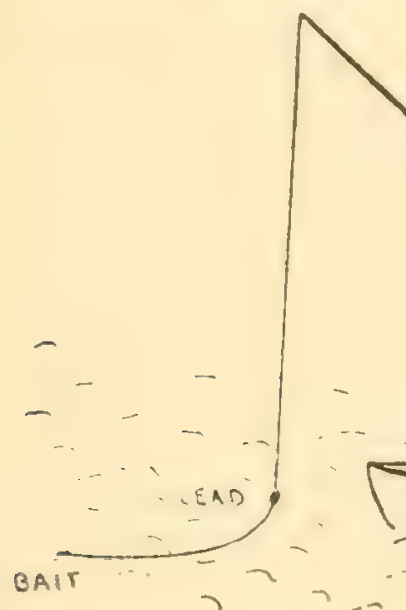

has hooked himself. Now is the most critical moment. Do not jerk to set the hook. If you do you will lose nine out of ten fish. These fishes have very tender mouths and the hooks tear out most readily unless they are carefully handled. Just lead the fish gently to the side of the boat and lift him quickly in. These little fellows are really quite gamy in proportion to their size and their tender mouth makes landing them quite a sporting proposition.

I have caught as high as fiftyfive of these fish in one afternoon by the use of this kink and did not wear out more than eight or nine tails for bait. One can also employ angleworms as bait in the same manner, hooking the worms but once through the middle of the body. The boat should be moved along very slowly, just keeping the bait in motion. A paddle can be profitably used in place of oars and two people can readily fish from the same boat by this method, with equal success.

\section{A FISH SAVER}

By L. J. Boughner

Slip into your tackle box a piece of shoemaker's wax the size of a hazelnut and half a dozen feet of silk thread. When ready to bait up, wax four inches of the end of your line and about a foot of the thread. Slip half the waxed end through the Cooper snap and double it back to form a loop. Hook the snap over a handy projection, and wind the thread about the upper end of the loop, hoiding the line in your left hand and using your left fore-finger to hold the turns. Wind back and forth for about half an inch pulling the thread tight at each turn but making no attempt at smoothness, and fasten the thread with a half hitch. The wax is waterproof.

This little kink will add a third 
to the strength of your line, or enable you to use a lighter line than formerly, with a consequent saving of expense and gain in ease of casting.

If you want to know why, make this experiment.

Fasten your favorite line to a Cooper snap and hook it on a spring scale. Take two or three turns in the line a foot or so away and pull steadily. The line will break at about the rated test. Twelve tests on a new 8-pound No. 6 line will give an average of about $81 / 4$ pounds.

Now make a loop as advised above (sime, one minute) and repeat the experiment. The scale will show $7 \mathrm{I} / 2-8-81 / 2-$ whoops! 9-whee! 91/2-what do you know about tinat? 10-well, I'll be darned, 10\% -oh, she breaks, somewhere between $10 \mathrm{r} / 2$ and 11 pounds. Twelve tests on the same new line will average about $10 \mathrm{~T} / 2$ pounds.

The interesting point in these experiments is that in the first the line invariably breaks at the knot. The tension at which it breaks has a range of a pound, owing to diffe-ences in applying the strain, but the break is always at the kriot. In the second test, however, the break occurs at no well-defined spot. Sometimes it is near the loop, sometimes near the other end.

A monent's thought gives the reason. Just as a rod breaks at the ferrule, because of the absence of elasticity, so the line breaks at the knot, where it is bound. Making a waxed loop, instead of a knot, retains the elasticity of the line to a certain extent, and compensates for what is lost by doubling the line. Onepiece rods and serrated ferrules, though expensive, justify themselves by adding elasticity, abolishing the knot in the line does the same thing. A tight knot puts two or three pounds strain on the line at least. The pull of the fish soon adds enough to break the line. Relieve every part of the line of artificial strain, and you have two or three pounds more for the fish. And two or three po:unds is the difference between the fish you've been catching and the ones that got away.

\section{SAVING SNAGGED BAITS}

By John T. Mitchell

Since acquiring the knowledge from an old bait-caster, I have never gone out without a considerable length of heavy cord (preferably chalk line) in the bag I carry over my shoulder while casting. A flat rock tied to the end of the heavy line has saved many an expensive plug, which otherwise would be dangling from an inaccessible branch or snag.

\section{PIG TAILS FOR BASS}

\section{By A. H. STERN}

Here is a kink for bass fishing I was going to send you some time ago, but it slipped my mind 
until I saw your Kink Contest in the August book.

I use a pig tail, either fresh or corned, which can be had at any meat dealer for a few cents, and four No. 22 or 24 eyed hooks. Fasten a hook about one inch pork is bent a little and tie the yarn on the tail as per sketch.

You will find that your bait will wabble, dive and give several varieties of tango movements that take the eye. It acts like a minnow that is hurt; wiggles, dives

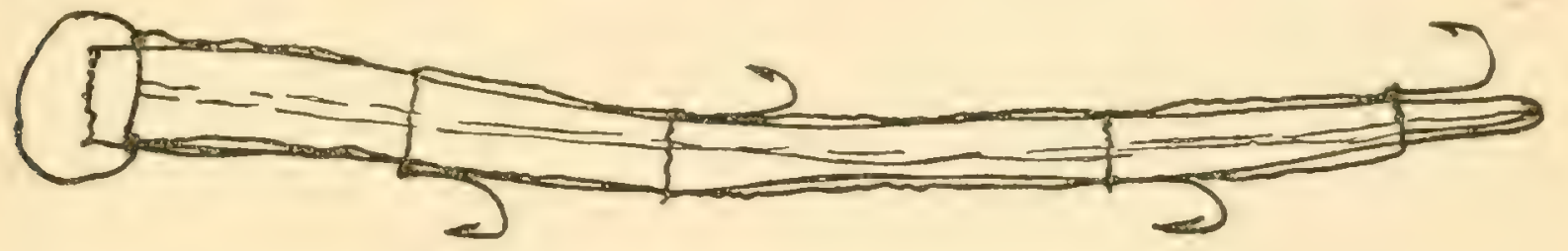

from the tip or small end and the others divided equally apart. The best way to fasten them is to tie with small size fishing line around the tail. Then join all of these with a line up each side to the top of the tail, but not too tight, as this would not let the tail be free to wobble like an eel. This bait can be kept in water after being used for a whole season. It was used by an old bass fisherman for years. Use only the small taper part of the tail.

\section{ANOTHER PORK RIND STUNT}

By Ed. J. Senberth

Take a piece of pork rind and shape to as near a minnow as you can. Then take red yarn, loop and makes other foolish moves. $I$ have tried it out and find it good. Got on to it by accidentally pulling the yarn too tight on one that I made.

\section{LIVE TROUT WHEN YOU WANT THEM \\ By F. MACKEY}

It was my pleasure to spend three months of 1912 and the same length of time in 1913 camping on the shore of beautiful Lake Alice, hidden in the Rocky Mountains of British Columbia. The fishing was uncertain, as it is on many lakes, but both the writer and his pal, "Bob," were fish eaters. (Bob, by the way, is my pointer dog.) So it occurred to me that if I could keep my fish alive I could have fish for camp

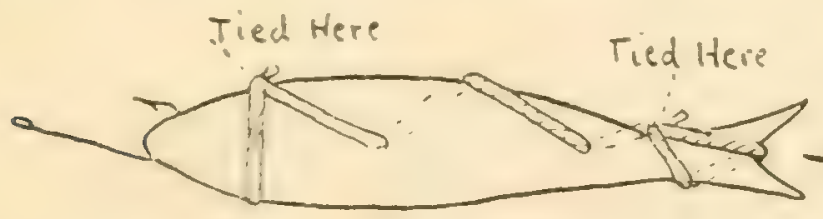

it over or around the neck and then stick it toward the tail, in and out, say, three times. Then pull the yarn a bit so that the

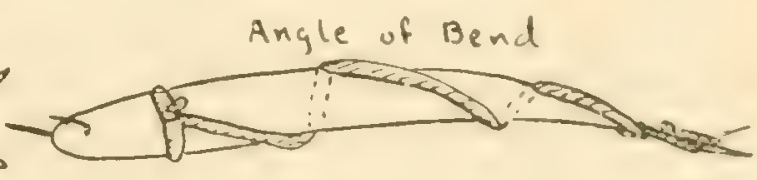

when they were not disposed to rise to the fly. And this is how I did it:

I purchased ten yards of 
chicken wire netting and packed it into camp. Then I cut cedar poles about three inches through for my posts. These were four feet high. The side pieces I made five feet long, the same size through. The ends were three feet. After squaring them at the ends, so they would fit nicely, I spiked them together. I now had my frame, and it was only necessary to fasten my chicken netting around this frame and my tank was completed.

I selected a nice sandy spot under the shade of a pine tree and let my fish tank down in about two and a half feet of water in the lake at my tent door. In order to have my fish in good condition for the home that they would have for the rest of their existence, I made two baskets of the same material by weaving the wire together at the sides and end. Then when that was done, I pushed it into the shape of a barrel. This I kept at the end of my raft, half submerged in the water. When I hooked a fish of a size to keep, and his gills had not been affected by the fly hook, he was put in the basket. I could have my evening fishing without having cccasion to visit my tank until the sport was over. My fish did well and were quite contented in their home. They afforded me great pleasure watching them rising to the insects that dropped on the water, and they also ate heartily of any grubs or worms I happened to throw in to them. I learned many things about trout that I never knew before, and it certainly helped me in my study of this "king" of lake fish. The trout likes plenty of shade, so be sure and have one end of your tank covered with boughs. When removing fish from your tank use the landing net and do it carefully, so as not to cause too much disturbance in the tank, as your fish may injure themselves on the wire and become diseased. I had as many as seventy fish in my tank at one time, some weighing as heavy as two pounds.

\section{PACKING PLUGS}

\section{By T. E. DroHan}

The wood and pasteboard boxes that artificial wooden baits are sold in, take up too much room in the ordinary bait caster's outfit. Yet if he leaves one single "plug" hole he is almost sure to regret it. I have been in that fix myself.

Now, however, I take plenty on every trip. I discard the boxes and roll the plug in a piece of white oil cloth such as used for covering pantry shelves, use a piece about 7 by 14 inches and snap a rubber band on it. In this way I am able to pack twenty plugs and spoons, besides one reel, a pair of pliers, a file, disgorger and a small bottle of 3 in 1 oil in my No. 2 Gem tackle box. On the cloth side is labeled in ink the name of each bait, so that they can be readily found and the 
wrapping is done so as to leave the label in view-a very simple matter.

The oil cloth will last a long time and is very cheap, and I hope that others in the fraternity will find it as practical and satisfactory as I have.

\section{THE NATURAL BAIT WOBBLER}

By E. R. ACRES

If you ever happen to be in need of a wobbler that will wobble and that a bass will swallow, try this kink. If he misses the
Book, the above quotation suggested that I might stretch a point in telling my pet way of handling - not the bait-but the fish.

While this little trick, which I have used with much success, may be very old to a great many of my brother fishermen, I have yet to find the man who claimed to be able to stop fish from "breaking water." That's my trick, or at least I think it is.

How often, Oh, fisherman! has your heart "stopped beating" as some wily old bass, or perhaps he was a trout, leaped into the air and shook himself from head

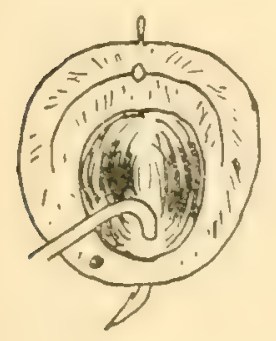

first time and you stop reeling, he will charge it like mad. Take a chub or round-bodied small fish and cut in the manner shown in the diagram.

If you want to fish in the weeds, reverse the hook. By the way, this will work well with rainbow trout if you use a wobbler about one and one-half inches long and do not cut at as steep an angle.

\section{HOLDING 'EM DOWN}

\section{By Rush McFarLand}

"Some pet way of handling a bait, etc.,"-

When reading of your Kink Contest in March issue of OUTER's to tail in his mighty effort to free himself of the hook. And that same old heart did not get to pumping again until you had strained your rod almost to the breaking point to keep from giving "slack" and you found that the fight was still on.

Let's see if you can't agree with me that my pet scheme is not better than inviting any lapse of heart action.

After striking your fish as soon as the battle is on, dip the tip of your rod into the water and keep it there until you have brought your fish to net. Keep plenty of "bow" in your rod, of course, but you'll find that it is not the spring 
of the rod that's tiring your fish so much as the friction of line and water, hence you are not only eliminating the possibility of frequent leaping of the fish, but you are going to net him in much less time.

In keeping the tip of your rod submerged your fish has possibly, under certain conditions, as much as ten or even twenty times the amount of line to "tote" through the water as when the rod is held nearly perpendicular. This when your fish is describing the arc of a circle or speeding along laterally to the angler's position, means ex-
But try it out yourself, brother sportsman. If it works for you, why then it's a good kink; if not, it's no kink at all.

\section{THE SHOE-EYELET AGATE}

\section{By J. H. Commiskey}

Would like to tell worthy brothers what happened to me on my fishing trip a short time ago. I was out bright and early one fine morning and had only got started when the agate tip on my rod broke. While rowing back to camp I hit upon the following
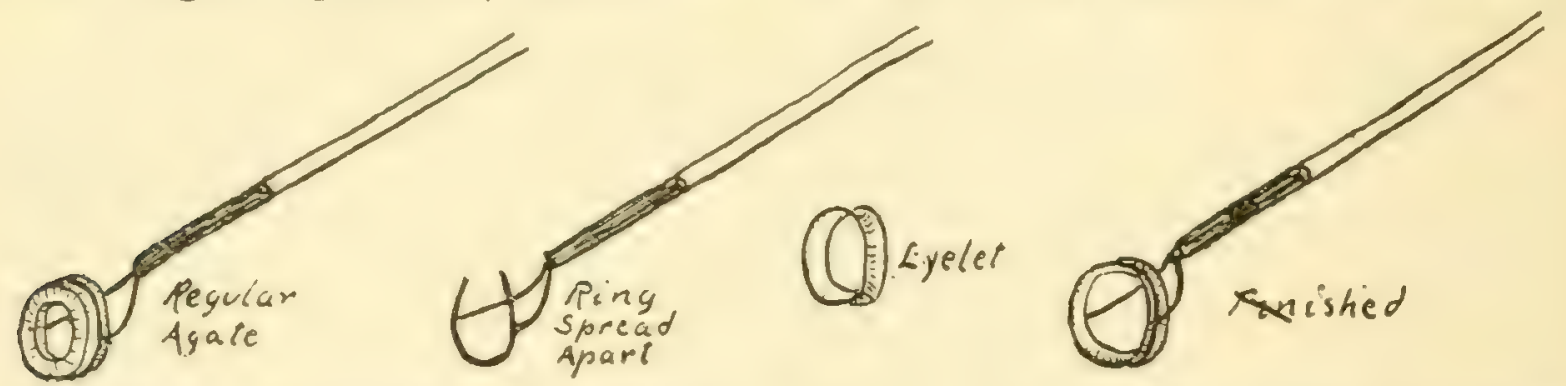

tra weight or tension on the fish without increasing the strain on the rod or endangering the breaking strength of the line.

When the rod is held perpendicularly, or nearly so, the tendency is to bring or hold the fish near the surface. The pull being always toward the surface, is it any wonder that the fish will occasionally "break water" when so ably assisted in his leaps by the angler himself? But if your fish be made to "tote," say, fifty feet of line or more to and above the surface, I think that you will find that his leaps will not be frequent, but as I contend, eliminated entirely. kink: I took an eyelet out of my boot and fastened it securely where the agate had been, and I used that same tip during entire trip.

\section{TAPE FOR REEL SEATS}

By G. W. Russell

My reel used often to loosen by the slipping of the rings which held it in place. I have seen others have this trouble also; and what is more distressing, it usually occurs just when you have set the hook in that big one.

To prevent this trouble I use half-inch electricians' tape on the reel seat. I set the reel in place 
and push the rings up firmly. Then I lash all in place with the tap which is wound on in the form of a figure 8. The tape will

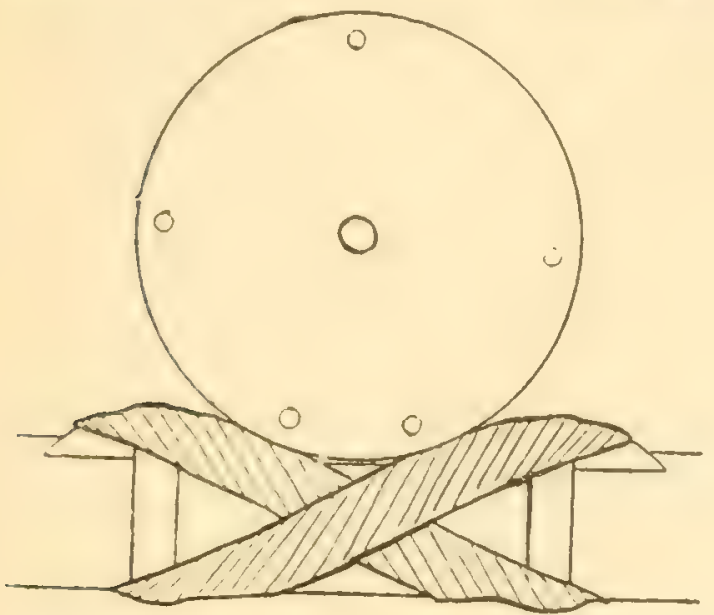

hold under all conditions, and is very easily removed at the end of the day.

\section{AN EYED FLY BOX}

By E. P. Cook, M. D.

I sent away and got a box for eyed flies, and such a monstrosity as it was-more of a load than the fish on many trips. I knew

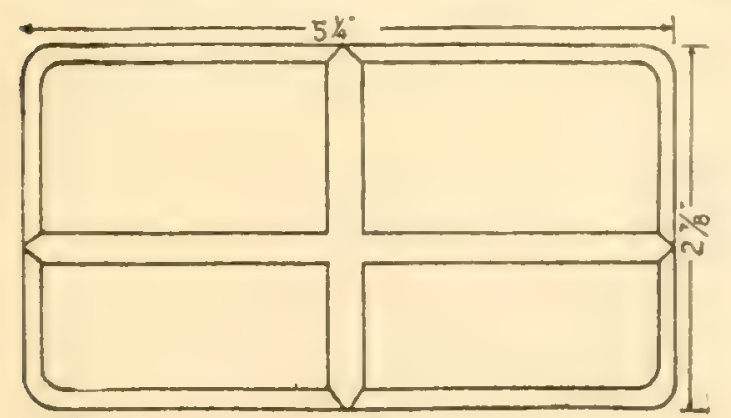

Fig 1

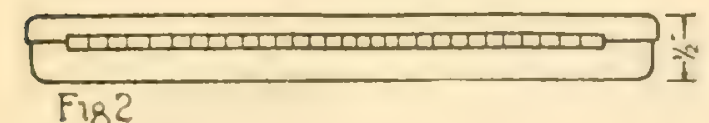

what I wanted, but could find nothing of the sort advertised. So I set about it to make one. A diccarded watercolor paint box, such as the children have at school, furnished just the right thing as to box. The inside of this box was painted with waterproof white enamel to prevent rusting. Next, sections of corks were glued to the inside, as drawings show, and the thing was done. Figs. 1 and 2 show the box closed, $5 \frac{1}{4}$ inches long, $27 / 8$ inches wide, $1 / 2$

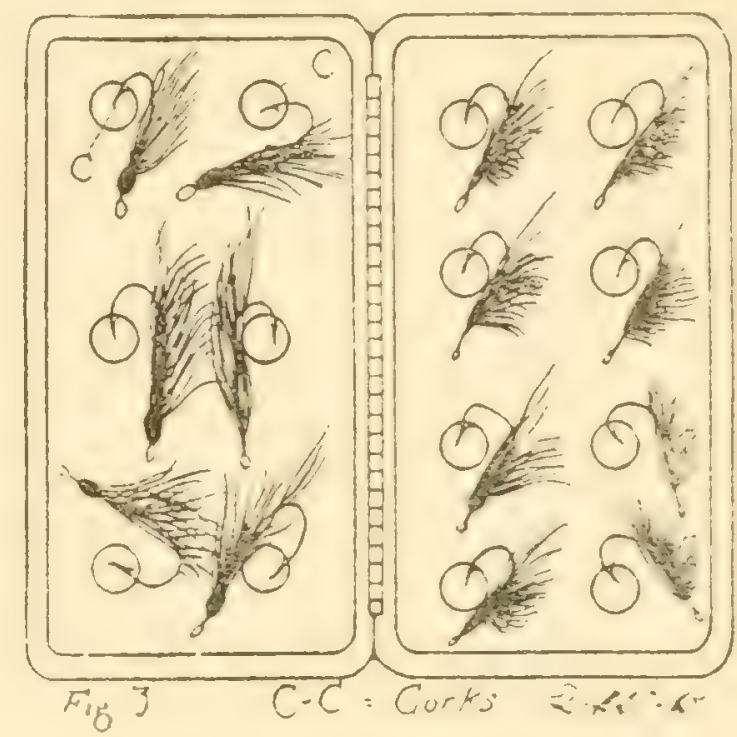

inch thick. Will hold twenty-five or thirty flies. Slip easily into a vest pocket.

\section{ROD CASE AND TRIPOD}

By George A. Wiggan

Having for several years combined fishing and photography, and being addicted to delicate bait rods and time exposures, I began to look round for a light, portable rod case, and the ditto in a tripod.

The rod case came first. I had already used a leather case-too heavy; bamboo-too bulky; fibre -a mortal foe to wet. What was I to do? No other style of case that I could find was made. An- 
swer, think it over and make one. The tripod presented like troubles. Wood ones were bulky and the three-legged metal ones were a load in themselves.

The solution to the tripod came first. A party of surveyors gave me the hunch. If a compass could be kept steady enough on a single rod, why not a camera. I straightway went to the nearest photo supply place and was promptly rebuked by the clerk for thinking that such a thing as a one-legged tripod existed. The idea! So back to the workshop to plan one of my own I went.

Let's see, the tripod ought to be about three feet long to be portable; long enough for all purposes. Three feet-somehow those words stuck to my mind. What was three feet? I looked around. There in its case stood my pet Heddon. Why, of course; that rod was just about three feet when taken down. Why not combine the two? So far, so good. But what material would answer all that I required? My friend, the tin smith, when called into consultation, said he could fix me up with a piece of heavy, retinned tin, and that he could make a case out of it to fit my rod and I could work out my salvation for the camera as best might appear.

In due time the case arrived. It was just large enough for two tips to fit in on either side of the butt. The handle fitted in nicely. On the bottom the tinsmith had put.a spiked ferrule so that it could be stuck into the ground. The top he fixed up with a screwon cap. Good for the rod but no place for the camera. The screwon part of a discarded tripod was commandeered and a hole bored in the case top. The screw was soldered in and when it was done made a solid place to fasten the camera to.

The whole thing was about three feet six inches long and about an inch and a quarter across. Empty, it weighed a trifle over a pound. The rod was protected perfectly and I had a solid rest for my camera and it carried as easily as the rod alone and was just about right for a walking stick.

\section{SHRIMP BAIT IN FRESH WATER}

\section{By Geo. C. Shupee}

I do not know if this "kink" is of any value, but $I$ have found that I could catch fish with it where others have failed with other baits. It may not be new and others may know of it, but it has always been new when I sprung it.

Take fresh salt water shrimp and leave it out in sun till it turns a delicate pink, say from two to five hours, depending on how hot the sun is (if you have a distance to go, your bait will generally be ready by the time you get there). One bait constitutes a single joint, or knuckle, impaled upon your favorite hook or spinner, and if 
there are any fish in the water they are yours.

It will have a very strong odor which some might object to, but a dip in the water removes this to some extent. The meat will be a clear white, ideal bass bait, and as I have learned, fish bite by smell and sight, and not by taste, the odor draws them, especially bottom feeding fish, and the clear white is the tempting morsel for Mr. Bass. I have also used it successfully for speckled trout.

As an illustration: A friend and I went to his ranch on the river near here (San Antonio, Tex.) $\mathrm{He}$ said he knew where the fishing was good, so all I had to do was follow him. I picked out a likely hole and began to cast with my shrimp bait. $\mathrm{He}$ had snails and grasshoppers. He told me to come with him, that I would catch none where I was, but I told him I would see him later. It was then about 7 a. $m$. About 9 a. m. he returned with one three-pound channel cat. I had run out of bait and had thirty-eight fish, all running from two pounds to four pounds. He had lived and fished there for three years, and it was my first trip-I lay it all to the bait, as. I find that it will work as well elsewhere.

The meat is firm and stays on the hook well, and answers every purpose of pork rind on spinners. Please, however, do not confuse with canned or dried shrimp, neither of which seems to work at all. If you should be going for two or four weeks, five to ten pounds will be sufficient. All I ever do is to leave it in a perforated can in the stream and use as needed, and the longer it is kept the better it is.

I hope this will enable some brother slave of Isaak Walton to realize his desires.

\section{"NOTHIN' BUT GLUE"}

\section{By D. B. Tolley}

I believe that most users of the wooden rod will agree with me in saying that the tying of an invisible knot at the end of each wind when wrapping such a rod is a nuisance; to some an almost intolerable nuisance. One winds good and tight and closely and then lets the silk slip at the finish and spoils the whole thing.

A few years ago I wound a rod spirally, and in the course of time the varnish became scratched and the silk broken. I did not relish the thought of rewinding my service rod in summer, so just applied some varnish to the scratch and kept on using it. The silk, held by the varnish, did not start a trifle. That made me wonder why a knot was necessary at all.

The next time a rod was wound I used glue to hold the end until the varnish had set. I used the kind of glue which must be heated to reduce from a solid to a liquid, and, believe me, it worked. I coated the last few laps of each wind with glue (roughly), wound 
them and applied a smear of glue to the finish, keeping the silk tight the while. I then snipped the silk and removed the surplus glue with a piece of chamois. That finish was ideal, almost invisible and very tight. The glue hardened so quickly that I could go right on winding without having the glue let go because of a little handling. The varnish obliterates any stain left on the silk by the glue.

My glue pot certainly saved me time and trouble last spring and yours will, to, if you'll only let it, Brother Angler.

\section{THE BOTTLE CAP FISH SCALER}

\section{By Thomas Maloney}

A very practical little device for removing fish scales can be made by taking a beer bottle cap (the sharp, scalloped-edge type illustrated in accompanying diagram) and a short piece of wood, capable of serving as a handle. The cap should then be tacked on one end of the handle, driving the nail through the under part of the handle, then bending over on top to fasten more securely. The result is a very serviceable little scaler.

\section{A CRICKET "FARM"}

By W. J. Fritz

The following kink will, I trust, save many a physical kink in the back of those Sons of Walton who are always prowling around looking for live bait, such as crickets, grasshoppers and the like. Its discoverey was purely acidental, but it has saved me many a valuable hour of fishing time, and what can be more precious than that to an angler?

For a long time there lay in our back yard the trunk of an old plum tree. Its function was supposedly as a base for running

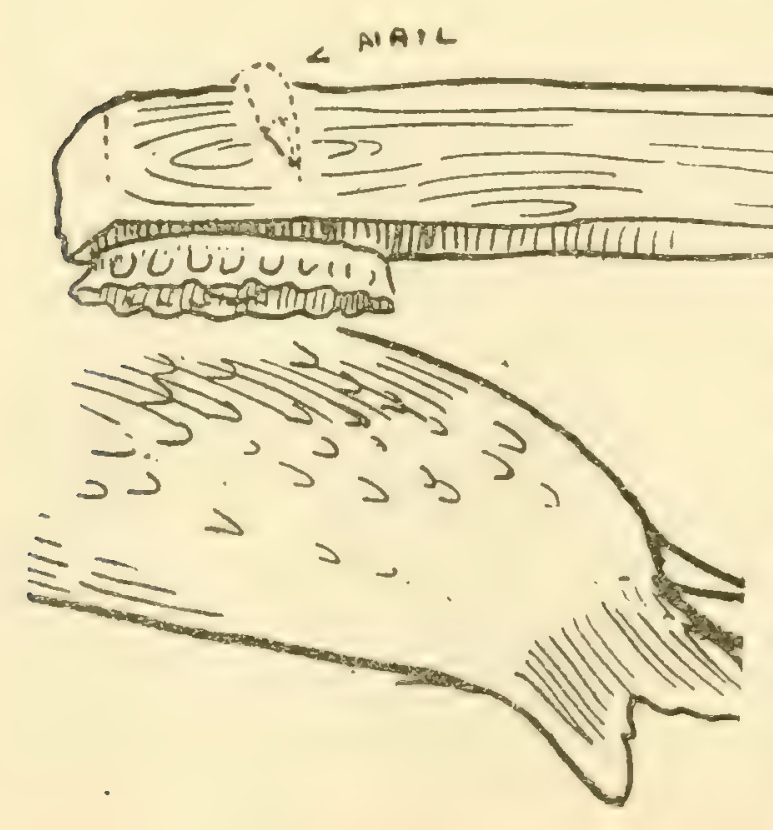

vines, which (under the subsequent circumstances) I am glad to say, refused to "run." One day, after a stretch of wet weather, an old carpet used as a door mat was thrown over the plum trunk to dry. On removing it some time later I was surprised to find beneath it about two 
dozen large, black crickets. The damp, cool place, together with the rough bark, evidently afforded them an excellent hiding place, which they had promptly adopted as a home. Crickets being at that time a seasonable bait, my surprise was a pleasant one. in certain little eddies and no way to catch them? That's what happened to me on several trips until I made a net out of minnow seine to carry in my pocket.

And this is how I made it: First, I cut a piece of seine about 16 in. wide by 24 in. long. Both

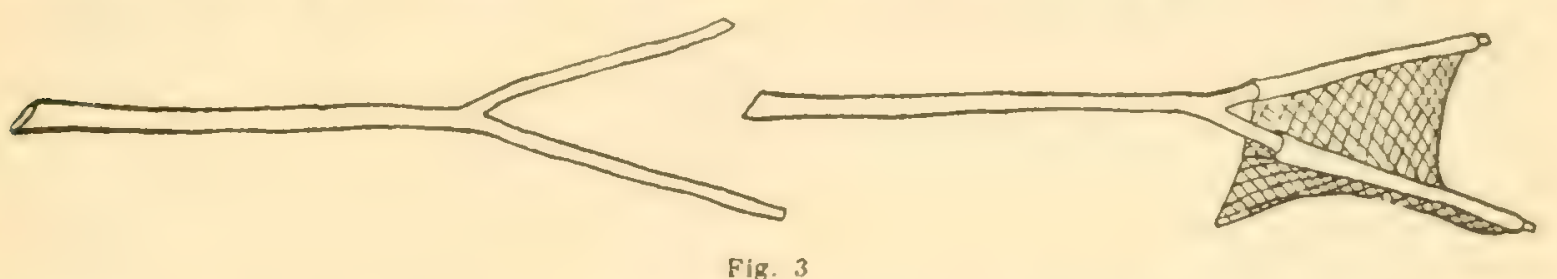

Now that cricket home has become permanent. I brought the tree trunk closer to the house and placed it near the cistern. I keep it covered with a couple of old gunny sacks, over which I occasionally douse a bucket of water. Whenever the bass down at the pond telegraph that they would like a few crickets for supper, all I do is to pick up one corner of my sacks and gather as many as needed, in a minute or two.

\section{A HANDY MINNOW NET}

By Harry E. Smith

Were you ever fishing when the trout wouldn't take a fly or when it was desirable to have some minnows; with thousands of them

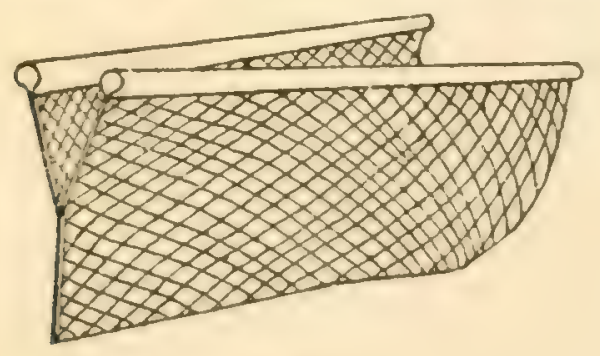

Fig. 2 sides of this I bound with strips of muslin about 3 in. wide, making loops or hems through which the handle could be pushed, as shown in Fig. 1.

Next, I doubled the hems or loops together and stitched the

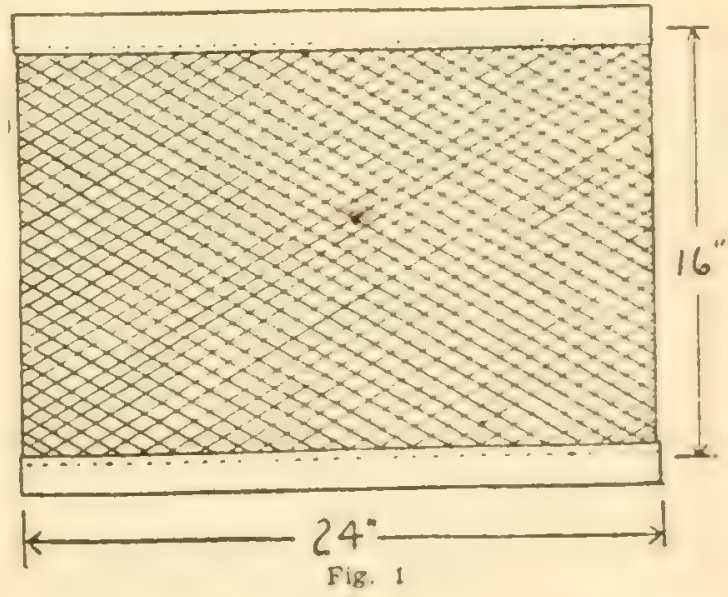

rear end together about half way to loops, as shown in Fig. 2. This gives us a sort of scoop shovel shape net which only lacks the handle and can be folded into a very small space.

The handle is cut from almost any convenient bush or tree in the shape of a crotched stick with the branches as long as the loops on 
the net. These may be sprung together and slipped into the loops and the net is ready for business, as shown in Fig. 3.

It can be carried almost as easily as a pocket handkerchief and may help us to a basket of trout when their appetites call for minnows.

\section{A GOOD SINKER FOR TROUT FISHING}

\section{By Frank E. Wilder}

I have used a Kink which works very well in any stream when fishing with worms. This is especially effective in streams which are frequently fished and where the trout are wise.

Most everyone knows that to make the bait look like worms which have naturally fallen into the stream, you let your hook, which is well baited with worms. drift down the stream before you and you don't use a sinker. There is one objection to this mode of fishing, which is, that you can't get to fish the deep holes where there is a current, and that is the very place where the big ones lie.

To get down in these holes and still have your bait look lifelike, tightly roll a piece of tinfoil, which is about three-quarters of an inch square, around your line just above your leader or about six or eight inches from your hook.

If no tinfoil can be found, melt a little lead and pour it on some smooth surface from a height of five feet. While pour- ing, keep the dish in motion so that the lead will not fall in the same spot, and the lead will flatten out in little pieces about as large as a penny.

When using one of these sinkers and you get your hook snagged on a log you can pull the sinker right through the end eye and work your hook loose with the tip of your pole without disturbing the hole.

As an example, to show how effective this sinker is in trout fishing, I will tell you about my last fishing trip. Three of us, two friends and I, went fishing. One of my friends used split buckshot, and the other fellow used no sinker at all. As usual, I used a piece of tinfoil. As a result, the total catch of my friends was three trout, while I caught twelve beauties.

\section{WAXING SILK THREADS FOR ROD WINDING}

\section{By Julius Frank}

For you who rewind and you who make your own rods complete, give heed to an easy and effective manner of waxing your threads.

Having almost completed a 5foot casting rod of bethabara, I suddenly remembered that the light, gaudy colored threads on a split bamboo rod which I rewound last winter were now dark and dull. I began formulating a plan to overcome this deterioration in the threads. I knew of the time-worn method of drawing the 
threads through light colored bees' wax, but natural bees' wax, no matter how light, always alters the color of the threads and only waxes the surface. Remembering that wax is soluble in gasoline, I finally decided a scheme that not only preserves the original color, but also "sets" it permanently, waxes every fiber in the thread and makes it thoroughly waterproof.

Here is the method and formula :

Scrape one ounce of paraffine with a knife from a white candle and after allowing a small electric "disc-plate" stove to become heated disconect it (a hot laundry iron propped upside-down will do as well). Put the paraffine in a half-pint common drinking cup, place it on the stove and wait until the paraffine becomes liquid. Then add one ounce of gasolene and mix thoroughly with a spoon and allow this preparation to remain on the heated stove. Submerge the vari-colored threads which should be previously wound separately on thin, stiff, white visiting cards cut to measure 1 by 3 inches and then notched like a slung-shot stock at both ends.

Remove the cards of threads after they have remained in the mixture about five minutes. Pierce the cards with pins and hang them in a shady place in the open where the air can reach the threads. Let them remain suspended for a few hours and then upon examination you will find that the gasoline has entirely evaporated and the threads are soft, pliable and thoroughly saturated with paraffine.

Threads treated in this manner make the rod moisture-proof where wound and where, by-theby, the varnish does not touch.

I wish that you, my fellow anglers, could see my finished rod. It reverses an old adage-My Joy Forever Is a Thing of Beauty.

\section{THE KINK OF KINKS}

\section{By James R. Allen}

To quote a short passage from your kink write-up in the June number of OUTER's, "A kink is just any special pet trick that you make use of in your fishing." According to this definition, I herewith submit the dandiest little kink that ever cavorted before your serene vision. I am a young dub, just learning to get the hunting and fishing fevers each fall and spring. But I don't know a whole lot about either hunting or fishing yet. My elder brother. (the big yap) says I'm a little too new to educate yet. $\mathrm{He}$ is some sportsman. Being one, he subscribes for OUTER's, of course. And here's where my kink comes in. Each month I sneak into his den and lift his latest copy of "The Joy Book." This little stunt, together with subsequent reading of the purloined magazine's contents, has helped my fishing more than any other kink I ever heard of.

P. S.-I am sitting in my 
brother's den now, knocking this kink out on his typewriter. I'd surely get mine if he were to slip in now and catch me. But he's out in the back yard trying out his three new reels, and he won't know anything about this until he sees my fool name under the blackface head "The Kink of Kinks" at the head of the first column of your announcement of the winners for the month of May, and when he sees that I have grabbed the big prize, he won't be very sore.

\section{EXTEMPORIZING A CAST- ING ROD}

By Roger Williams

I thought I would tell you of the scheme of rigging up a casting rod which $I$ use when going to the river after working hours and do not wish to be bothered about 2 feet from the reel. Screw the bent eyelet in the end and space the third eyelet in the middle as shown in the diagram. Then I am ready for the fish.

The screw eyes want to be of small size wire so as not to weaken the rod too much where they are screwed in.

Try this stunt once and you will be surprised how slick it works.

\section{IT GOT A BIG ONE}

By A. D. Wood

Last year on the Connesauga River, North Georgia, I had an experience that might possibly take the candy in your contest. If not, it may help some other fellow to bring home "the big one" some time.

I was lucky enough to catch plenty of beautiful Rainbows ten to thirteen inches in length, but

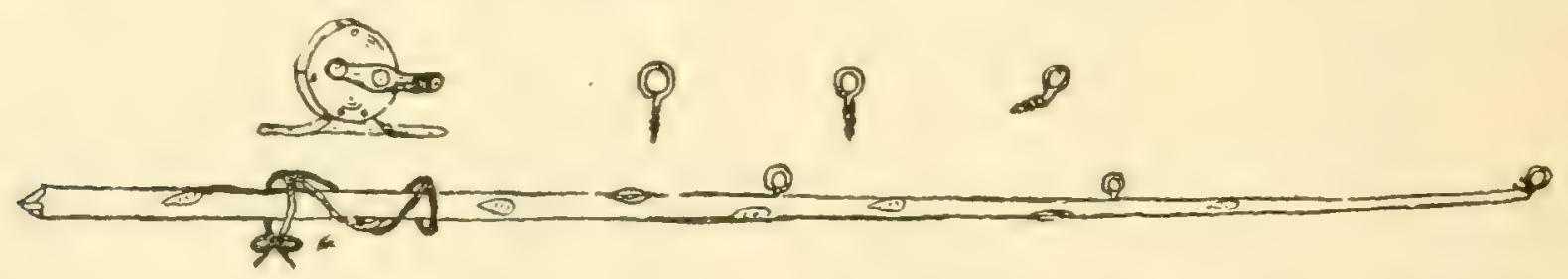

with taking tackle along. And sometimes I use this rod when I am fishing with bait and want more than one rod.

All that is necessary is a reel and three screw eyes, light weight with large eyes. The one for the tip I bend up so that it will be in line with the other two. I cut a straight stick-most generally willow-about 7 feet long. Tie the reel in place with a short piece of cord. Put the first screw eye in several deep, clear pools there were larger fish that I could not induce to strike at anything. I tried minnows without success. One day a mountaineer came down the stream fishing with grasshoppers. He fished with the hopper hooked through the body and caught small fish the same as I, but it gave me the idea just the same.

I got busy and caught about a dozen big, fat "hoppers." Then 
with a piece of sewing thread I tied a band around his body that would not interfere with his wings or legs and ran the hook under the thread so that it did not hurt the hopper at all. With this equipment I slipped carefully to one of the deep pools and tossed Mr. Grasshopper out over the pool. He tried to fly and did a little. But the hook weighed him down and in he went and up came one of the big Rainbows I was after, and the fight was on. I got this one $\mathrm{O}$. K., but I struck the next too soon and lost him. But the trick worked, and that is what I wanted.

\section{THREE PRACTICAL SUG- GESTIONS}

By George A. Wiggan

Anglers who use eyed flies and do not like to pay the high prices frequently asked for clip boxes, should try the following:

Get a flat tin tobacco box (not too deep) of the side-opening type. Scrape the paint off of this and give it a coat of tinner's varnish. Take some sheet cork about a quarter of an inch thick and cut it into strips as long as the box is wide and about a quarter of an inch broad. If sheet cork is not available, the strips may be cut out from long bottle corks. Use the smallest size brads to fasten the strips in place with. Drive the brads into the box from the outside. Then press a strip of cork over the points and clinch the ends of the brads with a tap of the hammer. Several dozen eyed flies can be carried in a box of this kind. A good idea is to solder a ring to one corner of the box and run a lanyard thru

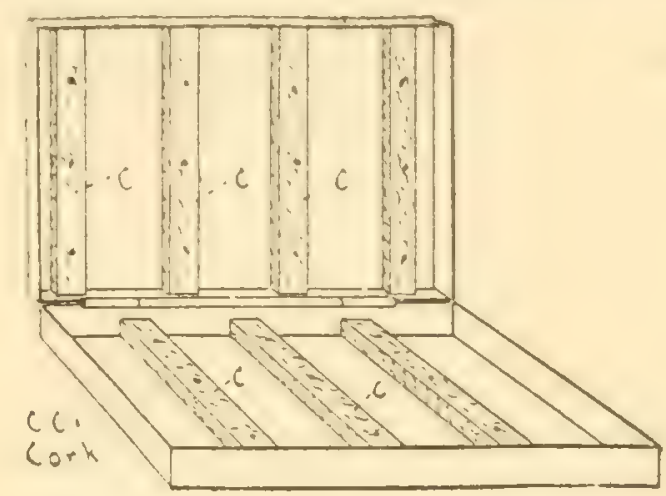

it. Hang this around your neck and you will never lose the box by having it fall out of your pocket.

Another good hunch for eyed-fly users, which I believe was mentioned some years ago in this magazine, is to fasten one of these patent finger-nail clippers to a cheap spring eyeglass holder. Stick this on your lapel and you will find it most handy for snipping off the ends of gut after fastening the flies to the leader.

Those who use minnows may welcome the following suggestion: For several years we had great difficulty in keeping "minnies" alive. At first we used a plain box with holes in it to allow the water to circulate. This would work only in deep water, because when placed in the shallows the wash soon killed the minnows. And because these little fish are essentially a shoal water species, the pressure of the deep water likewise affected them unfavor- 
ably. Then we tried using two boxes, one inside of the other. This worked better but was not yet entirely satisfactory, altho we were on the right track. Finally we disccvered that by tacking a triple
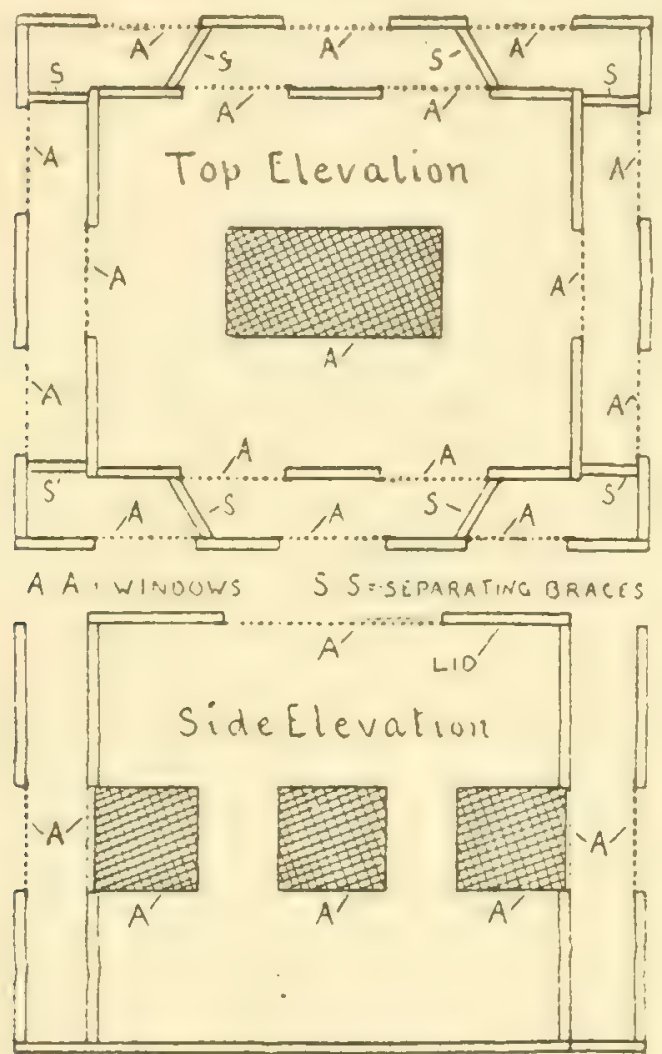

thickness of cheesecloth over the windows of the outside box the force of the waves was effectively broken and the minnows remained alive and fresh for days.

The outer box should be about 36 by 30 inches; the inner one 30 by 24 inches. Nail inch blocks of wood between the boxes to keep them apart. The inner box should have two 6-inch windows on each side and one on each end, covered with wire gauze. The outer box should have three windows on each side and two on each end. Cover these with wire gauze, then the triple layer of cheeseclcth and then another piece of gauze. If you have ever bought several dozen minnows at night and found them all dead in the morning, you will appreciate this box after a trial.

\section{A NOBLE USE FOR THE COCKROACH}

By C. E. Moyer

Here is a kink that I am sure will bring more pleasure to your readers and more fish to their strings than any you have ever published.

It is a live bait for perch. The bait consists in a common cockroach hooked from the under side with a very small hook. A No. 26 Cincinnati bass is the best hook I have tried. One BB split shot for a sinker and a porcupine quill for a float completes the best rig for perch ever used.

The roach is alive and kicks for several minutes. He will live for some time if lifted out of the

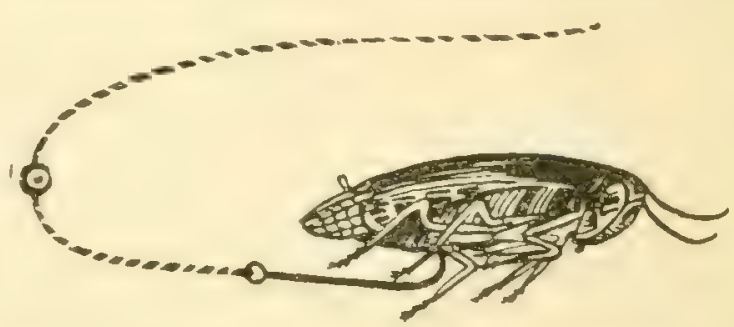

water so he can get air occasionally. He won't stay under the water very long if there is a perch in sight, and the largest perch always gets to him first.

Down here in Arkansas we have a small mouth perch called bream. $\mathrm{He}$ is just foolish about roaches. He averages about the size of a man's hand and no fish is sweeter 
when he comes from the frying pan. Roaches are also good bait for croppie, goggle eye perch and catfish.

I have known roachès to sell for 25 cents a dozen. I recently caught 46 bream which weighed 16 lbs, in one hour and a half. Another fisherman using red worms could not even get a bite, though his boat was almost touching mine.

The roaches are caught in grocery stores, butcher shops, restaurants, etc. Most anglers use regular screen wire roach traps, which can be bought at any hardware store, at 25 cents each. Bait them with raw potato and set where the roaches pass along the walls. They may also be caught in a slick new tin pan. Put raw potato in the pan and place a piece of cardboard for them to walk up on. They drop off into the basin and can't crawl out, and if they are thick you will have a hundred each morning.

They can be kept for days and weeks if fed liberally on raw potato. A damp cloth should be used to supply moisture. All varieties of perch will bite them more liberally than any bait I have ever used and you very seldom miss your fish.

\section{AN EMERGENCY LEADER}

\section{By M. A. Gurney}

By tying an ordinary single knot, as per diagram; then spreading points $\mathrm{b}$ and $\mathrm{c}$ and pass- ing loop $\mathrm{D}$ between them at point shown by arrow and drawing tight ends $A$ and $B$, you will have duplicate of the editor's "Middle Branch" knot. We used to call this a half hitch jam knot, though I was mighty glad to see it again, for it never occurred to me as just the thing for a dropper loop. And even though others may

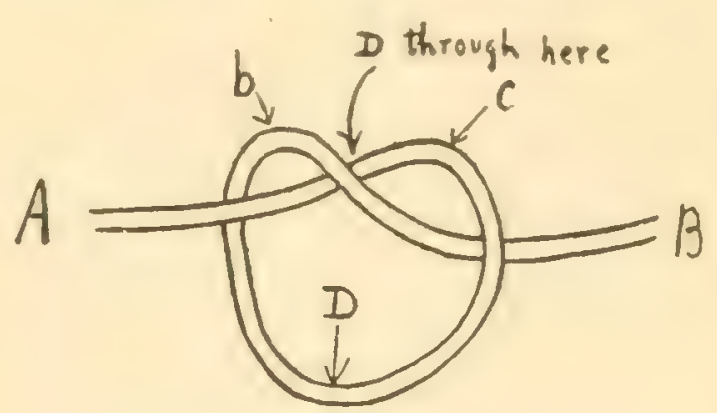

know the knot (though not your own way of tying it), I am sure bringing this new. use for it to their attention will be appreciated.

Here's a new wrinkle or mayhap an old one; but I dare say it is young, if not new, because the material has been on the market but a few years.

About three years ago I was fishing near a town about the size of a postoffice, general store and (of course) a saloon. During the day, through a mishap I lost every leader I had, even to the one I was using. I was surely up against it. Finally I mooched over to the general store, but just because I wanted a leader they didn't carry them.

That evening I was telling my troubles to a fellow trout fan, when he laughed and told me he 
could stake me to 10 yards of emergency leader for 10 cents, and he did.

From out of his tackle box he fished a spool of dental floss. Yes-it's silk-paraffined I guess, about size $\mathrm{H}$ or No. 6, and 9,999 lbs. test. Maybe a few pounds less, but anyway so strong you, I or the other fellow cannot break it without cutting our hands.

Did I use it? I did. And ever since, on any color water, you will find my dental floss leader at work. Best of it is, any old or young drug store carries it. Again, if you want to surprise yourself and are fishing a stream where one cannot cast (it's too light for casting), why tie two of the 10-yard lengths together and use them as a line. Hook a threepounder and I'll bet a nickel against every red beauty spot on him that he'll think he's on the south end of a tow line. No, he won't break it. Come over where we fish and I'll prove it. Of course, 20 yards or 60 feet costs one 20 cents, hence it might not be in keeping with a $\$ 30$ Leonard. Still, it's some leader and some line.

\section{THE COTTER PIN EMER- GENCY TOP}

By Dwight Harris

One day while on a week's fishing trip I happened to lose the tip joint of my favorite steel casting rod. As I did not want to miss a lot of fun, I decided to see what I could do about it. Rum- maging around in a box of old nails, screws and other junk, I found a cotter pin. Immediately an idea came to me. Fastening the cotter pin firmly by the ring end, I bent the shank to an angle of about 75 degrees. (Fig. 1.)
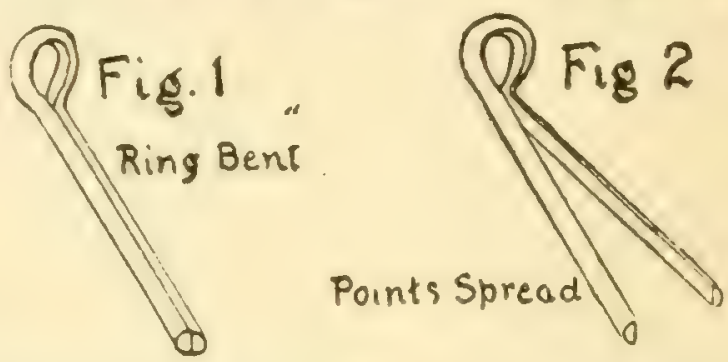

Then I sprung the points slightly apart (Fig. 2), and put my "emergency tip" in place. It really worked surprisingly well until I could obtain a new tip joint.

\section{A TROT-LINE KINK}

By George Krumsick

I take pleasure in passing on a little kink that I have found to be of much value to the trot-line fisherman. You realize that the average fisherman is not a fly or wooden minnow expert and depends upon the faithful old trotline for his "meat" when he pulls up camp. The trick I have discovered is in preparing the trotline staging in the manner shown on the rough sketch accompanying this letter. I make my stagings twelve inches long, and, in addition to trying on the hook in the usual manner, I split a wine bottle cork cn one side and draw the staging through it, leaving it about four inches above the hook. When the trot-line is set, the cork float holds the staging off the bot- 
tom of the river and puts the bait where it can move with the current and where the fish can see it. A trot-line staging fixed in the old way lies flat on the bottom of the river and often the minnows or crawfish used for bait get under small rocks or leaves with the hook and fish never find them, so that the fisherman comes to the conclusion that fish are not biting. Frequently when minnows are used for hait, crawfish chew them off and the fisherman thinks gars or other fish have stolen the bait. A staging held up with the cork a thick cushion in your pack, which is always so full anyway, is not to be thought of. Therefore, a stuffed seat cushion generally gets left at home on account of space.

I went to the carriage trimmer and got a piece of buggy top and made a cushion 12 by 14 inches. Sewed it all around except one end. which was left open, and in this open end holes were punched at intervals for shoestring lacings. This now folds flat and takes up only a little space, and when I get to my desti-

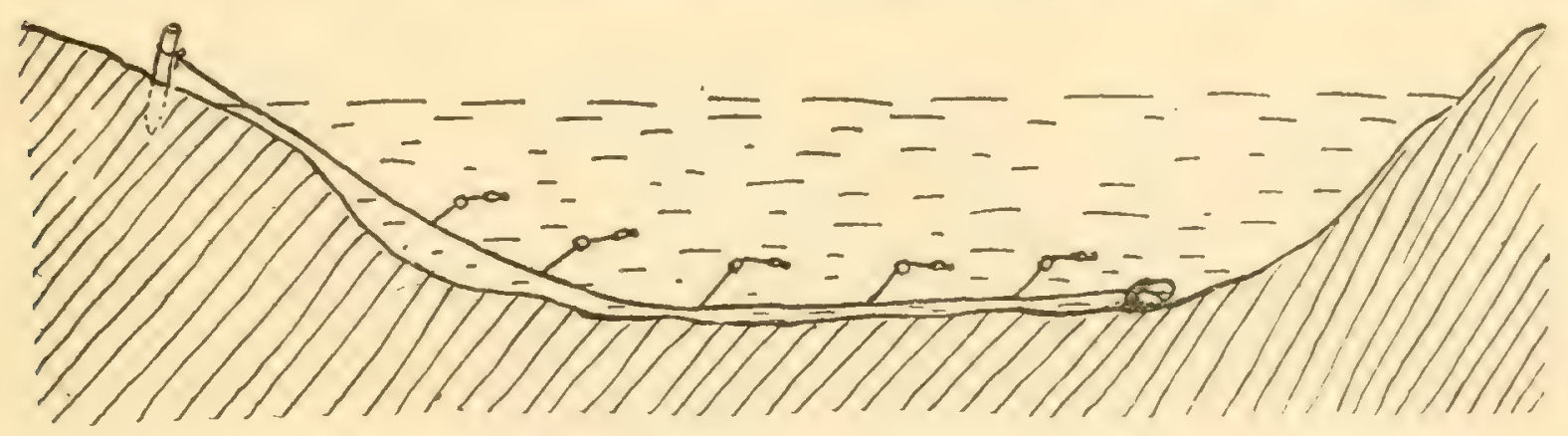

float swings free and every bait is visib!e. Fishermen who will try this will find that trot-line fishing will give them far better results than the old way.

\section{A BOAT CUSHION}

\section{By J. W. DE Long}

I expect a good many who, like myself, go fishing for a couple of weeks trip at some distant point, find that a boat seat gets awful hard on the upper side after a few days fishing without a good cushion. Air cushions, when you want them, always have something wrong-at least such has been my experience, and to put nation I fill it up with dry hay or excelsior or balsam boughs and lace it shut like a shoe. After a few days if it gets too flat, unlace it and fill it up and you have a dandy.

\section{LEADERS FROM HOOK SNELLS}

BY C. M. BYERLY

Here is a kink I have by which I make gut leaders from the snells of damaged hooks. First, remove the broken or damaged hooks. Then, soak the snells in water a few minutes or until they are soft. (If you try to tie them dry they will crack or break.) 
Then lay them as in Fig. 1, and tie a common knot in each and around the other, as in Fig. 2. Pull both knots tight as possible; hundred fish with this outfit. I can make them up for anyone very cheap, but any handy man can make it. I am not a sub-

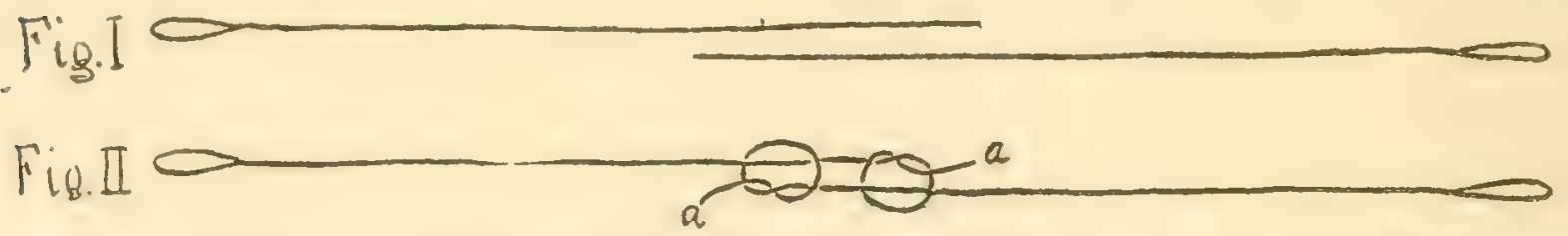

then pull them together tight and cut off the ends (a) close to the knot.

I now have a gut leader with a loop in each end and about 12 or 14 inches long. Two of them may be looped together, making once twice as long and so on till I have a leader of the desired length.

By using my old leaders this way I always have a good leader, free of all cost and also the satisfaction of making them myself.

\section{A GOOD SPINNER RIG}

By CHAS. O. REED

I am enclosing a pen description of a three-hook pork-rind spinner bait. I have made several of these, for bass, muskie and scriber to your magazine but I never miss a copy when it arrives at the news stand.

\section{A HOME-MADE ATTRACTOR}

By George Morton

Cut two and a half by threeeighths inches from a sheet of German silver and drill a small hole in each end for split rings. Round both ends with a file and then curve same, as illustrated. This can be accomplished in the hands without tools, and is very difficult to straighten out again by any pull or strain. Finish same by giving a brilliant polish (this is easily done with any metal polish).

In conjunction with this, get a
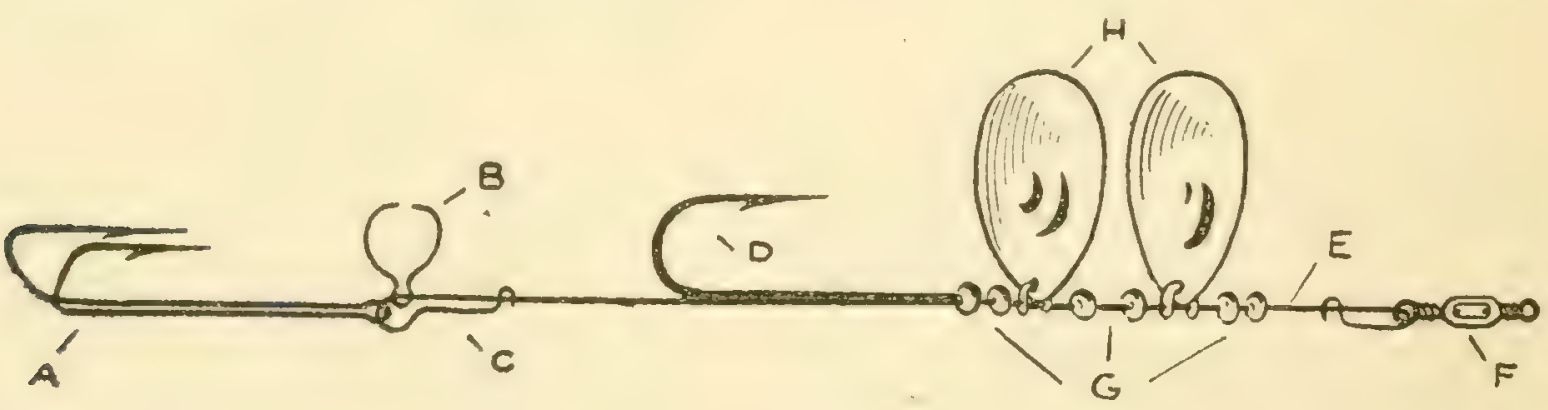

trout. They have no equal. Can be made in all sizes, both of spinners and hooks. I have in the last three months taken over one long shanked eyed hook (not too springy). Then wind on a small lip hook close to eye of the large one with both barbs in line (as 
illustrated). In using pork rind on these hooks, cut strip twice the length of the large hook and about one-quarter inch thick. Hook the middle of the rind on the small hook and let it hang down alongside of the large hook. This method will overcome the losing of fish on short strikes, as the hook is at the tail of the rind and rides between same with the barb upright, making it also weedless, while the spinner will impart found the lure had the same charm with the bass, pickerel and perch.

\section{AN EXCELLENT CRAPPIE BAIT}

By A. J. Hunter

While fishing a crapple bed last week I discovered an excellent substitute for the minnow. I had used my last minnow, and as they were very hard to obtain I looked

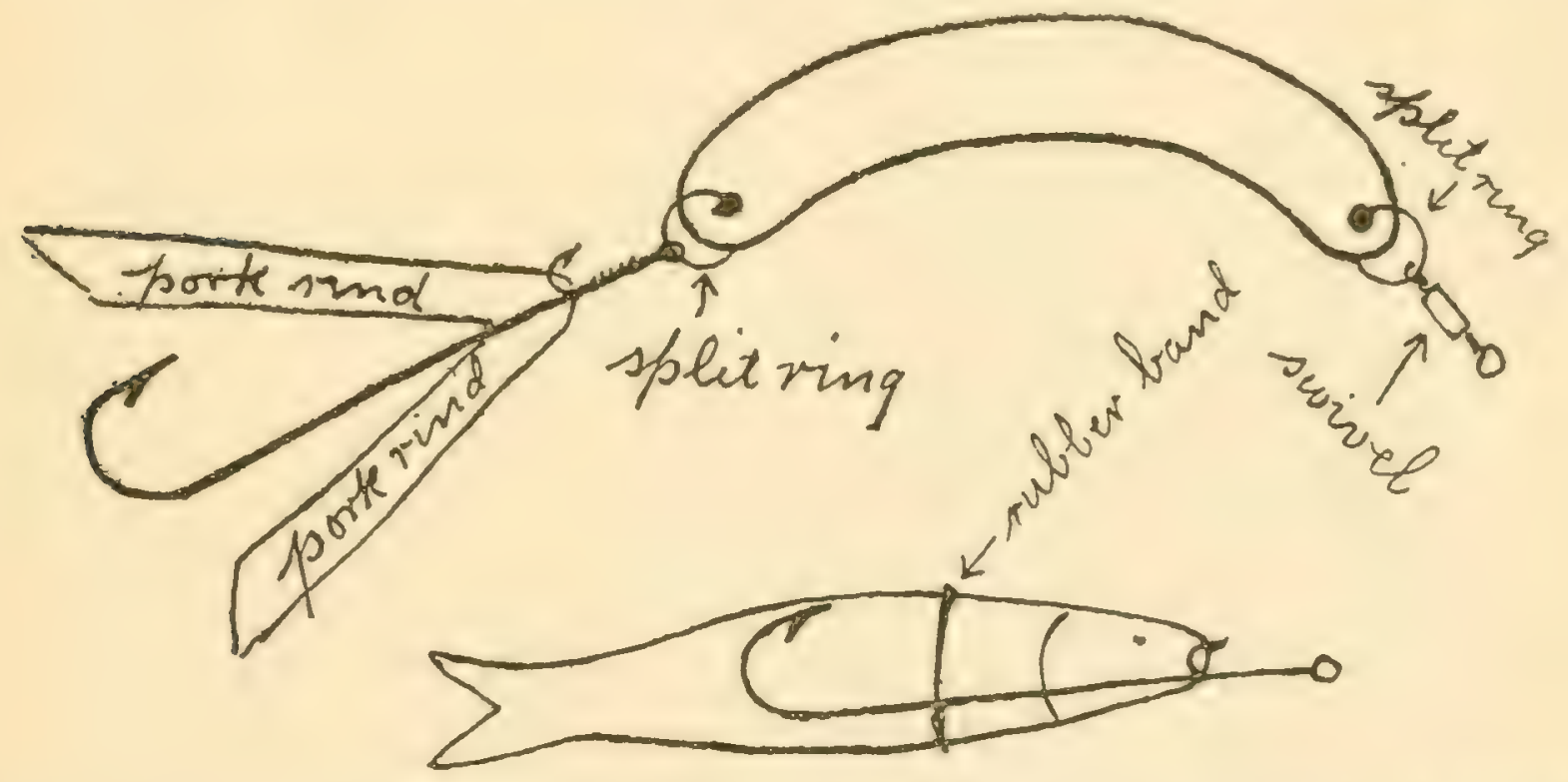

to the rig a wiggling, wormy action. They can't resist it. This rig can also be used with dead or live minnows by inserting small hook in lips and fastening large hook alongside of minnow with small rubber band (as illustrated). A fiy can also be used.

My first experiment with this rig was in salt water on blue fish and it was such a wonderful success (and grand sport with baitcasting outfit) that I have sold many by request. This induced me to try it in fresh water and I around for a substitute. I struck an idea that worked. Here it is. On the lower jaw of any fish you will find, at a point running from the forward tip of jaw to a point where the gills almost meet, a long thin piece of very tough white skin. Take your pocket knife and cut this out. When putting on hook be very careful not to stick yourself with hook, as this piece of skin is tough enough to make it hard to put a hook through it. When put in the water and moved to represent 
a minnow it makes an excellent bait. I caught twelve on one such bait. Hoping this will help some brother angler out of a trying situation I submit it to the kink contest.

\section{REST YOUR BONES}

\section{By A. W. Summers}

If you have two bucks that you can spare (and what enthusiastic disciple of Walton hasn't, if he has to steal it?), buy a fourteeninch red rubber invalid's ring. The only regret you will have is that you didn't do it sooner. It has as many uses as a pocket in a shirt. After you have sat on a hardwood plank in a boat for about three days, haven't you wished you had a Silver's recoil pad on the seat of your pants? The rubber ring will have the same effect.

Then when you made that extra long cast and fell out of the boat, or went under an overhanging snag and were scraped off, wouldn't a life preserver be about the finest thing you ever took hold of ? The rubber ring will support any man in the water. Then when you hit the hay and make a stab at wooing Morpheus but find that the buttons in the pants you are using for a pillow persistently come to the top and double-cross you in your wooing -take your rubber ring and find that it isn't half bad as a pillow.

Slip each arm through one and let rest on the shoulders and you will find that you can hardly get them off in the water unless you are a contortionist. A woman that never swam a lick can swim for miles with two of the rings arranged in this way. In case of sickness they come in handy. I heave heard they are one of the finest things in the world in a long drawn out session of the great American game of draw poker. (This latter suggestion will probably be of no use to a fisherman.) In a forty-mile ride in a buckboard and on numerous other occasions you will find it worth the money. It will take up about the same room in your tackle box as a reel and will go in a much flatter space. On the whole there are only a few things in my tackle box that are more prized than my cushion. Buy one and if you do not like it you can cuss the Editor all you like.

\section{THE FISH KITE}

\section{By M. A. Wright}

Several years ago when on an outing trip in northern Minnesota I saw an old gentleman fishing from the shore of a small lake. $\mathrm{He}$ was walking along the shore holding what looked like a hand line, but it seemed to stay out in the deep water and not drag to shore as one ordinarily does. On a little closer observation I found that his line was tied to a block of wood that seemed to have a peculiar way of staying out from shore. 
I approached the old gentleman and asked to examine his outfit, and also what he called it. $\mathrm{He}$ told me it was a "fish kite," and pulled it in for me to see. Although his kite was very crude, it had the right principle. I have one like the drawing and find the following good points in its favor when compared with casting: You have your bait in the water all the time, and at the desired

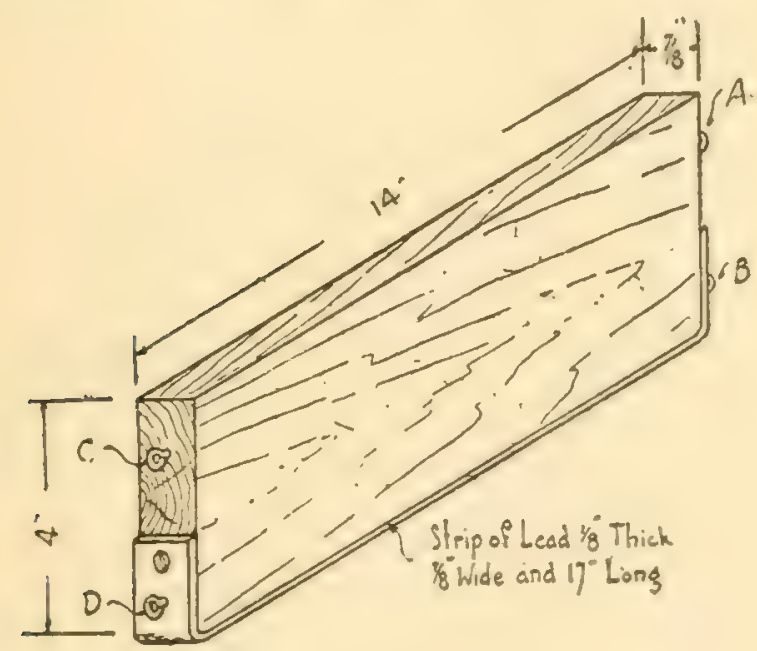

THE FISH KITE

distance from shore rather than fishing, crosswise on a strip of water, as in casting. One can troll a greater distance from shore than can be done with the longest cane pole, nor does it disturb the water as much as a boat. It is very convenient to carry, as the lines may be wound around the kite and the whole thing put in a coat pocket. The block should be of white pine or cedar and painted most any dull color. Nearly any kind of bait may be used, such as spoon hook, wobbler, minnow, frog or worms.
The belly-bands are tied from screw eyes $A$ to $D$, and from $B$ to $C$. The tow line is tied to the belly-bands a little closer to $C$ and $\mathrm{D}$ than to $\mathrm{A}$ and $\mathrm{B}$. The bait line is tied to D. The belly-bands and tow line should be adjusted so as to make the kite ride vertically and with the front end of the block farther from shore than the rear end. The kite should float with the top of the block about

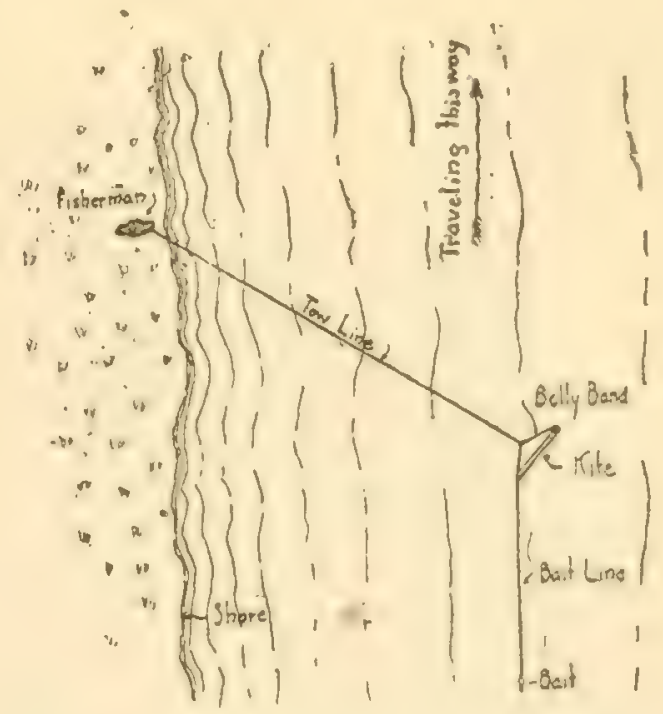

one-half of an inch above the water. The lead weight may have to be added to or lessened to get this result, due to the difference in the weight of different pieces of wood.

\section{A PARTNERSHIP KINK}

By H. S. BASSETT

The Kink Contest reminded me of a little experience I had while fishing with my friends, Alva Jones and W. H. Fry near Sullivan, Ill., late last season in the Okaw River, and I think you 
will agree with me in calling same a kink.

The Okaw at this point is not less than 125 feet wide and in trying for a likely "bass spot" near other side, my Shakespeare Yellow Perch hung on a submerged $\log$ in the center of the river. I of course tried various expedients to release it, but with no success. A few days before, I had hung up in practically the same manner and, hating to lose this favorite bait, I undressed and went in and got it. This time, however, both atmosphere and water were very cold, and I hesitated about going in, and sat down on a log to study the proposition over.

While sitting there I naturally put my hand in my pants pocket and encountered my ring of keys. It was then the idea was born. I yelled to one of my friends to come back opposite to me on the other shore. When he did so, I asked him to tie a heavy sinker on his line in place of his bait and cast it to me. This he did. taut line. Say, there was "nothing to it." That ring went direct to the minnow and disengaged it. I reeled it back, returned his line. I then put my keys back on the ring and in my pocket, and was happy, at least for that time. 1 got several bass that day, but that was the only time during the trip that we needed the kink.

\section{CASTING THE LOOP KINK}

By M. P. KeEFE

How many times, when fly casting, have you had your favorite fly or fly spinner snag in a pool that you did not wish to disturb by wading into? Or perhaps the pool was too deep to wade to where fly was caught on rock or

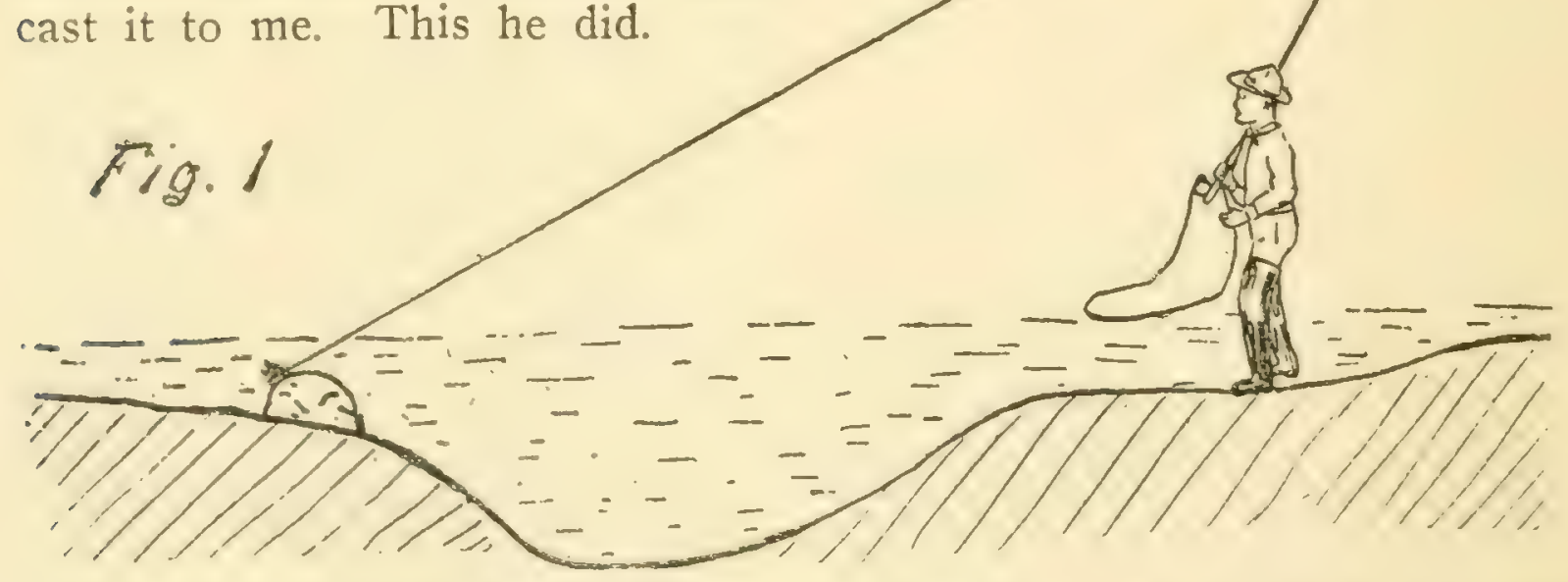

I then took my keys off the ring, put ring over my line, tied his line to it and asked him to reel in, I at same time keeping a gravel (or log, if hook is not in too deep).

Well, the next time you have this happen, try this kink: Draw 


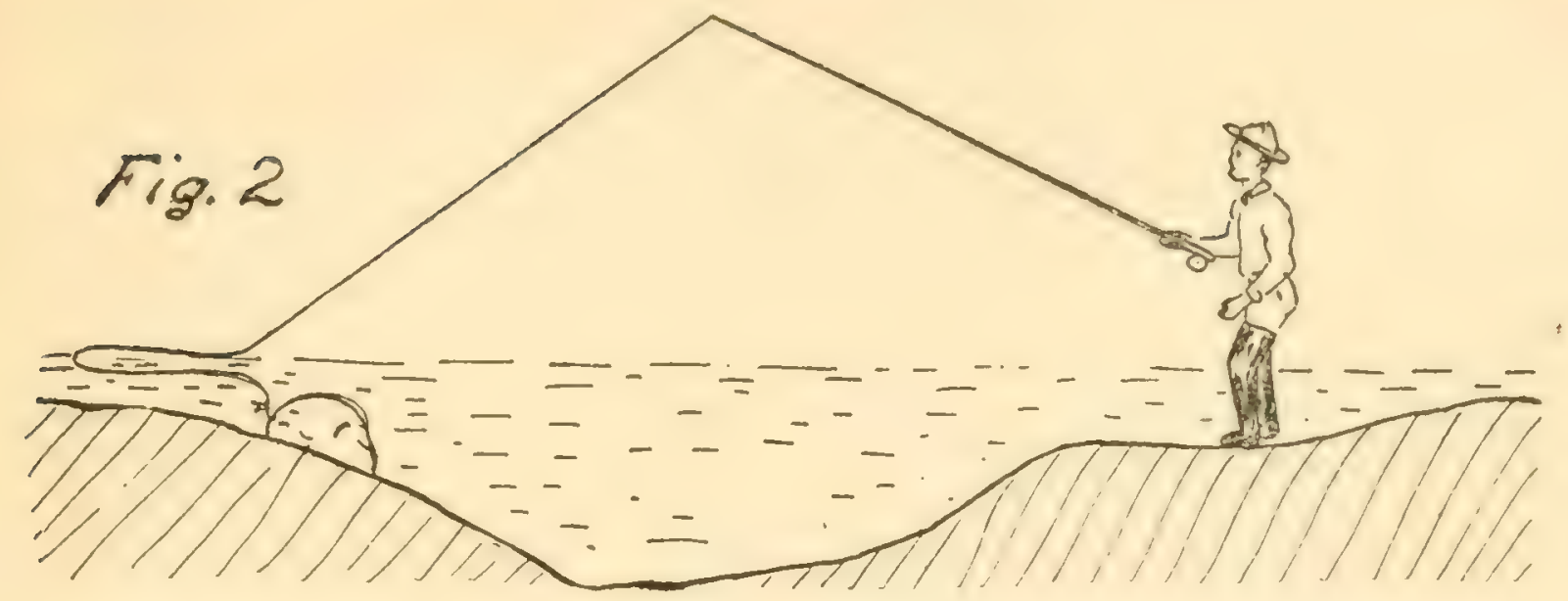

from reel 6 to 8 feet more line than it takes to reach snag when rod is in position for forward cast (Fig. 1). Cast forward sharply and line should land at least 3 feet past where snag is.

Now, let the line sink in the water a little. This is to get more friction from the water than if you should not let it sink. (Fig. 2.) Then retrieve line as in any back cast, only use a little more power than ordinary. (Fig. 3.) Your fly or spinner will

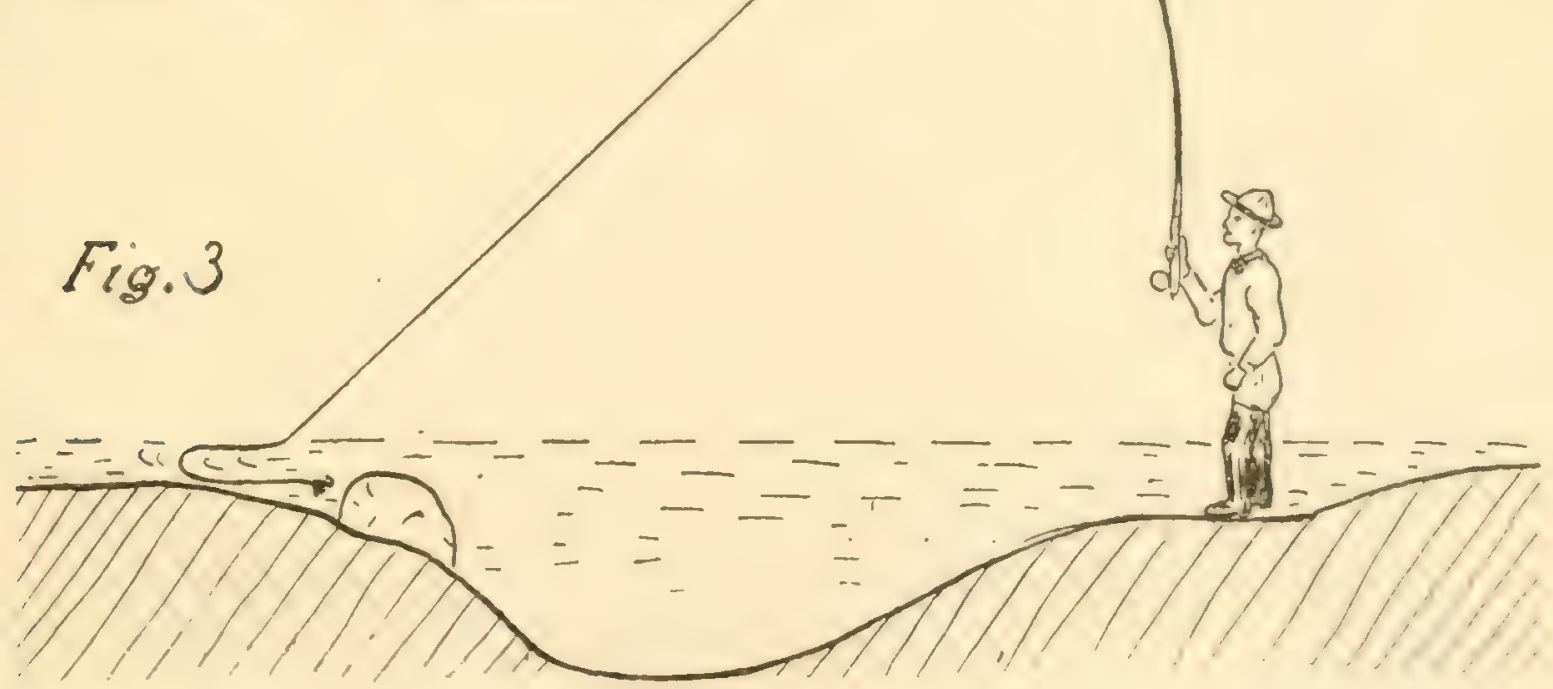

have saved many a fly and flyspoon by doing so.

\section{A KINKY LINE}

\section{By M. B. Anes}

Without doubt you have become more or less careless at times when trolling with two or 
times. When you attempt to reel in you get tangled more and more until you feel like throwing lines and all overboard. This is what happened to IVes. and me this spring while trolling for salmon in Sebago Lake, Maine.

We had had some good fishing and were trolling with three lines out when I got one of those "Dandy Strikes" (which we landed). In the meantime Wes. started to reel in the extra lines, which had become completely twisted and kinked, and you know what that means.

After landing the salmon and the excitement all over, for the time being, the next thing was, "Look at that line!" Fussing awhile with it, Wes. suggested going ashore and unsnarling which would take an hour or more. But having been in about the same mixup many times before, I suggested this old method of mine.

We took off everything, including the leader, from each line, and ther very carefully dropped the lines overboard into the water. As the boat was moving all the time, of course, it trailed behind. After putting it all out, each of us took a rod and began reeling in slowly, letting the twisted line unroll itself in the water. In a few minutes our lines were all reeled in ready to be fastened to the leader and resume fishing.

Hope this kink will be of use to some of the new fishermen if not to older ones, as it is a "life saver" for the lines in many cases.

\section{A KINK SPREADER}

By Chas, Forsyth

One day last spring the catfish were biting real well. Indeed they were swallowing the hook down into the stomach in the majority of cases, and not having any hook extractor, I came home at night with my fingers all chewed up. This was not the first time I have had that happen taking fish off the hook, but it was about the worst; so I set about to try and invent some way to obviate the trouble and save my fingers, and turned out the following simple little article that will do the work on any kind of a Eish.

The accompanying cut describes the "Kink Spreader" as well as words.

It is made from a rather heavy piece of spring wire, and as for size, is made according to the size of fish you are catching; the bigger the fish, the bigger the spreader has to be. The one I made for fish up to a couple of pounds is 6 inches long from A to $\mathrm{B}$ and $13 / 4$ inches wide at the loop A, with points C-C turned up about $1 / 4$ inch. These points want to be sharpened some, but not enough to pierce the mouth.

To use same, when your fish swallows the hook into the stomach-which quite often happens at certain times, especially with a catfish-press points together and insert inside the lips, let loose, and the mouth will be spread open 
to full extent, giving you plenty of room to get your fingers down inside and extract the hook. With the spreader in place, it is impossible for the fish to close its mouth and lacerate your fingers.

Another thing I find it quite handy for, is in cleaning the fish. You all know a fish-especially a cat-is rather an awkward thing to hold to, and more so, if they are alive. I always insert and hold to the spreader, then they can be them much in our local waters on account of the carp. These latter are hogs for the fat juicy lumps of crab meat.

Carp fisherman should try this one. Take a nice deep eddy and place your bait about six feet beyond it in the current. You will have better success than in dead water, as the fish prefer to feed on the edge of the current. Another thing to remember is that no matter how hard a carp hits
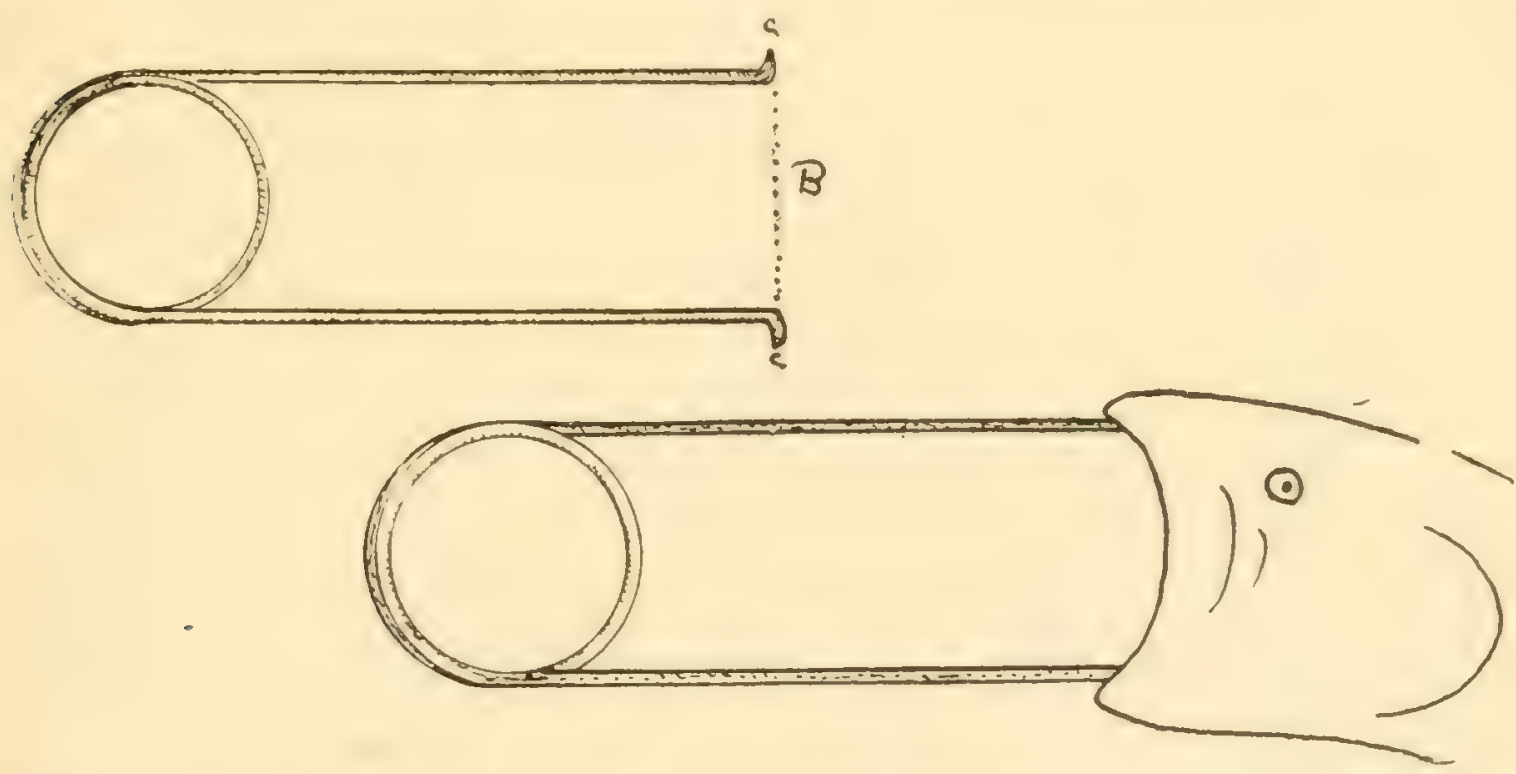

washed and their heads cut off with ease, and I run no risk of being stabbed.

\section{LIVE BAIT WISDOM}

By Fred RUPERT

For river fishing there are practically only two kinds of live bait that will stand the pounding of a good many throws and still remain ir: serviceable condition. These are the soft shelled crab and the helgramite. Of the two I prefer the crabs, but do not use the bait, never strike him until he runs. This rule also holds good in bass fishing.

In fishing with helgramitesfirst catch your bait. There are several good ways of doing this. First, if you have plenty of money, use some of it. Second, buy about six feet of wire screening with a quarter-inch mesh. Fasten this to sticks at either end, the same as with an ordinary net. Stretch your screen across below where you think the bugs are and rake the bottom down stream 
towards the net. The current will carry them into the net. Third, use your hands, but always turn your stone against the current.

There are a dozen ways of putting the helgramite on your hook. The best one I believe, is to turn the hook sideways and slip it under the collar. (See sketch.)

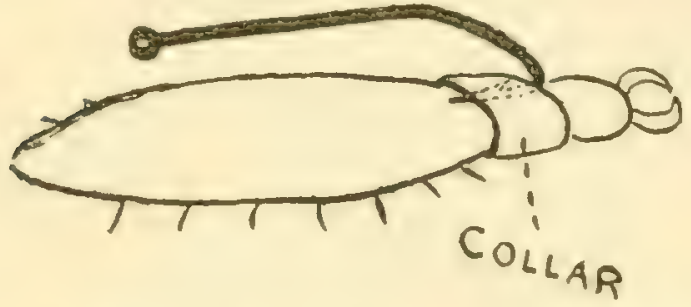

This keeps the barb of the hook from tearing the bug, and they are in better condition for use. I have several times caught four and five bass on one helgramite hooked in the manner described. And don't forget to move your bait every two or three minutes. Otherwise you may find that it has crawled under a stone.

I have kept helgramites alive two and three months at a time by filling a minnow bucket half up with dry, rotten wood and then putting in the bugs. Keep in a damp cool place (the cellar is good), but never put the bugs in water again until they are on your hook.

\section{SKINNING THE CAT}

By Charles W. Carter

"There is more than one way to skin a cat." So the old saw says. But as it does not tell of even one good way, I always considered it a perfectly useless old saw. What is true of cats in general is true of the catfish in particular. There is more than one way to get his hide. And I am going to go the old saw one better by giving the one best kink for skinning the cat with neatness and dispatch.

First, whittle a hardwood peg the size and shape of a pointed lead pencil. A meat skewer from the butcher shop does very well. If you are going to have much use for it, whittle it from a broom handle or a hardwood stick of similar size, leaving a comfortable handle on one end. (Fig. 1.) Next, with the point of the knife slit the skin of your cat from head to tail into convenient sized

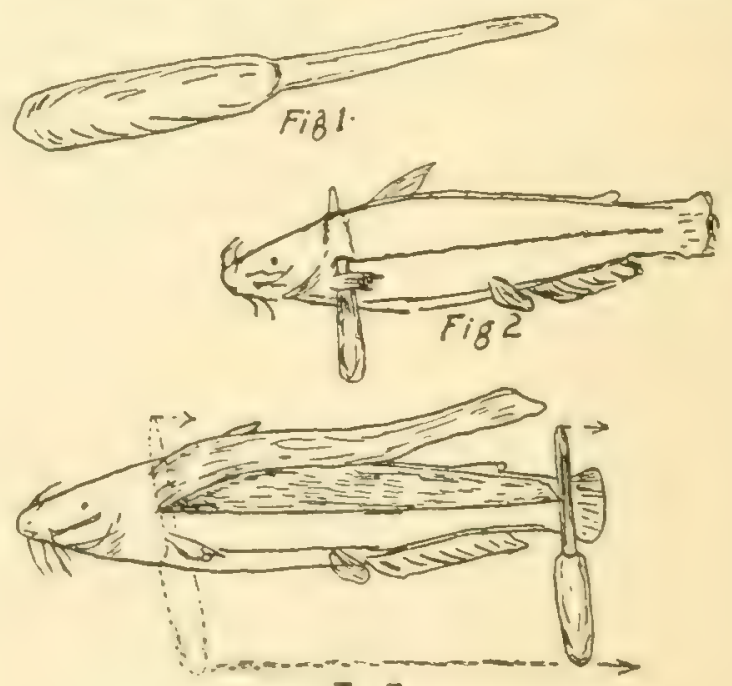

$F_{18} 3$

strips. Then holding the head of the fish in the left hand, thrust your peg through under the skin next the head, entering at one slit and emerging at the next one. (Fig. 2.) Now, holding the head firmly, move the peg quickly from head to tail with the same motion you would make in cutting a long 
shaving from a soft pine stick. (Fig. 3.) You will be surprised at the ease with which the strip of skin is removed. Treat each strip in a similar way, twist off the head, pull out the guts and your cat is cleaned.

Next, roll him in corn-mealbut you know the rest.

\section{GOING LIGHT}

By James A. Heller

One of the things which appeals to the caster of artificial baits is the facility with which he can pick up and go. He does not have to
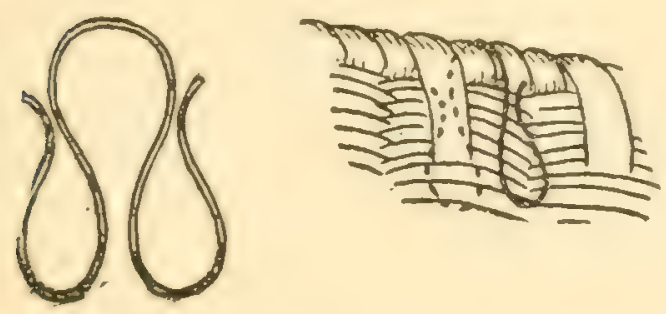

spend a day getting bait or lug around a lot of paraphernalia for getting it before he can start fishing. Just puts a couple of plugs in his creel or pockets and starts. But hold, I said a couple. I will take that back. There was a time when that was true, but now the up-to-date caster starts out with a remodeled edition of his father's tin cash box, which is not much better than a bucket of live bait when it comes to carrying it a few miles.

Now, by spending a few cents for some wire and cutting in lengths of say five inches and bending it as per sketch No. 1, these little wire hooks can be pushed over the rim of your creel and do not in any way interfere with the closing of the lid. You can hang a number of your baits on these little hooks on the inside and when you start fishing you can hang what you think you are going to use on the outside. (see No. 3). You will be surprised at the number of baits you can carry this way and the ease and rapidity with which you can change from one bait to another.

For a permanent attachment you can make little wire rings (see No. 2) and fasten around the rim.
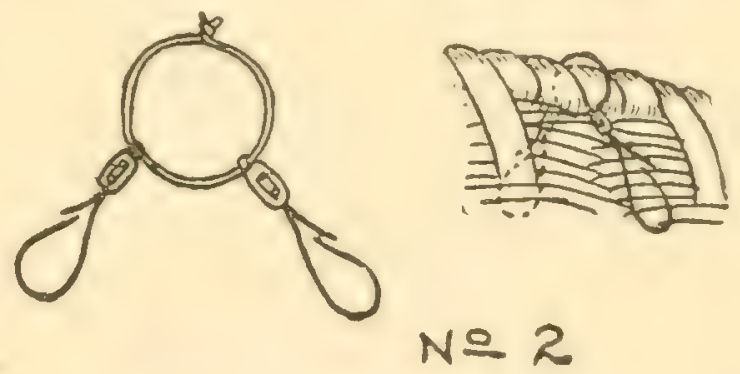

To these you should attach a small snap swived to which the bait can be attached and there is no chance of their being lost.

\section{A SURE HOOKING FLY}

By Geo. C. Knaur

Here is a kink that I hope will interest some one. Many bass strikes are lost on flies on account of the hook slipping between the jaws of Mr. Bass. If the hook has a sneck bend to it it's less apt to happen than with a straight hook. I have found one way to be sure of hooking Mr. Bass if he strikes the hook. 
Here it is: Take a treble hook and a small one so that the eye won't slip over the barb of the fly hook. Melt or file the solder off, releasing the third hook. That will spring over the fly hook and insure most any strike you may get. Then it is up to you to land your fish.

\section{A KINK ON FISH TRANS. PORTATION}

By George Raveling

Have you ever taken a trip to some isolated lake, fished for a couple of days and captured a fine mess of the finny beauties and on the morning of departure turned them all back out of your live box into the lake on account of not being able to procure ice, and a pail to carry them in, or because both were too cumbersome to handle while changing from one train to another?

Most of us have, however badly we have wanted to take just a mess home to our family or a couple to pass along to some doubting Thomas who seemed skeptical about our tales (tales, mind you, not tails), of what we caught. Here is how I succeeded in taking a nice little bunch home without being cumbersome and without ice on a warm June day, although the location of the fishing waters made it necessary to travel all day and make five changes en route.

First the fish were gutted and gilled and washed clean inside and out. Then the insides were stuffed with green cottonwood leaves and more leaves spread upon several thicknesses of paper upon which the fish were placed, and another layer of leaves over the fish. Then the bundle was rolled up, being careful to overlap the ends, and several more papers wrapped around the outside.

The package, upon being unwrapped after the journey, disclosed the fish in as fine shape as when they left the lake; and let me tell you, they look real tempting in a bed of nice green leaves.

If leaves are not available, good clean slough grass will serve the purpose just as well.

\section{THE PORK RIND FROG}

BY W. T. LEROW

Have you ever been fishing and after using every bait you had in your tackle box and getting nary a strike, had a farmer boy come rowing by with a string of fine bass and pickerel? What bait was he using? you ask. Just a common frog. Do you remember how you frantically rowed to the shore in search of some frogs and found plenty so small they still had the pollywog tails? There was just one frog of the right size for casting and after a mad scramble he got away. Well, I was in the same fix and I wanted fish because the folks at home would have the laugh on me if I 
didn't bring home at least one fish.

I sat down to think out how I could get a frog and at last the happy thought came-I would make one out of pork rind. I cut a piece of pork rind $3 \mathrm{~T} / 2$ inches long, 1 inch wide and $3 / 4$ inch thick. I cut it thick so it would weigh enough to cast well, but I cut down some and rounded it so it would be as near like a frog as possible.

I then cut a V (see Fig. 1) $13 / 4$ inches from one end, that left two streamers for the hind legs. Next make two cuts $1 / 2$ inch deep at the other end running the length of the strip. These are for the front legs; then shape the head to suit yourself, also the sides so they have the right curve.

Then try out your frog to see if it casts well.

In trimming up your frog don't cut away too much until you see if it casts well. If it is too heavy it is easy enough to cut away some more, but if it is not heavy enough you will have to make a new one or use a weighted hook.

I use a Stanley Weedless, either with or without a spinner, and mostly without a weight. With the Stanley you can cast in the lily pads and rushes and hook and land a fair per cent of the strikes.

The first time I tried the Pork Rind Frog I didn't have much success, so rowed 'way back in the lily pads near the shore and I took some of the green scum and rubbed it on the Pork Rind
Frog to give it a froggy color. Then I tried it out again and had fair success. You can take a little of the scum and rub on every

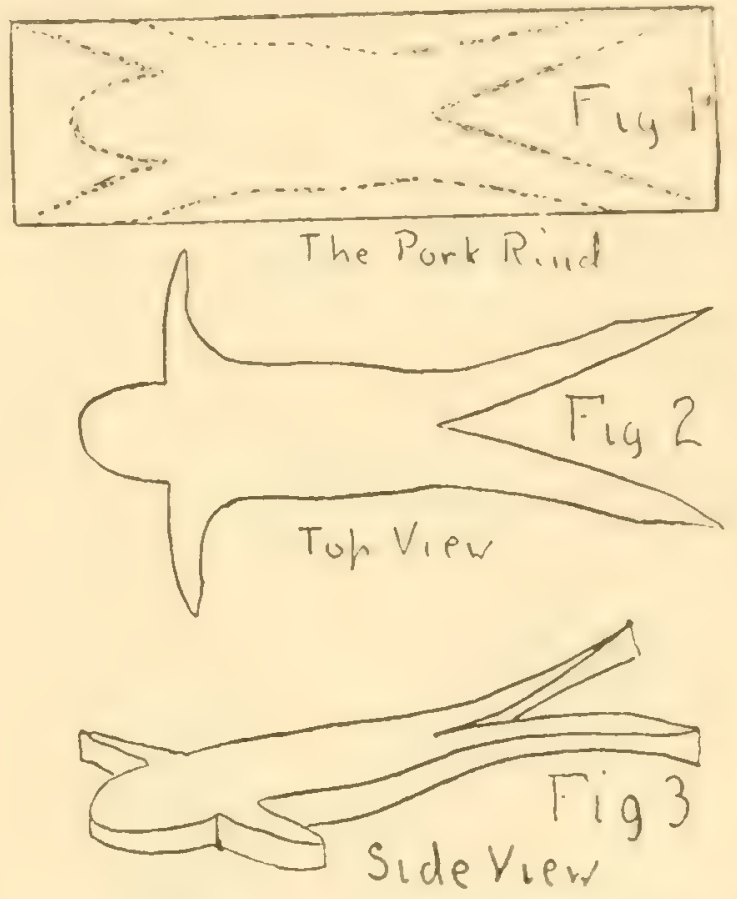

little while as the casting wears the color off.

While the Pork Rind Frog will catch fish, it is not quite as good as the real thing, but a few fish is better than none.

\section{FIXING MAD TOMS FOR BAIT}

By W. C. Money

Speaking of kinks, how many of you black-bass fishermen have put a nice lively mad-tom (catfish) on your hook, made your cast to a likely looking hole and let it stay there for a while, wondering why the fish do not take it? Then you get tired of waiting, try to reel in your line to change holes and find you cannot move it. Why? The tom has found a 
nice rock on the bottom and has gotten under it. And let me say right here, when a mad tom gets under a rock, he will come pretty near staying there, and if you pull your line trying to coax him out,

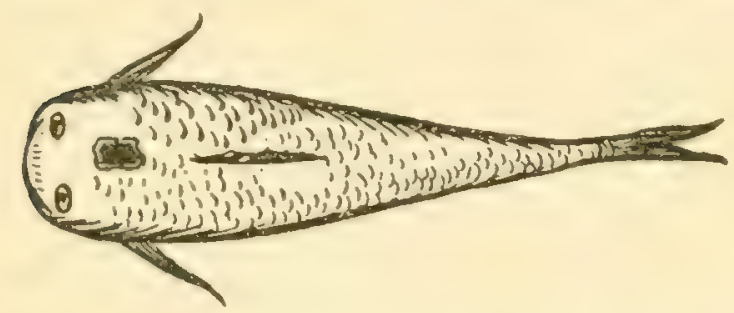

the first thing you know the line will come in minus the bait or cut by the rock. Many of you will say, "put a small cork on the snell of the hook and keep him out of the rocks." Well, that's a good idea but when Mr. Bass sees a mad-tom swimming, he knows he does not carry any bodyguard with him in the shape of a slug cork.

Now that you've read this explosion, I give you the kink.

Take Mr. Tom in your left hand (careful of his prongs), and with your sharp knife skin about a quarter of an inch of hide from the back of his head (see diagram). This well keep him out of weeds, rocks, and away from all growth that will impede his efforts to attract the fish. The idea is this: Suppose you had a wound on your hand-just some skin knocked off-and in some way the skinned surface came in contact with a board or your coat. You would pull it away, wouldn't you, and mighty quick, too? Well, so will the mad-tom. When he starts under a rock and scrapes his head he will come out, and if he scratches his head on some grass he will also come out. Try this, boys, and if you don't have more pleasure with less sweating and catch more fish then-I am stung.

\section{ROD WINDING WITH A NEEDLE}

\section{By R. W. Homer}

All of us have rewound our rods at some time and some of us have had a little trouble tying the ends of the wrapping. I remember when I wound my first rod, I spent more time fastening the ends of the thread than I did in making the wrap.

Of late I have used the following method and found it worked fine: I take a fine needle, just
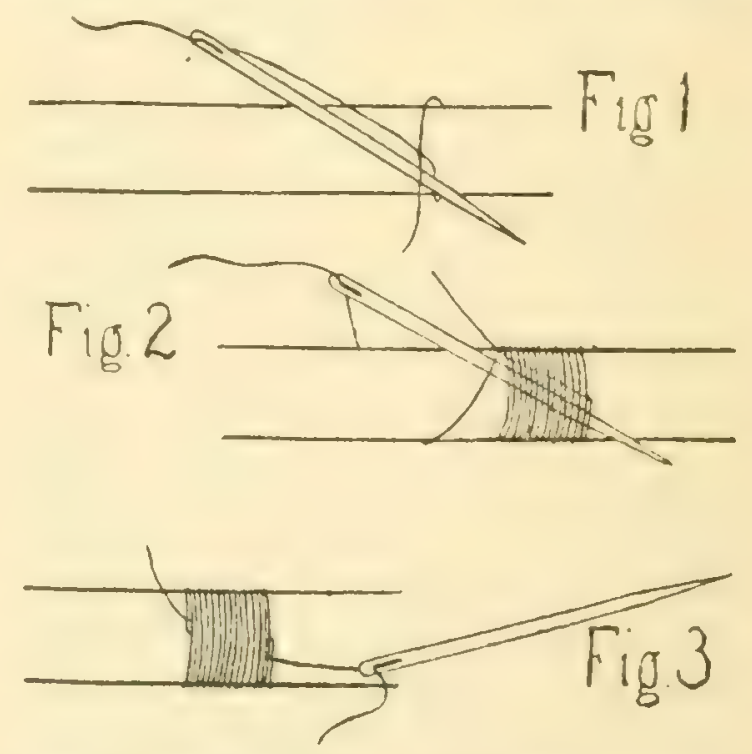

large enough to permit threading with the silk. Thread the needle and lay it along the rod (Fig. 1), allowing the needle to hold the thread against the rod at the point you wish to start 
winding. The thread thru the eye will hold the loose end until the wrap is started. Wind back toward the eye over needle, and loose end (which is thru the eye) till the winding is the size you wish. Then remove thread from eye and replace it with the end you have been wrapping from. Pull the needle thru and you have both ends entirely under the wrap and well tied down.

Where the rod is very thin, as at the tip, when the needle is removed the winding will be a little loose. This can be tightened by twisting the winding in the direction it was put on and pulling the ends till it becomes snug. Cut the loose ends close to the wrap and it will stay till the thread breaks, even if never varnished.

\section{A FLOAT KINK}

By Adolph Sickel

When placing the float upon my line one day, I found that I had lost the small brass clip and screw eye through which the line was ordinarily fastened. I therefore had to tie the line to the float, which was decidedly unhandy, as it would not slip up or down without untying the knots.

Upon returning home, I took a bit of wire and bent it into the shape of a small hairpin; I then made a twist about one-half inch from the bend, as shown in Figure A. The resultant loop was fastened to the stick on the float, by twisting the end of wire around it, and a similar loop was placed on the other end of the float.

To place this combination upon the line, pass a loop of the line
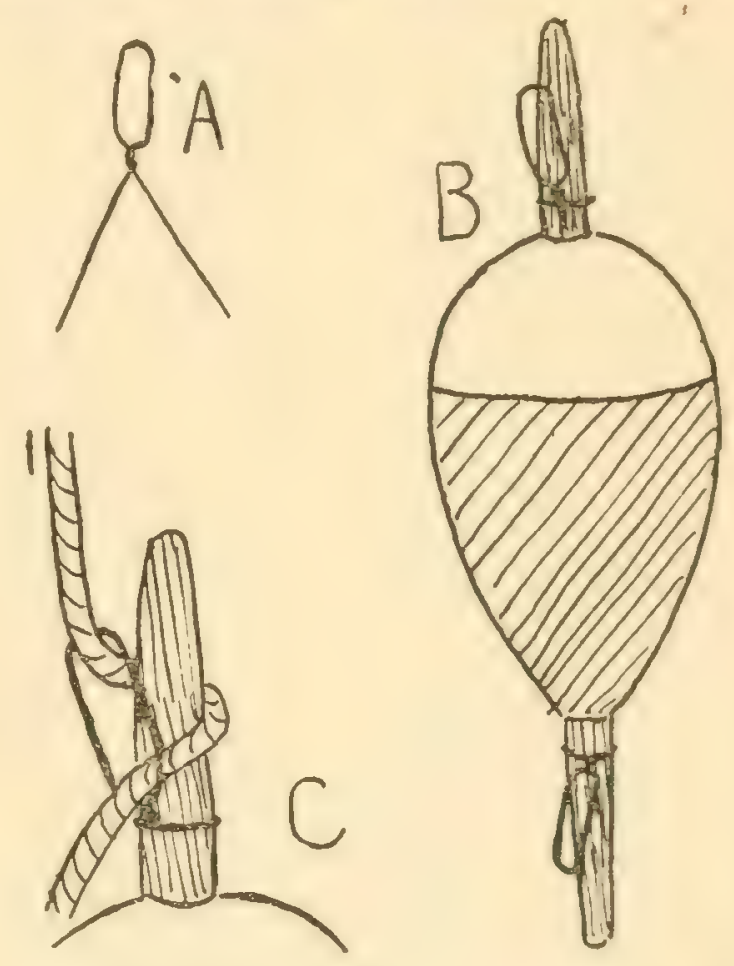

through the wire loop and over the stick, as shown in Figure C. Repeat this at the other end of the float, and the trick is done. These fasteners don't lose off. While the float is held tightly, it can readily be removed without taking the hook from the line, or slipped up and down, as desired.

\section{MAKING YOUR LINE WATERPROOF \\ By Geo. Krumsick}

There are a good many anglers who go fly-fishing and often have to use an ordinary line for this purpose, as all fly fishermen do not have an enamaled line handy 
at all times. I know this to be a fact, as I have been in the same boat on many occasions and had to do my fly fishing with a watersoaked line, which runs very poorly and makes the sport hard work. However, last summer I thought out a trick that works well in this case, and it is done as follows: Before going to the river or lake, hang your ordinary line out in the hot sun, rub it with wax, and then run it through your hands to smooth it off. Take the line in the shade, reel it up, and you are ready for business. A line treated in this manner will be fairly stiff and give you good results.

\section{A CARRY-ALL BAG}

By D. T. BARNetT

The rough sketches accompanying show a bag that my friends tell me has solved the carrying problem. I have made six of these bags so far, and they have been a real success.

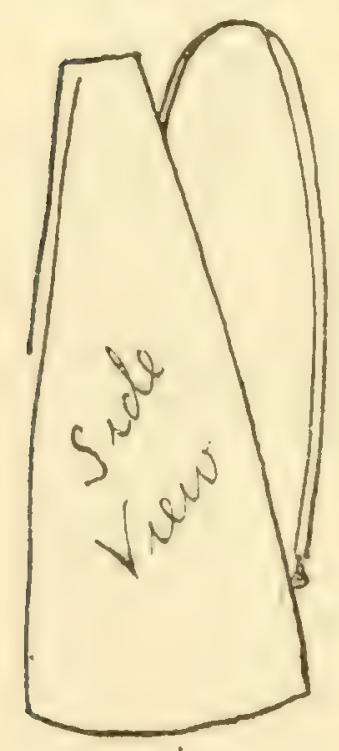

It is surprising what a lot of junk may be carried in a bag of this shape. Mine has often held a quart Thermos bottle at the bottom. Next a 14 by 10 by 4 -inch tackle box, a pair of hip boots, a raincoat or a silk wedge tent. And to top it all off, a light blanket.

This bag can be made out of any suitable material. The top is left any width to suit your fancy,
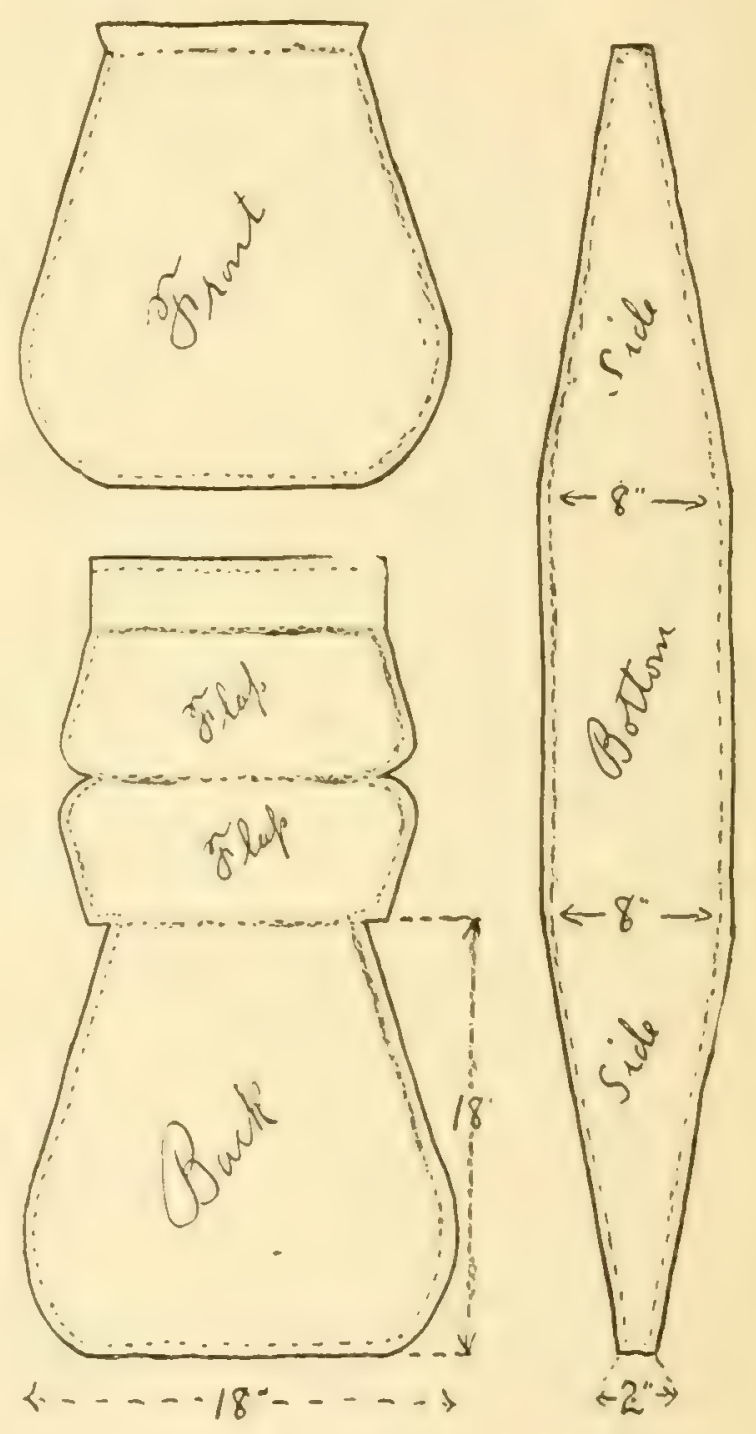

being pulled together with a drawstring after the bag is filled. The shoulder straps are 2 inches wide. The left one is sewed on at both ends. The right one is sewed on only at the top, fastening at the lower end by means of a harness snap to a D ring sewed to the bag. The flap is in two pieces, sewed together 
through the middle and then turned. This bag is "good medicine" and worth trying out.

\section{HANDY CLEANER FOR THE .22}

\section{By Roy Fields}

Here is a kink that may be appreciated by some of our "light armed." It is a cleaner for a 22 .

Get a speedometer "chain" of the type that is nothing more than a small coil spring. These are made of the best spring wire and are just the thing for a cleaner. Cut it off the right length. Coil it up and put it in your pocket and when you get ready for it you have it without the bother of a long brass wire, etc.

\section{FREEING THE LEADER}

\section{By A. C. Bigelow}

It may be possible to fish in a trout stream with a fly and never get the leader with the fly caught in some high-hanging branch of a tree; but I believe that one of the most frequent causes of justifiable profanity comes from this kind of an occurrence. In many cases, aside from the ordniary vexation, is added the loss of tackle because the branch is too high to be reached.

I now always carry a heavy hunting knife with keen edge, in the usual leather case, strapped on the belt about my waist. When my tackle is caught quite beyond my reach, I simply look about for a small straight sapling with small branch growing near the bottom. Then cut it off just below the branch, trim it to make a crotch (trimming all other branches off) and reversing the sapling, I loft the crotch end till I can hook on to the offending branch to bring it within reach and get my tackle. As the knife is always right to hand, I use it for all cutting purposes, instead of fishing in my pocket for my other knife. A fairly heavy knife will cut a good sized stick in short order.

\section{FOR CARRYING SPOONS}

By RAy E. PARKER

Here is a kink that may be of use to some brother who uses the fly-spoon and the regular spoons as well. Take a sheet of thin stiff metal (I used spring brass) and cut same into sizes same as the leaves of your fly book.

Now get some large brass hooks, such as are used on skirts,

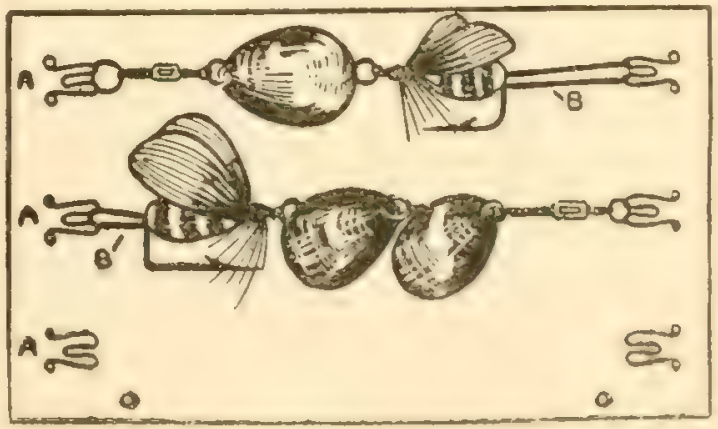

etc., and rivet or solder them in a row at each end of the sheets about $3 / 4$ of an inch apart and about $1 / 2$ inch from the ends of the sheets. Now put the tying end of the fly-spoon on one hook 
and, slipping a small rubber band over the fly hook, loop the other end on the hook opposite the one on which the other end of the spoon is fastened. Thus the spoons are easy to get at at all times and never become snarled as they do when carried loose in a tackle box, which sure saves a pile of cussing in the course of a season.

By placing hooks in similar fashion in the bottom and in the lid of a tobacco box which opens up flat-ways, the some good results can be obtained with spoons having treble hooks.

\section{MACARONI FOR BAIT}

\section{By Gilbert Dust}

Get a dime's worth of macaroni and put it in a pan of cold water, breaking the macaroni into lengths of about three inches. Put it on a fire and allow it to get hot through, or until it is tough and limber and then take it off and pinch into lengths of about one and one-half inches and it is then ready for use.

To bait your hook simply string on like a worm and you will doubtless find you have a good all-around substitute for such fish as channel cat, white perch, buffalo, carp and suckers.

\section{AN EXCELLENT PERCH BAIT}

By R. B. Hockings

Anglers who have fished for perch, find it very disgusting to keep changing the water on minnows every little while, and then having some of them die; having to put their hands in the pail to catch a minnow, and having a lot of trouble getting minnows at all when they want to go fishing. So I have a kink to tell you that will relieve you of all further trouble of this kind.

I was visiting with an old angler a short time ago and we got to talking about bass, pickerel; in fact, all kinds of baits.

After talking a while I got him to tell me how it was he always managed to catch so many perch.

$\mathrm{He}$ said he always used to use minnows until recent years, and
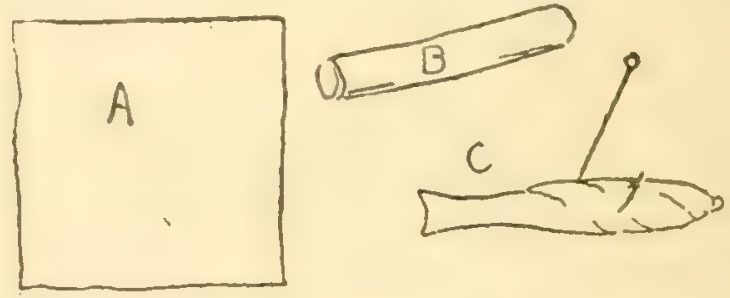

always with pretty good success. But one day, as he was walking along the street, he saw a piece of tinfoil lying on the sidewalk. He picked it up and began to smooth it out, when a thought came to him. Why not use tinfoil instead of minnows? He made up his mind then and there to try it the next day.

Bright and early the next morning he rowed out to his favorite fishing spot to try out his new bait. He dropped anchor, got out his poles, then took a piece of tin foil about $1 \frac{1}{2}$ inches square (Fig. $A$ in sketch) and rolled it (Fig. $B$ in sketch). Then took his hook 
and hooked it in about the middle of the rolled tinfoil. Then he twisted it about three times and bent the corners down on one end, making it pointed so that it looked about the shape of a minnow (Fig. C shows it completed). When this was done he tossed it into the water and in just a few minutes he was rewarded with a nice, big perch, and in a very little while he had a big string of fish. Then, too, he was able to catch from five to six perch on the one tinfoil bait, where with minnows, one perch usually meant one or more minnows.

Anyone trying this kink will find it an interesting, excellent and inexpensive perch bait.

\section{CATCHING CATFISH ON WILSON WOBBLERS}

By Geo. Krumsick

Here is a little kink that some of our stream fishermen might try when they go camping and get tired of eating bass at every meal. This kink is being used here by some of our anglers and is bringing them channel cat without using live bait. The stunt is simply this: When you have finished casting your wooden minnows in the deep pools for the day, tie them to a short trot-line and stretch it across the riffles where the water is swift and about two feet deep. The current will keep the wobbler going all night, and when Mr. Channel Cat comes up to feed he'll nab the plug and stay there. Here in the
Meramec River 'catfish weighing up to eight pounds are caught in this manner.

\section{A HANDY SWIVEL-SNAP}

\section{By Lee Stibie}

The wire shank and swivel taken from an old spoon makes an excellent snap for fastening baits on a bait-casting line. Remove the hooks, spoon and beads, leaving only the wire with the swivel at one end. Fasten the line to the swivel. The loop at

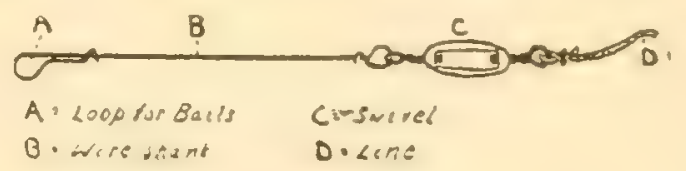

the other end of the wire forms a perfect snap for taking off and putting on bait. This rig has the special advantage that the swivel prevents the line from becoming twisted. The spoon may be left on the shank at times to make the bait more killing.

\section{A NEAT TRICK}

By JoHn M. SMITH

After casting along the edge of the weeds from a boat I found that for some reason I could not catch fish, although I had a number of strikes. So a thought came to me. I fitted out a hand line and fastened it to a 20 -foot cane rod, used both live minnows and grasshoppers for bait. After baiting the line I laid it in the boat and went on casting. When I had another strike I did not make a second cast for the fish, but 
dropped the bait, which was fastened to the cane rod, as near the spot where the fish struck as possible, and in a short time I had landed a good bass.

\section{ROD SPLICING}

\section{By H. J. Blacklidge}

Having never seen directions for splicing a broken rod in Outer's Book, I will give my method for the "Kink Korner." " $A$ " shows the broken ends, " $B$ " the way they should be whittled down to a long level. In my pocket tool kit I carry an eightinch, fine-tooth wood rasp. With this I smooth the irregularities left by the pocket knife until the two long bevels fit perfectly when placed together. Then they are covered with a thin layer of shoemaker's wax, and pressed tightly together.

Next they are wrapped with well waxed silk. Let the end lie

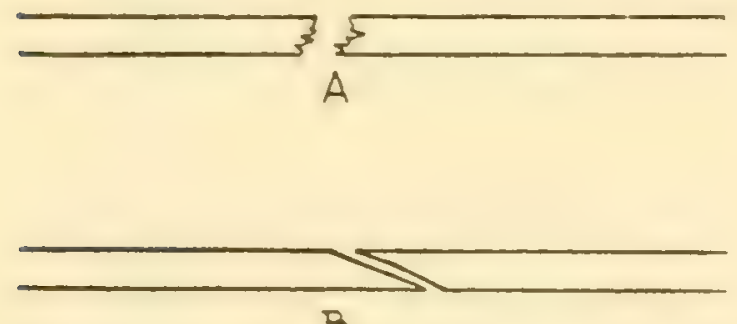

B

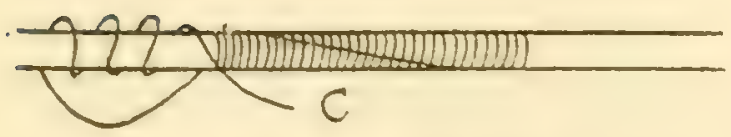

along the rod and wrap over it a dozen turns in beginning. Wrap carefully - conscientiously - until you have gone beyond the ends of the beveled part. Then to tie an invisible knot proceed as shown in the last sketch. Make four or five loose loops just as shown and pass the end under last lap of the winding. Now, as you go on winding, the loose loops you have just made will unwind. When they are all unwound, pull the end through and cut it off close up and-go on fishing. Of course, your rod will be a little lighter and a little stiffer than before, but that is better than quitting, isn't it?

It is well also to have a little bottle of shellac along with you and give the splice a coat of it. The shellac will dry while you are smoking one pipe-if not sooner.

\section{THE TROLLING LINE SPRING}

\section{BY.W. J. Fuller}

Here is a Kink that is the result of sad experience. While trolling one day, the long looked for "big one" hit my bait and immediately broke the line with his first heavy lunge. I thought the matter over on my way to town, and went to a hardware store and bought an ordinary coil spring, such as is used on screen doors. One end of this I hooked to a screw eye in the rowing seat at my right hand. At the other end I fastened my trolling line. In the stern of the boat I placed a yoke or fork through which the line ran out. An extra oar lock can be used for this purpose. 
For those who like to go trolling alone, this Kink will be very useful, as the spring does away with all chances of your line be-

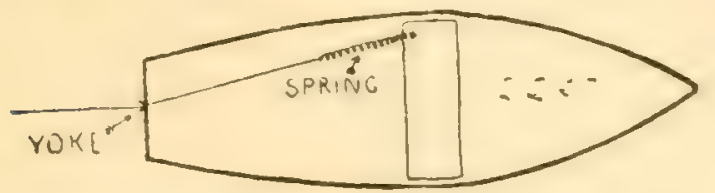

ing broken by the strike of a big fish or by being snagged.

\section{A SIMPLE LINE DRYER}

By Geo. C. Whitney

A very simple line dryer kink is to pull the line off the reel or spool into a pile or heap, just as it piles naturally on the floor, chair, table or dresser. Leave the end lying to one side so as to be easily found when dry. No folding contrivances or rusty nails whatever to bother with and always some place handy. When dry run top end through rod, fasten to reel and wind up. Simple as rolling off a log and no "kink" either.

A very handy back-lash tool, and I believe an improvement on Brother Field's, smaller, lighter and neater, is a woman's crochet needle, size No. 6 .

\section{AN EXCELLENT PERCH BAIT}

\section{BY N. D. HAGER}

By following these directions you can make a bait that will catch from one to a dozen perch before giving out.

We will assume that you have already caught a perch, that being necessary in order to make the bait.

Cut a section out of the top edge of the tail of the perch, about one-half inch thick and one and one-half inches long (see Fig. 1).

You will then have a piece shaped like Fig. 2.

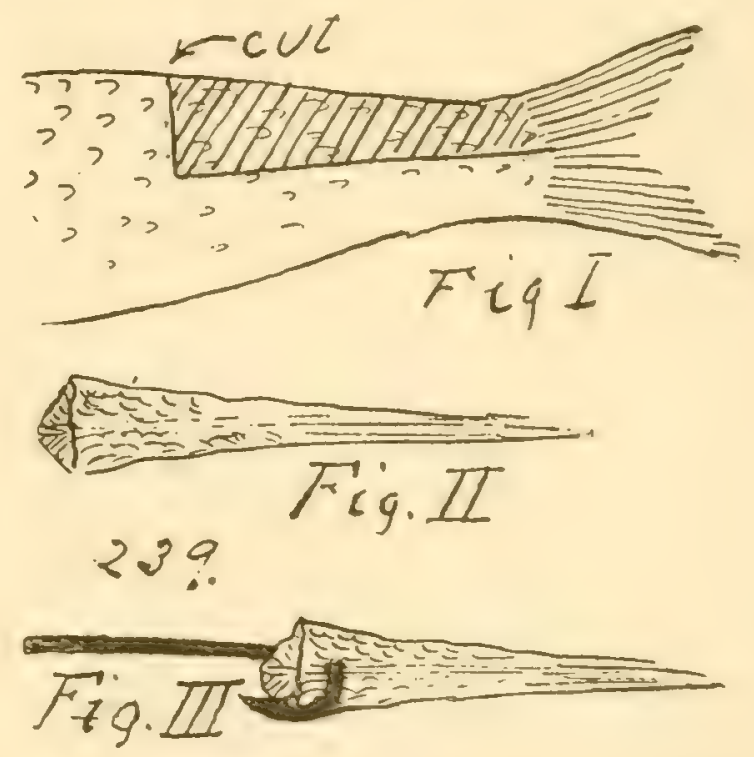

Put this on hook by running hook through, as shown in Fig. 3 , and your bait is ready.

You will find that perch will bite on this bait quicker than on a minnow.

Good luck to all who try it.

\section{FLOATING THE TROUT BAIT}

\section{By Thomas J. Lutton}

On small and very brushy streams, where one must fish for trout with bait if at all, a float or "bobber" is usually considered more of nuisance than a help. And indeed this is so over many parts of the stream. Many anglers, as a result of this, forget 
entirely that there is such a device and that it may possibly be of use to them sometimes.

But there is a time and a place for everything and the float has a most decided place on this kind of a stream. Often you come to beautiful little holes, but so brush covered and with such a slow current that it seems impossible to get your bait down into them. Here is where the float comes in. I always carry a good split cork, but a small branch or chip will do nearly as well. Fasten this on the line so that it will carry your bait just above the bottom. Then flip it into the water and watch it slowly carry your bait to the exact spot you want to reach. And it gets the fish, too, fish that you could not possibly connect with in any other way.

\section{BEADS FOR SALMON EGGS}

By E. S. Brooks

It is unlawful to use salmon eggs for bait in Oregon, but there is nothing said about amber beads. So I take a small vial, fiill it with

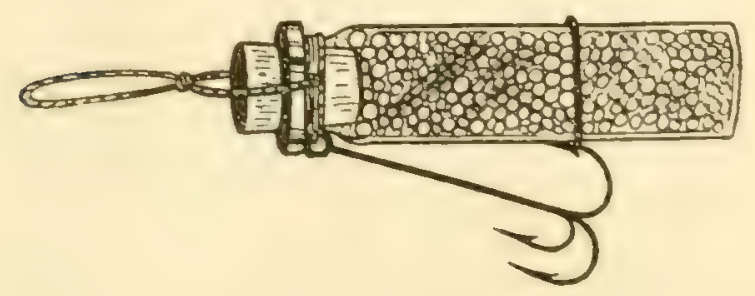

small amber beads the size of salmon eggs, put in some water and cork it up. I attach my triple hook with a small rubber band around one hook, tasten it to the neck of the vial with a few turns of a fine fish line, and there you are.

It works equally well with a good, fat grasshopper or grampus, but in that case I do not put any water in the vial, as they are surface baits. The glass being invisible in the water, the redsides go for the bait to beat three of a kind.

\section{A LITTLE TIME SAVER}

\section{By F. H. BонN}

When fishing for trout or other small fish one wastes considerable time and a good deal of patience while taking them off the hook. I have fourid that it pays well to kill them before taking them off. Just slip the thumb under the gill on one side and the forefinger on the other, and give a quick, hard squeeze with the nails, where the head and body connect. The fish is killed instantly and will not bother you by kicking and flopping while you are extracting the hook. I have found also that fish killed as soon as caught keep much longer and better than if they are allowed to die a lingering death in the basket or on a stringer.

\section{A HANDY ROD HANGER}

\section{By George H. Sackett}

Having had trouble in hanging up my Heddon $\$ 1.50$ rod (in order to straighten it), I devised the arrangement described here- 
with, which holds it straight and does it almost anywhere. The material is a piece of heavy gauge copper wire about seven inches long; this is doubled back on itself (Fig. 1). It is then twisted

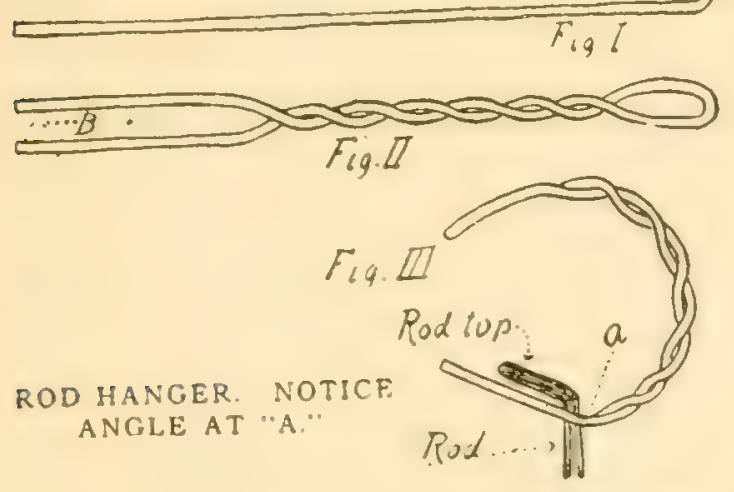

for about two-thirds its length, as shown in Fig. 2. It is then bent, as in Fig. 3, which shows finished holder with rod in place. The angle at A (Fig. 3) should be the same as the angle of the top, so that same will not turn. Now, it is finished. Slide the tip in the opening (shown in Fig. 2 at B), and hang it up by a ring from the ceiling or anything that the top of the holder will slip over.

\section{A CARP BAIT}

By Louis E. Myers

This is a "carp" bait kink of mine where I cannot catch anything else. To one pint of cornmeal mix one-half pint of flour and work until you can hold by small pieces and it will spring up and down. Make into balls about the size of small marbles. Drop in bunch of fishworms about the size of a walnut and also mix some sweet anise roots if you can get them, as it has such a sweet savor that if the carp come within 2 feet they will sure jump for this bait. Put the dough balls in hot water and cook about ten minutes, or until they will float. The balls will then be firm and slick. The sweet anise roots can be found along the sides of creeks or bluffs. This bait will get the carp if you want them. Try it, brothers.

\section{OILING FERRULES}

\section{By Sherwood BuckstafF}

Most anglers clean and oil their steel rods several times a year, but a bamboo rod does not require such attention, and most anglers do not take the bother to oil the ferrules regularly, often neglecting them for a whole trip. Consequently the joints stick annoyingly, and sometimes cause serious trouble, since if one attempts to loosen them by heating he runs the risk of melting or loosening the ferrule cement. I always carry with me a small piece of flannel which has been soaked in oil and squeezed as dry as possible. This does not make the pocket oily-indeed, one can hardly tell by feeling of it that it is oily-but it will oil a rod very nicely and keep it in perfect condition. Moreover, it will keep oily almost indefinitely. I picked mine up this winter when it had not been fixed since summer, and found it as good as ever. Try it and see. It may be a lifesaver some time. 
WHEN THEY STEAL THE BAIT

By Carroll Crank

While out fishing last fall I had the fortune, or misfortune, as you choose to call it, to find a place where the fish were well educated along the lines of bait stealing.

After my supply of minnows was nearly exhausted it occurred to me to change baits. But minnows were all I had, so I had to manufacture some.

I took a piece of white cotton wrapping cord from my pocket, doubled it several times, and tied a knot in the middle of it and hooked my hook through the knot. I then picked the ends apart till it was quite bushy. Then it was ready for the water.

I caught more fish in the next hour on that one bait than I had in the three hours previous, due to the fact that the fish could not steal my bait.
Of course, this bait would not be practical for still fishing, yet it will work to perfection while trolling.

\section{KEEPING CRAWFISH FRESH}

\section{By J. C. Athey}

While contemplating an extended fishing trip the keeping of crawfish came up. Having taken them alive several times without success, decided on the following method:

Get about one bushel of nice, large craws. Peel the tails while alive; put in a Mason jar and seal tightly. Place in your refrigerator and keep ice cold. On going out set jar in minnow bucket filled with crushed ice and bait will keep as fresh as when peeled.

If ice is not to be had, peel craws, put in water and bring to a boil, which will toughen and preserve them very satisfactorily.

\section{THE KINK WE'RE LOOKING FOR}

By S. W. EVERETT

Gosh all fish-hooks, Jake,

These yere kinks are some surprisin'!

Orter ketch a fish

If they're only half a risin'.
Yep, says I, they do seem fair,

Yet I'm leetle short o'dubious;

Ef you'd a had my luck

You wouldn't be so solubrious.

Fer the kind o' kinks I'm lookin' fer-

Just mark yer Uncle Benny-

Is how ter ketch a fish in this yer creek

When yer know there isn't any. 


\section{CONTENTS}

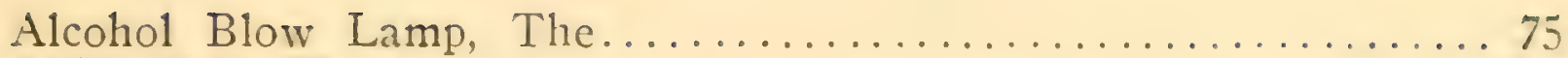

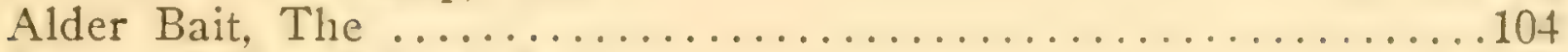

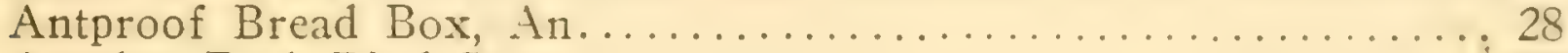

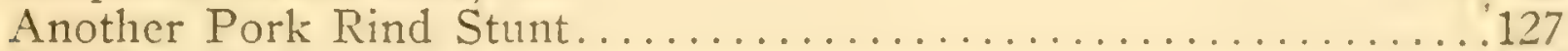

Another Porker ................................. 86

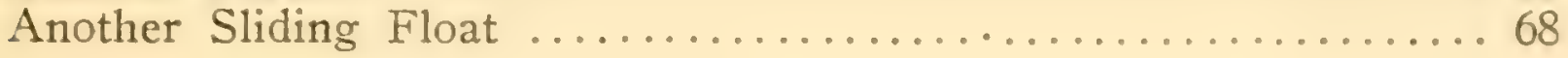

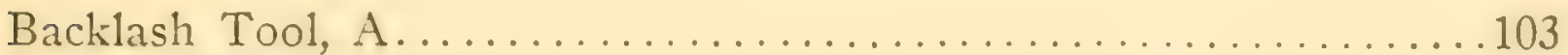

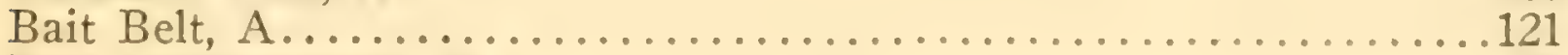

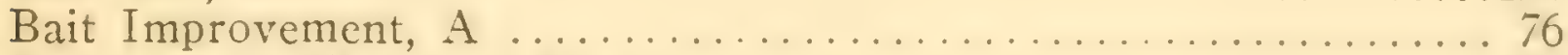

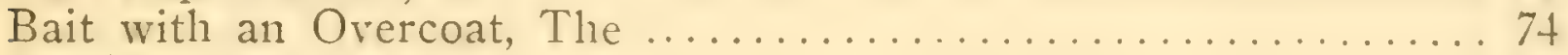

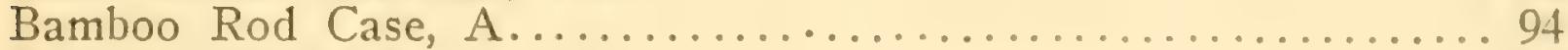

Barbecue Fork, A................................67

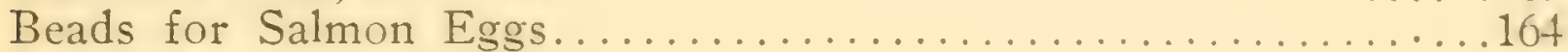

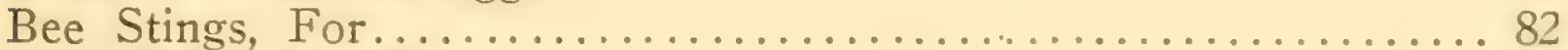

Bluegill Tip-Up, The .............................43

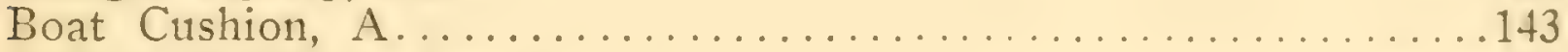

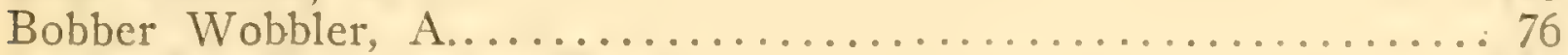

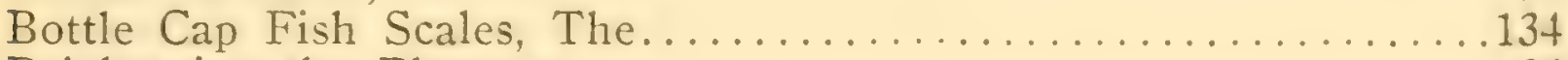

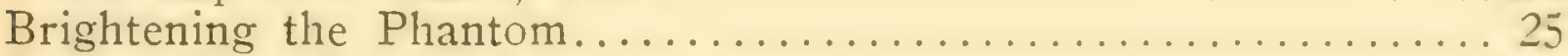

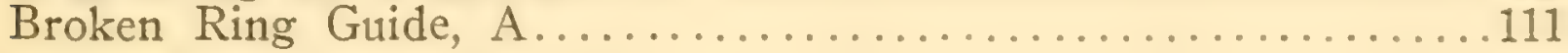

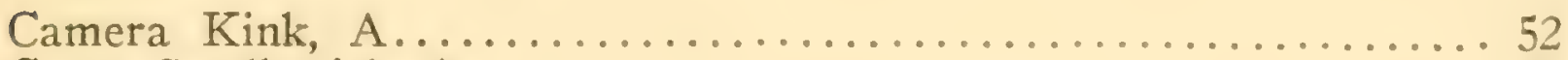

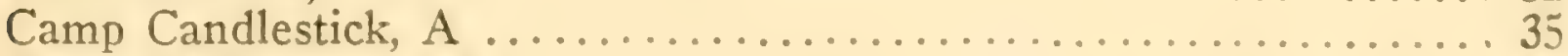

Camp Refrigerator, A........................... 82

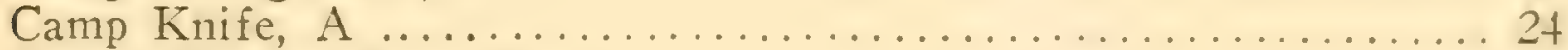

Canoe Shelter Tent, The............................. 46

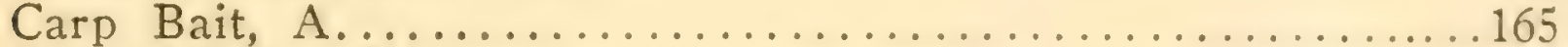

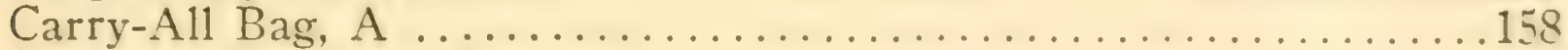

Carrying Creel or Canteen........................... 19

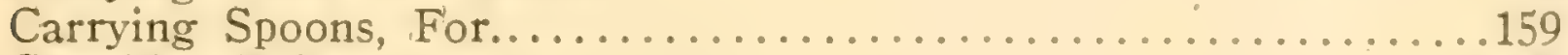

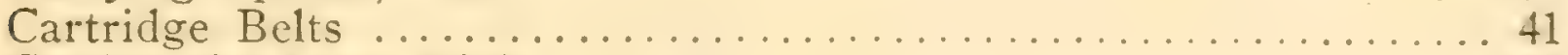

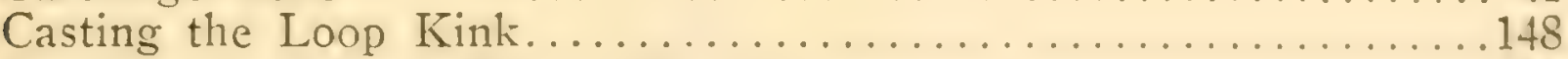

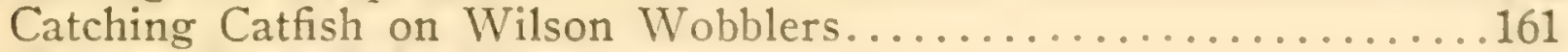

Chicken Neck Bait, The.................................. 101

Cigar Box Tackle Carrier, My......................... 56

Clothes Hook Rod Hanger, The.........................102

Clothespin Plug, A ...........................60

Collapsible Landing Net, A........................ 52

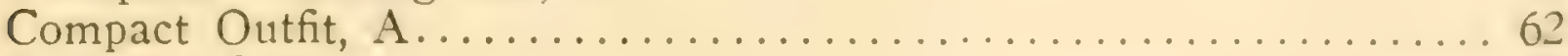

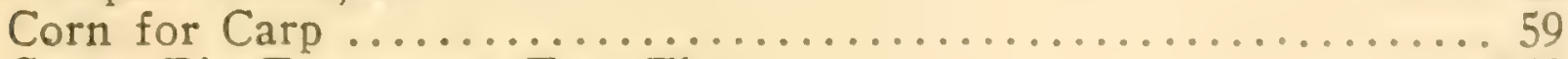

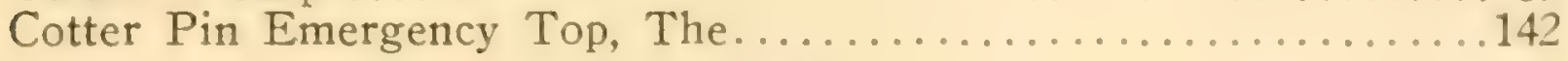




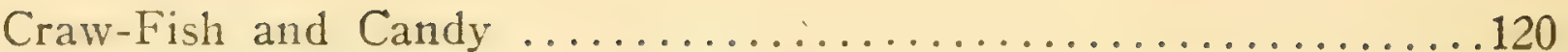

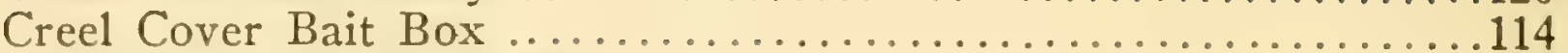

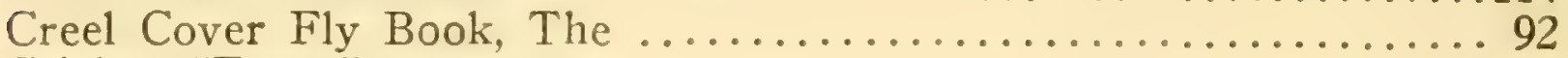

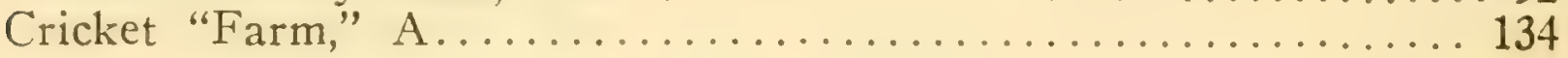

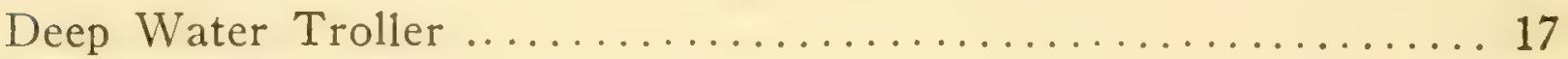

Doctoring the Leader ......................... 8

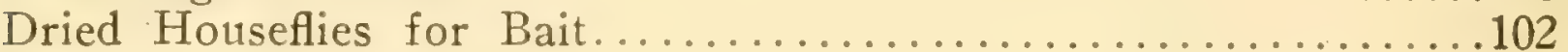

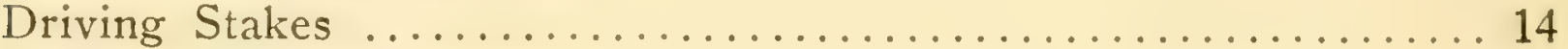

Driving Splitting Stakes .......................... 44

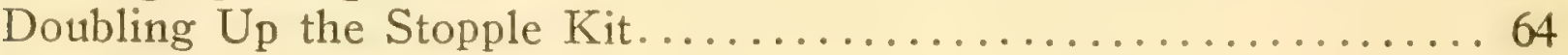

Duck Kink, A ................................. 7

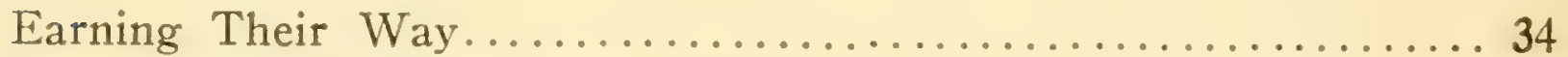

Easily Made Live Box, An......................... 81

Emergency Anchor, An............................ 89

Emergency Foot Rest, An............................ 12

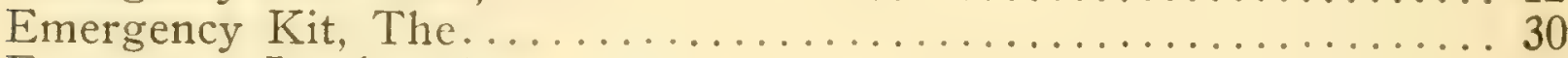

Emergency Leader, An.................................141

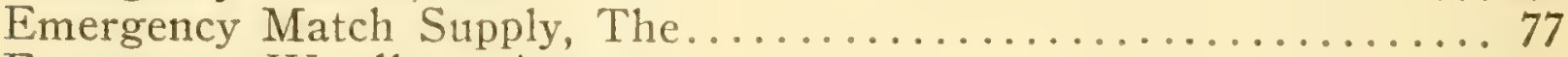

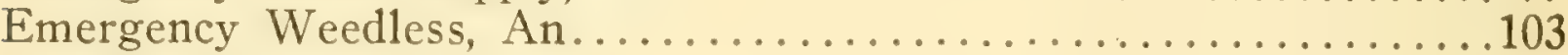

Excellent Crappie Bait, An.......................... 145

Excellent Float for Live Bait, An....................... 78

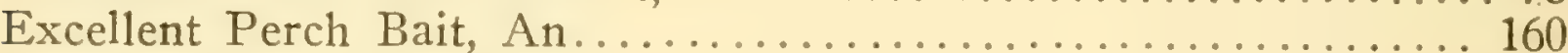

Excellent Perch Bait, An............................. 163

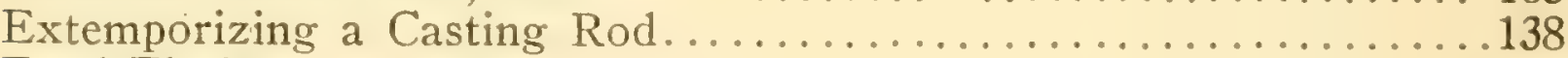

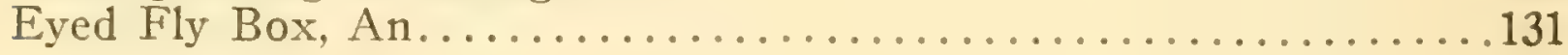

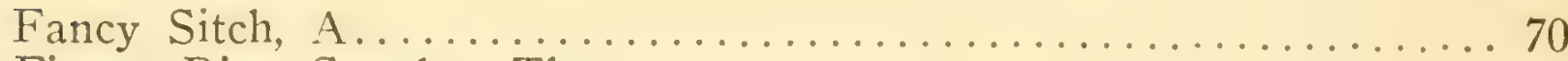

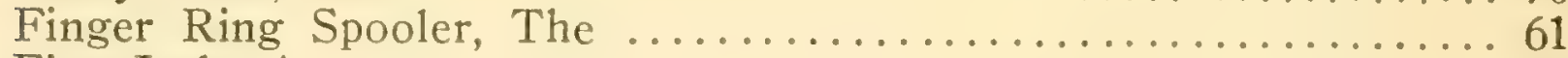

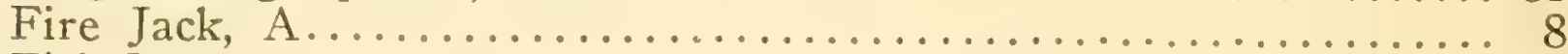

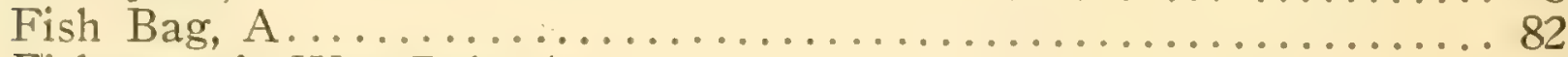

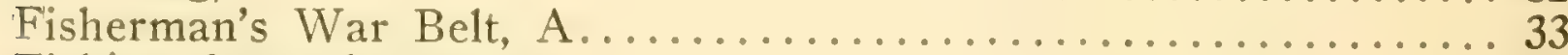

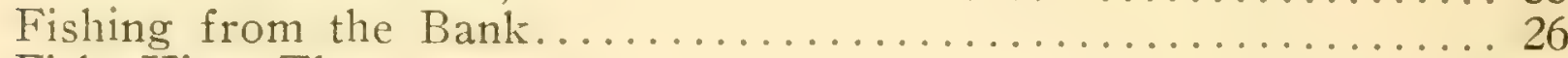

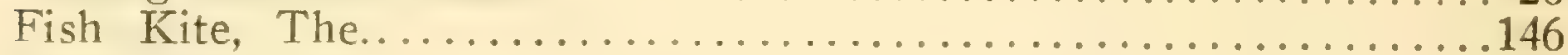

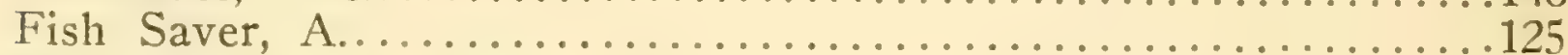

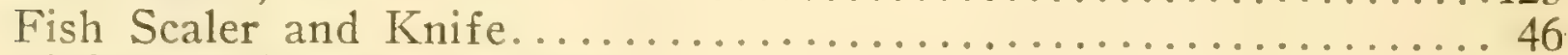

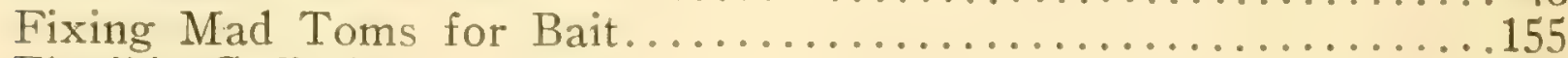

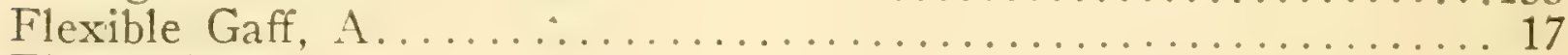

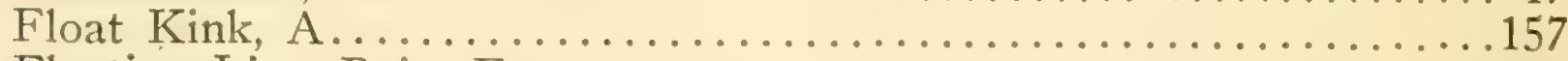

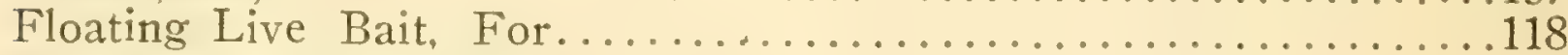

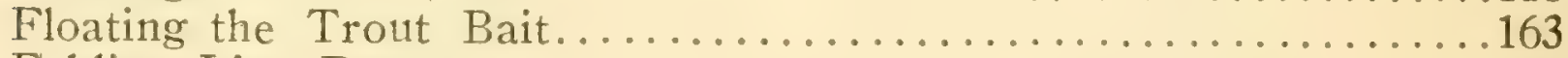

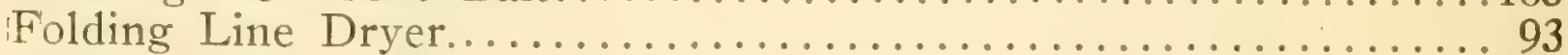

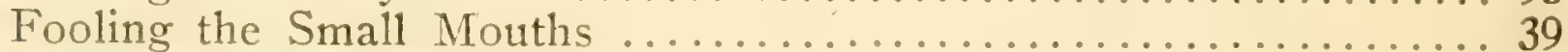

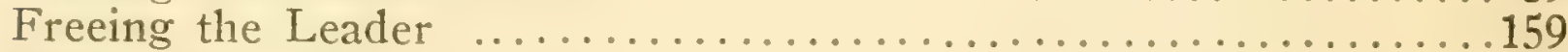

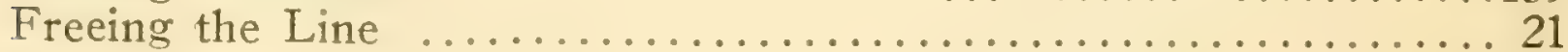

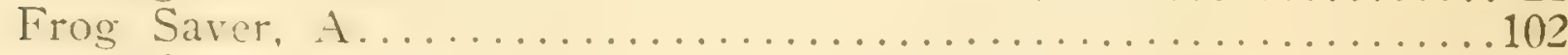




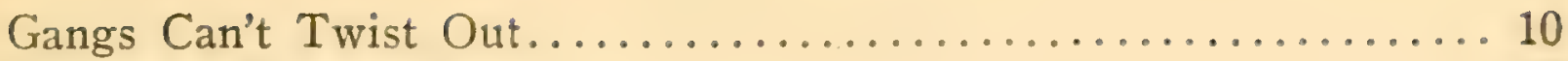

Gathering Information............................... 89

Getting Them Off the Hook..........................63

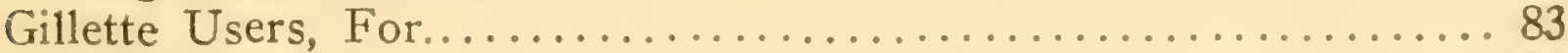

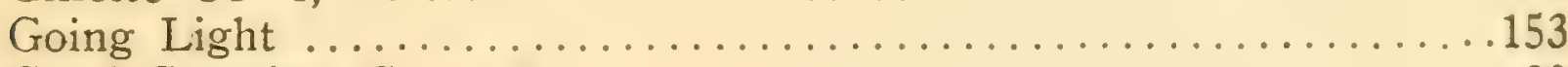

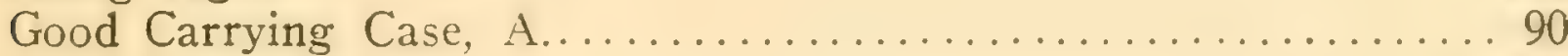

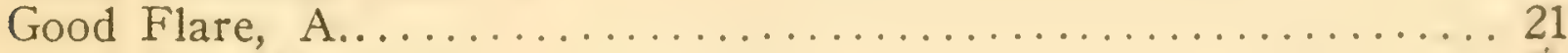

Good Frog Hook, A ............................. 78

Good Hook Tie, A................................ 29

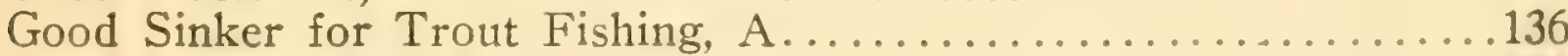

Good Spinner Rig, A................................ 144

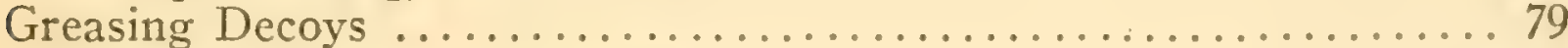

Handy Berry Pickers' Can, A......................... 58

Handy Can-Handle Kink, A........................ 26

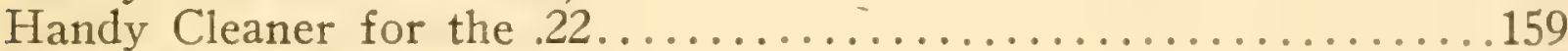

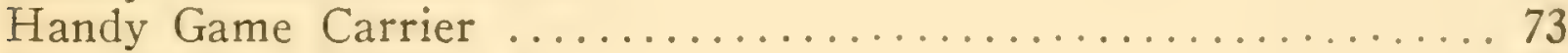

Handy Hook Holder, A............................ 49

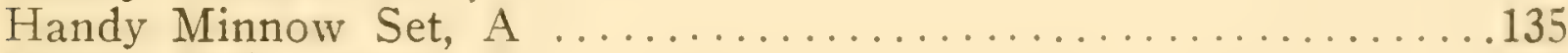

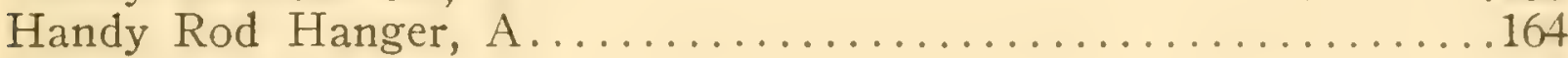

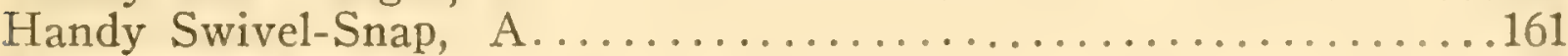

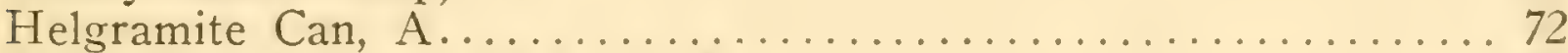

Helgramite Harness De Luxe, A....................... 96

Hinge Fire Rack, A............................... 13

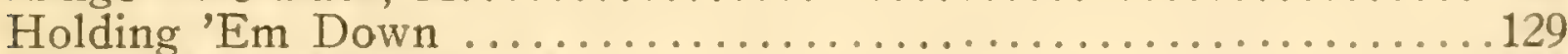

Home-Made Attractor, A............................... 144

Home-Made Bait Socket ......................... 71

Home-Made Camp Stove, A.......................... 23

Home-made Enamel for the Plug............................ 108

Home-made Folding Net, A....................... 31

Home-Made Rod Tip, A........................... 47

Home-Made Tackle Box, \y....................... 40

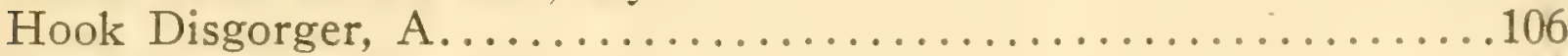

Hook They Can't Swallow, A........................ 11

Hooking Your Fish............................. 50

Hot Biscuits to Order.............................. 43

Ice Creepers ........................................ 54

Improved Oar Lock Fastening ....................61

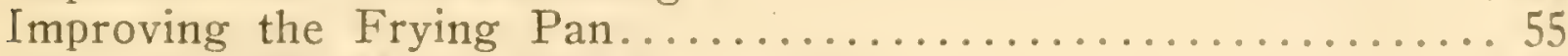

Improving the Model 1914 Savage $22 \ldots \ldots \ldots \ldots \ldots \ldots \ldots \ldots$

Improving the Minnow Can......................... 7

Improving Tube Tips............................. 12

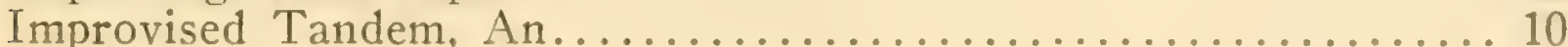

Indexing Kinks .............................. 25

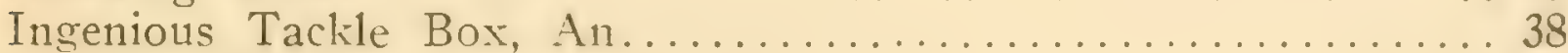

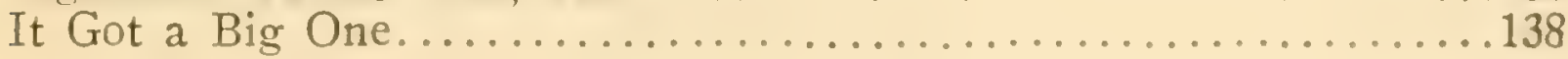


Just Adhesive Plaster............................. 85

Keep Your Hopper Alive............................. 12

Keeping Agate Tip from Chipping or Breaking............ 72

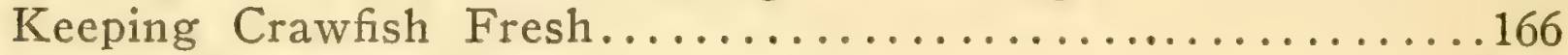

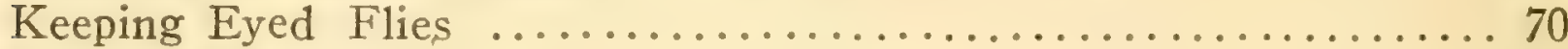

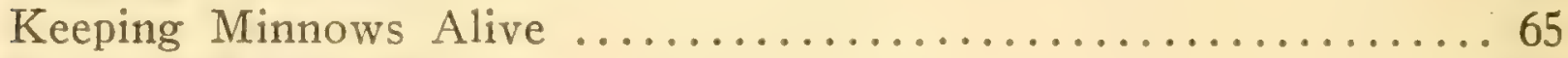

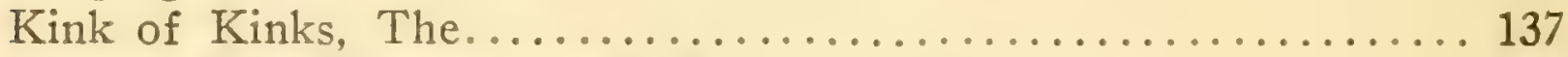

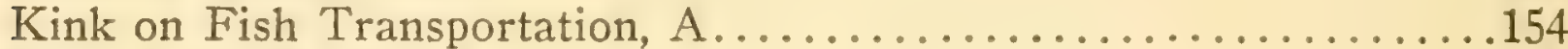

Kink Pole Holder, A.............................. 98

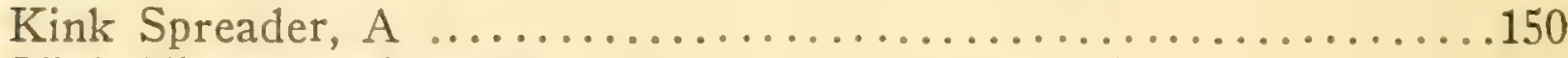

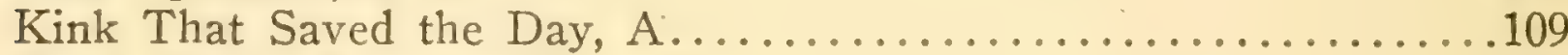

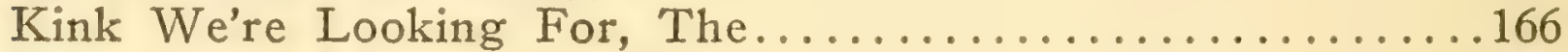

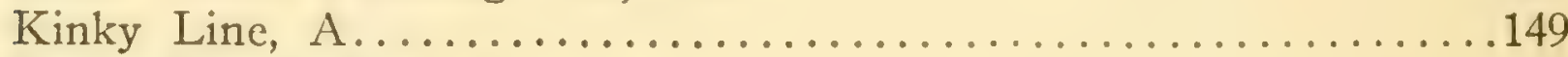

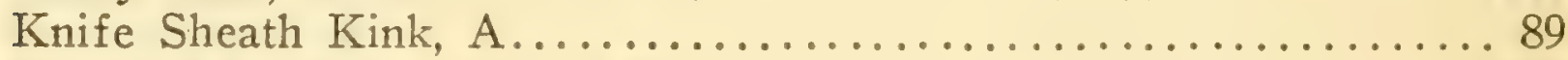

Knocked-down Fire Grate, A........................... 29

Leaders from Hook Snells.................................. 143

Left-Handed Casting Reel, A........................... 77

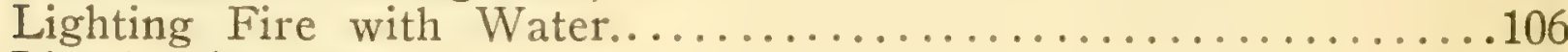

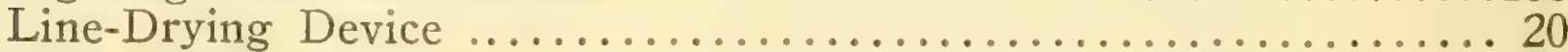

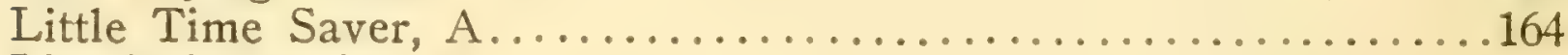

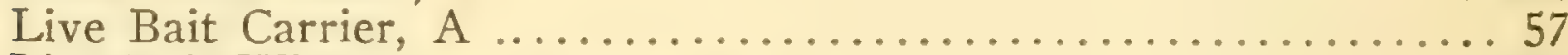

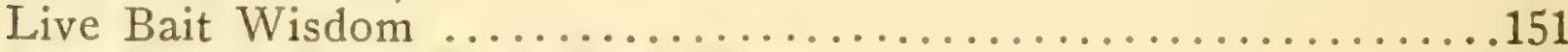

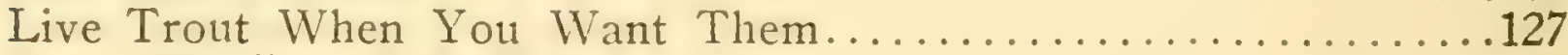

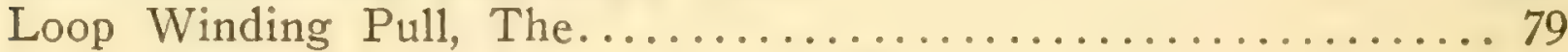

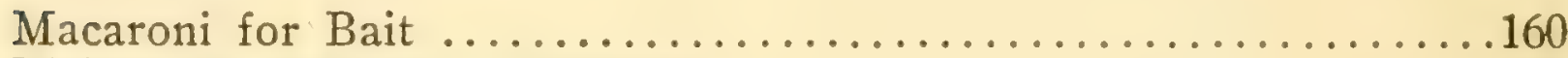

Makes for Accurate Statements........................ 80

Make Your Reel Self Striking ........................ 9

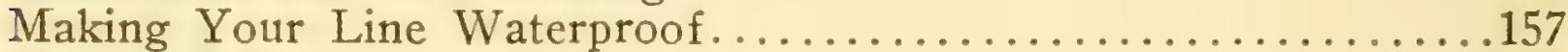

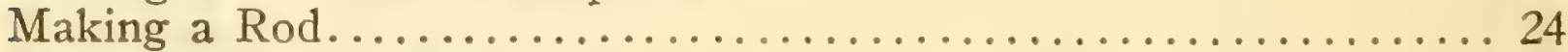

Measuring by the Rod.............................. 99

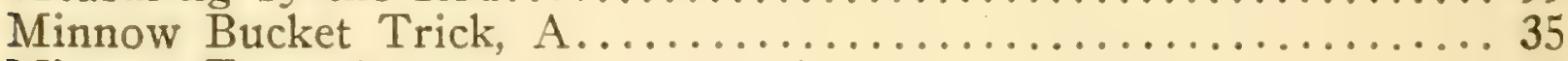

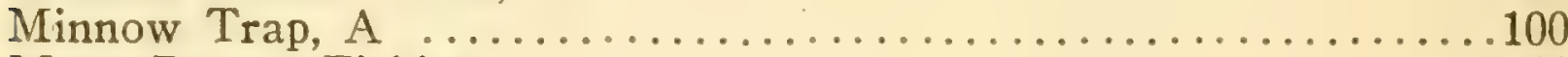

More Bream Fishing............................62 62

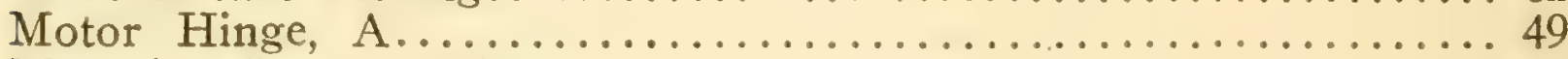

Mounting Leaders Simply............................. 42

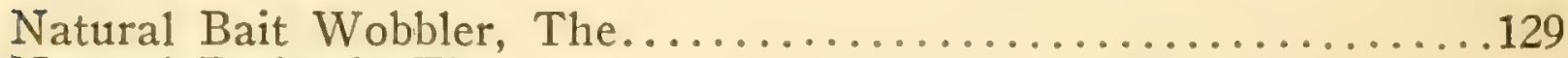

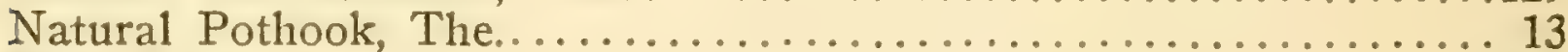

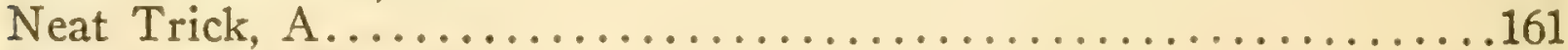

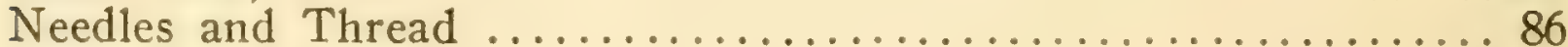

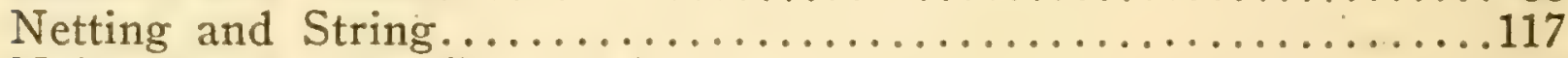

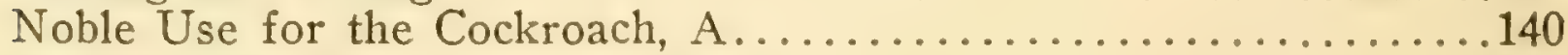

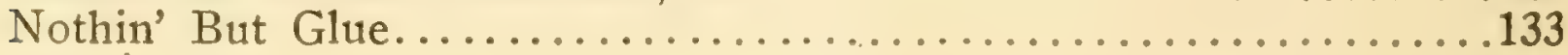




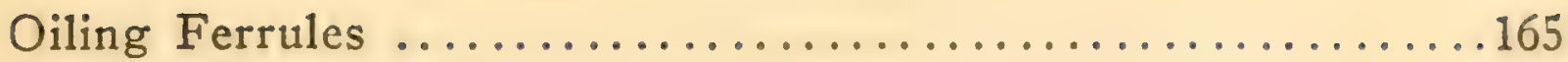

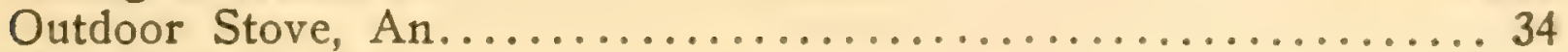

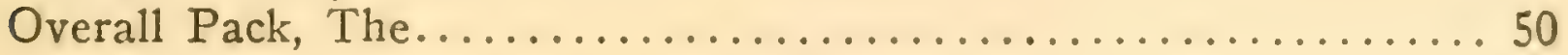

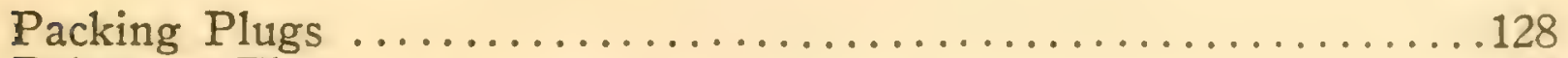

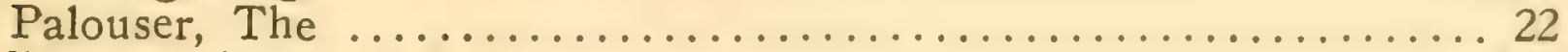

Partnership Kink, A.................................147

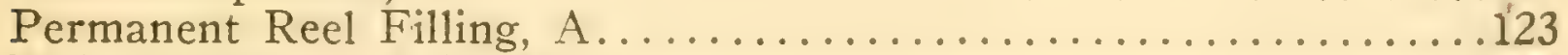

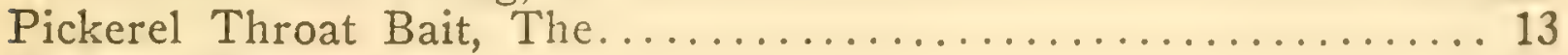

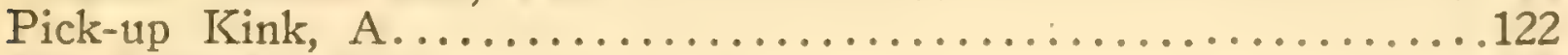

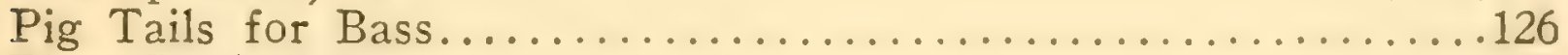

Plug Carrier, A.................................... 80

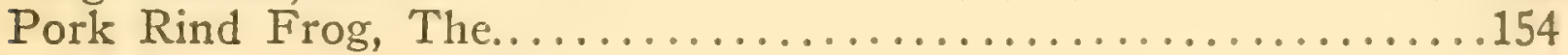

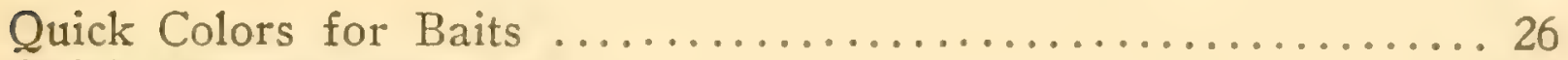

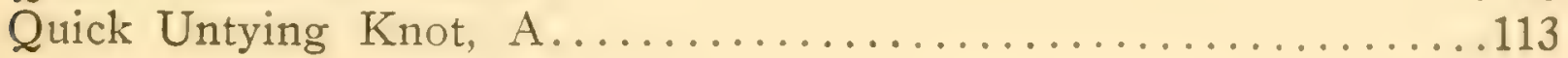

Rapid Fire Fish Cleaning ...........................69

Raw Onion Poultice for Snakebite....................... 86

"Real" Oil for Reels, A................................ 85

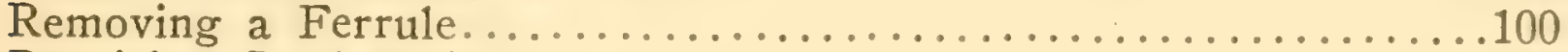

Repairing Steel Rods...............................66 66

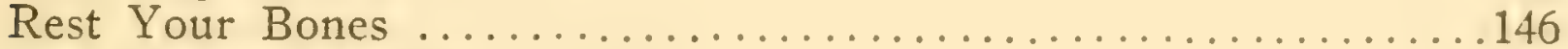

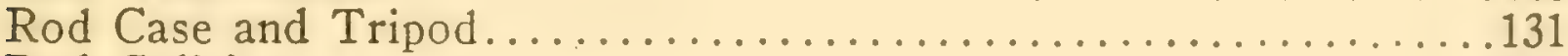

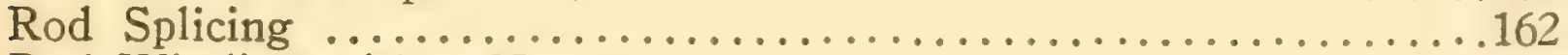

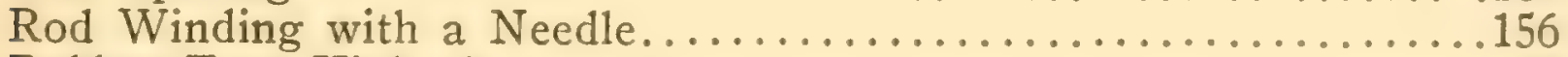

Rubber Tape Kink, A.............................. 74

Safeguarding the Reel............................. 14

Safety-First Belt, A.............................67

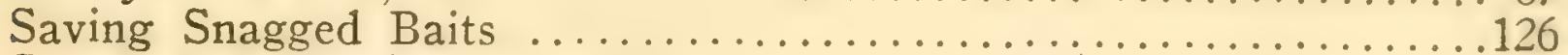

Self-Pulled Winding Knot, The........................ 71

Self-Striking Hook, A.............................. 66

Setting Your Watch by Compass....................... 74

Shingle Creel, A................................ 58

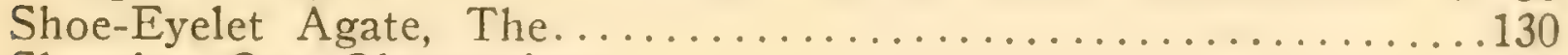

Shooting Our Obstructions ........................ 50

Shotgun Cleaner, A.................................. 90

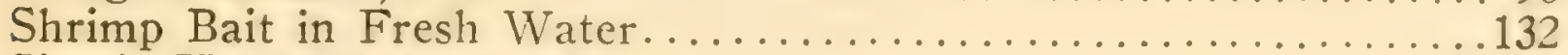

Simple Hook Remover, A............................. 28

Simple Knot, A ................................. 11

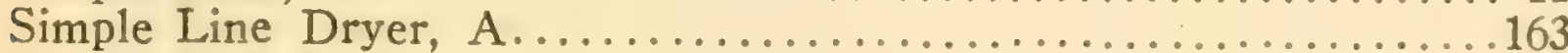

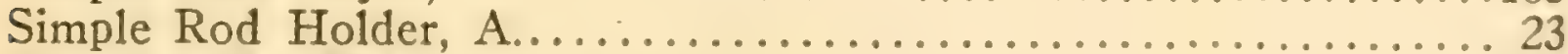

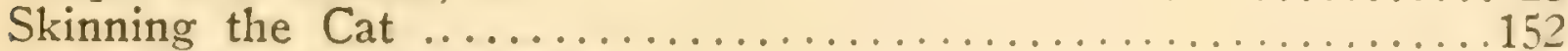

Slide Float Arrangement, A......................... 48

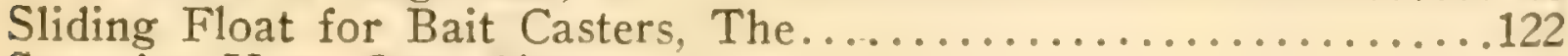

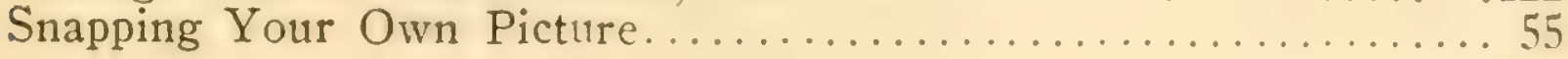


Snelled Hook Carrier, A.......................... 83

Splicing a Break in a Bamboo Rod....................... 64

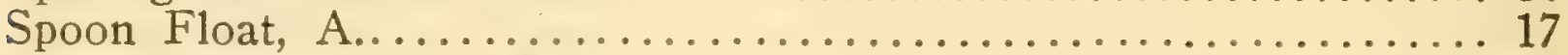

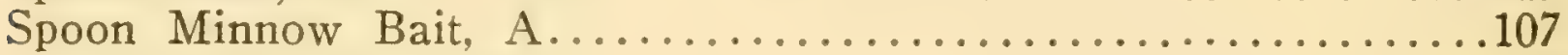

Squirrel Tail Bait, The............................... 9

Steel Ring Guides .................................. 59

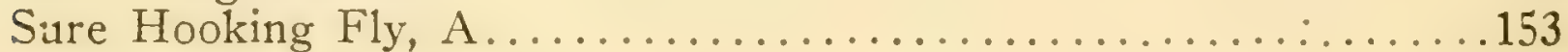

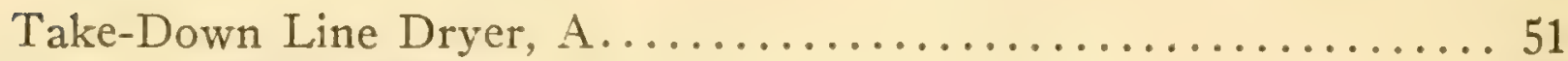

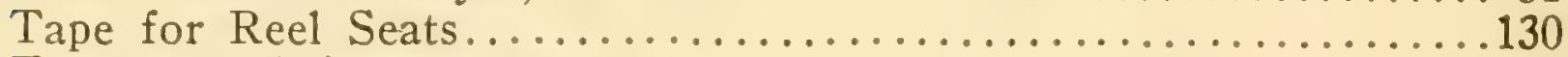

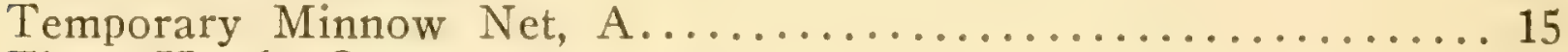

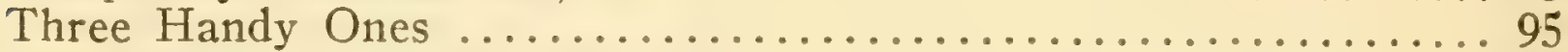

Three Kinks from One Kinker........................ 90

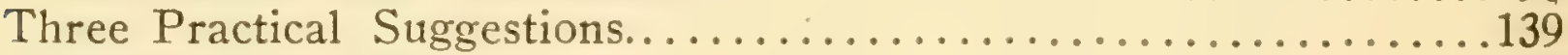

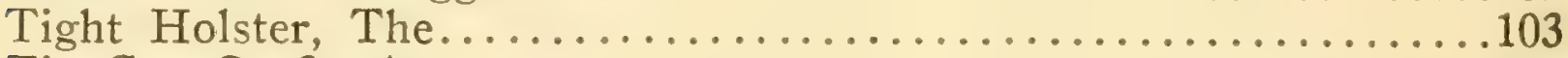

Tin Can Outfit, A............................... 44

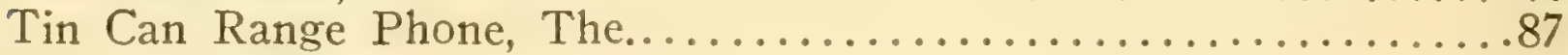

To Get the Frogs............................... 53

To the Bait Caster and Duck Hunter.................... 116

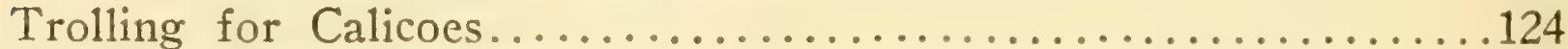

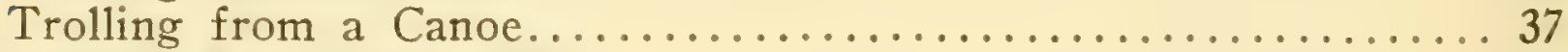

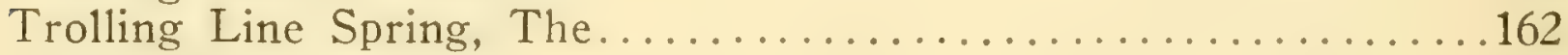

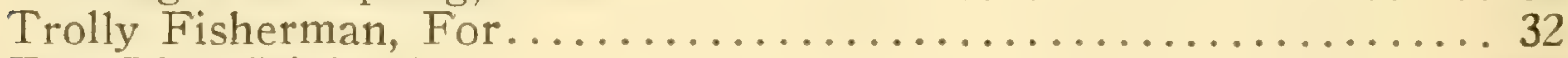

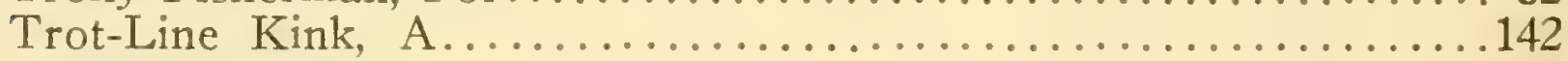

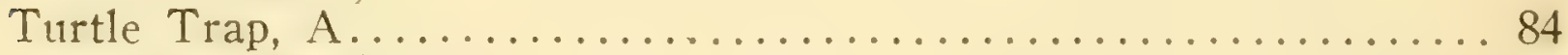

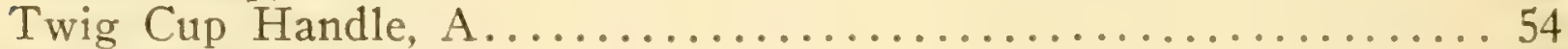

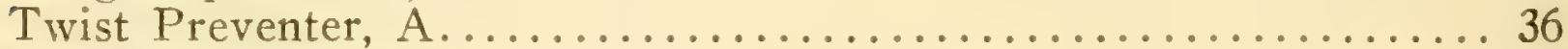

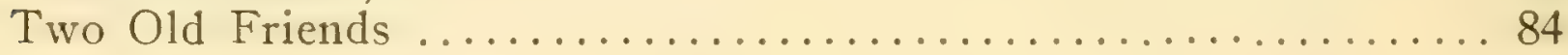

Unhooking the Bullhead............................. 81

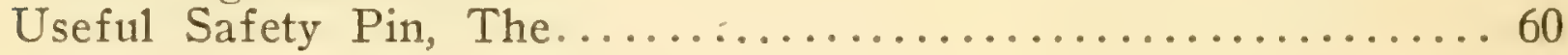

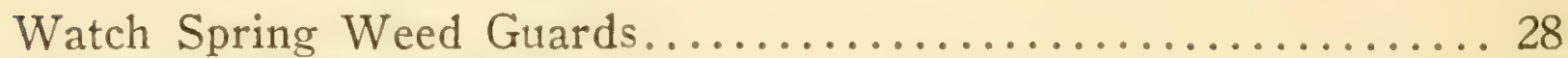

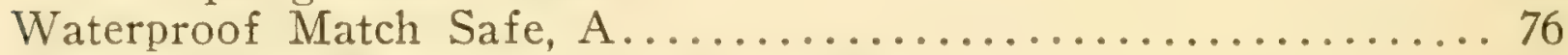

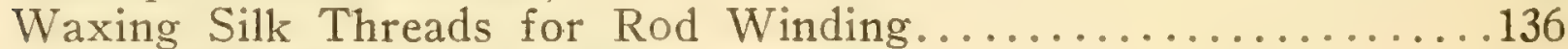

When the Stream Got Roily......................... 32

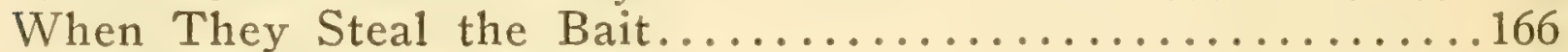

Wire Game Carrier, A............................. 85

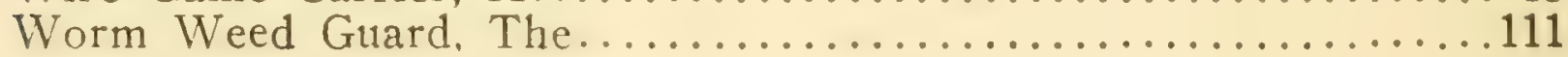




\section{SUPPLEMENTAL INDEX}

Because of the impossibility of making a satisfactory classification of the contents of the Kink Book, the publishers realize that the foregoing index is not as helpful as it should be. Doubtless every reader will find kinks to which he will want to refer irequently, and for his convenience the following pages are provided so that he may make his own index of favorite kinks.

Title 


\section{G VERY purchaser of "Kinks" should be a regular reader of OUTER'S BOOK}

-the magazine with the camp-fire flavor. Besides the regular Kink Department appearing in each issue, the OUTER'S BOOK publishes a vast amount of practical information for the hunter, angler and camper. If you want expert advice on guns, rods, reels or any piece of sporting paraphernalia, you are privileged to consult our several editors, who will be pleased to serve you.

Buy a copy today and get acquainted with the livest sportsman's magazine published.

Ask your news dealer.

\section{OUTER'S BOOK}

9 S. Clinton St.

Chicago 




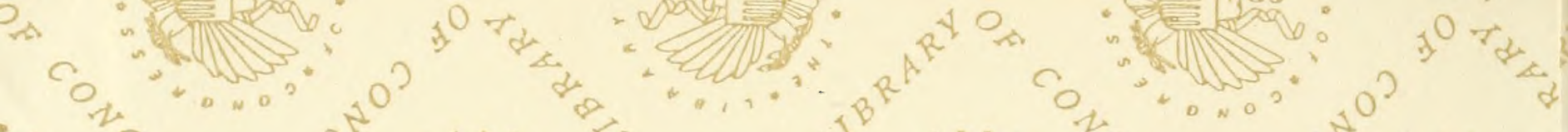

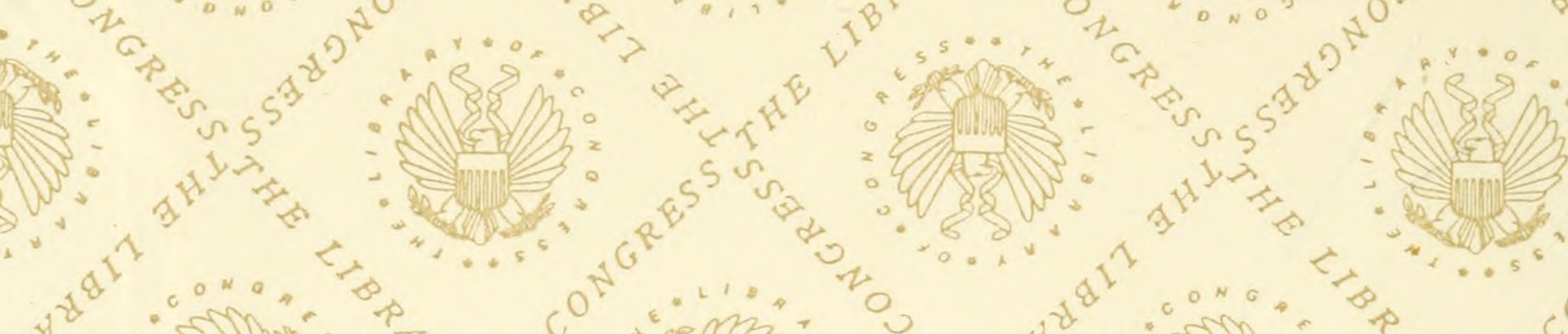

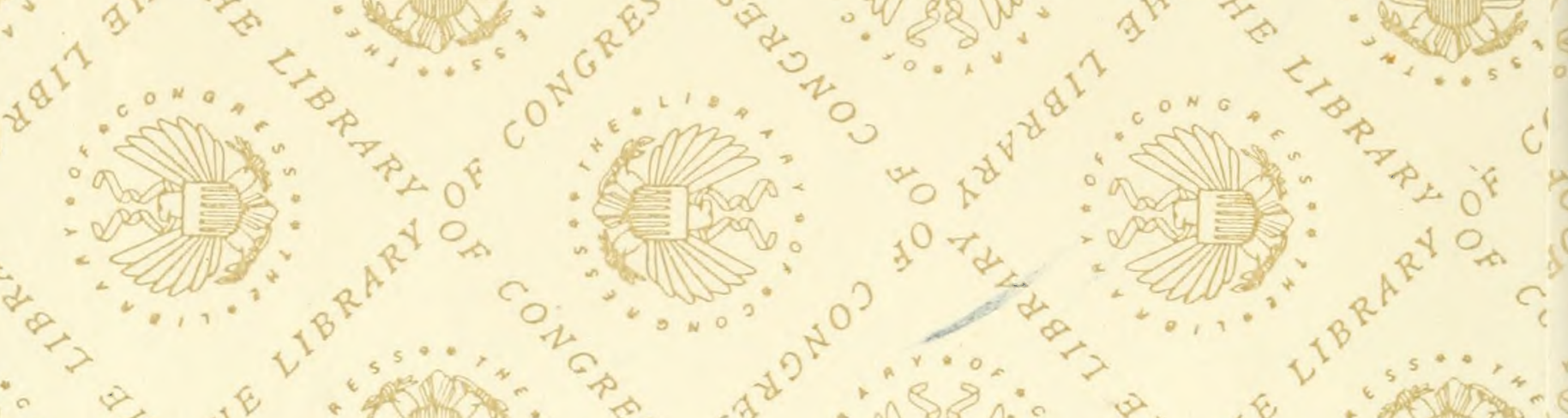
:

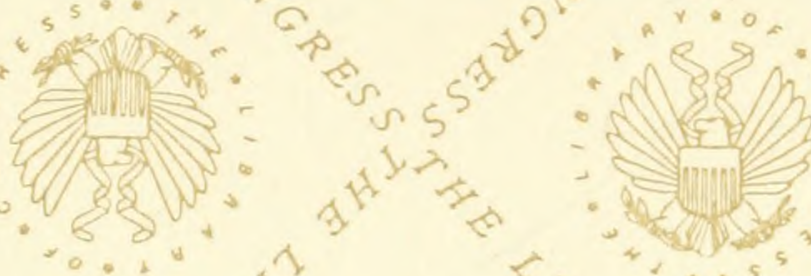

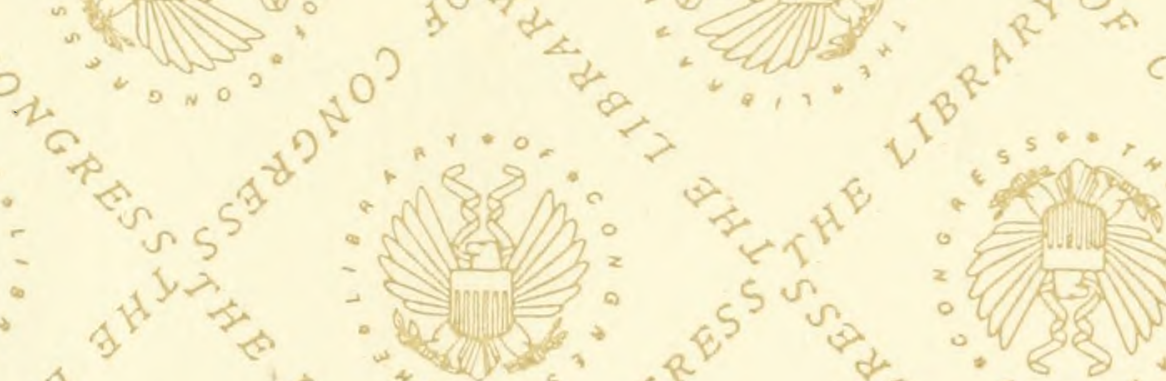

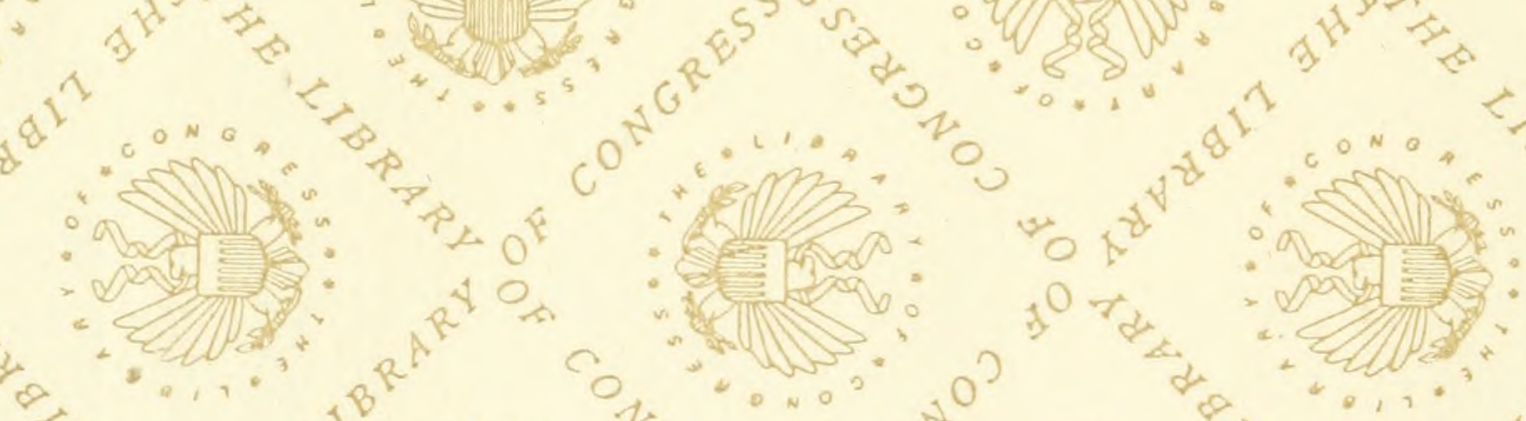
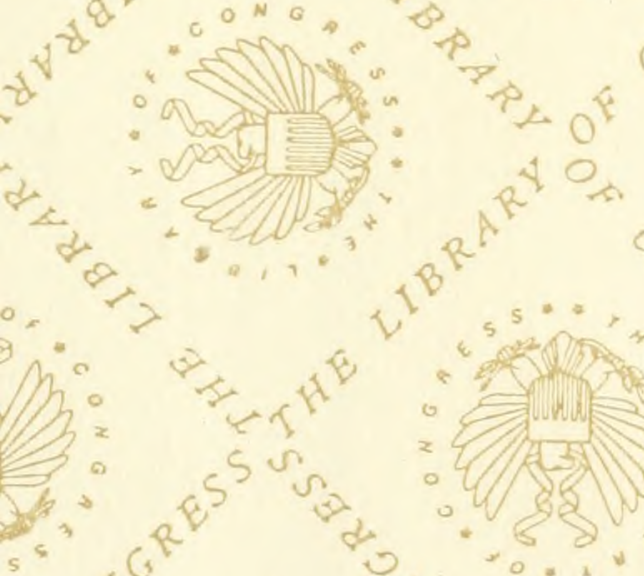

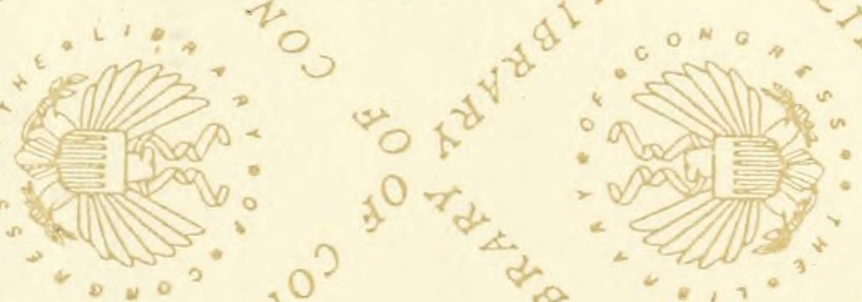

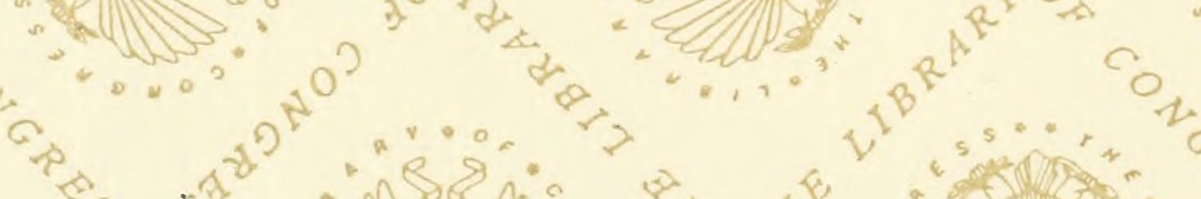

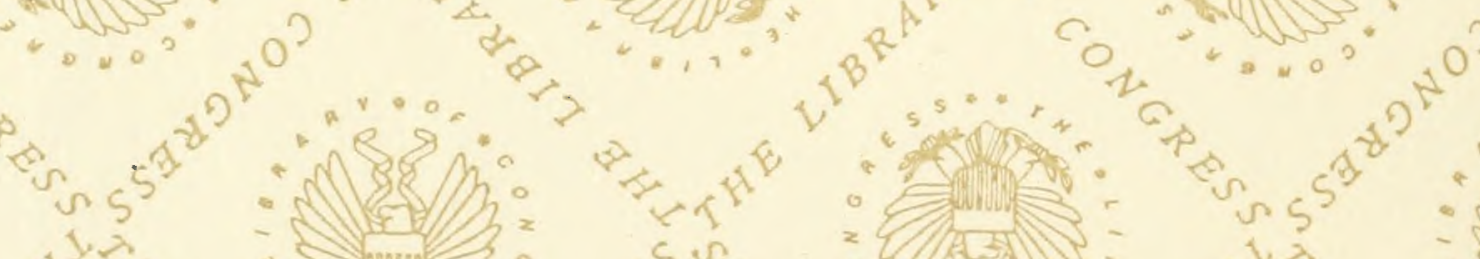
(1) 
$3 x^{2}+2 x+2$ 


\section{LIBRARY OF CONGRESS}

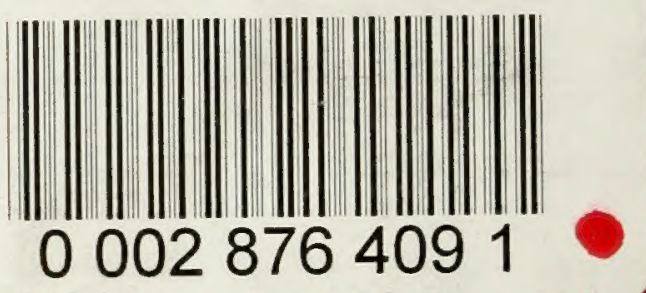

